Universidade de São Paulo-UsP

Escola de Engenharia de São Carlos

Departamento de Engenharia Elétrica e de Computação

Programa de Pós-Graduação em Engenharia Elétrica

\author{
Rafael Marsolla
}

\title{
Estimação Fasorial em Tempo Real Utilizando um Algoritmo Genético Compacto Multiobjetivo
}





\section{Rafael Marsolla}

\section{Estimação Fasorial em Tempo Real Utilizando um Algoritmo Genético \\ Compacto Multiobjetivo}

Dissertação de Mestrado apresentada ao Programa de Engenharia Elétrica da Escola de Engenharia de São Carlos como parte dos requisitos para a obtenção do título de Mestre em Ciências.

Área de concentração: Sistemas Elétricos de Potência

Orientador: Prof. Tit. Denis Vinicius Coury

São Carlos

2015

Trata-se da versão corrigida da dissertação. A versão original se encontra disponível na EESC/USP que aloja o Programa de Pós-Graduação de Engenharia Elétrica. 
AUTORIZO A REPRODUÇÃO TOTAL OU PARCIAL DESTE TRABALHO, POR QUALQUER MEIO CONVENCIONAL OU ELETRÔNICO, PARA FINS DE ESTUDO E PESQUISA, DESDE QUE CITADA A FONTE.

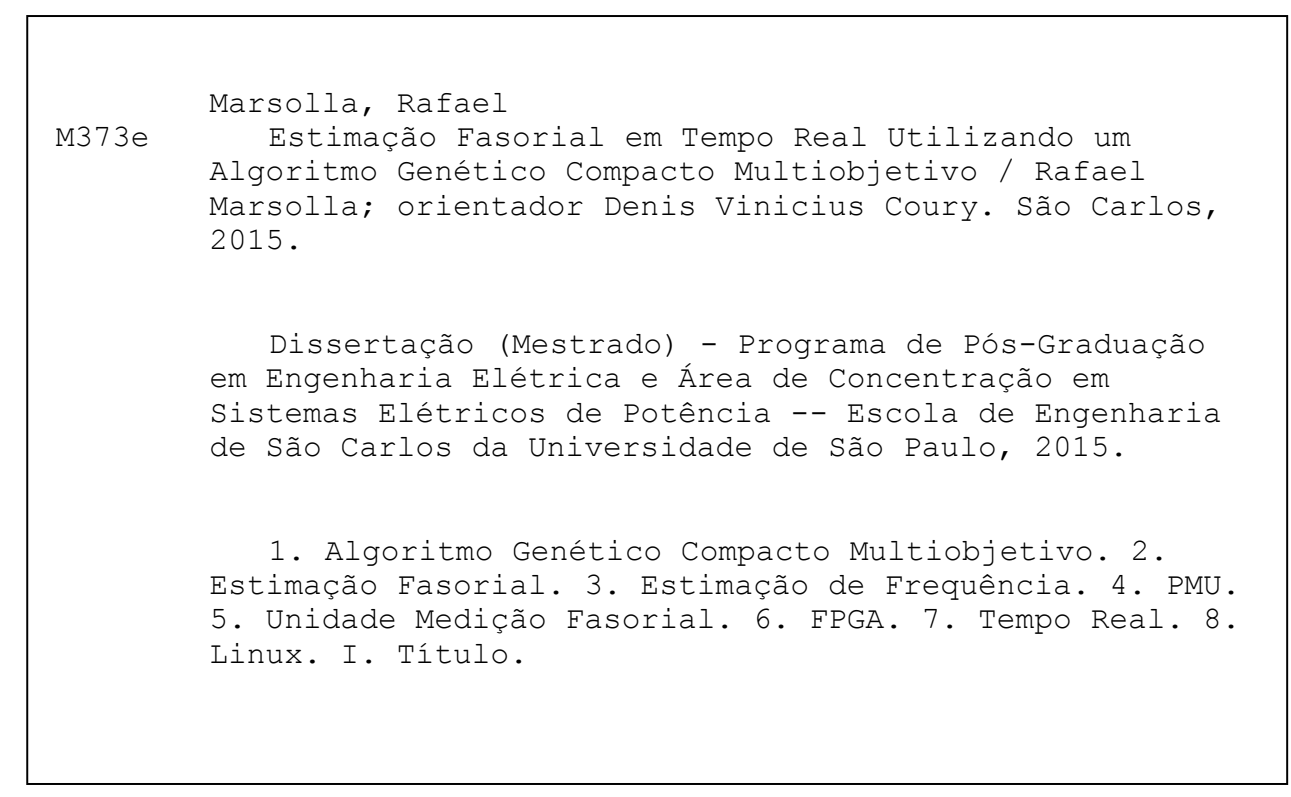




\section{FOLHA DE JULGAMENTO}

Candidato: Engenheiro RAFAEL MARSOLLA.

Título da dissertação: "Estimação fasorial em tempo real utilizando um algoritmo genético compacto multiobjetivo".

Data da defesa: 17/04/2015

Comissão Julgadora:

Resultado:

Prof. Titular Denis Vinicius Coury (Orientador)

APROVADO

(Escola de Engenharia de São Carlos/EESC)

Prof. Associado Alexandre Claudio Botazzo Delbem

APROVADO

(Instituto de Ciências Matemáticas e Computação/ICMC)

Prof. Dr. Walmir de Freitas Filho

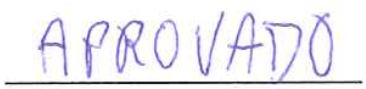

(Universidade Estadual de Campinas/UNICAMP)

Coordenador do Programa de Pós-Graduação em Engenharia Elétrica: Prof. Associado Luis Fernando Costa Alberto

Presidente da Comissão de Pós-Graduação:

Prof. Associado Paulo César Lima Segantine 



\section{Agradecimentos}

Meus sinceros agradecimentos ao Professor Titular Denis Vinicius Coury pela orientação e oportunidade concedida, ao Professor Dr. Alexandre C.B. Delbem pela paciência e ensinamentos da aplicação de algoritmos evolutivos, ao agora Professor Dr. Renato Monaro, que por muitos momentos auxiliou no desenvolvimento do trabalho, ao Professor Dr. Daniel Barbosa, que auxiliou executando as simulações dos casos de testes e validações, e aos professores Mário Oleskovicz e José Carlos de Melo Vieira Júnior pela atenção e apoio, assim como todos os colegas do Laboratório de Sistemas de Energia Elétrica (LSEE).

Agradeço também ao Departamento de Engenharia Elétrica e de Computação da Escola de Engenharia de São Carlos pelo suporte oferecido juntamente com o Conselho Nacional de Desenvolvimento Científico e Tecnológico - CNPq. 

"Na adversidade, uns desistem, enquanto outros batem recordes." (Ayrton Senna) 



\section{Resumo}

Marsolla, Rafael Estimação Fasorial em Tempo Real Utilizando um Algoritmo Genético Compacto Multiobjetivo. 160 p. Dissertação de Mestrado - Escola de Engenharia de São Carlos, Universidade de São Paulo, 2015.

A medição fasorial sincronizada é utilizada hoje como forma de aprimorar a operação de um Sistema Elétrico de Potência (SEP), empregando unidades de medição fasorial estrategicamente localizadas e instaladas. Estas realizam a aquisição do sinal elétrico e posteriormente a estimação dos fasores de tensão e corrente sincronizados no tempo, os quais indicam o comportamento do SEP em uma localidade específica.

Este trabalho multidisciplinar propõe a análise e implementação de um método computacional evolutivo, o Algoritmo Genético Compacto Multiobjetivo (AGCM) aplicado ao problema de medição fasorial, amplamente utilizado por exemplo, no monitoramento de um SEP, comportando-se assim como uma unidade medidora de fasor, ou Phasor Measurement Unit (PMU).

O AGCM aqui apresentado tem como principal característica a análise multiobjetiva do problema. Pelo fato de todo SEP ser trifásico, é proposto esta nova abordagem, onde é considerando para a estimação fasorial as três fases de forma conjunta, e não mais estimadas independentemente. Assim o AGCM proposto considera em seu mapeamento genético dos indivíduos, as características do sinais das três fases, diferentemente da abordagem mono-objetivo, onde cada fase do SEP é modelada sobre um indivíduo diferente.

Posteriormente para garantir a eficácia do método evolutivo quando em operação em um cenário de tempo real, é proposto uma plataforma de aquisição de dados e processamento, inspirada em trabalhos anteriormente desenvolvidos, permitindo a integração de todos os módulos que formarão um PMU para análise fasorial em tempo real. Aqui um sistema de Global Positioning System (GPS) existente é proposto como forma de sincronismo entre os PMUs, sincronizando uma gama de equipamentos em um única referência de tempo, com a precisão necessária. 
Para auxiliar na integração dos módulos necessários, uma biblioteca de funções desenvolvida no LSEE será expandida permitindo a execução do método evolutivo diretamente em uma interface Field Programmable Gate Array (FPGA) a qual atuará como um coprocessador genético da plataforma de tempo real.

Os resultados aqui apresentados foram obtidos seguindo especificações normativas, através de sinais gerados sinteticamente, e também utilizando o Alternative Transient Program (ATP), permitindo assim ensaios mais realísticos para a validação dos métodos evolutivos.

Palavras-chave: Algoritmo Genético Compacto Multiobjetivo, Estimação Fasorial, Estimação Frequência, FPGA, Tempo Real. 


\section{Abstract}

Marsolla, Rafael Real Time Phasor Estimation using a Multiobjective Compact Genetic Algorithm. 160 p. Master Dissertation - São Carlos School of Engineering, University of São Paulo, 2015.

The synchronized phasor measurement is used today as a way to enhance the operation of an Electric Power System (EPS), using phasor measurement units strategically located and installed. They perform the acquisition of the electrical signal and then, the estimation of the voltage and current phasors, synchronized in time, which indicates the SEP's behavior in a specific location.

This multidisciplinary work proposes the analysis and implementation of an evolutionary computing method, the Multibjective Compact Genetic Algorithm (MCGA) applied to the phasor estimation method used in EPS, known as an Phasor Measurement Units (PMUs).

The MCGA presented here has as a main characteristic the multiobjective analysis of the problem. Because all EPSs have three phases, this new approach is proposed, which is considering the phasor estimation for the three phases together, instead of doing it for each phase independently. Thus the proposed MCGA includes in its genetic mapping of individuals, the characteristics of the signals of the three phases, unlike the monoobjective where each phase of the Electric Power System (EPS) is modeled using a different individual.

In order to ensure the effectiveness of the evolutionary method when operating in a real time scenario, a platform for data acquisition and processing is proposed, inspired by previous work, allowing the integration of all the modules that composes a PMU for real-time phasor analysis. A Global Positioning System (GPS) is proposed as a way to synchronize different PMUs, integrating pieces of equipment in a single time reference, with the precision required.

In order to assist in the integration of the required modules, a library of functions 
developed in the Laboratory of Electric Power Systems will be expanded allowing the execution of the evolutionary method directly on a Field Programmable Gate Array (FPGA) interface, which will act as a genetic co-processor of a real-time platform.

The results presented here were obtained following normative specifications, through signals generated synthetically, and also using the Alternative Transient Program (ATP), allowing more realistic tests to validate the evolutionary methods.

Keywords: Multiobjective Compact Genetic Algorithm, Phasor Estimation, FPGA, RealTime. 


\section{Lista de ilustrações}

Figura 1 Medição fasorial sincronizada entre duas subestações. . . . . . . . . . . 30

Figura 2 Esquemático de uma PMU. . . . . . . . . . . . . . . . . . . . . . 31

Figura 3 Arranjo de um Sistema de Medição Fasorial Sincronizado. . . . . . . . . 34

Figura 4 (a) Diagrama de Blocos Típico do PLL (b) Representação do Sistema de Controle do PLL. . . . . . . . . . . . . . . . . . . . . . . . 41

Figura $5 \quad$ Representação do Indivíduo . . . . . . . . . . . . . . . . . . 46

Figura 6 Cruzamento de Um Ponto. . . . . . . . . . . . . . . . . . . . . 47

Figura 7 Cruzamento Uniforme. . . . . . . . . . . . . . . . . . . . . 48

Figura 8 Mutação Genética . . . . . . . . . . . . . . . . . . . 48

Figura 9 Vetor de Probabilidade do Algoritmo Genético Compacto (AGC) . . . 49

Figura 10 Fluxograma de Execução do AGC . . . . . . . . . . . . . . . . . . . . . 50

Figura 11 Distribuição das Solução na Fronteira de Pareto . . . . . . . . . . . . . 52

Figura 12 Estrutura de Tabelas do AGCM . . . . . . . . . . . . . . . . . . 53

Figura 13 Extração dos Valores Estimados pelo AGCM . . . . . . . . . . . . . . 53

Figura 14 Codificação do Problema em Um Único Indivíduo . . . . . . . . . . . . 57

Figura 15 Sinal Trifásico com Degrau de Magnitude de $-10 \%$. . . . . . . . . . 64

Figura 16 Sinal Frequência com Degrau de Magnitude de -10\%. . . . . . . . . . . 65

Figura 17 TVE para os Quatro Algoritmos Genéticos - Degrau de Magnitude de $-10 \%$. . . . . . . . . . . . . . . . 66 6

Figura 18 Sinal Trifásico com Degrau de Ângulo de Fase de 90 . . . . . . . . . . . 67

Figura 19 Sinal Frequência com Degrau de Ângulo de Fase de 90 . . . . . . . . . 68

Figura 20 TVE para os Quatro Algoritmos Genéticos - Degrau de Ângulo de Fase

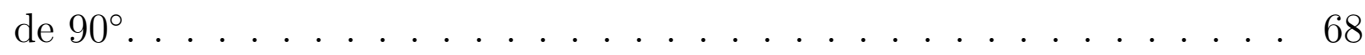

Figura 21 Sinal Trifásico com Degrau de Frequência de +5 Hz. . . . . . . . . . . 69

Figura 22 Sinal Frequência com Degrau de Frequência de +5 Hz. . . . . . . . . . 70

Figura 23 TVE para os Quatro Algoritmos Genéticos - Degrau de Frequência de $+5 \mathrm{~Hz} . \ldots \ldots \ldots$. . . . . . . . . . . . . . . 71 
Figura 24 Sistema Elétrico Quatro Barras Simulado no ATP . . . . . . . . . . . 73

Figura 25 Sinal Trifásico de Tensão Resultante da Simulação do ATP - Falta e Atuação da Proteção . . . . . . . . . . . . . . . . . . . . . . . . . 74

Figura 26 Sinal Trifásico de Corrente Resultante da Simulação do ATP - Falta e Atuação da Proteção . . . . . . . . . . . . . . . . . . . . . . . . . 75

Figura 27 Amplitude das Tensões Trifásicas Estimadas para o Caso 01. . . . . . . 76

Figura 28 Amplitude das Correntes Trifásicas Estimadas para o Caso 01. . . . . . 77

Figura 29 Frequência Estimada para o Caso 01. . . . . . . . . . . . . . . 78

Figura 30 Detalhe da Amplitude das Tensões Estimadas para o Caso 01. . . . . . 79

Figura 31 Detalhe da Amplitude das Correntes Trifásicas Estimada para o Caso 01. . . . . . . . . . . . . . . . . . 80

Figura 32 Detalhe da Frequência Estimada para o Caso 01. . . . . . . . . . . . . 81

Figura 33 Erro da Frequência Estimada para o Caso 01. . . . . . . . . . . . . . . 82

Figura 34 Amplitude das Tensões Trifásicas Estimadas para o Caso 02. . . . . . . 83

Figura 35 Frequência Estimada para o Caso 02. . . . . . . . . . . . . . 83

Figura 36 Detalhe da Amplitude das Tensões Estimadas para o Caso 02. . . . . . 84

Figura 37 Detalhe da Frequência Estimada para o Caso 02. . . . . . . . . . . 85

Figura 38 Erro da Frequência Estimada para o Caso 02. . . . . . . . . . . . . . 86

Figura 39 Amplitude das Tensões Trifásicas Estimadas para o Caso 03. . . . . . . 87

Figura 40 Frequência Estimada para o Caso 03. . . . . . . . . . . . . . . . 88

Figura 41 Detalhe da Amplitude das Tensões Estimadas para o Caso 03. . . . . . 89

Figura 42 Detalhe da Frequência Estimada para o Caso 03. . . . . . . . . . . . 90

Figura 43 Erro da Frequência Estimada para o Caso 03. . . . . . . . . . . . . . . 91

Figura 44 Amplitude das Tensões Trifásicas Estimadas para o Caso 04. . . . . . . 92

Figura 45 Frequência Estimada para o Caso 04. . . . . . . . . . . . . . . . . 92

Figura 46 Detalhe da Amplitude das Tensões Estimadas para o Caso 04. . . . . . 93

Figura 47 Detalhe da Frequência Estimada para o Caso 04. . . . . . . . . . . . . 94

Figura 48 Erro da Frequência Estimada para o Caso 04. . . . . . . . . . . . . . . 95

Figura 49 Amplitude das Tensões Trifásicas Estimadas para o Caso 05. . . . . . . 96

Figura $50 \quad$ Frequência Estimada para o Caso 05. . . . . . . . . . . . . . . 97

Figura 51 Detalhe da Amplitude das Tensões Estimadas para o Caso 05. . . . . . 98

Figura 52 Detalhe da Frequência Estimada para o Caso 05. . . . . . . . . . . . . 99

Figura 53 Erro da Frequência Estimada para o Caso 05. . . . . . . . . . . . . . . 100

Figura 54 Amplitude das Tensões Trifásicas Estimadas para o Caso 06. . . . . . . 101

Figura 55 Frequência Estimada para o Caso 06. . . . . . . . . . . . . . . 102

Figura 56 Detalhe da Amplitude das Tensões Estimadas para o Caso 06. . . . . . 103

Figura 57 Detalhe da Frequência Estimada para o Caso 06. . . . . . . . . . . . . 104

Figura 58 Erro da Frequência Estimada para o Caso 06. . . . . . . . . . . . . . 105

Figura 59 Amplitude das Tensões Trifásicas Estimadas para o Caso 07. . . . . . . 106 
Figura 60 Frequência Estimada para o Caso 07. . . . . . . . . . . . . . . . . . 107

Figura 61 Detalhe da Amplitude das Tensões Estimadas para o Caso 07. . . . . . 108

Figura 62 Detalhe da Frequência Estimada para o Caso 07. . . . . . . . . . . . . 109

Figura 63 Erro da Frequência Estimada para o Caso 07. . . . . . . . . . . . . . . 110

Figura 64 Amplitude das Tensões Trifásicas Estimadas para o Caso 08. . . . . . . 111

Figura 65 Frequência Estimada para o Caso 08. . . . . . . . . . . . . . . . . 112

Figura 66 Detalhe da Amplitude das Tensões Estimadas para o Caso 08. . . . . . 113

Figura 67 Detalhe da Frequência Estimada para o Caso 08. . . . . . . . . . . . . 114

Figura 68 Erro da Frequência Estimada para o Caso 08. . . . . . . . . . . . . . . 115

Figura 69 Influência do Filtro de Média Móvel na Estimação da Amplitude das Tensões do AGCM para o Caso 01. . . . . . . . . . . . . . . . . . . . 117

Figura 70 Influência do Filtro de Média Móvel na Estimação da Amplitude das Tensões do AGCM para o Caso 06. . . . . . . . . . . . . . . . . 118

Figura 71 Influência do Filtro de Média Móvel na Estimação da Frequência do AGCM no Momento da Falta - Caso 6. . . . . . . . . . . . . . . . . . . 119

Figura 72 Influência do Filtro de Média Móvel na Estimação da Frequência do AGCM no Momento da Falta - Caso 8. . . . . . . . . . . . . . . . . . . 119

Figura 73 Diagrama da Matriz FPGA. . . . . . . . . . . . . . . . . . 122

Figura 74 Módulo PCI FPGA Virtex 5 . . . . . . . . . . . . . . . . . 123

Figura 75 Dimensões Módulo Padrão PCI/104 . . . . . . . . . . . . . . . . . . . 124

Figura 76 Diagrama do PMU. . . . . . . . . . . . . . . . . . . . 125

Figura 77 Arquitetura RETAI. . . . . . . . . . . . . . . . . . . . 128

Figura 78 Organização Comedi. . . . . . . . . . . . . . . . . . . . . . 129

Figura 79 Organização Biblioteca OpenRelay. . . . . . . . . . . . . . . . . . 130

Figura 80 Organização das Classes da Biblioteca OpenC37118. . . . . . . . . . . . 131 



\section{Lista de tabelas}

Tabela 1 Mapeamento dos Valores de Amplitude Utilizando Lookup-tables. . . . 56

Tabela 2 Codificação dos Parâmetros no AGCM. . . . . . . . . . . . . . . 61

Tabela 3 Tempo de Recuperação para os Algoritmos Genéticos Testados de Acordo com Norma IEEE C37.118-2011. . . . . . . . . . . . . . . . . . 71

Tabela 4 Parâmetros de Simulação do Gerador Utilizados no ATP. . . . . . . . . 73

Tabela 5 Parâmetros de Simulação dos Transformadores Utilizados no ATP. . 74

Tabela 6 Custo Estimado da Plataforma PMU. . . . . . . . . . . . . . . 132 



\section{Lista de siglas}

AE Algoritmo Evolutivo

AG Algoritmo Genético

AGC Algoritmo Genético Compacto

AGM Algoritmo Genético Multiobjetivo

AGCM Algoritmo Genético Compacto Multiobjetivo

API Application Programming Interface

ATP Alternative Transient Program

Comedi Control and Measurement Device Interface

DFT Discrete Fourier Transform

DTFT Discrete Time Fourier Transform

EPS Electric Power System

FPGA Field Programmable Gate Array

GPS Global Positioning System

GPL GNU Public License

ISA Industry Standard Architecture

IEEE Institute of Electrical and Electronics Engineers

LSE Least Square Error

LSEE Laboratório de Sistemas de Energia Elétrica

Linux Sistema Operacional GNU Linux 
MSE Mean Square Error

MCGA Multibjective Compact Genetic Algorithm

PCI Peripheral Component Interconnect

PDC Phasor Data Concentrator

PLL Phase Locked Loop

PMU Phasor Measurement Unit

PPS Pulse per Second

PTP Precise Time Protocol

RLS Recursive Least Squares

RTAI Real-Time Application Interface

RTDS Real-Time Digital Simulator

RMSE Root Mean Square Error

RMS Root Mean Square

SCDR Symmetrical Component Distance Relay

SMFS Sistema de Medição Fasorial Sincronizado

SEP Sistema Elétrico de Potência

SO Sistema Operacional

TVE Total Vector Error

TC Transformador de Corrente

UFSC Universidade Federal de Santa Catarina

VCO Voltage Controlled Oscillator

VHDL VHSIC Hardware Description Language 


\section{Sumário}

1 Introdução $\quad 25$

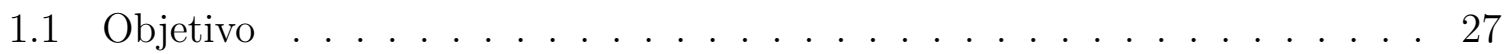

1.2 Estrutura do Trabalho . . . . . . . . . . . . . . . . . . . 27

2 Revisão Bibliográfica 29

2.1 Phasor Measurement Unit (PMU) . . . . . . . . . . . . . . . . . . . . . . 30

2.1.1 Funcionamento de um PMU . . . . . . . . . . . . . . . 30

2.1 .2 Utilização . . . . . . . . . . . . . . . . . . . . . . . 31

2.2 Sistema de Medição Fasorial Sincronizado . . . . . . . . . . . . . . . . . . 33

2.2.1 Arquitetura de um Sistema de Medição Fasorial Sincronizado . . . 33

2.3 Especificação - Norma IEEE C37.118-2011 . . . . . . . . . . . . . . . . . 35

2.4 Métodos de Estimação Fasorial Convencionais . . . . . . . . . . . . . . 36

2.4.1 Discrete Fourier Transform (DFT) . . . . . . . . . . . . . . 36

2.4.2 Phase Locked Loop (PLL) . . . . . . . . . . . . . . . . . . . . . . . 39

2.4.3 Método dos Mínimos Quadrados - Least Square Error (LSE) . . . 41

2.4.4 Métodos Computacionais Evolutivos . . . . . . . . . . . . . . 43

3 Utilização do Algoritmo Genético Compacto Multiobjetivo na Estimação Fasorial 45

3.1 Algoritmos Evolutivos . . . . . . . . . . . . . . . . . . . 45

3.2 Indivíduos . . . . . . . . . . . . . . . . . . . 46

3.3 Função de Avaliação . . . . . . . . . . . . . . . . . . . . . . . . . . . 46

3.4 Operadores Genéticos . . . . . . . . . . . . . . . . . . . . 47

3.4 .1 Seleção . . . . . . . . . . . . . . . . . . . . . . 47

3.4 .2 Elitismo .......................... 47

3.4.3 Cruzamento . . . . . . . . . . . . . . . 47

3.4 .4 Mutação . . . . . . . . . . . . . . . . . . . . . . . 48

3.4.5 Predação . . . . . . . . . . . . . . . . . . . . . 48 
3.5 Algoritmos Genéticos Compactos . . . . . . . . . . . . . . . . . . . . 48

3.6 Algoritmos Genéticos Compactos Multiobjetivo . . . . . . . . . . . . . 50 3.6.1 Algoritmos Genéticos Compactos Multiobjetivo Utilizando Tabelas 52

3.7 Métodos Paralelos . . . . . . . . . . . . . . . . . . . . 54

3.8 Modelagem do Problema de Estimação Fasorial . . . . . . . . . . . . . . . 54

3.8.1 Modelagem Multiobjetivo do Problema . . . . . . . . . . . . . 55

3.8.2 Representação Binária . . . . . . . . . . . . . . . . . 56

3.8.3 Representação Cromossômica . . . . . . . . . . . . . . . 57

3.9 Dinâmica dos Parâmetros do AGCM . . . . . . . . . . . . . . . . . . . . 59

3.9 .1 Métrica de Informação Mútua ........... 59

3.9.2 Método de Regularização . . . . . . . . . . . . . . . . . . . 60

4 Testes e Resultados da Aplicação da Metodologia Proposta 63

4.1 Casos de Testes Especificados na Norma IEEE C37.118-2011 . . . . . . . 64

4.2 Casos de Testes Simulados com ATP . . . . . . . . . . . . . . . . . . . 72

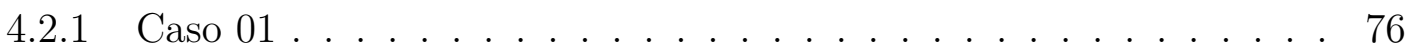

4.2 .2 Caso $02 \ldots \ldots \ldots \ldots$. . . . . . . . . . . . . . . 80

4.2 .3 Caso $03 \ldots \ldots \ldots \ldots$. . . . . . . . . . . . . . . . . . 86

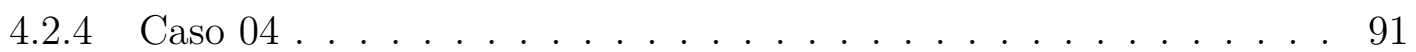

4.2 .5 Caso $05 \ldots \ldots \ldots \ldots$. . . . . . . . . . . . . . . 96

4.2 .6 Caso $06 \ldots \ldots \ldots 10 . \ldots \ldots$

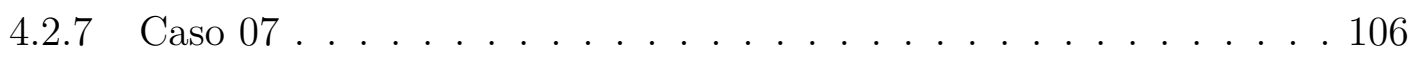

4.2 .8 Caso $08 \ldots \ldots \ldots \ldots 111 \ldots \ldots \ldots \ldots$

4.3 Aplicação de Filtro de Média Móvel . . . . . . . . . . . . . . . . . . 116

5 Implementação da Plataforma PMU em Tempo Real 121

5.1 Field Programmable Gate Array (FPGA) . . . . . . . . . . . . . . . . . . 122

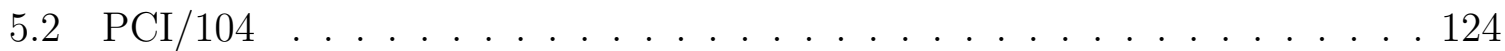

5.2.1 Cubo $2 \ldots \ldots \ldots \ldots \ldots$

5.3 Sistemas de Tempo Real . . . . . . . . . . . . . . . . . . . . 126

5.4 GNU/Linux e Real-Time Application Interface . . . . . . . . . . . . . . 127

5.5 Comedi . . . . . . . . . . . . . . . . . . . . . . . . 128

5.6 Biblioteca OpenRelay . . . . . . . . . . . . . . . . . . . . . 129

5.7 Biblioteca OpenC37.118 . . . . . . . . . . . . . . . . . . . 130

5.8 Custo de Projeto . . . . . . . . . . . . . . . . . . . . . . . . 132

6 Conclusão $\quad 135$

6.1 Conclusão deste Trabalho . . . . . . . . . . . . . . . . . . . . . . . 135

6.2 Propostas Futuras e Heranças . . . . . . . . . . . . . . . . . . . 136

$\begin{array}{ll}\text { Referências } & 139\end{array}$ 
APÊNDICE A Implementação do Algoritmo Genético Compacto Multiobjetivo (AGCM) em linguagem $\mathrm{C}$ 



\section{Introdução}

Com o crescente aumento da demanda de consumo de energia elétrica, faz-se necessário a ampliação permanente do Sistema Elétrico de Potência (SEP), tornando muitas vezes complexo seu gerenciamento. Padrões de qualidade, de confiabilidade e de continuidade de fornecimento da energia elétrica são exigidos e devem ser garantidos em todos os SEPs segundo normas estabelecidas.

O ponto crucial para garantir os padrões normativos é a forma como são observados os eventos que ocorrem no SEP. Seja um equipamento de proteção ou monitoração, é imprescindível que este opere de forma rápida e precisa, garantindo medições e respostas em condições de regime ou com durante a ocorrência de eventos inesperados no SEP.

Para ilustrar a necessidade de uma medição precisa, uma medição incorreta realizada sobre um Transformador de Corrente (TC) mal dimensionado, poderá fazer com que um sistema de proteção atue de forma indevida, ocasionando muitas vezes a interrupção do fornecimento da energia elétrica para uma dada localidade. Já uma medição fasorial incorreta podem indicar um falso estado de operação do SEP, ocasionando operações desnecessárias, e muitas vezes prejudiciais para a conformidade do serviço e qualidade da energia ofertada.

No contexto de qualidade de energia, a análise fasorial é uma ferramenta utilizada como forma de análise e monitoramento do SEP. Neste contexto, os fasores são ferramentas básicas para análise de circuitos de corrente alternada, representando as formas de ondas senoidais referentes aos sinais elétricos existentes no circuito ou ainda servindo de variáveis para outros sistemas computacionais.

Um circuito de corrente alternada tem seus sinais elétricos formado por várias formas de onda senoidais de tensão e corrente. Medições fasoriais desses sinais permitem caracterizar o estado do SEP em relação a amplitude, ângulo de fase e frequência dos sinais ali existentes.

Quando esta análise é realizada em diferentes sinais, e em diferentes pontos de um circuito, faz-se necessário o sincronismo da amostragem das formas de onda, como modo de garantir uma referência de tempo comum entre todas as formas de ondas amostradas 
e pertencentes ao mesmo circuito.

Existem hoje diversas formas de sincronia que podem ser utilizadas garantindo uma referência precisa, seja ela local ou remota. Em casos de subestações é fácil obter uma sincronia com outros equipamentos já existentes, enquanto que em localizações geográficas remotas, faz-se necessário o uso de sistemas mais complexos de sincronia e referência, como o Global Positioning System (GPS).

O sistema de GPS foi desenvolvido pelo Departamento de Defesa Americano e é composto de uma constelação de 24 satélites orbitando a Terra em uma altitude de 20.200 $\mathrm{km}$ a uma velocidade de $11.265 \mathrm{~km} / \mathrm{h}$, circundando a terra a cada 12 horas. A forma como a constelação foi planejada, garante que em qualquer ponto do Terra, em qualquer momento, este ponto estará coberto por pelo menos 3 satélites. Este é o número mínimo de satélites necessários para o funcionamento do sistema.

Todos os 24 satélites pertencentes ao sistema GPS são sincronizados entre si, através de um sinal de referência, gerado por um relógio atômico embarcado capaz de fornecer uma fonte de referência altamente precisa, baseado no decaimento atômico do elemento radioativo ali utilizado.

Este sinal de referência, também é utilizado para gerar um sinal pulsante com frequência de $1 \mathrm{~Hz}$ e precisão de 1 microssegundo, emitido em direção a terra, o Pulse per Second (PPS), podendo, portanto, ser utilizado para as mais diversas aplicações síncronas.

Neste contexto, utilizando-se dos métodos de estimação fasorial e sincronismo existentes em 1988, pesquisadores da Virginia Polytechnic Institute desenvolveram o primeiro protótipo de um equipamento de medição fasorial, o Phasor Measurement Unit (PMU), sendo aplicado como uma ferramenta de monitoração do SEP (PHADKE, 2002).

Com o crescente interesse em equipamentos PMU, em 1995 o Institute of Electrical and Electronics Engineers (IEEE) emitiu a norma 1344-1995 (IEEE, 1995) visando definir formatos e garantir padrões de compatibilidade entre diferentes fabricantes. Posteriormente esta normal foi revista, e em 2005 a norma C37.118-2005 (IEEE, 2005) foi emitida. Em 2011, esta norma foi revista e um protocolo de comunicação entre os dispositivos foi especificado, assim a norma IEEE C37.118-2011 (IEEE, 2011) foi emitida com os padrões necessários vigentes hoje.

Existem diversos métodos matemáticos convencionais utilizados para a estimação dos fasores de um sinal, entre os mais comuns podem-se citar o método de Discrete Fourier Transform (DFT), um dos mais populares para estimação espectral em sinais elétricos devido à sua simplicidade e aos bons resultados apresentados. O método de Phase Locked Loop (PLL) também é utilizado para estimação fasorial. Uma malha PLL é configurada para rastrear e extrair uma componente de frequência e fase, que posteriormente com operações adicionais relacionadas aos termos senoidal e cossenoidal, extraem a amplitude (GOMES, 2007). Alguns outros métodos, como o Least Square Error (LSE), também podem ser encontrados na literatura (KAMWA; GRONDIN, 1991). 
Adicionalmente aos algoritmos computacionais para a estimação fasorial conhecidos na literatura, os Algoritmos Evolutivos (AEs) têm sido aplicado com grande sucesso para a estimação de variáveis do SEP. Dentre os métodos evolutivos utilizados, os Algoritmos Genéticos (AGs) destacam-se pela simplicidade de implementação e precisão dos resultados obtidos. Este algoritmo utiliza um processo de ajuste de curvas (Curve Fitting) através de uma fórmula matemática (função objetivo) para extrair os parâmetros que compõe os fasores (CARVALHO et al., 2009).

\subsection{Objetivo}

O objetivo deste trabalho é o desenvolvimento de uma plataforma em tempo real inteligente de estimação fasorial, baseado em um Algoritmo Genético Compacto Multiobjetivo (AGCM), que estime fasores, superando as deficiências encontradas em métodos matemáticos convencionais quando enfrentam transitórios ocorridos no SEP. O sistema proposto deve ser capaz de estimar os fasores de tensão e corrente das 3 fases existentes em um SEP. Assim, alguns passos intermediários são necessários para realizar tal objetivo, dentre eles:

$\square$ Mapeamento genético do problema, fazendo com que o AGCM seja capaz de estimar as variáveis que compõem a medição fasorial.

- Configuração e validação dos parâmetros de configuração do AGCM através dos resultados obtidos em laboratório.

$\square$ Desenvolvimento de um hardware de tempo real, permitindo a amostragem de sinais síncrona em diferentes pontos do SEP.

\ Paralelização do método genético visando aumentar a performance durante a execução em tempo real - FPGA.

$\square$ Migração e integração do sistema genético junto a plataforma de tempo real, permitindo a medição fasorial síncrona.

Assim, a seguir, é apresentado a estrutura deste trabalho que contempla os resultados de alguns passos já executados em busca do objetivo.

\subsection{Estrutura do Trabalho}

Neste trabalho, o Capítulo 2 aborda uma breve revisão bibliográfica sobre sistema de medições fasoriais síncronas, métodos hoje utilizados, suas vantagens e desvantagens. Introduz também a regulamentação normativa existente para este propósito, finalizando por apresentar os métodos hoje conhecidos, utilizados para medições fasoriais. 
O Capítulo 3 trata exclusivamente sobre Algoritmos Genéticos (AGs), suas características, métodos de implementação e mapeamento do problema utilizando análise multiobjetiva, originando assim o AGCM aqui aplicado à estimação fasorial, além de descrever a modelagem do problema e a representação de suas informações quando utilizado o método evolutivo.

O Capítulo 4 demostra a metologia utilizada durante os testes laboratoriais executados para garantir o correto funcionamento do método genético, considerando casos normativos e simulados. Os resultados obtidos estão divididos em dois grupos de sinais de entrada, sintéticos e simulados, permitindo uma melhor análise.

Uma vez validado o método, o Capítulo 5 apresenta um protótipo de uma plataforma de tempo real, a qual permitirá a aplicação do método em um SEP real.

No Capítulo 6 é apresentado a conclusão desta pesquisa, assim como propostas para continuação e heranças deixadas para a conclusão da plataforma de tempo real. 


\section{Revisão Bibliográfica}

Neste capítulo, é feito uma revisão referente às técnicas de medição fasorial, os conceitos envolvidos, seu funcionamento e aplicações.

Um fasor é uma representação de uma função senoidal invariante no tempo, onde os termos de amplitude, frequência e ângulo de fase que compõem o sinal senoidal são tratadas como três grandezas variáveis.

Então, a medição fasorial é a técnica matemática que calcula fasores para análises de sinais senoidais. Esta técnica é aplicada com sucesso na análise do comportamento de um SEP, onde através da análise e processamento das formas de ondas de tensão e corrente alternadas, é possível caracterizar o comportamento do SEP em um dado momento, com base nos valores apresentados pelos fasores.

Baseado em algoritmos de proteção de linhas de transmissão do tipo Symmetrical Component Distance Relay (SCDR), e com o poder computacional disponível na época, pesquisadores da Virgínia Polytechnic Institute em 1988 desenvolveram o primeiro protótipo de uma unidade de medição fasorial, ou Phasor Measurement Unit (PMU).

Este protótipo ao longos dos anos foi incorporado pela indústria, que através de melhorias e inovações como sincronismo preciso utilizando um sistema receptor GPS, conversores analógico-digital de 16 bits, interfaces homem-máquina mais flexíveis e interfaces de comunicação, deram origem aos equipamentos PMU hoje utilizados.

Com esta evolução, foram desenvolvidos também, os concentradores de dados fasoriais ou Phasor Data Concentrator (PDC), servindo como ponto comum de coleta de dados entre um sistema com vários PMU interconectados e sincronizados em uma mesma referência de tempo.

Com a crescente demanda de consumo de energia elétrica, a elevação do padrão de qualidade sobre o produto ofertado, e garantias de disponibilidade de serviço, a análise fasorial tem ganhado importância no cenário elétrico. Como exemplo prático da aplicação de equipamentos PMUs no Brasil, o projeto MedFasee desenvolvido pela Universidade Federal de Santa Catarina (UFSC) em parceria com empresas privadas e outras instituições de pesquisas, efetua o monitoramento do SEP em diversos pontos no território nacional 
através da análise fasorial.

\subsection{Phasor Measurement Unit (PMU)}

Técnicas de monitoramento em tempo real têm utilizado do conceito das medições fasoriais síncronas, através do uso de equipamentos Phasor Measurement Units (PMUs), os quais realizam medições em diferentes localidades geográficas pertencentes a um mesmo SEP, para assim estimar o estado atual de todo o sistema, garantindo a qualidade e a conformidade da energia elétrica ofertada.

A PMU é o elemento responsável por efetuar a medição fasorial do SEP. Através da aquisição dos sinais de tensões e correntes ali existentes, este equipamento amostra o sinal em janela de dados, processando-os e efetuando a medição fasorial.

\subsubsection{Funcionamento de um PMU}

Quando necessário a medição dos fasores em subestações separadas geograficamente, os dados ali amostrados devem ser sincronizados precisamente e enviados a um ponto remoto comum, onde, utilizando-se da estampa de tempo, pode-se alinhar as medições obtidas em cada subestação envolvida. A Figura 1 ilustra o processo sincronizado.

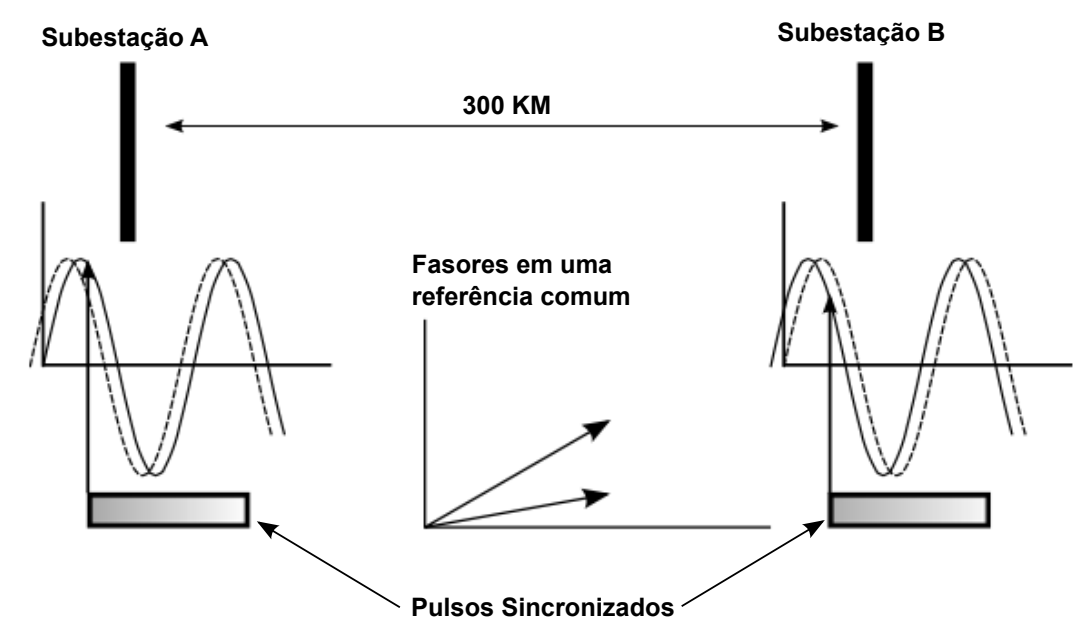

Figura 1 - Medição fasorial sincronizada entre duas subestações.

Adaptado de (SILVA, 2012a)

Para que a PMU seja capaz de amostrar os sinais de tensão e corrente do SEP, sincronizar as amostras obtidas e enviá-las ao concentrador remoto, é necessário um arranjo computacional, descrito e ilustrado pela Figura 2 de forma simples.

Basicamente a PMU é composta de transformadores de potencial (TP) e corrente (TC) adequando os níveis de tensão e corrente dos sinais, filtros para o condicionamento dos sinais vindos dos TPs e TCs, um dispositivo de captura de amostras do tipo sample e hold conectado a um conversor analógico digital, um microprocessador que realiza a 


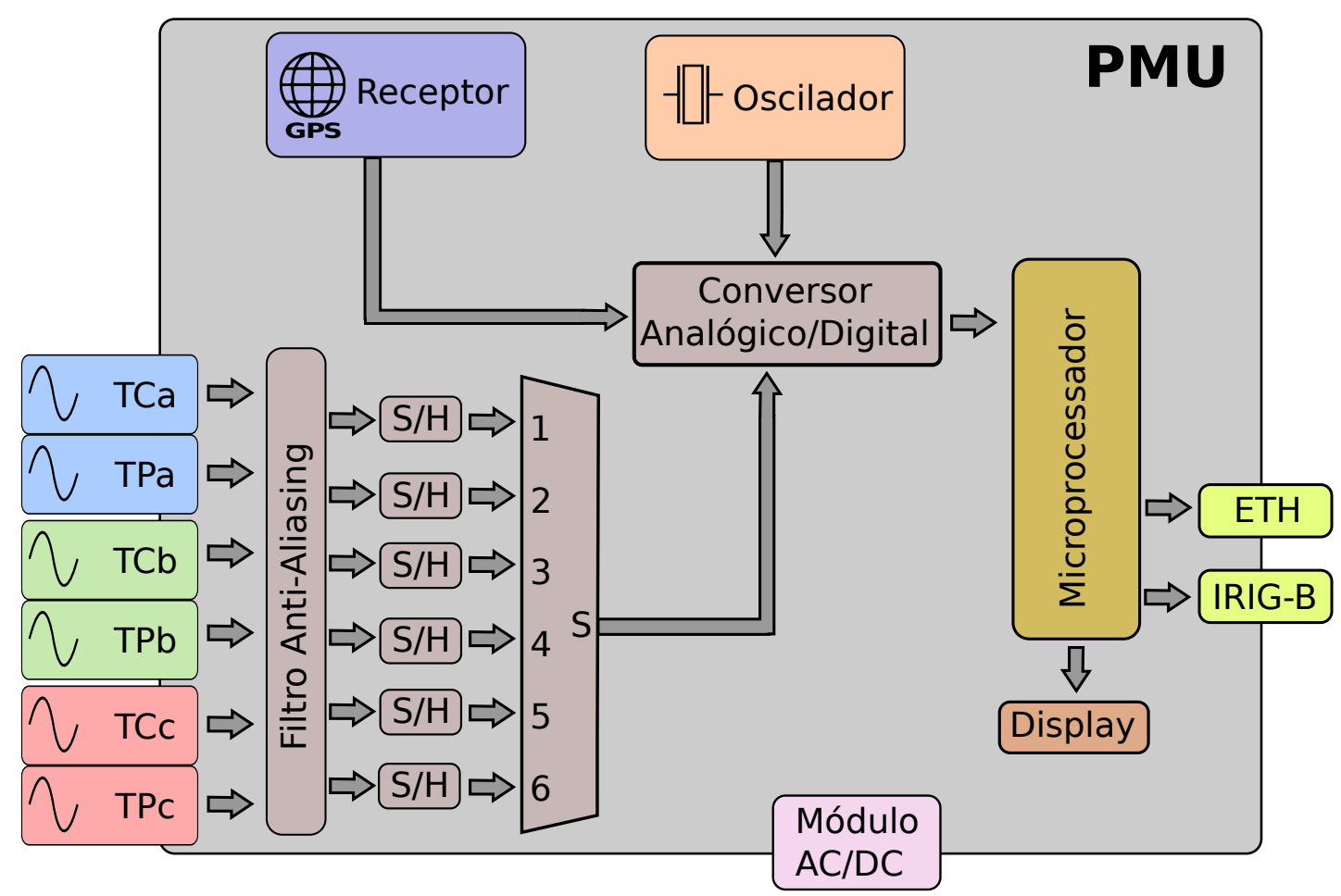

Figura 2 - Esquemático de uma PMU.

estimação dos parâmetros que caracterizam o sinal lido, um sistema de sincronia de tempo, normalmente baseado em um sistema GPS, e interfaces de comunicação para envio e recebimento de dados e comandos de controle da PMU.

\subsubsection{Utilização}

Segundo Burnett, Butts e Sterlina (1994) equipamentos PMUs são utilizados geralmente para verificar a consistência de modelos teóricos de SEPs em relação ao sistema real. Aplicações em monitoração são as mais comuns, se comparadas com aplicações de proteção e controle. A seguir são elencadas algumas aplicações conhecidas na literatura, não se limitando somente a eles:

\subsubsection{Detecção e Localização de Faltas}

Uma abordagem do uso da PMU para detecção e localização de faltas em linhas de transmissão do SEP foi proposta em 2000 por (JIANG et al., 2000b). Ele propôs, em seu trabalho divido em duas partes, um método adaptativo para detecção e localização de faltas utilizando PMUs. A primeira parte do trabalho trata da teoria e algoritmos desenvolvidos (JIANG et al., 2000b), enquanto que a implementação e resultados são apresentados na segunda parte do artigo (JIANG et al., 2000a). Este trabalho também propõe uma nova abordagem da DFT, capaz de eliminar ruídos, presença de harmônicas e erros de medições, obtendo assim resultados mais precisos extraídos dos sinais de tensão e 
corrente do SEP, mostrando-se eficaz na localização da falta.

\subsubsection{Proteção Avançada de Redes}

Tratando-se da teoria de proteção, a lógica diferencial é amplamente utilizada para proteção de grandes transformadores de potência, e também para quase todos os sistemas onde a saída de corrente se encontra próxima à entrada (COURY; OLESKOVICZ; GIOVANINI, 2011). Assim, uma lógica diferencial de alta precisão pode ser implementada utilizando as estimações fasoriais fornecidas pelo PMU.

\subsubsection{Monitoração de Magnitudes e Ângulos de Tensões}

Monitorando-se os parâmetros de magnitude e ângulos do sinal de tensão, a PMU informa aos operadores do sistema seu estado em relação aos limites de operação prédeterminados. Através da análise dos ângulos, é possível também calcular o fluxo de potência entre duas barras de um SEP, identificando assim a direção do fluxo de potência ativa no sistema.

\subsubsection{Análise de Distúrbios e Oscilações}

Como consequência da monitoração e altas taxas de amostragem dos sinais analisados pela PMU, é possível analisar precisamente os distúrbios ocorridos em um determinado período de operação do SEP. Além da análise de distúrbios já ocorridos, a visão global do estado do sistema possibilita aos operadores determinar condições de pré-falta antes mesmo que ela ocorra (AGOSTINI, 2006).

Analisando as oscilações dos parâmetros de tensão, frequência e fluxo de potência ativa e reativas em linhas de transmissão, também é possível identificar oscilações eletromecânicas devido a falta de torque de amortecimento nos rotores dos geradores (AGOSTINI, 2006)

\subsubsection{Melhoria na Estimação de Estados}

O estimador de estado fornece uma estimativa dos dados do SEP que usualmente são utilizados em análises de otimização da operação. Entre os parâmetros utilizados geralmente estão a magnitude da tensão e corrente, fluxos de potência ativa e reativa nas linhas e injeção das potências ativa e reativa.

Segundo (AGOSTINI, 2006), a contribuição dada pela medição fasorial depende fortemente da precisão da medição. Como as técnicas modernas de sincronização via satélite de alta precisão $\left(1 \mu \mathrm{s}\right.$ ou $\left.0.0216^{\circ} \mathrm{em} 60 \mathrm{~Hz}\right)$, as medidas fasoriais contribuem significativamente para a melhoria da solução do estimador. 


\subsubsection{Validação de Modelos de Planejamento}

Uma das maneiras de prever o comportamento de um SEP em determinada condição de operação, é fazendo uso de modelos de planejamento baseado na interpretação dos fenômenos observados. Neste contexto, as informações precisas fornecidas pelas PMUs são importantes para o refinamento dos modelos do SEP.

\subsubsection{Monitoração de Temperatura de Linhas de Transmissão}

O aquecimento das linhas de transmissão podem limitar a transferência de potência quando a esta não é restringida por outros meios para garantir a estabilidade da operação do SEP. Em (ZIMA; LARSSON, 2005), é proposto a aplicação de monitoração da temperatura de linhas de transmissão baseado em medidas fasoriais de tensão e corrente em ambos os terminais da linha monitorada. Através das medições fasoriais é possível calcular a variação da resistência da linha, a qual denota a variação térmica do material do condutor devido as propriedades intrínsecas do material e sua dependência térmica da resistência.

\subsection{Sistema de Medição Fasorial Sincronizado}

Com o surgimento dos Sistema de Medição Fasorial Sincronizado (SMFS) foi possível conhecer simultaneamente pontos específicos de um SEP, tornando-se assim uma ferramenta de monitoração e análise robusta e poderosa. Um SMFS é basicamente composto de equipamentos PMU e PDC integrados por um canal de comunicação de dados, permitindo que os dados coletados nos equipamentos sincronizados, sejam concentrados e posteriormente analisados com o auxílio de um software.

\subsubsection{Arquitetura de um Sistema de Medição Fasorial Sincroni- zado}

Considerando a instalação de um PMU para cada um dos diferentes pontos geográficos importantes de um SEP, e garantido a sincronia entre eles, pode-se concentrar os dados coletados em diferentes pontos, utilizando um PDC.

Para que a análise fasorial seja válida, existem algumas restrições sobre o erro dos valores encontrados como forma de condicionar medidas confiáveis do sistema, visto que um fasor é altamente sensível a variação dos parâmetros que o compõe. Um erro de $1 \mu \mathrm{s}$ nas medições corresponde a um erro de $0,0216^{\circ}$ em um sinal com frequência fundamental de $60 \mathrm{~Hz}$ (PHADKE, 2002), denotando o quão adequada necessita ser a precisão da sincronia de tempo.

A sincronia da informação gerada e transmitida é garantida utilizando um sistema GPS responsável pela referência de sincronismo do relógio existente nas unidades PMUs. 
Juntamente com o sinal de geo-localização, o sistema GPS emite um sinal de $1 \mathrm{~Hz}$ de frequência, o PPS, com jitter nulo, baseado no relógio atômico interno dos satélites que compõem o sistema GPS.

Uma vez que todos os relógios dos PMUs estão sincronizados em uma mesma referência de tempo, o PPS, o PMU então faz uso de uma estampa de tempo (timestamp) anexada a cada dado amostrado e processado. Posteriormente, essa informação "estampada" com o tempo, é transmitida para o concentrador de forma assíncrona.

A Figura 3 ilustra um SMFS composto por unidades PMUs espalhadas por diferentes localizações, referenciadas por satélites GPS para suas sincronização e interligadas a um concentrador PDC utilizando um meio de transmissão de dados, permitindo a armazenagem dos dados coletados para uma posterior análise.

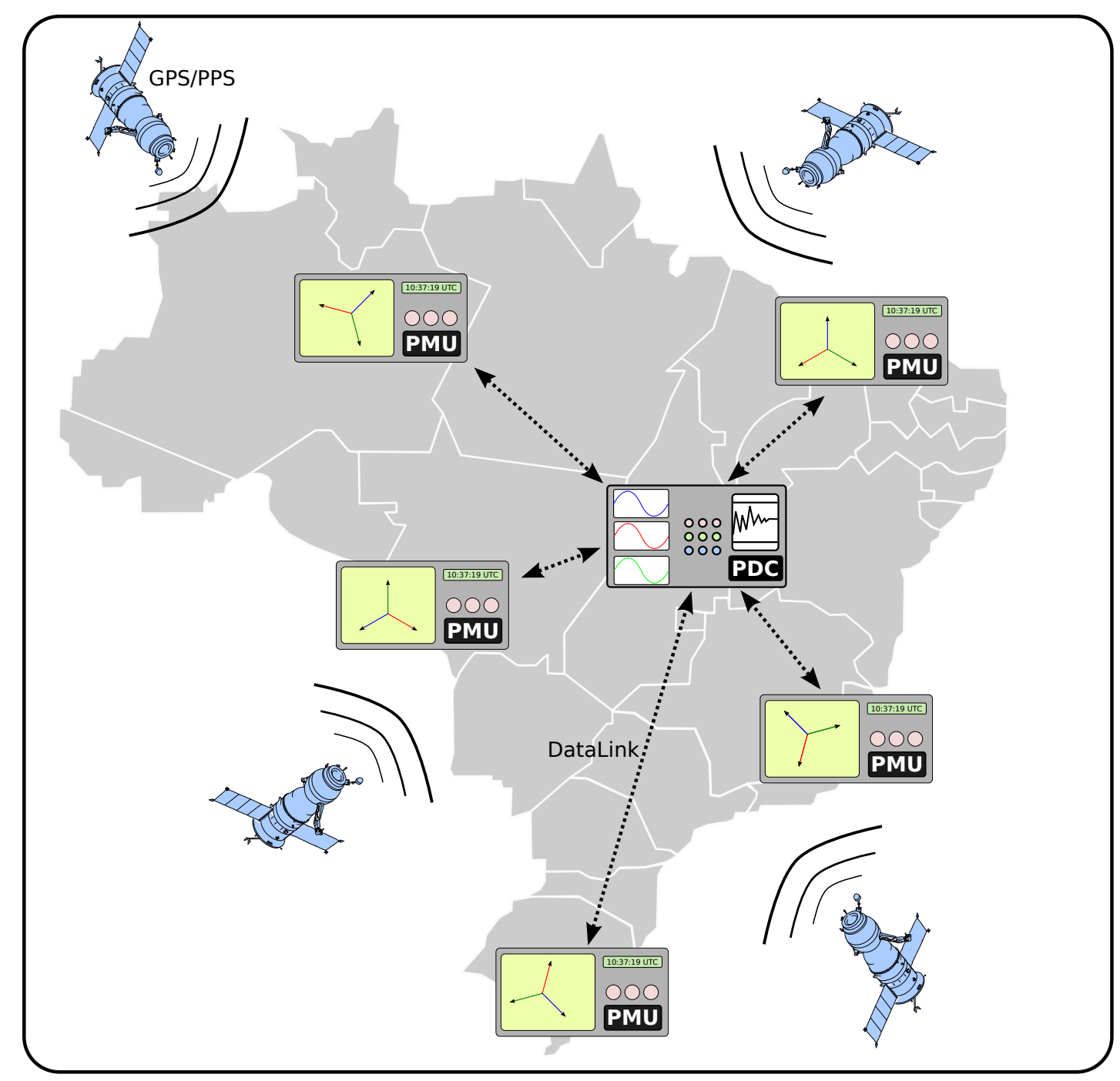

Figura 3 - Arranjo de um Sistema de Medição Fasorial Sincronizado. 


\subsection{Especificação - Norma IEEE C37.118-2011}

Esta norma publicada pelo IEEE em 2011 define os requisitos e especificações para a medição fasorial síncrona hoje em vigor (IEEE, 2011). Ela especifica padrões e precisão de medidas fasoriais, fornecendo assim requisitos para o trabalho proposto.

Segundo especificado, a precisão de uma medida fasorial é definida como a diferença vetorial entre o valor medido e o valor ideal do fasor em um determinando instante de tempo. Esta métrica recebe o nome de Total Vector Error (TVE) e é aqui aplicada como uma das forma de mensurar os resultados obtidos.

Matematicamente, o TVE pode ser descrito conforme Equação 1:

$$
T V E_{(t)}=100 \% \times \frac{\left|F_{\text {medido }}-F_{\text {estimado }}\right|}{\left|F_{\text {estimado }}\right|}
$$

É importante ressaltar que a norma considera que todas as medições são efetuadas em regime permanente, não especificando qualquer situação no caso da ocorrência de eventos inesperados no SEP. Desta forma, as medidas de amplitude, frequência e ângulo de fase são considerados constantes no período de sinal amostrado.

Durante a estimação fasorial, quatro medidas podem contribuir para o erro da medição fasorial, são elas: erro de magnitude, ângulo de fase, frequência, além do tempo de sincronização. Para ilustrar a precisão necessária, um erro de $1 \%$ no valor de magnitude medido, reflete diretamente em um erro de 1\% no TVE. Já quando medido o ângulo de fase, com um erro de $0,573^{\circ}$ na medição, também refletirá em $1 \%$ de erro no TVE. O mesmo acontece quando existe um erro de sincronização de tempo de 26,5 $\mu s$, em um sistema de frequência fundamental de $60 \mathrm{~Hz}$, que também levará a um resultado de $1 \%$ de erro no valor do TVE (SILVA, 2012a).

Para auxiliar no cenário de testes, a norma sugere três tipos básicos de sinais sintéticos: O primeiro é um degrau de magnitude de $-10 \%$, posteriormente é sugerido um degrau de ângulo de fase de $90^{\circ}$, finalizando com um teste do tipo degrau de frequência de $+5 \mathrm{~Hz}$. Note que os casos sugeridos ficam distantes do real cenário de operação de um SEP. No Capítulo 4 é possível verificar estes casos de testes, quando processado pelo método aqui desenvolvido.

A norma em nenhum momento especifica qual o método de medição deve ser utilizado, tampouco a frequência de amostragem dos sinais, algoritmos e métodos de sincronismo do mesmo. Esta margem permite que sejam estudados e comparados diferentes métodos de medição fasorial, resultando em trabalhos como este.

Por se tratar de um método inovador empregado à estimação de fasorial, é necessário garantir a qualidade dos resultados segundo a normatização vigente, assim como têm sido feito com os trabalhos mais atuais sobre o tema e comentados na Seção 2.4.

Os resultados disponíveis no Capítulo 4, são encontrados as recomendações de testes para mensurar o desempenho de uma PMU conforme descritos no Anexo G da norma 
IEEE C37.118-2011, além de casos simulados com o uso do software ATP para situações mais reais de operação de um SEP.

\subsection{Métodos de Estimação Fasorial Convencionais}

Pelo fato da norma IEEE C37.118-2011 não especificar os métodos de medições fasorial que devem ser utilizados, diferentes técnicas tem sido propostas ao longo dos anos, sempre em conformidade com as especificações normativas.

Hoje, conforme a literatura, são conhecidos vários métodos de estimação fasorial. Dentre eles podemos citar a DFT, PLL, LSE e também os métodos computacionais evolutivos.

\subsubsection{Discrete Fourier Transform (DFT)}

A Discrete Fourier Transform (DFT), é um dos algoritmos mais utilizados para estimar fasores da componente de frequência fundamental em relés digitais de proteção. Este método é capaz de remover componentes harmônicas, porém a presença da componente CC pode introduzir erros significativos nos fasores estimados. Além da sua importância teórica, a DFT desempenha um papel fundamental em implementações computacionais para uma variedade de algoritmos de processamento digital de sinais.

A DFT é definida em si, como uma sequência ao invés de uma função variável contínua, e que corresponde às amostras, igualmente espaçadas na frequência, da transformada de Fourier do sinal (OPPENHEIM et al., 1989). Antes da definição da DFT, faz-se necessário o entendimento da Discrete Time Fourier Transform (DTFT) representada pela Equação 2:

$$
X(j \omega)=\sum_{n=-\infty}^{n=+\infty}(x[n]) e^{-j \omega n}
$$

onde $\omega=2 \pi f / f_{s}$.

A Equação 2 representa matematicamente a transformada de Fourier para um dado sinal amostrado. Entretanto para propósitos práticos, esta equação pode ser reescrita segundo a Equação 3, equivalendo assim a um processo de amostragem do sinal, utilizando de um janelamento retangular de comprimento $N$ (RUBEENA, 2014).

$$
X_{N}(j \omega)=\sum_{n=0}^{N-1}(x[n]) e^{-j \omega n}
$$

A DFT de ciclo completo (1 ciclo) utiliza o comprimento da janela retangular $N$ selecionado como $N=\frac{f_{s}}{f_{n}}$, onde a frequência de interesse é dada por $F_{n}$. Em aplicações de sistemas de proteção elétricos, a DFT pode ser aproximada de uma DTFT (RUBEENA, 
2014), calculada para $N$ frequências igualmente espaçadas entre 0 e $2 \pi$, conforme ilustrado pela Equação 4.

$$
X=\frac{2}{N} \sum_{n=0}^{N-1} x[n] e^{-j 2 \pi \frac{f_{n}}{f_{s}} n}
$$

Conhecendo $N=\frac{f_{s}}{f_{n}}$ tem-se:

$$
X=\frac{2}{N} \sum_{n=0}^{N-1} x[n] e^{-j 2 \pi \frac{n}{N}}
$$

Para um sinal sinusoidal puro, denotado por $x(t)=A \cos \left(2 \pi f_{n} t+\theta\right)$, tem-se:

$$
x[n]=x \frac{n}{f_{s}}=\operatorname{Acos}\left(2 \pi \frac{n}{N}+\theta\right)
$$

Igualando $x[n]$ da Equação 6 com a Equação 5, obtém-se a Equação 7:

$$
X=\frac{2}{N} \sum_{n=0}^{N-1} A \cos \left(2 \pi \frac{n}{N}+\theta\right) e^{-j 2 \pi \frac{n}{N}}
$$

A qual pode ser reescrita utilizando a identidade de Euler conforme a Equação 9.

$$
\begin{aligned}
& X=\frac{1}{N} \sum_{n=0}^{N-1} A\left(e^{j \theta}+e^{-j\left(4 \pi \frac{n}{N}+\theta\right)}\right) \\
& X=A e^{j \theta}+\frac{A e^{-j \theta}}{N} \sum_{n=0}^{N-1} e^{-j 4 \pi \frac{n}{N}}
\end{aligned}
$$

Assumindo $r=e^{-j 4 \pi \frac{1}{N}}$ como uma progressão geométrica, a soma desta progressão geométrica finita é dada pela Equação 10.

$$
\sum_{n=0}^{N-1} r^{n}=1+r+r^{2}+\cdots+r^{N-1}=\frac{1-r^{N}}{1-r}
$$

E quando simplificada, é denotada pela Equação 11.

$$
\sum_{n=0}^{N-1} e^{-j 4 \pi \frac{n}{N}}=\frac{1-e^{-j 4 \pi \frac{N}{N}}}{1-e^{-j 4 \pi \frac{1}{N}}}=0
$$

Assim a equação que representa o fasor, para qualquer sinal sinusoidal, com uma frequência fundamental $f_{n}$ é dado pela Equação 12 .

$$
X\left(f_{n}\right)=\frac{2}{N} \sum_{n=0}^{N-1} A \cos \left(2 \pi \frac{n}{N}+\theta\right) e^{-j 2 \pi \frac{n}{N}}
$$

A qual pode ser reescrita em função dos termos real e imaginário que compõe o fasor conforme Equação 13.

$$
X\left(f_{n}\right)=\frac{2}{N} \sum_{n=0}^{N-1} A \cos \left(2 \pi \frac{n}{N}+\theta\right) e^{-j 2 \pi \frac{n}{N}}=\hat{Y}_{r e a l}^{h}+\hat{Y}_{i m a g}^{h}
$$


Durante a estimação fasorial, utilizando o método de DFT, as estimativas das partes real e imaginária do fasor, de frequência $f_{h}=h f_{1}$, sendo $h$ a ordem do harmônico de interesse e $f_{1}=60 \mathrm{~Hz}$, são dadas pelas Equações 14 e 15 respectivamente (BENMOUYAL, 1995).

$$
\begin{gathered}
\hat{Y}_{\text {real }}^{h}=\frac{2}{N} \sum_{n=0}^{N-1} x[n] \cos \left(\frac{2 \pi}{N} n h\right) \\
\hat{Y}_{\text {imag }}^{h}=\frac{2}{N} \sum_{n=0}^{N-1} x[n] \operatorname{sen}\left(\frac{2 \pi}{N} n h\right)
\end{gathered}
$$

Desta forma pode-se obter os valores de amplitude e ângulo de fase através das Equações 16 e 17 respectivamente.

$$
\begin{aligned}
& A=\sqrt{\left(\hat{Y}_{\text {real }}^{h}\right)^{2}+\left(\hat{Y}_{\text {imag }}^{h}\right)^{2}} \\
& \theta=\arg \left(\hat{Y}_{\text {real }}^{h}+j \hat{Y}_{\text {imag }}^{h}\right)
\end{aligned}
$$

Vários trabalhos tentam atenuar as deficiência do método DFT com relação as componentes harmônicas e componente CC. Métodos baseados em diferentes tipos de janelamento de sinal foram explorados por Harris (1978), enquanto que um método de janelamento de tamanho adaptativo foi por proposto por (HART et al., 1997).

Conforme citado no trabalho de Machado et al. (2011), estudos realizados por Benmouyal (1995), sugerem que a aplicação de um filtro digital mímico pode remover completamente a componente CC nos fasores, desde que a constante de tempo do sistema seja igual a constante de tempo considerada no algoritmo. Esta condição não é factível em um SEP real, pois a constante de tempo e a amplitude da componente CC são desconhecidas, variando em função da resistência, posição e ângulo da tensão no instante de um evento (YU; GU, 2001). Assim Yu e Gu (2001) apresentaram um novo algoritmo, que remove harmônicas através do uso de filtros analógicos passa-baixas e utiliza um método DFT de meio-ciclo de onda para eliminar as componentes CC.

Visando aperfeiçoar os resultados obtidos pelo método de DFT, Wang e Sun (2004) propuseram um outro método, o qual considera o erro total da fase para obtenção de equações de correção de amplitude, ângulo de fase e frequência corrigindo assim os erros existentes. Seguindo esta linha, foi proposto por Lee, Kang e Nam (2008), um algoritmo de DFT modificado, decompondo o processo de DFT convencional em 2 outras DFTs, uma utilizando amostras pares e outra amostras ímpares. Desta forma o efeito da componente CC é eliminado usando a relação recursiva entre as saídas das DFTs pares e ímpares.

Assim, aplicando o método de DFT tradicional de ciclo completo ou seus variantes mais precisos, em um período definido do sinal elétrico, é possível estimar as partes reais e imaginárias que compõem os fasores correspondentes em uma dada frequência. Como 
na prática, pequenas variações da frequência fundamental ocorrem no sistema, pequenos desvios nas medições de amplitude e fase do sinal são esperados, contribuindo para um erro no resultado da estimação final.

\subsubsection{Phase Locked Loop (PLL)}

Um outro método muito utilizado são os sistemas em malha do tipo Phase Locked Loop (PLL). PLL são métodos empregados para a geração de um sinal sincronizado utilizando para isto um sinal de referência. Malhas PLL são utilizadas em diversas áreas como sistemas de controle, instrumentação, telecomunicações, originando aplicações em equipamentos como filtros ativos, restauradores de tensão, instrumentos de medições relacionados a qualidade de energia e monitoração de faltas (JUNIOR, 2012). Entre as funcionalidades de uma malha PLL, a sintetização de senoides visando a estimação fasorial é aqui relevante.

Seja $u(t)$ um sinal de tensão ou corrente do sistema, contínua e quase sempre periódica, pode-se definir uma componente senoidal desta função, $u(t)=A \operatorname{sen} \phi(t)$, onde $A$ é a amplitude, $\phi(t)$ representa a fase total desde componente. Quando a frequência é fixa, o termo $\phi(t)$ pode ser expresso como $\omega t+\delta$, em que $\omega$ é a frequência expressa em radianos e $\delta$ é a constante de fase. Em regime permanente, os parâmetros $A, \omega$ e $\theta$ são grandezas fixas. É observado na prática que $u(t)$ diverge do modelo teórico esperado, sendo em uma situação típica, denotado conforme Equação 19 (ZIARANI; KONRAD, 2004).

$$
u(t)=\sum_{i=0}^{\infty} A_{i} \operatorname{sen} \phi_{i}+n(t)
$$

onde $n(t)$ denota o ruído superimposto.

Como deseja-se extrair a componente senoidal de $u(t)$, tal componente pode ser expressa como $y(t)=A \operatorname{sen} \phi(t)$, incorporando todas as variações de fase no termo $\phi(t)$. Para incorporar o conceito de frequência instantânea na fase global, define-se a Equação 20:

$$
y(t)=A(t) \operatorname{sen}\left(\int^{t} \omega(\tau) d \tau+\delta(t)\right)
$$

Seja $M$ um conjunto contendo todos os sinais senoidais definidos como:

$$
M=A(t) \operatorname{sen}\left(\int^{t} \omega(\tau) d \tau+\delta(t)\right) \mid \begin{cases}A(t) \in, & {\left[A_{\text {min }}, A_{\text {max }}\right]} \\ \omega(t) \in, & {\left[\omega_{\min }, \omega_{\max }\right]} \\ \delta(t) \in, & {\left[\delta_{\min }, \delta_{\max }\right]}\end{cases}
$$

Procura-se uma componente em $M$ que melhor represente a componente de interesse existente no sinal $u(t)$, definindo-se um vetor de parâmetros conforma Equação 21:

$$
\Psi(t)=[A(t) w(t) \delta(t)]^{T}
$$


Assim a saída definida como a componente senoidal desejada pode ser expressa conforme a Equação 22.

$$
y(t, \Psi(t))=A(t) \operatorname{sen}\left(\int^{t} \omega(t) d \tau+\delta(t)\right)
$$

Definindo-se uma função custo, e utilizando o método dos gradientes descendentes apresentado no trabalho de Ziarani e Konrad (2004) e resumido por Silva (2012a), é possível obter as três equações diferenciais simplificadas propostas no trabalho de KarimiGhartemani, Karimi e Iravani (2004), as quais regem o comportamento da malha PLL, necessárias para obter os parâmetros de amplitude (Equação 23), frequência (Equação 24) e ângulo de fase (Equação 25) esperadas como saída da malha PLL durante o processo de estimação fasorial.

$$
\begin{gathered}
\frac{A(t)}{d t}=\mu_{1} e(t) \operatorname{sen}(\phi(t)) \\
\frac{\omega(t)}{d t}=\mu_{2} e(t) \cos (\phi(t)) \\
\frac{\phi(t)}{d t}=\omega(t)+\mu_{3} e(t) \cos (\phi(t))
\end{gathered}
$$

As equações diferenciais apresentadas pode ser implementada em circuitos eletrônicos, para tal utilização, faz-se necessário a discretização da equações utilizando o método de Euler Forward, resultando nas Equações 26, 27 e 28 responsáveis por estimar, respectivamente, os parâmetros de amplitude, frequência e ângulo de fase do sinal amostrado.

$$
\begin{gathered}
A[n+1]=A[n]+\mu_{1} T_{s} e[n] \operatorname{sen}(\phi[n]) \\
\omega[n+1]=\omega[n]+\mu_{2} T_{s} e[n] \cos (\phi[n]) \\
\phi[n+1]=\phi[n]+T_{s} \omega[n]+\mu_{3} T_{s} e[n] \cos (\phi[n])
\end{gathered}
$$

Uma malha PLL quando implementada em circuitos eletrônicos, é composta basicamente de três estruturas conforme ilustrado pela Figura 4 (GOMES, 2007):

O detector de fase (Phase Detector), é responsável por gerar um sinal de erro proporcional à diferença de fase entre o sinal de referência interno $u_{\text {out }}$ e a componente fundamental do sinal de entrada $u_{i n}$, gerando o sinal $u_{d}$. Em seguida, o sinal de erro gerado $\varepsilon$, considerado como uma referência para a correção da frequência do sinal, é submetido a um filtro passa-baixas (Loop Filter) onde são minimizados os ruídos indesejáveis.

Uma vez que o sinal de erro esteja filtrado, o sinal $u_{f}$ é então utilizado com referência para o terceiro módulo da malha PLL, o oscilador controlado por tensão, ou Voltage Controlled Oscillator (VCO). Este oscilador é responsável por sintetizar um sinal senoidal 


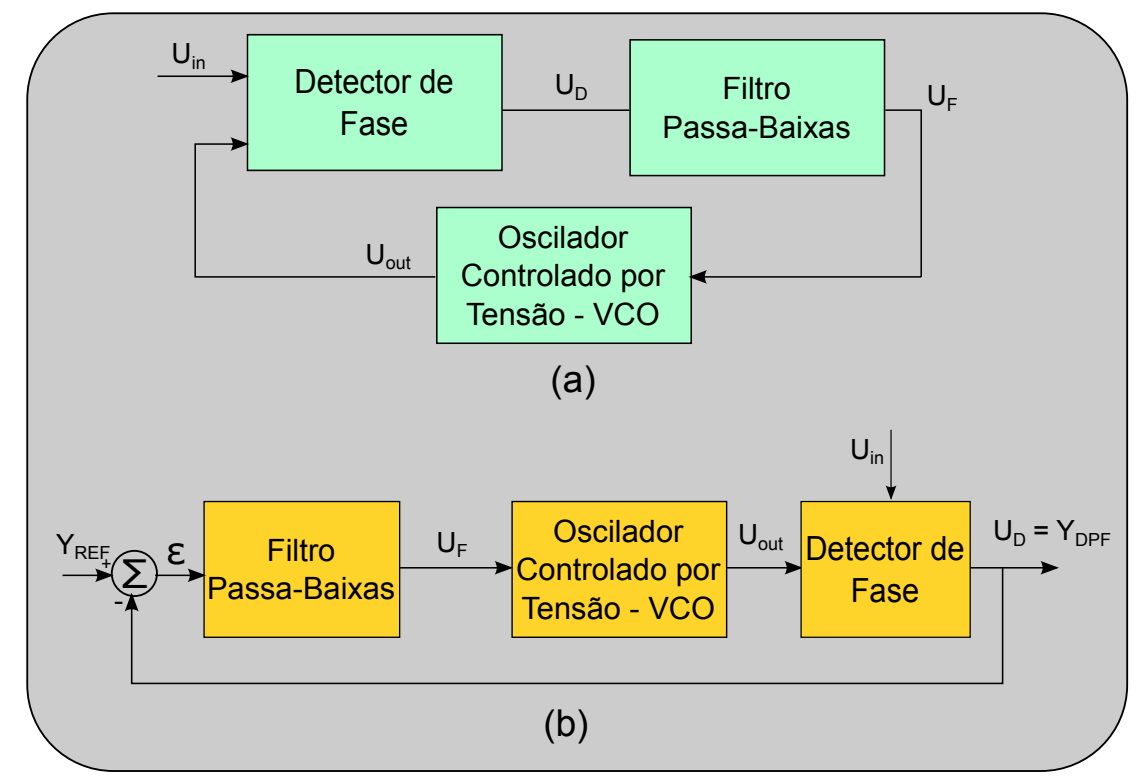

Figura 4 - (a) Diagrama de Blocos Típico do PLL (b) Representação do Sistema de Controle do PLL. Adaptado de (JUNIOR, 2012)

$Y_{D P F}$, cuja frequência é diretamente proporcional a sua referência de controle (GOMES, 2007).

Quando em regime, o sistema tende a um erro $\varepsilon=0$. Desta forma, após o período adaptativo da malha PLL, o resultado obtido $Y_{D P F}$ será um sinal senoidal, sincronizado em fase e frequência com o sinal amostrado $Y_{R E F}$. Embora este método apresente uma alternativa ao método de DFT, faz-se necessário o ajustes de determinados parâmetros da malha PLL, que quando mal dimensionados, muitas vezes, torna o período adaptativo da malha lento, prejudicando sua aplicação.

Visando diminuir o efeito do ruído nos sinais, Ziarani e Konrad (2004) propõem o emprego de filtros na estrutura PLL. Karimi-Ghartemani, Karimi e Iravani (2004) também apresentam a mesma estrutura proposta, porém considerando-se dois filtros passa-baixas aumentando assim a imunidade do sistema ao ruído.

\subsubsection{Método dos Mínimos Quadrados - Least Square Error $(\boldsymbol{L S E})$}

O método dos mínimos quadrados ou LSE, também apresenta-se como alternativa aos métodos de DFT e/ou PLL. Os métodos de estimação fasorial baseados em mínimos quadrados são divididos em algoritmos sequenciais e recursivos. Os algoritmos sequenciais se caracterizam por estimar os fasores utilizando todas as amostras do sinal contida na janela, de uma única vez. Já os algoritmos recursivos estimam os fasores para cada nova amostra do sinal contida na janela.

O método dos mínimos quadrados é uma técnica de ajuste de curvas, no qual se ajusta uma função matemática pré-definida $\hat{y}$ a um conjunto de amostras de uma grandeza 
qualquer $y$. O melhor ajuste é alcançado quando a soma dos quadrados dos erros entre os valores estimados e os reais é minimizada (FORMIGA, 2012). O modelo para o sinal y(t) pode ser representado pela série de Fourier conforme Equação 29.

$$
\hat{y}(t)=a_{0}+\sum_{n=1}^{\infty}\left[a_{n} \cos \left(n \omega_{0} t\right)+b_{n} \operatorname{sen}\left(n \omega_{0} t\right)\right]
$$

onde $\omega_{0}$ é a frequência angular fundamental, $a_{n}$ e $b_{n}$ as amplitudes e $n$ a ordem harmônica considerada no modelo. Generalizando o modelo apresentado pela Equação 29, obtém-se o novo modelo, mais simples, conforme a Equação 30.

$$
\hat{y}(t)=\phi_{1} \Psi_{1}+\phi_{2} \Psi_{2}+\ldots+\phi_{p} \Psi_{p}
$$

onde $\phi_{1}, \phi_{2}, \ldots, \phi_{p}$ são os chamados regressores e $\Psi_{1}, \Psi_{2}, \ldots, \Psi_{p}$ são os parâmetros a serem determinados. Após algumas manipulações algébricas conforme descritas por (FORMIGA, 2012), pode-se aproximar a janela de amostras do sinal $y(t)$ pelo modelo matemático do sinal conforme a Equação 32.

$$
\begin{array}{r}
y(1)=\phi_{1}(1) \Psi_{1}+\phi_{2}(1) \Psi_{2}+\ldots+\phi_{p}(1) \Psi_{p}, \\
y(2)=\phi_{1}(2) \Psi_{1}+\phi_{2}(2) \Psi_{2}+\ldots+\phi_{p}(2) \Psi_{p}, \\
\ldots \\
y(N)=\phi_{1}(N) \Psi_{1}+\phi_{2}(N) \Psi_{2}+\ldots+\phi_{p}(N) \Psi_{p},
\end{array}
$$

A modelagem do sinal através da aproximação matemática citada, pode ser reescrita em forma matricial $Y=M \Psi$, onde $\Psi$ é o vetor dos parâmetros a serem encontrados:

$$
\begin{gathered}
M=\left[\begin{array}{cccc}
\phi_{1}(1) & \phi_{2}(1) & \ldots & \phi_{p}(1) \\
\phi_{1}(2) & \phi_{2}(2) & \ldots & \phi_{p}(2) \\
\vdots & \vdots & \ddots & \vdots \\
\phi_{1}(N) & \phi_{2}(N) & \ldots & \phi_{p}(N)
\end{array}\right] \\
Y=[y(1) y(2) \ldots y(N)]
\end{gathered}
$$

Desta forma, a solução dos mínimos quadrados minimizará a soma dos quadrados dos erros $v$, conforme ilustra a Equação 34:

$$
v=\sum_{k=1}^{N}(\hat{y}-y)^{2}
$$

A determinação do vetor dos parâmetros $\Psi$, que minimiza o erro quadrático é denominada solução de mínimos quadrados, obtida quando deriva-se a Equação 34 e igualando-a a zero (FORMIGA, 2012). 
Já o algoritmo LSE recursivo, quando inicializado, tem a vantagem de necessitar de um menor esforço computacional em relação ao algoritmo tradicional sequencial já que apenas a nova amostra de dados na janela é realmente processada. Entre os trabalhos de estimação fasorial que utilizam este método, Kamwa e Grondin (1991) propuseram dois diferentes métodos para estimar a amplitude e fase dos fasores de tensão e corrente, enquanto que a frequência é obtida através do valor estimado da fase. Tais métodos são conhecidos como: Recursive Least Squares (RLS) e Mean Square Error (MSE), ambos de caráter recursivo. Posteriormente para remover eventuais ruídos do resultado é proposto a utilização de um filtro de média móvel.

Em 1998, Almeida e Lima (1998) modificaram o algoritmo LSE tornando-o mais eficiente em suas estimativas fasoriais. Esta melhoria sugere às modificações apresentadas na matriz de covariância no processo.

\subsubsection{Métodos Computacionais Evolutivos}

O aperfeiçoamento dos sistemas computacionais ao longo dos anos e a facilidade de acesso à processadores mais rápidos, possibilitaram que novos métodos computacionais fossem estudados e codificados, permitindo novas abordagens de resolução para problemas de estimação fasorial. Uma das abordagens computacionais utilizadas é o uso dos métodos computacionais evolutivos para solução de problemas de otimização. Como o nome propõe, métodos computacionais evolutivos são algoritmos inspirados em mecanismos de seleção e genética natural.

Os trabalhos publicados por El-Naggar e Youssef (2000) investigam uma nova abordagem da resolução do problema de estimação de parâmetros aplicado à relés de frequência utilizando computação evolutiva, enquanto que em 2003, Macedo et al. (2003) desenvolvera um método de estimação de harmônicos, também utilizando computação evolutiva.

O AG é um método evolutivo que, dado um conjunto de indivíduos, novos indivíduos serão gerados a partir dos melhores existentes neste conjunto. Para elencar os melhores, os indivíduos têm seus cromossomos (strings) analisados por uma ou mais funções de avaliação, resultando em um valor de aptidão (fitness). Quanto melhor for a representação de um cromossomo em relação a uma possível solução do problema, maior a chance deste sobreviver e gerar novos indivíduos mais aptos. Este mecanismo de geração faz uso da geração genética e da geração evolutiva para criar novos indivíduos. No mecanismo de geração genética, são utilizados operadores de cruzamento e mutação, produzindo novos indivíduos através da troca das informações genéticas entre os indivíduos selecionados. Já o mecanismo de geração evolutiva é responsável por determinar quais os indivíduos que sofrerão cruzamento e mutação. Esta evolução termina quando encontra-se um ótimo indivíduo na população. Maiores detalhes desta técnica serão apresentados no próximo capítulo. 
Recentemente, Silva (2012b) e Silva (2012a) propuseram algoritmos genéticos para estimação fasorial de alta precisão, utilizando, assim como Carvalho et al. (2009), uma plataforma Field Programmable Gate Array (FPGA) como forma de garantir o desempenho do método em tempo real. Silva (2012b) utilizou-se de um Algoritmo Genético (AG) para o problema de estimação da frequência em tempo real, enquanto que Silva (2012a) faz uso de um Algoritmo Genético (AG) e um Algoritmo Genético Compacto (AGC) para a resolução do problema de estimação fasorial. O AGC também foi utilizado por Casseb (2012) e pode ser comparado como uma simplificação do AG utilizado por Silva (2012b).

Tomando como base os trabalhos de Silva (2012a) e Casseb (2012) que utilizam da computação paralela evolutiva para estimação fasorial, juntamente com a análise multiobjetivo do problema utilizada por (SILVA, 2012b),é proposto então o desenvolvimento de um novo AGCM para estimação fasorial.

Quando agregado uma plataforma FPGA referida por Carvalho et al. (2009), o método aqui proposto pode ser aplicado à estimação fasorial em tempo real, motivador deste trabalho. 


\section{Utilização do Algoritmo Genético Compacto Multiobjetivo na Estimação Fasorial}

Este capítulo descreve os métodos evolutivos e suas configurações para resolução do problema de estimação fasorial de sinais elétricos de um SEP.

\subsection{Algoritmos Evolutivos}

Algoritmo Evolutivo (AE) é o termo que designa uma classe de algoritmos computacionais para resolução de problemas, cujo funcionamento tem como base mecanismos de evolução que se aplicam sobre uma população, assim como acontece com os seres vivos na natureza.

Os AEs têm sido explorados em problemas de otimização, onde mesmo que não se conheça o que está sendo otimizado, é possível encontrar uma solução ótima.

Holland (1975) propôs estudar o processo evolutivo dos seres vivos e seus métodos adaptativos diante dos recursos oferecidos pela natureza. A técnica base consiste em mapear cada possível solução do problema como um indivíduo de uma população (ecossistema).

Assim como na biologia, os indivíduos desta população sofrem mudanças como forma de melhor se adaptar a situação existente. Entre os indivíduos, podem ocorrer seleção natural, cruzamento e mutação, permitindo assim que os indivíduos evoluam até atingir as melhores soluções para um determinado cenário.

Os Algoritmos Genéticos (AGs) utilizam desta teoria evolucionária para então explorar problemas complexos, destacando-se devido sua simplicidade de codificação, precisão nos resultados obtidos e sua arquitetura altamente paralelizável.

Nos AGs, os indivíduos são avaliados e evoluem em sua população em busca da solução ótima. Os AGs são definidos por codificar meta-variáveis de problemas como sendo genes 
em um cromossomo. Para evoluir esta população, são então aplicados os operadores genéticos, como mutação e crossover diretamente sobre os genes do indivíduo (HOLLAND, 1975).

Esta característica evolutiva permite utilizar os AGs em situações onde o espaço de busca da solução é desconhecido, quantificando a qualidade da solução encontrada em cada época durante a evolução da população.

Este capítulo apresenta os principais conceitos sobre AGs, suas variações e seus operadores. A Seção 3.4 mostra os principais operadores genéticos conhecidos. Na Seção 3.5, é apresentado o Algoritmo Genético Compacto (AGC), enquanto que na Seção 3.6 é proposto o Algoritmo Genético Compacto Multiobjetivo (AGCM). Finalmente a Seção 3.7 trata do uso de métodos paralelos na criação de AGs.

\subsection{Indivíduos}

Para garantir que os indivíduos sejam capaz de encontrar as melhores soluções de um cenário existente, deve-se criar uma correta representação do problema utilizando os genes de cada indivíduo, garantindo assim, que todo o possível espaço de busca de soluções seja explorado.

Uma forma comum de representar os genes de cada indivíduo é utilizar a codificação binária, onde cada gene contém o valor 0 ou 1 indicando o quão significativo é aquele gene (característica) para a solução. Uma maneira simples e muito utilizada para a inicialização dos genes de cada indivíduos é iniciá-los com valores aleatórios.

A solução representada pelo indivíduo através de seus genes conforme, Figura 5, é também chamada de genótipo, pois armazenam as características intrínsecas do próprio indivíduo (HAUPT; HAUPT, 1998).

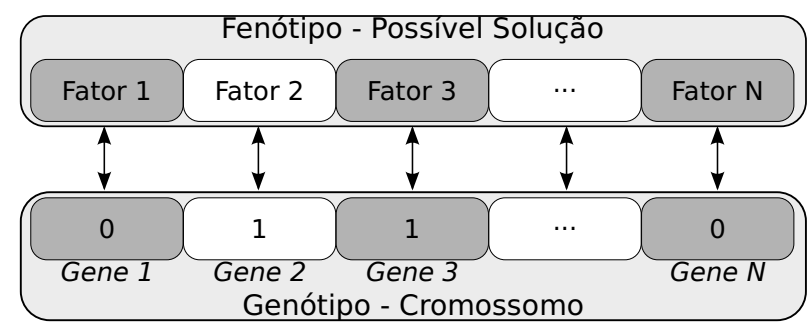

Figura 5 - Representação do Indivíduo

\subsection{Função de Avaliação}

A função de avaliação consiste em qualificar os indivíduos existentes em uma dada população utilizando os valores de seu genótipo para o cálculo de sua aptidão. Para cada indivíduo existente, é então avaliado a sua aptidão, permitindo posteriormente que eles 
sejam selecionados sempre em busca das soluções ótimas. Assim, a aptidão ou fitness é o resultado da expressão matemática que mapeia o problema e avalia os indivíduos em busca de soluções.

Devido ao número de indivíduos existentes em uma população, métodos de processamento paralelo têm sido usado com grande sucesso para aumentar a velocidade de avaliação dos indivíduos, visto que trata-se de uma mesma operação matemática executada inúmeras vezes consecutivamente.

\subsection{Operadores Genéticos}

Os operadores genéticos são os responsáveis pela evolução dos indivíduos, alterando suas características, onde apenas os melhores indivíduos evoluirão até as melhores soluções. Segundo Goldberg (2002) os operadores genéticos mais utilizados são:

\subsubsection{Seleção}

A seleção consiste na escolha do melhor indivíduo para um dado momento da população. Os métodos de torneio e roleta são os mais comumente utilizados. O método de torneio consiste em selecionar o indivíduo mais apto entre dois ou mais. Já o método de roleta seleciona os indivíduos aleatoriamente de forma proporcional à sua aptidão (GOLDBERG, 2002).

\subsubsection{Elitismo}

Este operador consiste em selecionar o melhor indivíduo de uma dada população e mantê-lo inalterado, não sendo aplicado assim qualquer operador sobre ele, aumentando, portanto, a velocidade de convergência do algoritmo (GOLDBERG, 2002).

\subsubsection{Cruzamento}

O operador de cruzamento (crossover) consiste em combinar os genótipos de dois ou mais melhores indivíduos selecionados em uma dada população. Desta forma o novo indivíduo, o filho, herda as melhores características dos indivíduos selecionados, seus pais. Na Figura 6 é apresentado um modelo de cruzamento simples de um único ponto (GOLDBERG, 2002).

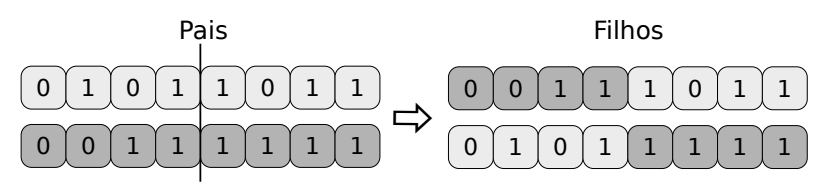

Figura 6 - Cruzamento de Um Ponto. 
Outro método utilizado é o cruzamento uniforme representado pela Figura 7, onde os bits dos indivíduos pais, são copiados aleatoriamente gerando um novo filho.

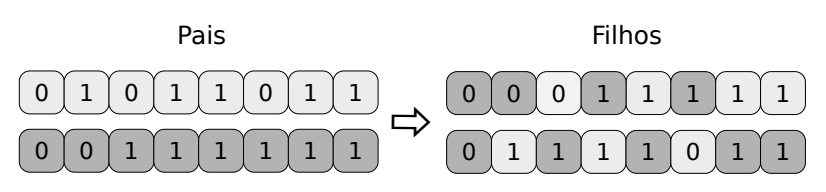

Figura 7 - Cruzamento Uniforme.

Ainda existem outros métodos de cruzamento, como o cruzamento aritmético, onde uma operação matemática é aplicada nos indivíduos pais, para se obter um novo filho.

\subsubsection{Mutação}

Este operador atua de forma aleatória nos genótipos de cada indivíduo, gerando pequenas alterações muitas vezes impossíveis de se obter via operador de cruzamento, garantindo assim a variabilidade genética da população (GOLDBERG, 2002). Um exemplo de mutação pode ser observado na Figura 8.

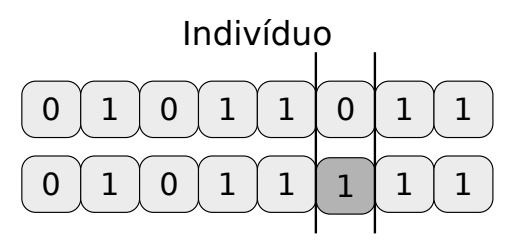

Figura 8 - Mutação Genética

\subsubsection{Predação}

A predação visa eliminar os indivíduos de menor aptidão de uma dada população, onde além de aumentar a velocidade de convergência do algoritmo, também permite inserir novos indivíduos mais aptos à solução.

Embora existam outros operadores genéticos, estes são os mais comumente utilizados. Alguns subtipos de AGs não utilizam alguns operadores citados, ou ainda têm seu comportamento embutidos implicitamente na codificação, como o caso do Algoritmo Genético Compacto (AGC) (GOLDBERG, 2002).

\subsection{Algoritmos Genéticos Compactos}

O Algoritmo Genético Compacto (AGC) é uma simplificação do AG a qual consiste em representar a população dos indivíduos através de uma distribuição de probabilidade em todo espaço de soluções. Desta forma um AGC é equivalente a um AG com operador de cruzamento uniforme (HARIK; LOBO; GOLDBERG, 1999). 
Uma característica padrão do AGC é a pouca memória de sistema utilizada para a representação de toda a população. Mapeando-se os indivíduos sobre um vetor de probabilidade, faz-se necessário gerar apenas os indivíduos que realmente serão utilizados e, a partir deste ponto, atualizar este mesmo vetor com base nos genes dos indivíduos gerados como provável solução.

Inicialmente o vetor de probabilidade é inicializado com o valor de 0,5 (50\%), cujo valor representa a probabilidade daquele gene em específico assumir o valor de 0 ou 1 (representação binária). Note também que é necessário um vetor de probabilidade de $X$ posições para um indivíduo com $X$ genes em seu genótipo. A Figura 9 ilustra a relação e o comportamento entre o vetor de probabilidade e os genes do indivíduo.

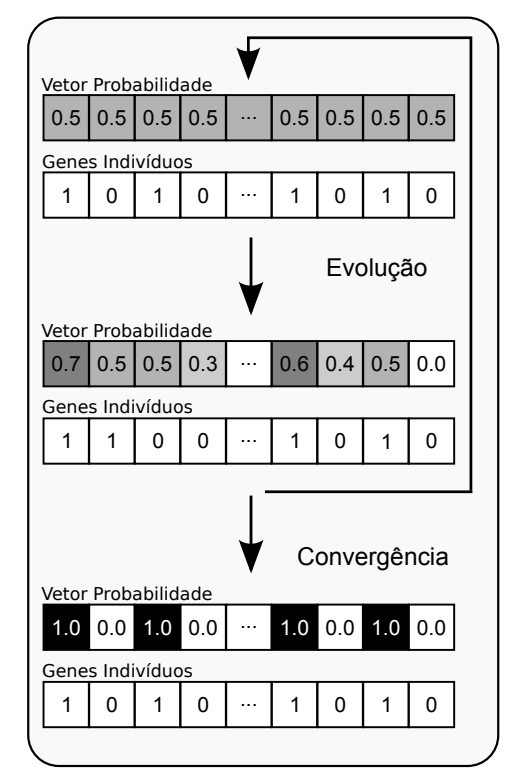

Figura 9 - Vetor de Probabilidade do AGC

Após gerado os $N$ indivíduos que representam uma população, o fitness de cada indivíduo é calculado e um torneio de dois ou mais realizado para a seleção do indivíduo mais apto. Conhecido então o melhor indivíduo, o vetor de probabilidade é atualizado em uma razão de $1 / N$ unidades baseado nos genes deste individuo. Esta razão de $1 / N$ é responsável por simular uma população de $N$ indivíduos, sem a necessidade de gerá-los todos ao mesmo tempo.

O critério de parada da convergência das soluções ocorre quando um número de épocas é atingido ou quando o vetor de probabilidade possuir apenas chances máximas (100\%) ou nulas (0\%). Segundo os resultados apresentados pelo trabalho de Casseb (2012), operadores de mutação não influenciaram significativamente na eficiência do algoritmo genético compacto, simplificando ainda mais sua implementação.

Conforme ilustrado pelo fluxograma da Figura 10, inicialmente o vetor de probabilidade $p(t)$ tem seus valores inicializados com 0.5 , denotando a probabilidade do gene assumir valores de 0 ou 1 . O próximo passo é gerar $X$ indivíduos aleatórios, considerando 
a informação existente no vetor de probabilidade para obter o valor de cada gene que os formarão. Para este fluxograma foram gerados 2 indivíduos, $A$ e $B$.

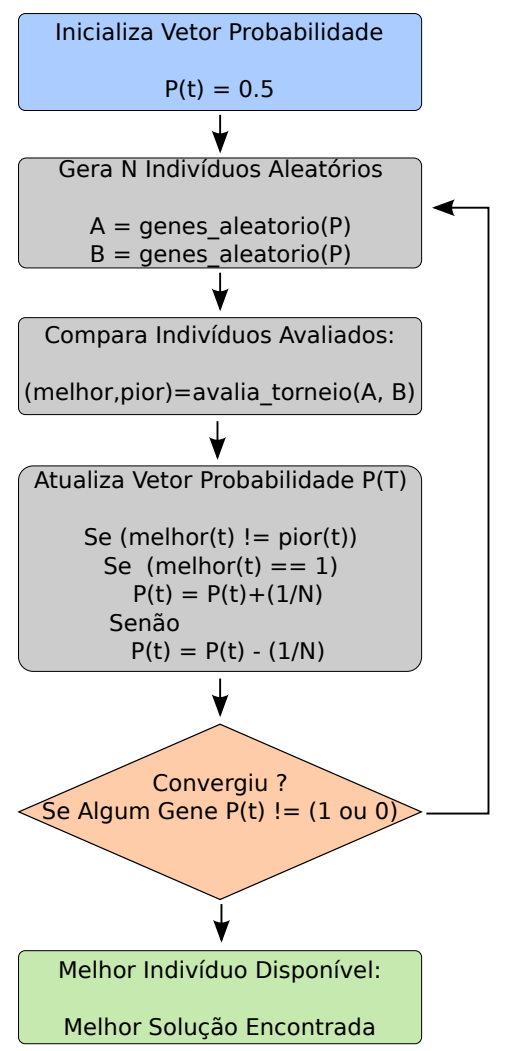

Figura 10 - Fluxograma de Execução do AGC

Posteriormente o método de seleção por torneio, de 2 indivíduos no caso, é aplicado, escolhendo assim o melhor e o pior indivíduo com base em sua aptidão.

Baseado no melhor indivíduo escolhido, a atualização do vetor de probabilidade ocorre então em uma razão de $\pm 1 / N$ conforme o valor do seu gene seja 0 ou 1 , onde, $N$ é o parâmetro que representa o tamanho da população desejada.

Este processo se repete até que toda informação existente no vetor de probabilidade, $p(t)$, seja igual a $0(0 \%)$ ou $1(100 \%)$,indicando assim a probabilidade de ocorrência daquele gene no indivíduo.

Uma vez convergido o vetor de probabilidade, o indivíduo gerado considerando a probabilidade dos genes indicada pelos valores contidos no vetor $p(t)$ será uma ótima solução para o problema.

\subsection{Algoritmos Genéticos Compactos Multiobjetivo}

Diferentemente dos problemas com objetivo único, ou mono-objetivos, em que uma solução ótima é obtida através da minimização (ou maximização) de uma função objetivo de variáveis de decisão sujeitas a restrições, a análise multiobjetivo se define por trabalhar com um conjunto de funções objetivo selecionando a solução de melhor compromisso, 
considerando um conjunto de fatores que devem ser ponderados. Desta forma um problema de otimização multiobjetivo se define então por trabalhar com um conjunto de funções objetivo, implicando que os critérios de análise e julgamento da soluções devem ser balanceados conforme uma métrica pré-determinada.

A análise multiobjetivo possibilita o apoio ao processo de decisão na escolha da mais adequada das soluções não-dominadas, utilizando os critérios de avaliação adotados para as condições peculiares do problema. Cada um dos aspectos do problema sujeitos ao processo de decisão, é então mensurado através de uma função objetivo pertinente, as quais podem utilizar como métrica diferentes unidades de medidas.

Utilizando-se do conceito da análise multiobjetiva, os Algoritmos Genéticos Compactos Multiobjetivo (AGCMs) são AGs cujo problema mapeado é complexo e composto de metavariáveis, ou seja, nesta classe de problemas, uma solução é aceitável quando investigado um conjunto de soluções que satisfaçam o objetivo, porém sem que estas exerçam qualquer dominância sobre as soluções envolvidas. A ideia principal deste método multiobjetivo é utilizar diferentes funções objetivo como forma de qualificar a aptidão de um dado indivíduo.

Segundo Dias e Vasconcelos (2002) existem duas abordagens mais comumente utilizadas nos AGs multiobjetivos, são elas: Combinar as funções de aptidão para cada objetivo em uma única função composta, assim o problema passa a ponderar pesos das funções para obter a melhor solução, ou então determinar um conjunto de soluções do ótimo de Pareto e nesse espaço escolher a que apresenta melhores resultados ao problema em questão.

As soluções do ótimo de Pareto refere-se a um termo derivado da economia, no qual diz que um determinado valor não pode ser melhorado sem prejudicar os demais (SILVA, 2012b). Em um conjunto de soluções do ótimo de Pareto é possível percorrer toda a fronteira entre as soluções considerando a perda e o ganho entre diferentes objetivos (STEUER, 1996).

Em problemas de otimização multiobjetivo é necessário garantir a maior cobertura possível da fronteira de Pareto, implicando assim um bom conjunto de soluções aptas aos objetivos desejados. A Figura 11a ilustra uma boa cobertura da fronteira, enquanto que a Figura 11b mostra uma distribuição indesejada.

Fazendo uma analogia do problema de otimização multiobjetivo com o problema de estimação fasorial aplicado em um SEPs trifásico, é proposto então esta abordagem multiobjetivo para se avaliar as três fases deste, relacionando-as em diferentes funções objetivo. O uso deste modelo aumenta a precisão e flexibilidade da solução desenvolvida, deixando-o mais tolerante em casos de variações do sinal analisado, como por exemplo faltas francas ocorridas no SEP, garantindo assim a qualidade da informação analisada. É importante lembrar que na abordagem multiobjetivo, como cada indivíduo é avaliado por mais de uma função de avaliação, este processo pode consumir mais recursos compu- 


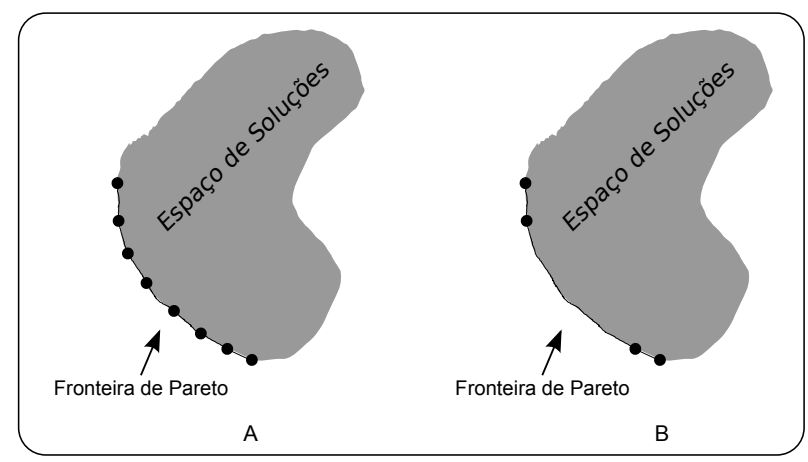

Figura 11 - Distribuição das Solução na Fronteira de Pareto

tacionais quando comparado com uma análise mono-objetivo, o qual utiliza apenas uma função de avaliação.

\subsubsection{Algoritmos Genéticos Compactos Multiobjetivo Utilizando Tabelas}

Uma vez que cada indivíduo gerado é avaliado por diferentes funções objetivo, faz-se necessário a organização dos melhores indivíduos de acordo com cada objetivo. Para organizar os melhores indivíduos foram idealizadas tabelas conforme descritas por (DELBEM et al., 2004), modeladas através de quatro diferentes vetores de probabilidade, um para cada objetivo analisado. Esta modelagem inspirada em métodos de tabelas foi escolhido devido a sua simplicidade de implementação, uma vez que requer poucas alterações se comparado com um algoritmo mono-objetivo, indiferentemente da linguagem de programação utilizada.

O número de vetores de probabilidade utilizados está relacionado com o número de funções objetivo, porém é comum adicionar mais um vetor de probabilidade (tabela) a qual refere-se a ponderação de todos os outros objetivos. A Figura 12 demonstra a estrutura de tabelas que inspiraram a modelagem utilizando vetores de probabilidade, utilizada neste trabalho. Neste contexto, a função objetivo referente a soma ponderada das outras três funções, permite que o algoritmo amplie seu espaço de busca de soluções entre os espaços já conhecidos pelas outras funções objetivos.

É importante salientar que no AGCM não há separação das populações, ou seja, cada indivíduo gerado será obrigatoriamente avaliado por todas as funções objetivo, e caso apresente uma boa aptidão, será incluído na tabela adequada, substituindo o de pior aptidão. No modelo probabilístico apenas o indivíduo de melhor aptidão será utilizado na atualização do vetor de probabilidade.

Quando aplicado ao problema de estimação fasorial, após a convergência do método genético, os melhores valores estimados das variáveis de amplitude, frequência e ângulo de fase que compõe o fasor estarão indicados pelos vetores de probabilidade. Conforme ilustrado pela Figura 13, gerando novos indivíduos com base na probabilidade informada 


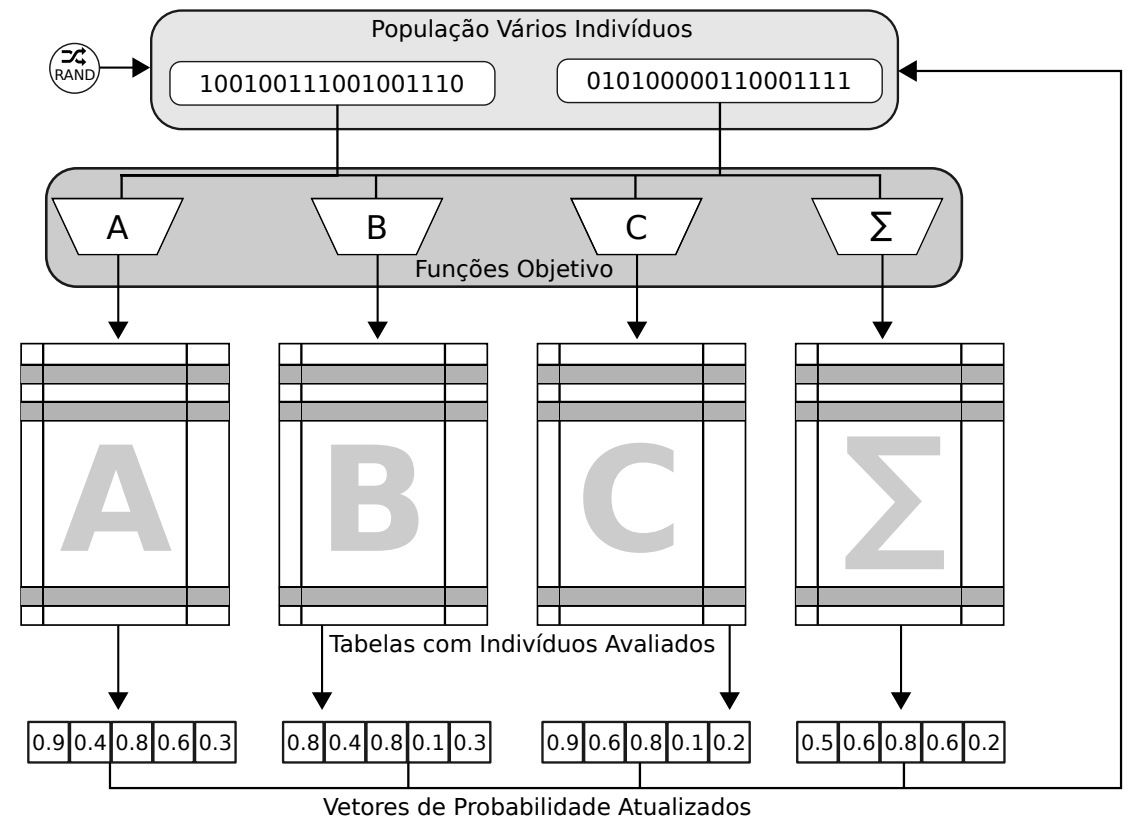

Figura 12 - Estrutura de Tabelas do AGCM

por estes vetores, pode-se obter os indivíduos que contêm as estimativas das variáveis que melhor descrevem o sinal.

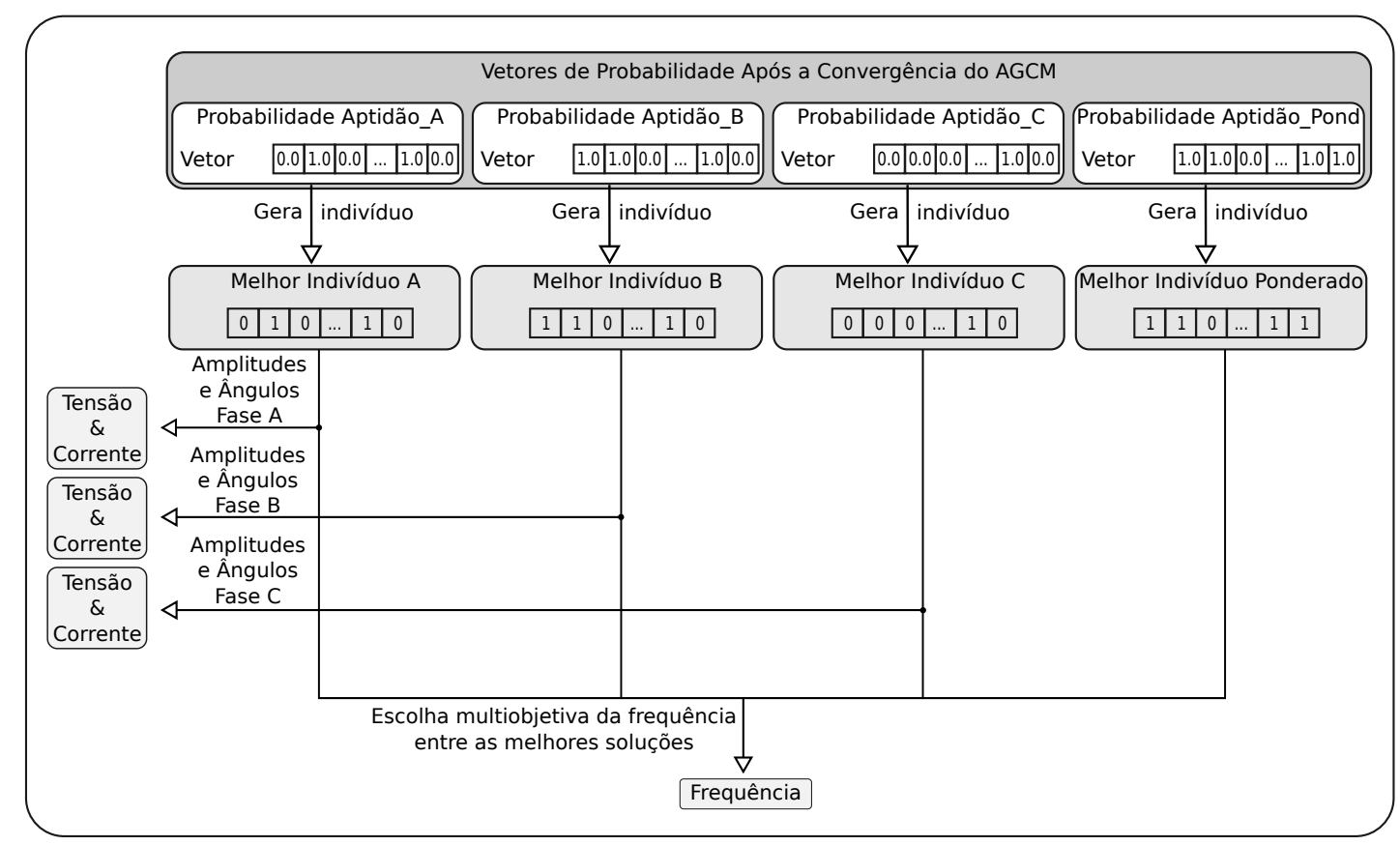

Figura 13 - Extração dos Valores Estimados pelo AGCM

Deste modo, ao término da evolução dos indivíduos, os valores das variáveis de amplitude e ângulo de fase relativo a cada uma das fases estimadas podem ser extraídos utilizando o modelo probabilístico representado pelo vetor referente àquela fase.

Já para extrair a estimação da variável da frequência, é utilizado um critério de seleção do melhor modelo probabilístico entre os quatro vetores disponíveis fornecendo assim um 
único valor de frequência estimada.

\subsection{Métodos Paralelos}

Algoritmos computacionais tradicionalmente trabalham em uma ordem de processamento sequencial, onde cada operação é executada apenas após o término da operação corrente. Vários são os esforços em busca de uma maior eficiência de processamento, resultando em tecnologias como pipelines e hyperthreading que melhoram a eficiência deste processadores sequenciais.

Com a facilidade de acesso à novos componentes, é comum observarmos computadores multi cores que consistem basicamente em um único processador, mas composto de vários núcleos que executam seu processamento de forma independente. Embora não apresente um paralelismo 100\% real devido a forma como a arquitetura de Von Neumann foi concebida (STALLINGS, 2006), sua capacidade de processamento tem auxiliado a sociedade em seus trabalhos.

Arquiteturas distribuídas também tem sido empregadas com grande sucesso em trabalhos de simulações e processamento de grande porte. Normalmente são equipamentos robustos e interconectados via rede de dados, formando um sistema aglomerado, ou cluster.

Uma arquitetura que permite um processamento realmente paralelo e relativamente de baixo custo, são os chamados hardwares reconfiguráveis, como os FPGAs, os quais tem como característica principal, a flexibilidade, robustez e velocidade necessárias para um processamento, sem a necessidade de interconexões para comunicação entre os módulos de processamento.

Uma vez que no AGCM cada um dos indivíduos contém a sua própria informação relacionada ao problema, diferentes soluções podem ser avaliadas simultaneamente, permitindo assim que um conjunto definido de indivíduos sejam avaliados ao mesmo tempo, aplicando-se a mesma função objetivo para cada um deles. Neste trabalho o FPGA é empregado como coprocessador genético da solução e descrito posteriormente na Seção 5.1.

\subsection{Modelagem do Problema de Estimação Fasorial}

Explorando a flexibilidade oferecida por um Algoritmo Genético Compacto (AGC), o qual permite representar um problema complexo, de forma simplista através de sua correta representação sobre os indivíduos, empregando uma função objetivo previamente conhecida, e, aliado com critério da análise multiobjetivo do problema, é possível modelar um algoritmo para a estimação fasorial de sinais elétricos. Assim, é proposto a modelagem do problema de estimação fasorial para a utilização de um AGCM como forma de estimar 
os fasores de um SEP de forma precisa, capaz de refletir o estado de operação do SEP em um dado instante de tempo.

A configuração do AGCM aqui utilizada é focada para a resolução do problema de estimação dos fasores de tensão e corrente dos sinais elétricos de um SEP. Matematicamente, um sinal de tensão ou corrente pode ser descrito conforme a Equação 35:

$$
\begin{gathered}
X(t)=A \operatorname{sen}(\omega t+\theta) \\
\text { ou ainda como, } \\
X(t)=A \operatorname{sen}(2 \pi f t+\theta)
\end{gathered}
$$

onde $A$ é a amplitude, $f$ a frequência, $\theta$ o ângulo de fase do sinal e $t$ o instante de tempo. Para a correta estimação dos fasores é necessário que estes parâmetros sejam precisamente conhecidos. O AGCM então, considerando as três fases mapeadas em um único indivíduo, minimizará uma função de erro entre o valor medido e o valor esperado, cujo resultado após a convergência será os valores de amplitude, frequência e ângulo de fase necessários que melhor caracterizam o sinal medido.

\subsubsection{Modelagem Multiobjetivo do Problema}

Com a modelagem multiobjetivo do problema, a aptidão de cada indivíduo é avaliada segundo diferentes métricas, utilizado quatro diferentes funções objetivo, três delas referentes as estimações de cada uma das fases do SEP e uma quarta função contemplando a ponderação das aptidões.

As Equações 37, 38 e 39 denotam matematicamente a aptidão de cada indivíduo segundo a função objetivo, e os termos $\operatorname{Sinal}_{a}(t), \operatorname{Sinal}_{b}(t)$ e $\operatorname{Sinal}_{c}(t)$, representam a amostra do sinal no instante de tempo $t$ para cada uma das fases do SEP. Já a equação 40 denota uma soma ponderada entre as três aptidões permitindo ao algoritmo encontrar soluções não-dominadas que os métodos mais conhecidos não conseguem (SANTOS et al., 2010).

$$
\begin{aligned}
& \operatorname{Aptidão}_{a}=\sum_{t=0}^{n-1}\left|\operatorname{Sinal}_{a}(t)-V_{a} \operatorname{sen}\left(2 \pi f_{a} t+\theta_{a}\right)\right| \\
& \operatorname{Aptidão}_{b}=\sum_{t=0}^{n-1}\left|\operatorname{Sinal}_{b}(t)-V_{b} \operatorname{sen}\left(2 \pi f_{b} t+\theta_{b}\right)\right| \\
& \operatorname{Aptidão}_{c}=\sum_{t=0}^{n-1}\left|\operatorname{Sinal}_{c}(t)-V_{c} \operatorname{sen}\left(2 \pi f_{c} t+\theta_{c}\right)\right|
\end{aligned}
$$




$$
\text { Aptidã } o_{\text {ponderada }}=\frac{\text { Aptidã } o_{a}+A p t i d \tilde{a} o_{b}+A p t i d \tilde{a} o_{c}}{3}
$$

Assim, para cada janela do sinal amostrado, são calculadas todas as funções objetivo para um mesmo indivíduo, que resultam na diferença entre o sinal amostrado e o sinal codificado no cromossomo para cada uma das fases, no mesmo instante de tempo $t$, denotando o erro da medição realizado em uma janela de dados. Como o problema exige que o erro das medições seja o mínimo possível, considera-se o indivíduo mais apto aquele que apresentar o menor erro de medição quando considerado os objetivos. Desta forma o algoritmo aqui desenvolvido buscará a convergência para valores de amplitude, frequência e ângulo de fase próximos do ideal, possibilitando ao término de sua execução, como resultado, a estimação dos fasores que melhor caracterizam os sinais do SEP em um dado instante.

\subsubsection{Representação Binária}

A maioria dos computadores só executam operações aritméticas básicas onde não é possível o cálculo direto das funções seno e cosseno de um dado valor. Assim, normalmente para este cálculo, computadores utilizam métodos numéricos, como a aproximação utilizando séries de Taylor, mesmo que essas operações envolvam um grande custo computacional quando utiliza-se de grande precisão dos valores.

Uma solução normalmente utilizada para diminuir o custo computacional nestes casos, consiste em calcular previamente, de maneira uniforme, vários valores da função, como por exemplo a função seno(x), compondo assim uma lista de valores.

Posteriormente, para encontrar um valor da função mapeada na lista, busca-se a posição da lista indicada pelo valor de $x$, cujo conteúdo será o valor da função esperado. Esta estrutura de dados, utilizada para armazenar dados de maneira indexada, é chamada de lookup-table.

Para representar as informações do problema, foi utilizado uma codificação binária, baseada nas estruturas de dados do tipo lookup-table, evitando o cálculo de funções computacionalmente custosas, contribuindo para o desempenho do método genético.

Um exemplo da estrutura utilizada é ilustrado pela Tabela 1.

\begin{tabular}{c|c}
\hline \multicolumn{2}{c}{ Amplitude Sinal $(\mathbf{p u})$} \\
\hline Posição Tabela & Valor Armazenado \\
\hline 0000000000000000 & 0,000 \\
\hline 0000000000000001 & 0,008 \\
\hline$\ldots$ & $\ldots$ \\
\hline 1111111111111110 & 1,991 \\
\hline 111111111111111 & 2,000 \\
\hline
\end{tabular}

Tabela 1 - Mapeamento dos Valores de Amplitude Utilizando Lookup-tables. 
Esta estrutura permite que a codificação binária dos indivíduos possa ser convertida em valores reais que serão utilizados na estimação fasorial. Como cada parâmetro é explorado individualmente, foi necessário então três tabelas para mapear as grandezas de amplitude, frequência e ângulo de fase do sinal, e uma quarta tabela para os valores da função seno, evitando assim operações matemáticas complexas.

\subsubsection{Representação Cromossômica}

O indivíduo ou cromossomo é utilizado para codificar a amplitude, a frequência e o ângulo de fase necessários para estimação fasorial. O cromossomo aqui é representado por uma cadeia de 64 bits, separados em 3 blocos conforme Figura 14, mapeando assim as variáveis de amplitude, ângulo de fase e frequência do sinal. Este mapeamento é utilizado para as três fases do SEP envolvidas na medição, gerando indivíduos que possam melhor caracterizar a forma de onda amostrada em cada uma delas.

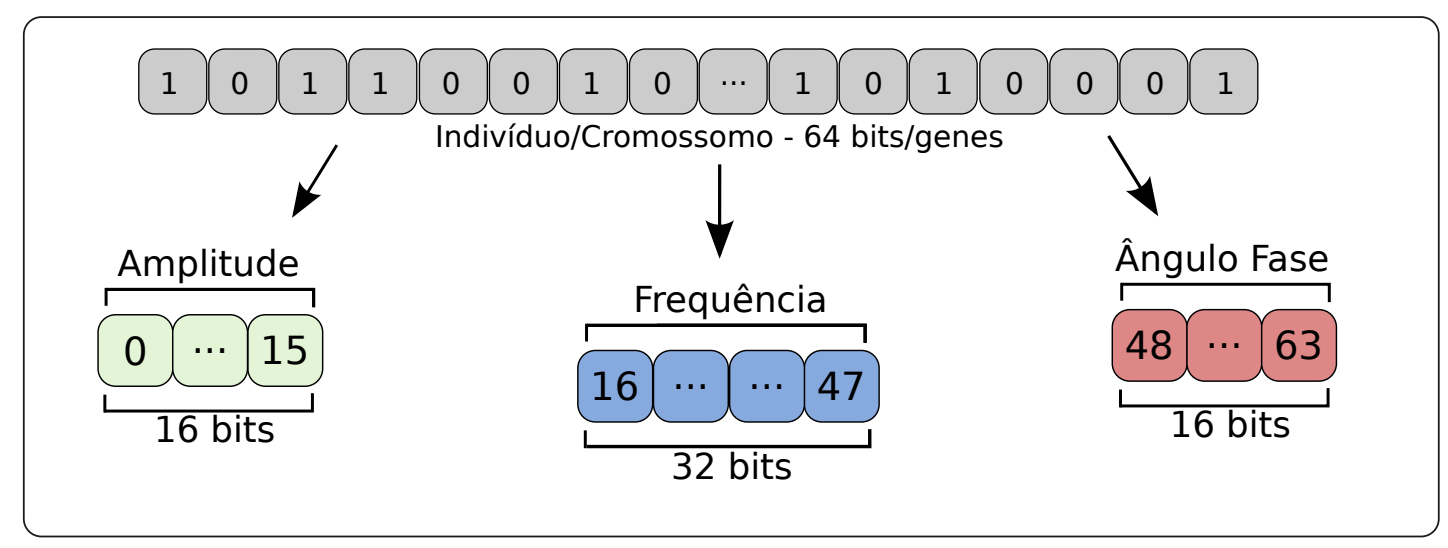

Figura 14 - Codificação do Problema em Um Único Indivíduo

Foram considerados os seguintes valores restritivos para o problema, garantindo sempre uma precisão centesimal dos valores representados: 
Amplitude $_{A, B, C}=$ intervalo de 0 a $2 \mathrm{pu}-16$ bits comprimento cada.

65.535 níveis de quantização possíveis.

$\square$ Frequencia $_{A, B, C}=$ frequência sistema de $0 \mathrm{~Hz}$ a $96,15 \mathrm{~Hz}-32$ bits comprimento.

$2^{32}-1$ níveis de quantização possíveis.

$\square \theta_{A, B, C}=$ ângulo fase de 0 a $2 \pi-16$ bits comprimento cada.

65.535 níveis de quantização possíveis.

$\square$ Tamanho do torneio em 2 indivíduos.

\ Tamanho da população em 8 indivíduos, evoluídos em 750 gerações, simulando uma população de 6000 indivíduos quando comparado com a população de um AG tradicional.

A precisão do conversor analógico utilizado é de 16 bits. Esta mesma precisão foi utilizada para mapear o intervalo de 0 a 2 pu, suficiente para a medição da amplitude dos sinais, visto que o valor de 2 pu não deverá ser alcançado devido a atuação de sistemas de proteção pré existentes no SEP.

O intervalo de $0 \mathrm{~Hz}$ a $96,15 \mathrm{~Hz}$ para a estimação da frequência também foi sugerido com base nos conhecimentos da dinâmica de operação do gerador e nos sistemas de proteção e controle envolvidos. Raramente um gerador será conectado ao SEP operando em faixas de frequência fora deste intervalo estabelecido. Como o valor da frequência varia entre os vários pontos de uma janela de dados analisado, o valor codificado no cromossomo corresponde ao valor da frequência na amostra de tempo $t=8$, presente no meio da janela de dados. Para estimar então a frequência real em função do valor informado no cromossomo é aplicado a equação 41, onde $f$ é o valor real da frequência, $f i$ é o valor da frequência codificada e informada pelo cromossomo, $F_{a}$ é o valor da taxa amostral do sinal de entrada, aqui fixo em $960 \mathrm{~Hz}$, e $N_{b}$ o número de bits utilizado na quantificação do valor, no caso 32 bits.

$$
f=\frac{f i}{8} \times \frac{F_{a}}{N_{b}}
$$

Como o valor da frequência é representado por 32 bits, e o ângulo de fase por 16 bits, apenas os 16 bits mais significativos de cada instante são considerados. Os 16 bits menos significativos são utilizados para diminuir erros de aproximação do processo de soma.

Note que a precisão do ângulo de fase é limitado pela precisão do sinal de entrada, neste caso também de 16 bits. Para o valor do ângulo de fase é considerado todo intervalo do círculo trigonométrico, ou seja de 0 a $2 \pi$. As demais condições de restrições aqui impostas ajudam a garantir e fornecer um cenário propício para a busca de boas soluções, 
assim como também obedecem a norma IEEE C37.118-2011, garantindo os requisitos necessários para uma análise fasorial adequada.

O tamanho populacional é um parâmetro importante na configuração do AGCM visto que ele representa o espaço de busca de soluções para o problema. Caso este espaço de busca seja subdimensionado, as melhores soluções podem não estar ali contidas, prejudicando fortemente os resultados apresentados pelo método genético. Para estimar o tamanho da população do AGCM de forma a garantir a completa representação do problema no espaço de soluções, foi utilizado o método de informação mútua, ou Mutual Information (ZHANG; HU, 2005), o qual permite analisar informações relevantes das variáveis do problema até então não conhecidas.

\subsection{Dinâmica dos Parâmetros do AGCM}

Para que o AGCM seja capaz de estimações robustas e precisas, todo conhecimento prévio específico do problema é importante. Neste caso, além do estudo do gerador de números aleatórios, utilizando a métrica de informação mútua, também foi necessário considerar a dinâmica da inércia do gerador elétrico, através do uso de uma função de regularização.

\subsubsection{Métrica de Informação Mútua}

Em teoria da informação, a métrica de informação mútua é comumente utilizada para calcular a dependência mútua entre duas variáveis. A incerteza de uma variável randômica $C$ é medida pela sua entropia $H(C)$. Para duas variáveis, $X$ e $C$ a entropia condicional $H(C / X)$ mede a incerteza sobre $C$ quando $X$ é conhecido e $I(X ; C)$ mede a certeza sobre $C$ quando resolvido por $X$ (ZHANG; HU, 2005).

A informação mútua pode, em princípio, ser calculada exatamente quando a função densidade de probabilidade dos dados é conhecida, no entanto, na maioria dos casos, como nos AGs, os dados não são distribuídos em um padrão fixo e a informação mútua tem de ser estimada.

Para o problema apresentado, foi considerado um bloco representativo (Building Block) composto pelo primeiro bit mais significativo de cada um dos parâmetro de amplitude, frequência e ângulo de fase que compõem o indivíduo. Desta forma, um estudo da variância do gerador de números aleatórios foi executada sobre esse bloco de 7 bits, permitindo estimar a variância dos indivíduos gerados em cada população, especialmente em suas características mais significativas para a resolução do problema.

Notou-se que o parâmetro varia demasiadamente conforme a lógica de implementação do gerador de números aleatórios utilizado para inicializar os indivíduos, ou ainda conforme a arquitetura computacional utilizada. Assim foi estimado através de exaustivos 
testes um tamanho populacional de seis mil indivíduos (6.000), o qual representa o espaço de busca de soluções, e que ao mesmo tempo, satisfaz as necessidades do problema, onde a diversidade dos indivíduos é grande o suficiente para que se encontre uma ou mais ótimas soluções, sem que ocorra ao mesmo tempo o uso desnecessário de recursos computacionais.

\subsubsection{Método de Regularização}

Em momentos transitórios, os sinais elétricos do SEP podem não conter informações corretas sobre as fases do sistema, ou até inexistir, e para estes casos o AGCM poderia ter sua estimação comprometida. Para evitar que mudanças bruscas do sinal influenciem na estimação, um sistema de regularização baseado na inércia do gerador foi proposto.

Segundo Silva (2012b) a técnica de regularização é empregada para resolver problemas de desvios na estimação ou ainda evitar a especialização excessiva do indivíduo (overfitting). Para que a técnica seja utilizada, são adicionadas ao algoritmo, informações relevantes do domínio do problema, prevenindo soluções inadequadas através de penalizações, limitando a faixa de variação dos parâmetros conforme sugerido por Golub, Hansen e O'Leary (1999) e suavizando a variação do parâmetro.

A variável de frequência de um gerador elétrico, pode ser estimada utilizando a equação de Swing (Equação 42), a qual por sua vez considera a constante de inércia do gerador elétrico existente no SEP.

$$
\frac{2 H}{w_{s}} \frac{d^{2} \delta}{d t^{2}}=P_{m}-P_{e}
$$

Valores para a constante de inércia do gerador, $H$, podem variar de 3 a 12 segundos (BEATY; MAHROUS; SEIDMAN, 2001) em regime normal de operação, assim a constante de inércia $H$ utilizada na modelagem do método de regularização foi de $6 \frac{M W}{M V A} s$. As demais variáveis como, $P_{m}$ e $P_{e}$ são respectivamente potência mecânica e elétrica, $\delta$ é a posição angular do rotor em radianos e $w_{s}$ a sua velocidade em rad/s conforme encontrado na literatura de Stevenson (1975). Sabendo que $f_{0}=\frac{1}{2 \pi} w_{s}$ e assumindo $f_{0}=60 \mathrm{~Hz}$, é possível estimar a variação da frequência, $\Delta f$ conforme demonstrado pela Equação 43.

$$
\Delta f=f_{0} \frac{P_{m}-P_{e}}{2 H} \Delta t
$$

Ainda conforme Coury et al. (2012), para evitar dependência de informação sobre os valores de carga no sistema, é assumido $P_{m}-P_{e}=1$ p.u., originando assim a Equação 44.

$$
\Delta f=f_{0} \frac{1}{2 H} \Delta t
$$

$O$ valor de $\Delta t$ é o valor referente ao intervalo de tempo entre cada amostra do sinal. Neste trabalho, foi utilizado uma taxa amostral de $960 \mathrm{~Hz}$ durante a digitalização dos 
sinais, fornecendo assim um intervalo entre as amostras $\Delta t=0.001$ segundos. Ao aplicar estes valores fornecidos, na Equação 44, é possível obter o valor máximo esperado na variação da frequência entre duas amostras do sinal, $\Delta F$ igual a $\pm 0.005 \mathrm{~Hz}$.

Este valor, é o máximo valor que a estimação da frequência poderá divergir entre duas amostras do sinal, desta forma reduzindo o espaço de busca de valores para a variável da frequência em um intervalo de $|f-\Delta f, f+\Delta f|$. Esta técnica guia o processo de estimação para a solução mais plausível e menos ruidosa, pois qualquer estimação fora deste intervalo será penalizada, forçando a estimação para o intervalo aceitável.

Como todo espaço de busca de soluções necessita de limites pré-definidos, foi necessário então definir valores de frequências máxima e mínima de estimação do algoritmo. Os limites não são estabelecidos pela norma IEEE C37.118-2011, desta forma foram escolhidos limites de operação conforme descritos no Submódulo 10.11 dos Procedimentos de Operação de Rede (ONS, 2010), do Operador Nacional do Sistema Elétrico (ONS), o qual estabelece através do item 8 e seus subitens, os limites aceitáveis de variação da frequência de um SEP.

Dentre os limites de variações de frequência descritas no procedimento, encontra-se como uma das métricas, o intervalo entre $58,0 \mathrm{~Hz}$ e $62,0 \mathrm{~Hz}$. Considerando esta informação, o método de regularização aqui proposto foi configurado para estimar a variável de frequência com desvio máximo de $\pm 0.005 \mathrm{~Hz}$ entre amostras, até o limite superior de $62,0 \mathrm{~Hz}$ e inferior de 58,0 Hz. A Tabela 2 consolida os valores reais dos parâmetros de amplitude, frequência e ângulo de fase, codificados no AGCM, assim como os valores restritivos de operação escolhidos.

\begin{tabular}{c|c|c|c|c}
\hline \multicolumn{5}{c}{ Codificação dos Parâmetros no AGCM. } \\
\hline Parâmetro & $N^{\circ}$ Bits & Valores Inteiros & Valores Reais & Valores Restritivos \\
\hline$V_{m}$ & 16 & {$[0 ; 65.535]$} & {$[0$ p.u.; 2,0 p.u. $]$} & {$[0$ p.u.; 2,0 p.u. $]$} \\
\hline$f$ & 32 & {$\left[0 ; 2^{32}-1\right]$} & {$[0 \mathrm{~Hz} ; 96,15 \mathrm{~Hz}]$} & {$[58,0 \mathrm{~Hz} ; 62,0 \mathrm{~Hz}]$} \\
\hline$\theta$ & 16 & {$[0 ; 65.535]$} & {$[0 ; 2 \pi]$} & {$[0 ; 2 \pi]$} \\
\hline
\end{tabular}

Tabela 2 - Codificação dos Parâmetros no AGCM.

Uma vez modelado o problema de estimação fasorial contemplando a técnica de regularização da frequência com os parâmetros descritos, foi obtido um software em linguagem C disponível no Apêndice A, o qual deverá ser testado, garantindo os requisitos de operação segundo padrão normatizado pela norma IEEE C37.118-2011 e explorando sua robustez em simulações de um SEP, como é apresentado no Capítulo 4 com os testes propostos e executados. 


\section{Testes e Resultados da Aplicação da Metodologia Proposta}

Para fins de validação dos métodos evolutivos desenvolvidos, foram criados dois diferentes cenários de testes. O primeiro deles, o cenário sugerido pela norma IEEE C37.1182011, é composto de três diferentes tipos de sinais representados por funções degrau. Essas funções especificadas na norma, permite com a ajuda do software Octave, sintetizar tais sinais para sua posterior utilização. Este cenário sintético permite avaliar de forma simples a precisão das estimações fasoriais efetuadas.

É sabido que os casos apresentados neste primeiro cenário não condizem com a realidade de operação de um SEP. Desta forma, foi criado um segundo cenário, este composto de oito diferentes casos simulados com o auxílio do Alternative Transient Program (ATP). Estes casos contemplam os sinais das três fases existentes no SEP, em regime e durante a ocorrência de diversos eventos, tais como, faltas, atuação do sistema de proteção e rejeição de carga em barramentos.

Como métrica de análise dos resultados aqui apresentado, é utilizado o Total Vector Error (TVE) para o cenário proposto pela norma IEEE C37.118-2011, enquanto que para os casos simulados com o auxílio do software ATP é utilizado o valor Root Mean Square (RMS) calculado posteriormente pelo método de DFT para as variáveis de amplitude de tensão e corrente, e o Root Mean Square Error (RMSE) para avaliar o erro da variável da frequência. Estas métricas foram utilizadas como forma de garantir a correta precisão na medição, além de permitir a análise da correta representação cromossômica dos indivíduos, explorando cada variável que compõe o fasor de forma independente.

Os resultados apresentados neste capítulo ilustram o comportamento do Algoritmo Genético Compacto Multiobjetivo (AGCM) proposto quando comparado com os outros três tipos de algoritmos genéticos já implementados, o Algoritmo Genético (AG) e Algoritmo Genético Multiobjetivo (AGM) implementados por Silva (2012b) e o Algoritmo Genético Compacto (AGC) desenvolvido por Silva (2012a). 


\subsection{Casos de Testes Especificados na Norma IEEE C37.118-2011}

No cenário descrito pela IEEE C37.118-2011 é utilizado um sinal senoidal trifásico com amplitude de 1 p.u., frequência fundamental de $60 \mathrm{~Hz}$ e com $120^{\circ}$ de defasagem entre os ângulos de fases, simulando os sinais de um sistema elétrico trifásico devidamente equilibrado. Os três tipos de função degrau propostos afetam diretamente as variáveis envolvidas na estimação fasorial, são elas: Degrau de Magnitude, Degrau de Frequência e Degrau de Ângulo de Fase como já explicado anteriormente.

Os sinais sintetizados tem duração total de 10 segundos cada, com a ocorrência do degrau no instante $t=5$ segundos. Para este caso é analisado a qualidade da estimação fasorial através do TVE assim como o tempo de convergência do algoritmo, ou tempo de recuperação, que é o tempo necessário para que os algoritmos voltem a apresentar uma estimativa fasorial com TVE menor que $1 \%$ após a ocorrência do degrau.

O primeiro caso proposto para análise das estimações fasoriais, é uma função degrau de $-10 \%$ na magnitude ilustrada pela Figura 15. Esta função ocasiona uma atenuação na magnitude do sinal de 1 p.u. para 0,9 p.u., mantendo inalterados a frequência e o ângulo de fase do sinal.

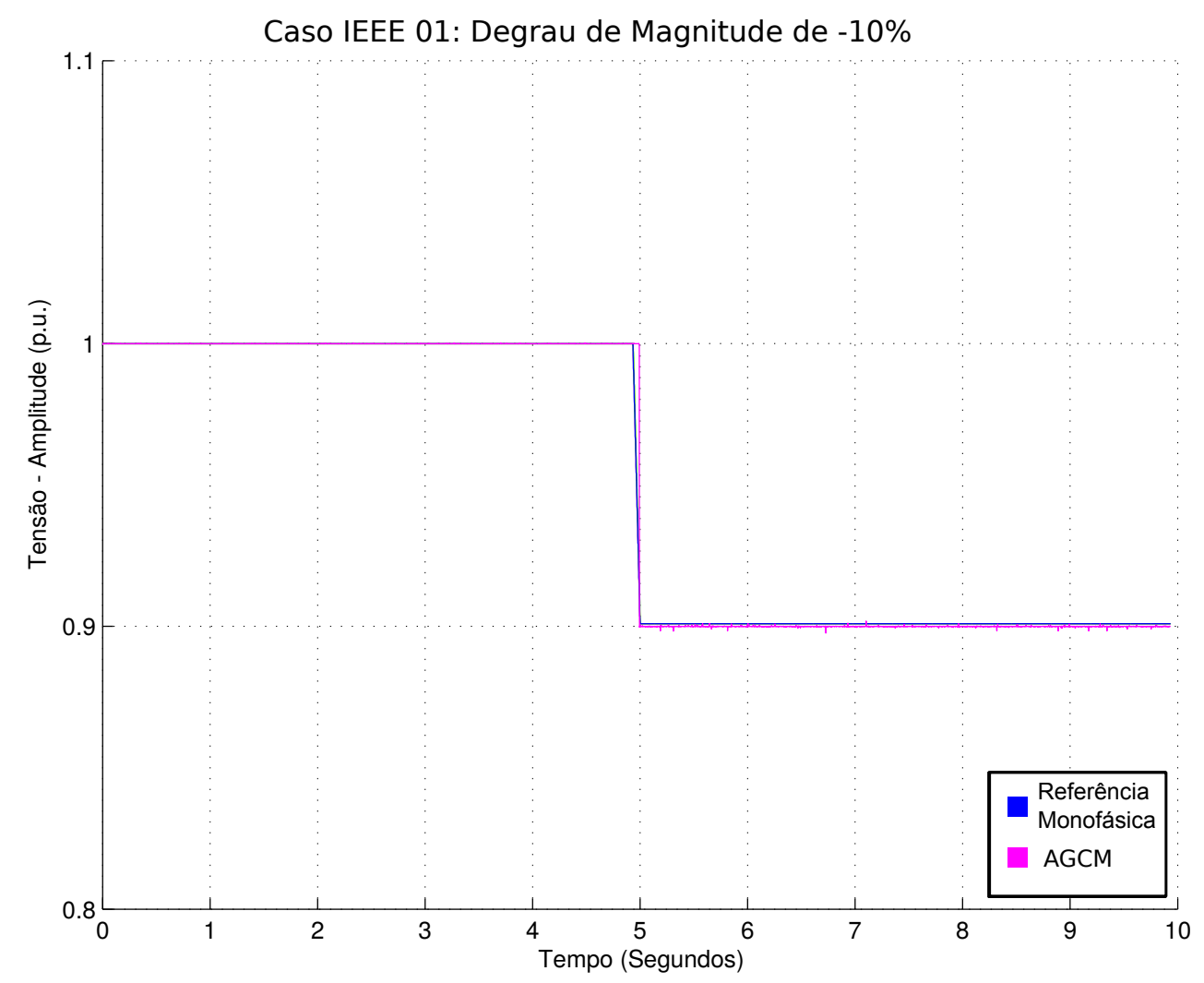

Figura 15 - Sinal Trifásico com Degrau de Magnitude de -10\%.

É possível notar que o método AGCM estima precisamente a função degrau de amplitude, considerando a informação das três fases e apresentando um decaimento de $-10 \%$ 
assim que encontra as primeira amostra do sinal em sua nova magnitude. Devido a precisão da estimação, as linhas dos gráficos estão sobrepostas, dificultando a visualização de cada uma das fases de forma independente. A Figura 16 mostra de maneira clara que o parâmetro da frequência do sinal não se altera durante toda duração do sinal.

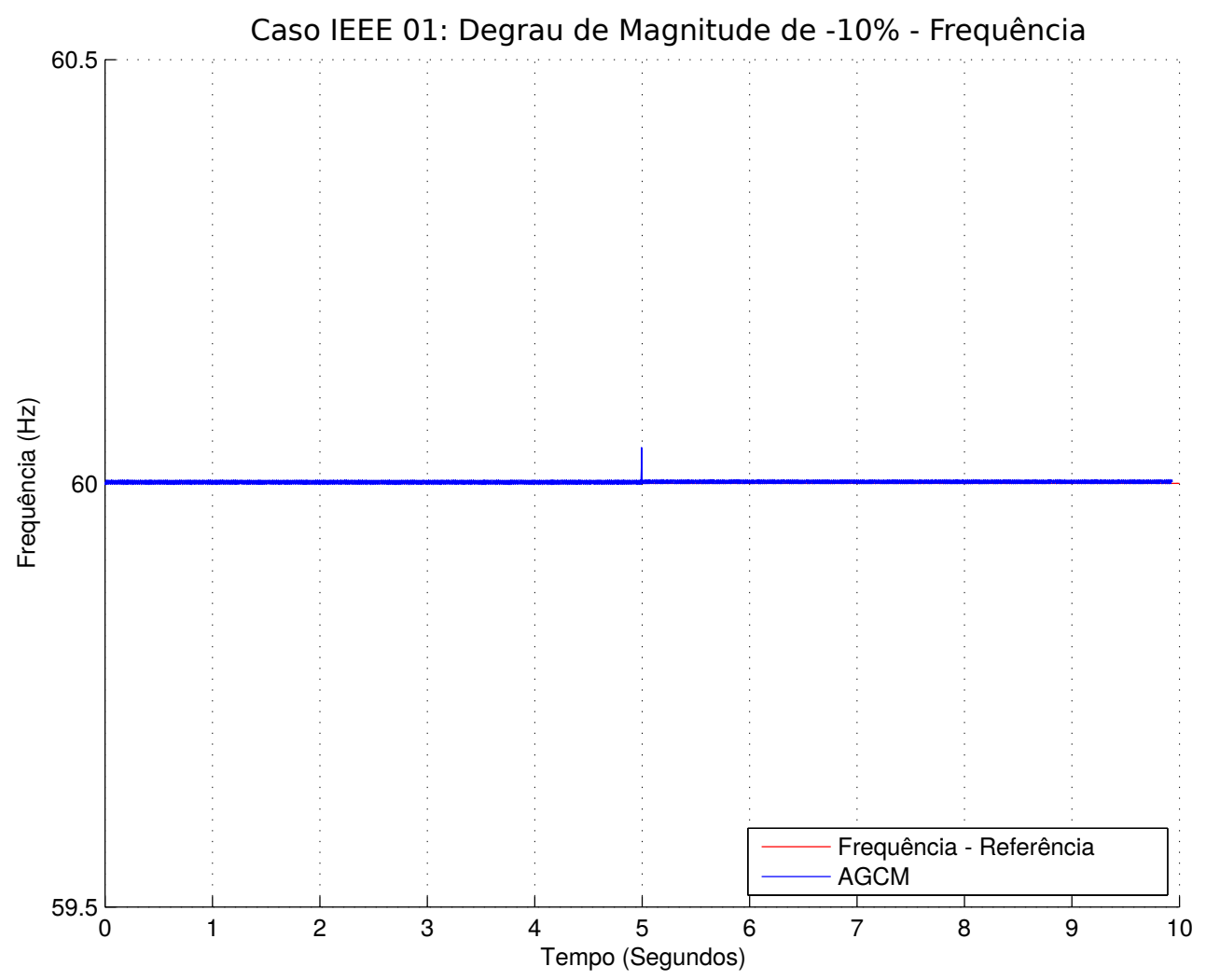

Figura 16 - Sinal Frequência com Degrau de Magnitude de -10\%.

Nota-se também um pequeno espúrio em $t=5 \mathrm{~s}$ durante a estimação do variável da frequência, momento em que ocorre o degrau de magnitude. Esta variação pode ser desprezada devido ao tempo de sua duração. Esta afirmação se apoia no fato de que quando calculado o TVE para esta estimação, o tempo de recuperação do algoritmo permanece abaixo de meio-ciclo de sinal, tempo suficientemente baixo para esta aplicação. O TVE apresentado pela Figura 17 compara os erros da estimação fasorial do método AGCM com os outros três métodos evolutivos aqui apresentados.

Neste gráfico do Total Vector Error (TVE) representado pela Figura 17, pode-se observar o TVE associado a estimação fasorial para o caso Degrau de Magnitude, quando utilizado quatro diferentes tipos de algoritmos genéricos: O Algoritmo Genético (AG), o Algoritmo Genético Compacto (AGC) ambos com critério de otimização mono-objetivo, e os métodos AGM e AGCM com critérios multiobjetivos de otimização. Esta forma de apresentação dos resultados persiste para os dois próximos casos que serão apresentados.

É possível observar que todos os métodos apresentam estimação fasorial com TVE menor que $1 \%$ em regime. No momento de ocorrência do degrau, aqui representado por $t=0 \mathrm{~s}$, o valor da estimação diverge do esperado, atingindo valores superiores a $5 \%$. Após 


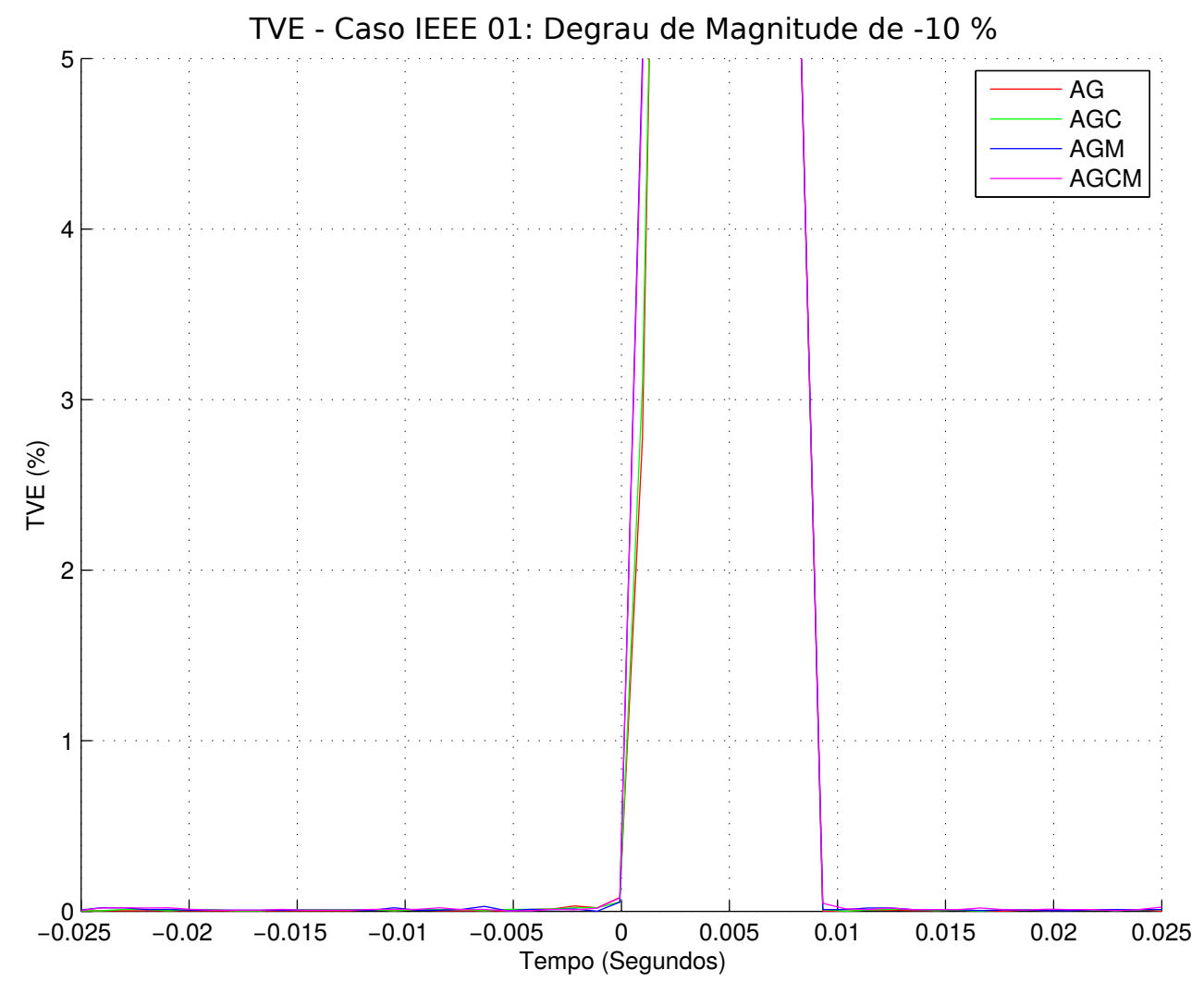

Figura 17 - TVE para os Quatro Algoritmos Genéticos - Degrau de Magnitude de -10\%.

o tempo de recuperação de 8,4 milissegundos, ou meio ciclo do sinal, novamente todos os métodos genéticos testados apresentam uma estimação confiável com TVE menor que 1\% como esperado.

Como durante pequenos instantes as estimativas apresentam um TVE maior que 5\%, atingindo valores de até $100 \%$, optou-se por truncar a escala do gráfico apresentado, permitindo um melhor detalhamento nos valores de TVE próximo ao valor máximo de 1\% especificado pela norma IEEE C37.118-2011.

Segundo especificado na norma IEEE C37.118-2011, a medição fasorial é considerada aceitável e precisa, quando o valor do TVE calculado em regime for menor que $1 \%$. Neste caso, este requisito foi cumprido por todos os métodos genéticos, inclusive o AGCM desenvolvido, como esperado. Em nenhum momento a norma especifica o TVE mínimo ou qualquer outra métrica para avaliar a precisão da estimação fasorial no instante em que ocorre o degrau.

A próxima função degrau proposta neste cenário, trata-se da função degrau de ângulo de fase de $90^{\circ}$. Este degrau afeta diretamente o ângulo de fase do sinal, podendo existir um reflexo também na variável da frequência. Conforme ilustrado pela Figura 18 o método AGCM estima corretamente a amplitude do sinal, 1 p.u. como esperado, inclusive no instante em que ocorre o degrau de ângulo de fase, onde é possível observar uma pequena variação da amplitude das fases do SEP. Devido a precisão da estimação dos resultados a Figura 18 exibe as três fases do SEP escondidas sobre o sinal estimado pelo AGCM 
dificultando a visualização fora do instante da ocorrência do degrau.

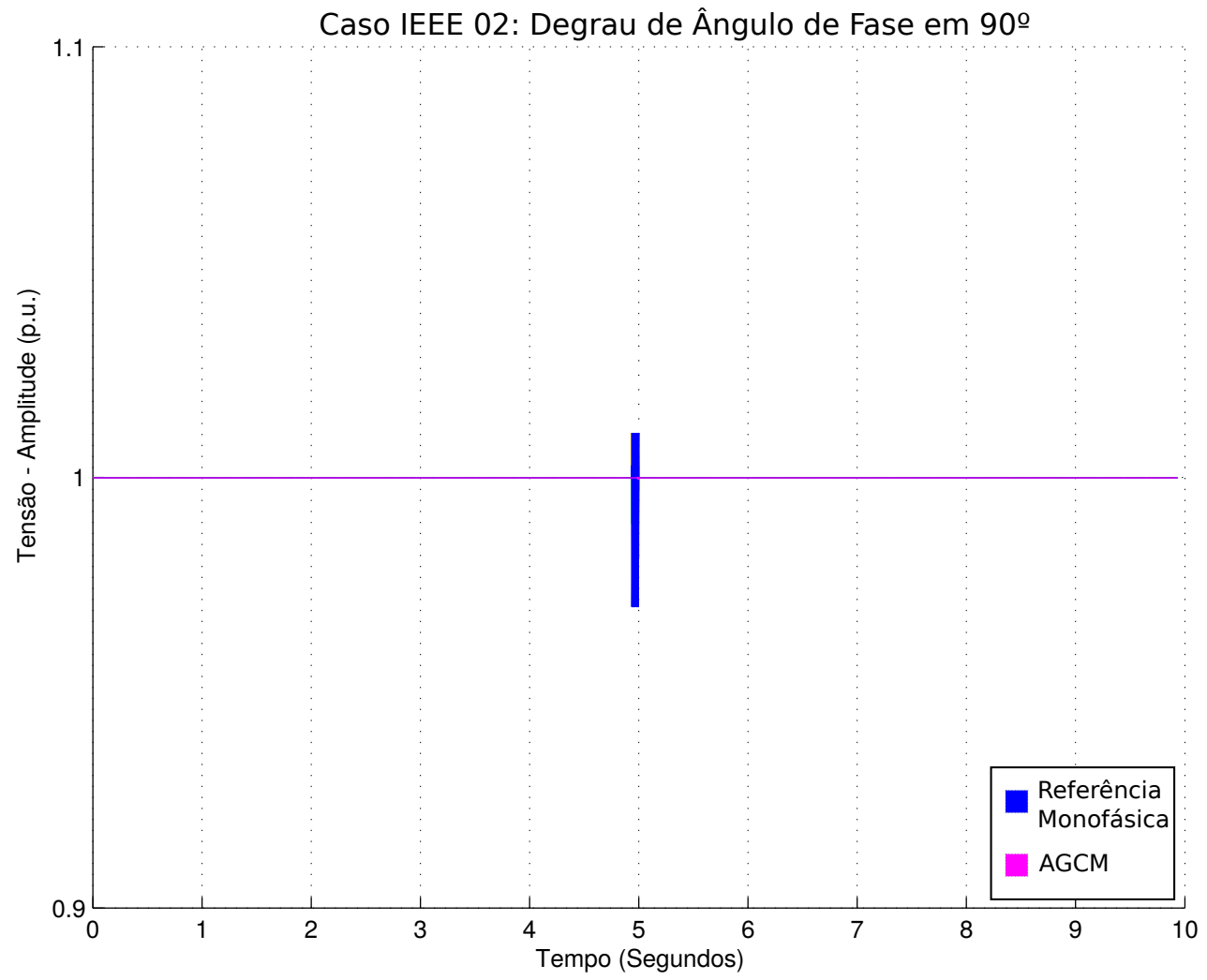

Figura 18 - Sinal Trifásico com Degrau de Ângulo de Fase de $90^{\circ}$.

Como a variável do ângulo de fase é utilizada juntamente com a variável da frequência para o cálculo da função seno necessária para a estimação fasorial, optou-se por ilustrar através da Figura 19, a estimação da variável da frequência durante toda a duração do sinal.

É possível verificar novamente um pequeno espúrio na estimação da variável da frequência, no instante $t=5 \mathrm{~s}$, de curta duração. Como forma de avaliar a precisão da estimação fasorial para este tipo de degrau, a Figura 20 exibe o resultado dos TVEs calculados para a estimação dos quatro métodos evolutivos. 


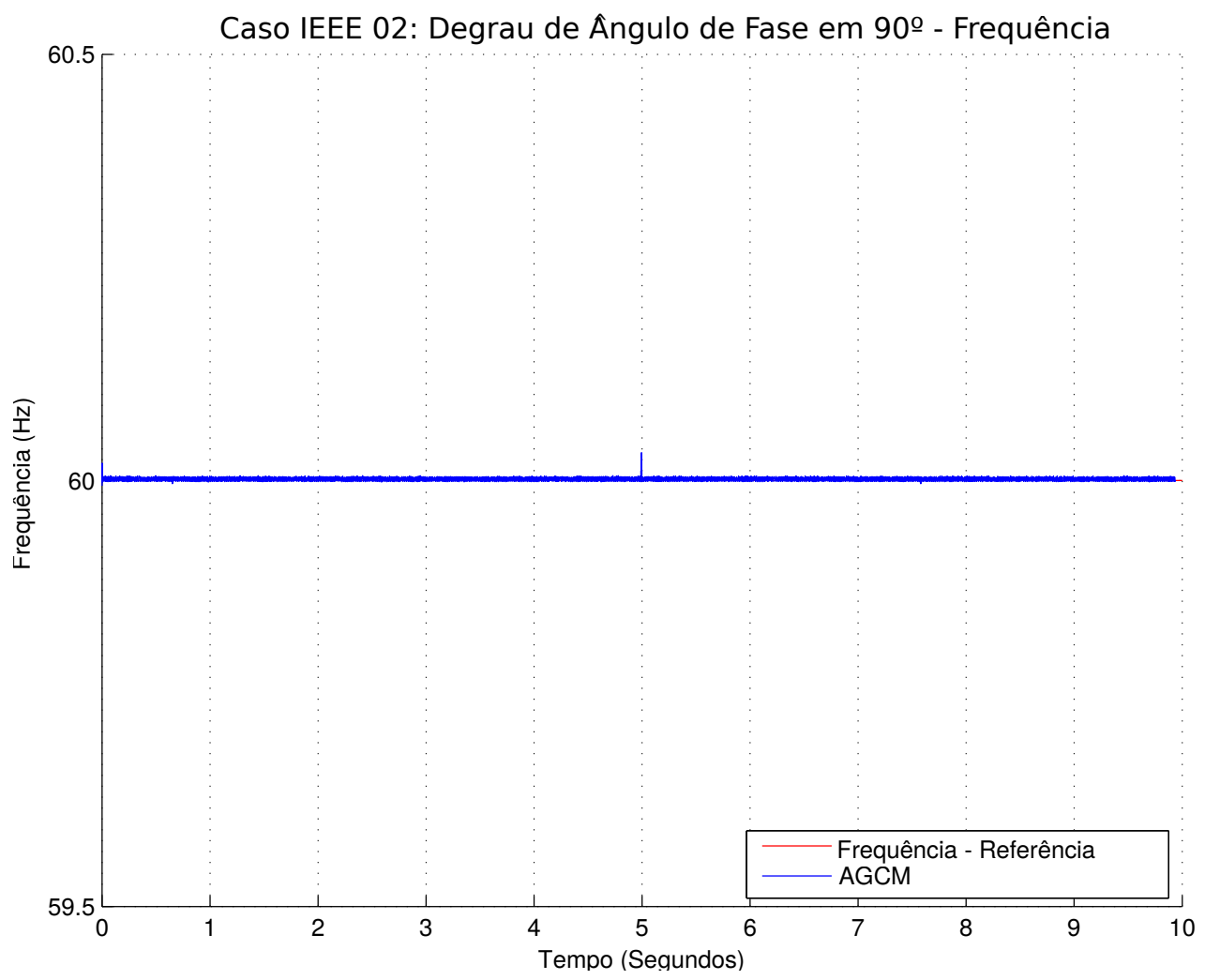

Figura 19 - Sinal Frequência com Degrau de Ângulo de Fase de $90^{\circ}$.

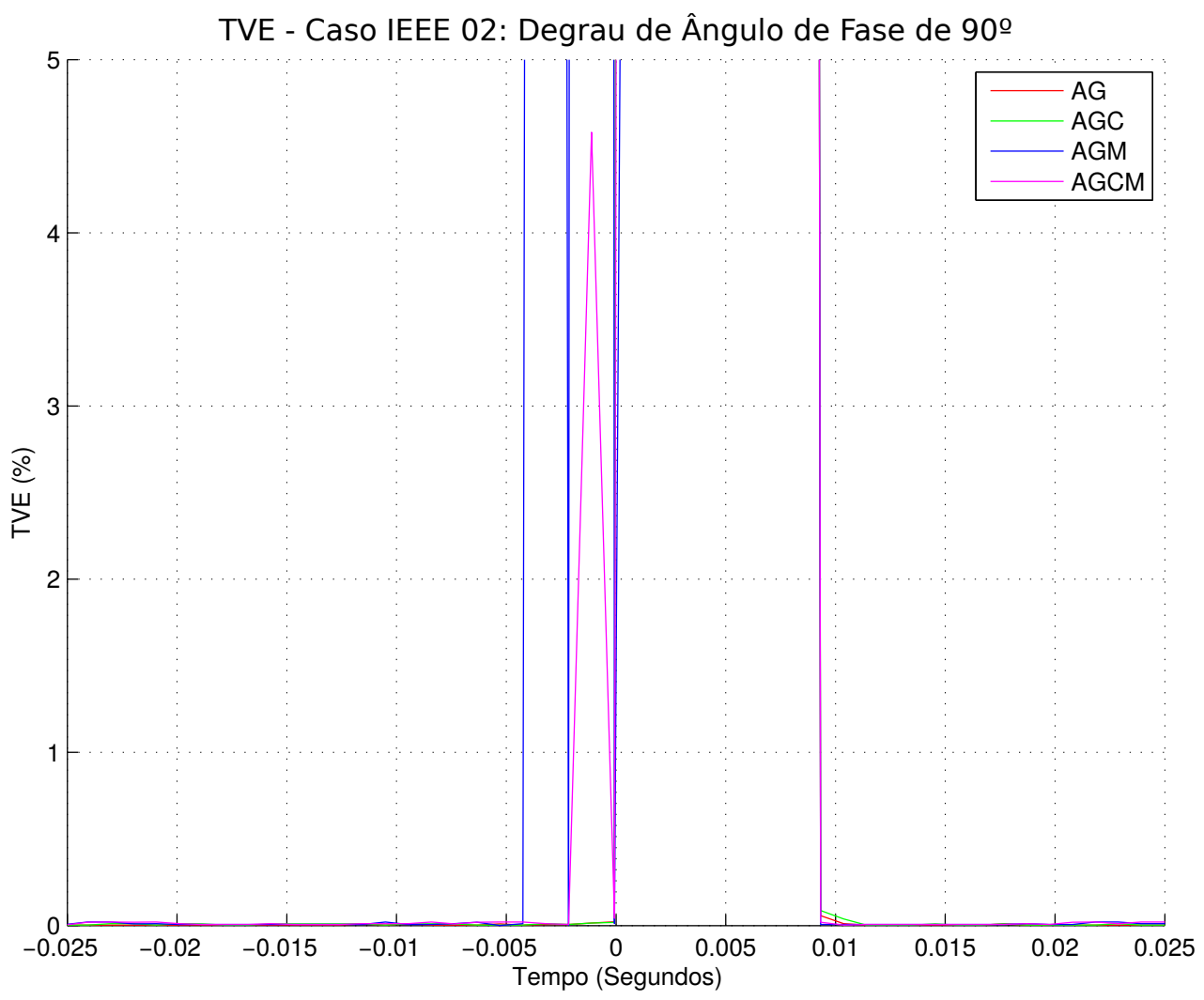

Figura 20 - TVE para os Quatro Algoritmos Genéticos - Degrau de Ângulo de Fase de $90^{\circ}$. 
Conforme a Figura 20, é observado que o TVE encontrado nas estimações fasoriais em regime são sempre inferiores a 1\%, indiferente do algoritmo utilizado. Ao detectar as primeiras amostras do degrau do sinal, os algoritmos multiobjetivos AGM e AGCM, têm sua estimação comprometida antes dos métodos mono-objetivos AG e AGC, que neste caso tiveram o comportamento idêntico nas estimações. Os algoritmos genéticos, AG e AGC, resultaram em um tempo de recuperação de 8,4 milissegundos, ou aproximadamente meio ciclo do sinal, assim como no caso anteriormente apresentado. Já o algoritmo genético multiobjetivo, AGM obteve um tempo de recuperação maior, igual a 13,6 milissegundos enquanto que sua versão compacta, o AGCM obteve um tempo de recuperação de 10,9 milissegundos. Todos os métodos genéticos apresentaram valores de TVE satisfatórios conforme regulamenta a norma IEEE C37.118-2011, e, no momento do degrau, apresenta um tempo de recuperação sempre menor que um ciclo de sinal amostrado.

O terceiro e último tipo de função degrau proposto para este cenário é a função degrau de $+5 \mathrm{~Hz}$ na variável da frequência. Esta função degrau sintetiza um sinal de frequência de $60 \mathrm{~Hz}$ em regime, o qual, quando na ocorrência do degrau, tem sua frequência alterada para $65 \mathrm{~Hz}$. A Figura 21 exibe a estimação da amplitude do sinal onde é possível notar o instante $t=5 \mathrm{~s}$ a ocorrência do degrau.

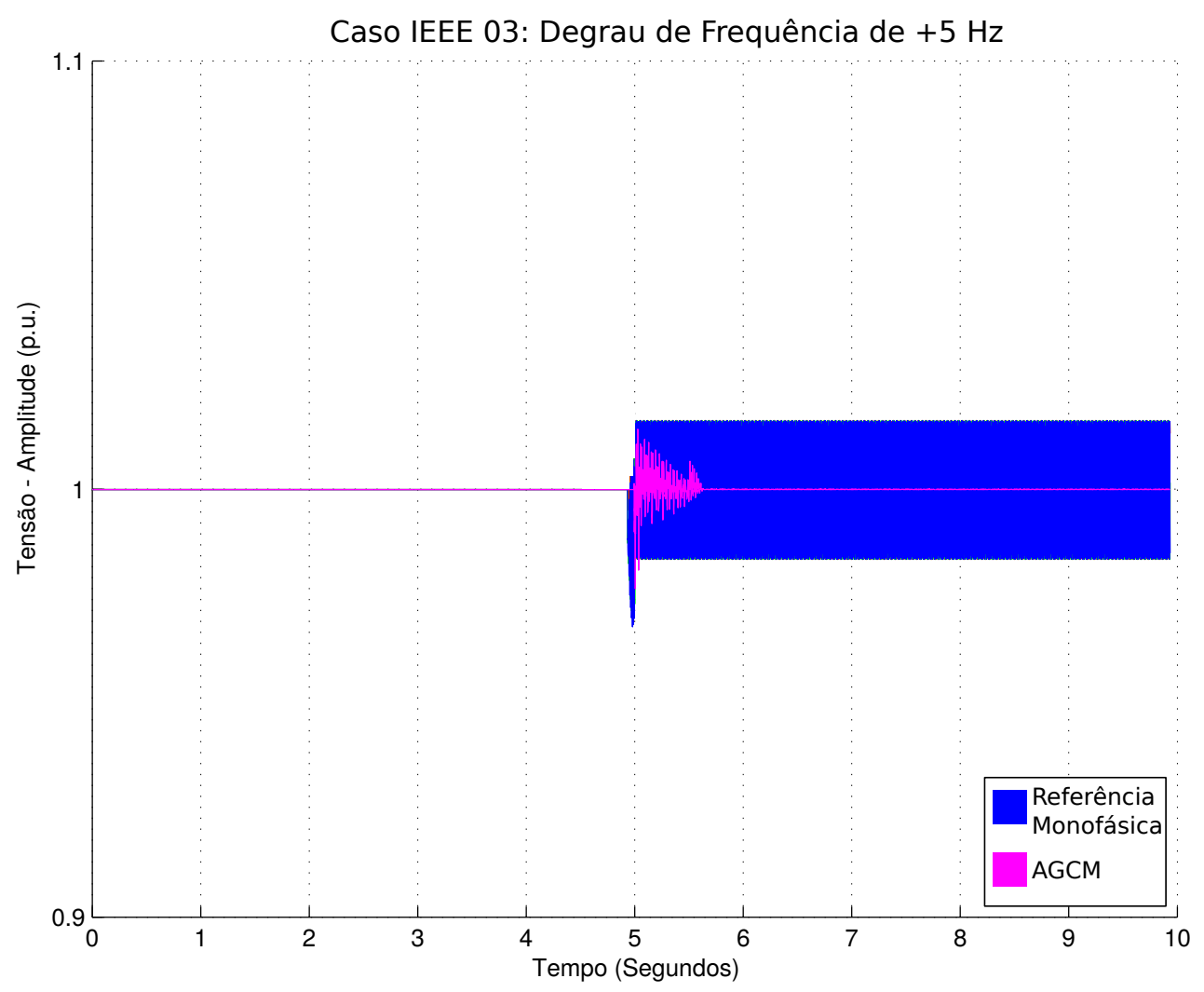

Figura 21 - Sinal Trifásico com Degrau de Frequência de +5 Hz. 
Ao analisar exclusivamente a estimação da variável da frequência para este tipo de degrau, é importante lembrar que este caso sintético dificilmente refletirá um sinal existente em um SEP real. É conhecido que uma variação abrupta e instantânea da frequência não ocorre devido a dinâmica do sistema de geradores, os quais contam com uma inércia mecânica, impossibilitando a variação instantânea. Este fato foi considerado na modelagem do AGCM através da função de regularização descrito na Seção 3.9.2, e afeta diretamente esta estimação deste tipo de degrau, de acordo com a constante de inércia $H$ utilizada.

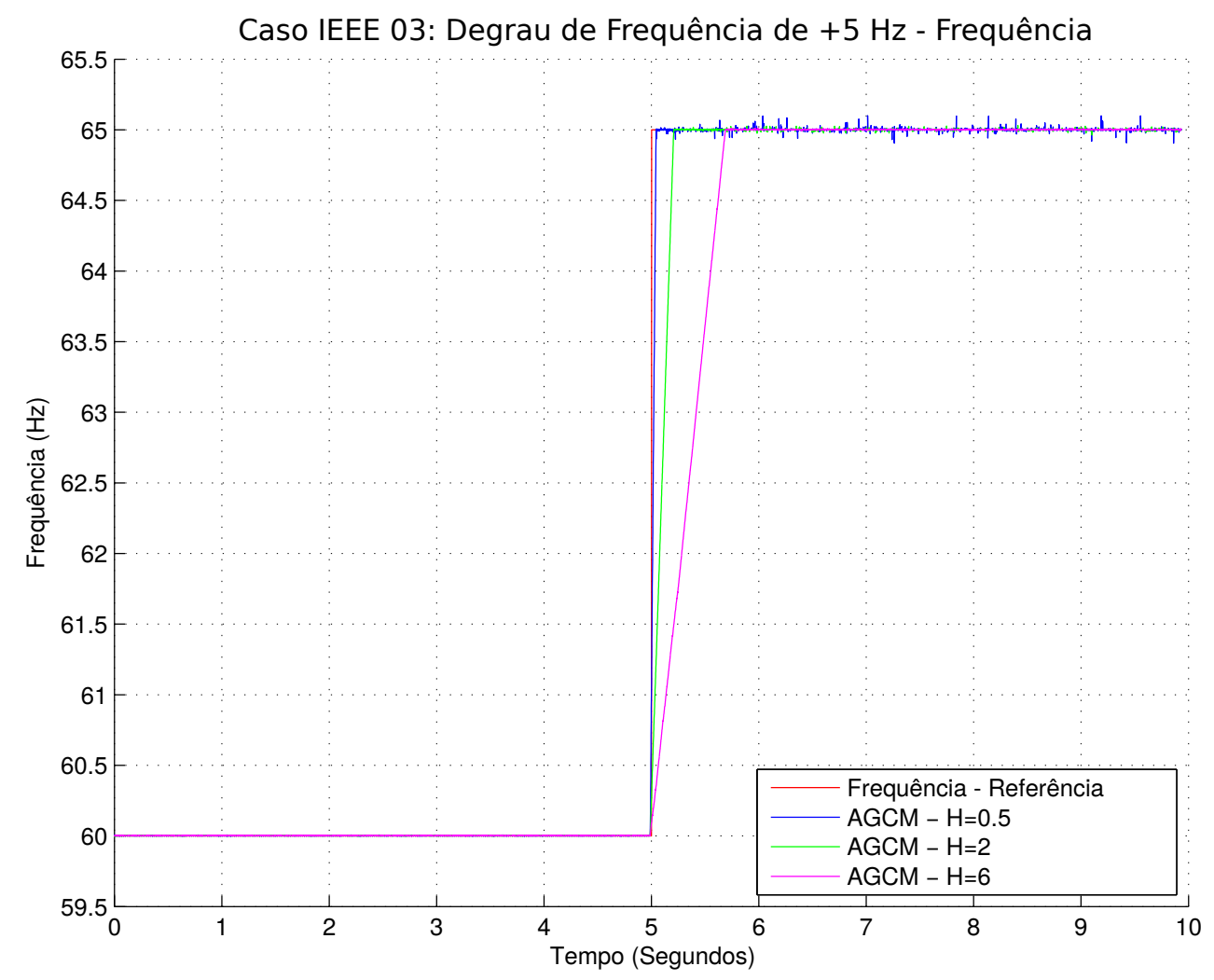

Figura 22 - Sinal Frequência com Degrau de Frequência de $+5 \mathrm{~Hz}$.

É observado através da Figura 22 que quanto maior a constante de inércia do gerador, maior a inclinação do sinal degrau, apresentando assim um maior tempo de recuperação em relação ao sinal sintético. Embora tenha sido utilizada uma constante de inércia $H$ de $6 \frac{M W}{M V A} s$, aqui uma estimação foi executada utilizando as constante de inércia iguais a 1,5 $\frac{M W}{M V A} s$ e $0,5 \frac{M W}{M V A} s$, sintetizando um comportamento do gerador o mais próximo de uma variação instantânea da frequência.

Para o cálculo do TVE apresentando na Figura 23, foi então utilizado a constante de inércia igual a $0,5 \frac{M W}{M V A} s$ para todos os algoritmos genéticos testados. 


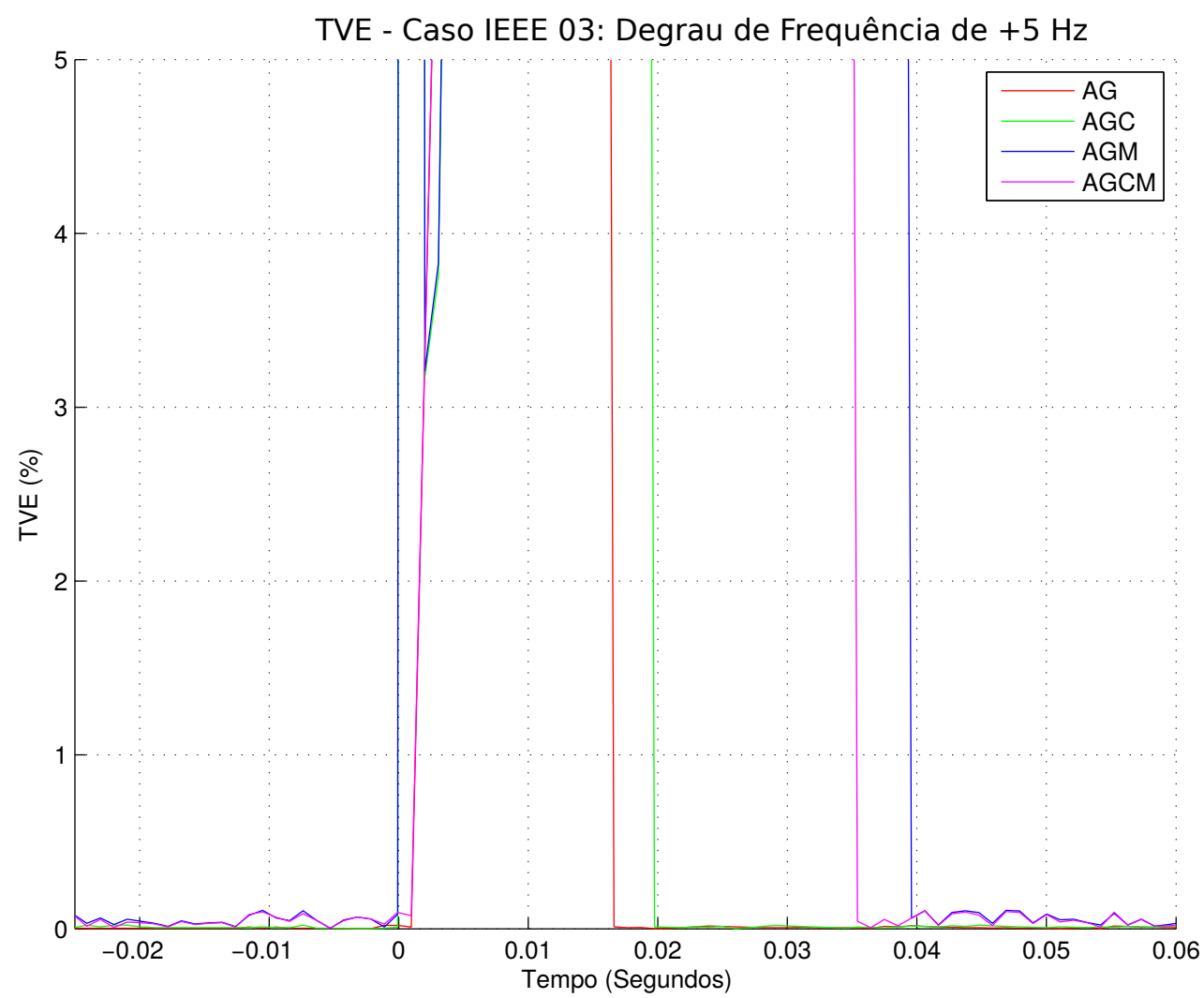

Figura 23 - TVE para os Quatro Algoritmos Genéticos - Degrau de Frequência de +5 Hz.

Para este teste, é possível notar que os métodos multiobjetivos AGM e AGCM apresentam um maior tempo de recuperação, em relação aos métodos mono-objetivos AG e AGC. Os métodos mono-objetivos apresentaram um tempo de recuperação de 15,9 milissegundos para o AG e 19,2 milissegundos para o AGC. Já Para os métodos multiobjetivos, o AGCM apresentou um tempo de recuperação de 35,3 milissegundos, enquanto que o AGM gastou 39,5 milissegundos para sua recuperação. Como forma de consolidar os tempos de recuperação obtidos pelos algoritmos genéticos aqui apresentados, de acordo com cada caso testado, é apresentado a Tabela 3.

Tempo de Recuperação para Estimativas com TVE inferior a $1 \%$.

\begin{tabular}{c|c|c|c|c}
\hline Caso & AG & AGC & AGM & AGCM \\
\hline Degrau Amplitude & $8,4 \mathrm{~ms}$ & $8,4 \mathrm{~ms}$ & $8,4 \mathrm{~ms}$ & $8,4 \mathrm{~ms}$ \\
\hline Degrau Ângulo & $8,4 \mathrm{~ms}$ & $8,4 \mathrm{~ms}$ & $13,6 \mathrm{~ms}$ & $10,9 \mathrm{~ms}$ \\
\hline Degrau Frequência & $15,9 \mathrm{~ms}$ & $19,2 \mathrm{~ms}$ & $39,5 \mathrm{~ms}$ & $35,3 \mathrm{~ms}$ \\
\hline
\end{tabular}

Tabela 3 - Tempo de Recuperação para os Algoritmos Genéticos Testados de Acordo com Norma IEEE C37.118-2011.

Analisado a estimação realizada referente aos três tipos de funções degrau propostos, os resultados mostram que o AGCM esta apto para a resolução do problema de estimação fasorial conforme descrito pela norma IEEE C.37-118-2011 e também quando comparado com outros algoritmos genéticos anteriormente desenvolvidos. É sabido que os testes 
realizados neste momento estão distantes da realidade operacional de um SEP, assim, na Seção 4.2 é apresentado um novo cenário de testes e resultados para um SEP simulado, permitindo visualizar os resultados do AGCM em diversos cenários de ocorrência de eventos.

\subsection{Casos de Testes Simulados com ATP}

Embora tenha-se criado um cenário de testes conforme descrito pela norma IEEE C37.118-2011, foi notado que os casos apresentados não são suficientes para garantir a estabilidade e precisão da estimação fasorial do método, pois um SEP real está sujeito aos mais diversos tipos de ocorrência de eventos e não apenas condições de regime como proposto pela norma. Eventos de diversos tipos podem ocorrer em um SEP podendo variar desde um simples evento de operação de chaveamento/rejeição de carga dos barramentos até faltas e transitórios ocasionadas por fatores inesperados. Para permitir a criação de um cenário de testes mais realístico, foi então utilizado o Alternative Transient Program (ATP), responsável por simular um SEP previamente modelado. Este modelo permite a variação dos parâmetros do SEP durante sua operação, refletindo diretamente nos sinais das três fases analisadas, casos desconhecidos para o AGCM, que também deve realizar sua estimação a mais correta possível.

Nesta Seção são apresentados oito diferentes casos simulados, contemplando alguns tipos de eventos, os quais foram simulados no ATP utilizando o SEP ilustrado pela Figura 24. O SEP ilustrado consiste em um gerador síncrono de $13,8 \mathrm{kV}$ e 76 MVA, transformadores trifásicos de 25 MVA, para adequação dos níveis de tensão de distribuição (13,8:138 kV) e consumo (138:13,8 kV), três linhas de transmissão de 80, 100 e 150 km de comprimento e cargas de 5 a 25 MVA conectadas com um fator de potência indutivo igual a 0,92. A conexões dos transformadores são do tipo delta e estrela, respectivamente para a alta e baixa tensões.

As tabelas 4 e 5 consolidam os parâmetros utilizados pelo gerador síncrono e transformadores na modelagem do SEP utilizando o ATP.

Tem-se como resultado da simulação do SEP efetuada pelo ATP os sinais elétricos trifásicos referentes ao comportamento do sistema em regime e também na presença de eventos inesperados, aplicados durante o caso de teste simulado. As Figuras 25 e 26 demonstram os sinais de tensão e corrente respectivamente para o Caso 01, com evento do tipo falta bifásica AB-T na linha LT1, resultantes da simulação do software ATP. Todos os casos são descritos posteriormente na Seção 4.2.1 onde é possível observar os sinais trifásicos de acordo com o tipo de evento ocorrido. Este sinal trifásico resultante de cada caso ensaiado, é posteriormente amostrado pelo AGCM e utilizado como entrada para a estimação das variáveis propostas neste trabalho. 


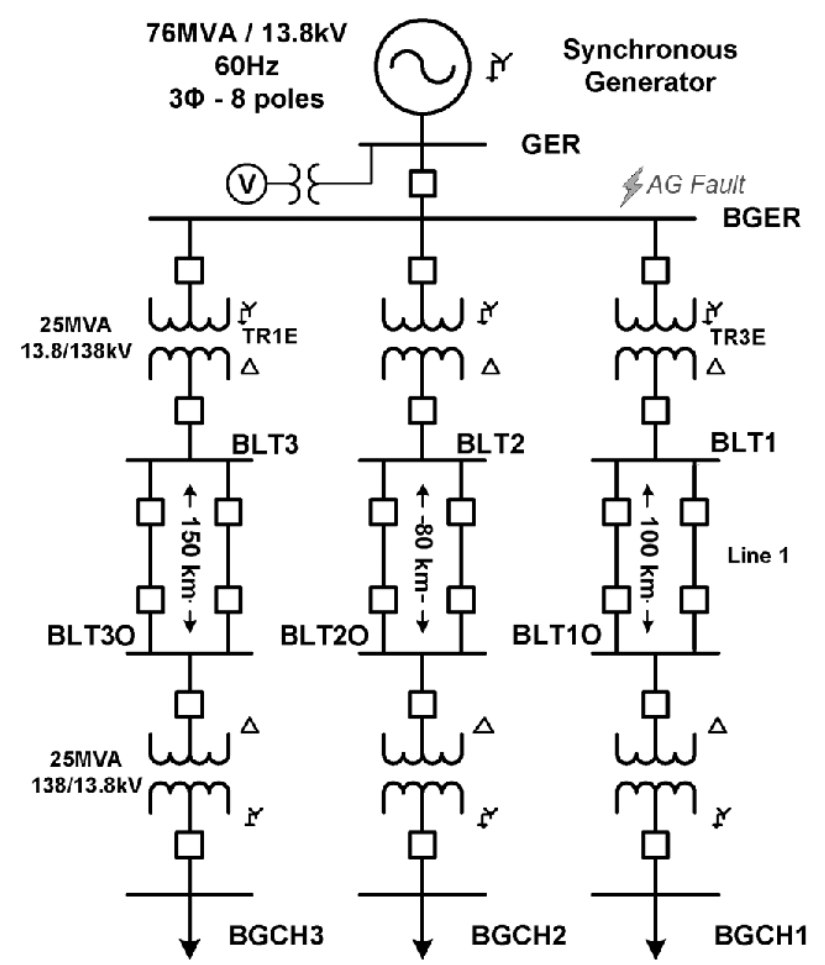

Figura 24 - Sistema Elétrico Quatro Barras Simulado no ATP

\begin{tabular}{c|c|c}
\hline \multicolumn{3}{|c}{ Parâmetros de Simulação do Gerador } \\
\hline Parâmetro & Descrição & Valor (unidade) \\
\hline$S$ & Potência Aparente & $76(\mathrm{MVA})$ \\
\hline$H$ & Nonstante de Inércia do Gerador & $6\left(\frac{M W}{M V A}\right)$ \\
\hline$N_{p}$ & Tensão De Operação na Linha & 8 \\
\hline$V_{L}$ & Frequência Elétrica de Operação & $13,8\left(\mathrm{k} V_{r m s}\right)$ \\
\hline$f$ & Corrente de Campo & $60(\mathrm{~Hz})$ \\
\hline$I F D$ & Resistência da Armadura & $250(\mathrm{~A})$ \\
\hline$R_{a}$ & Reatância de Dispersão não Saturada & 0,004 (p.u.) \\
\hline$X_{l}$ & Reatância de Sequência Zero & 0,175 (p.u.) \\
\hline$X_{0}$ & Reatância Síncrona do Eixo em Quadratura & 0,132 (p.u.) \\
\hline$X_{d}$ & Reatância Transitória do Eixo Direto & 0,685 (p.u.) \\
\hline$X_{q}$ & Reatância Sub-transitória do Eixo Direto & 0,310 (p.u.) \\
\hline$X_{d}^{\prime}$ & Reatância Sub-transitória do Eixo em Quadratura & 0,210 (p.u.) \\
\hline$X_{d}^{\prime \prime}$ & Constante Tempo Transitória em Vazio do Eixo Direto & 5,182 (p.u.) \\
\hline$X_{q}^{\prime \prime}$ & Constante Tempo Sub-transitória em Vazio do Eixo & 0,036 (p.u.) \\
\hline$\tau_{d O}^{\prime}$ & Direto & 0,073 (p.u.) \\
\hline$\tau_{d 0}^{\prime \prime}$ & Constante Tempo Transitória em Vazio do Eixo em & \\
\hline$\tau_{q 0}^{\prime}$ & Quadratura &
\end{tabular}

Tabela 4 - Parâmetros de Simulação do Gerador Utilizados no ATP. 


\begin{tabular}{c|c|c}
\hline \multicolumn{3}{c}{ Parâmetros de Simulação dos Transformadores } \\
\hline Elemento & $R_{+}(\Omega)$ & $L_{+}(\mathrm{mH})$ \\
\hline Primário & 1,7462 & 151,37 \\
\hline Secundário & 0,0175 & 1,514 \\
\hline
\end{tabular}

Tabela 5 - Parâmetros de Simulação dos Transformadores Utilizados no ATP.

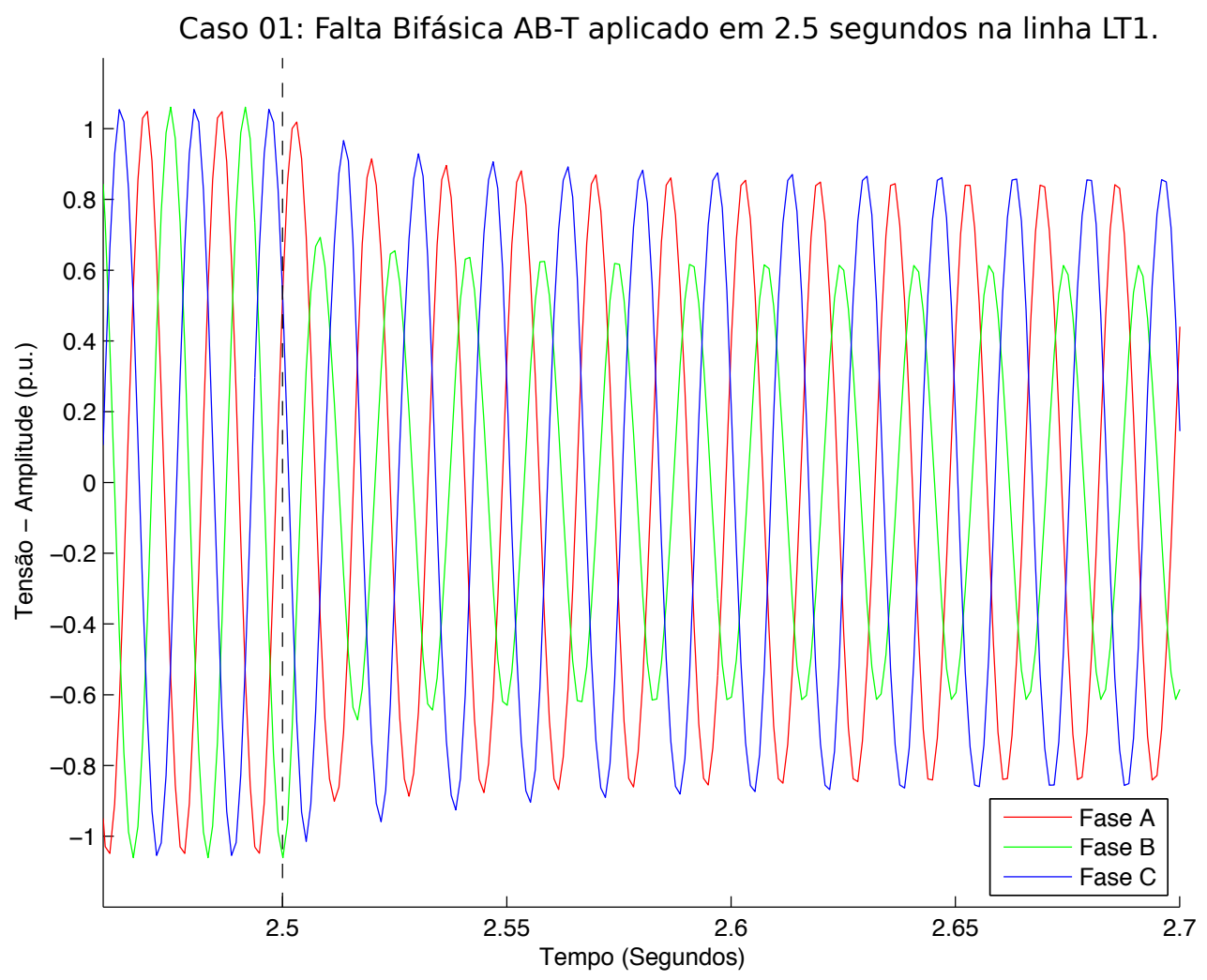

Figura 25 - Sinal Trifásico de Tensão Resultante da Simulação do ATP - Falta e Atuação da Proteção

Nos oito casos simulados descritos na Seção 4.2.1, foi possível analisar de forma independente a variável de amplitude e frequência dos sinais, sendo os resultados aqui apresentados. Embora estimado pelo AGCM, não foi aqui ilustrado os resultados da estimação do ângulo de fase, pois o software ATP não é capaz de fornecer os ângulos das fases em relação ao tempo, dificultando uma análise comparativa. Toda medição apresentada foi realizada no barramento do gerador (BGER). Embora estudos de medições em outros pontos do sistema, como os barramentos BCGH1, BCGH2, BCGH3 também tenham sido realizados, os mesmos não são aqui apresentados devido a similaridade dos resultados de estimação obtidos.

Vale ressaltar que alguns casos simulam o comportamento da atuação do sistema de proteção, inclusive quando durante sua atuação, a informação de algumas das fases envolvidas na medição torna-se inexistente. Neste aspecto não é esperado que o AGCM escolha a melhor fase, em um melhor momento de medição, e sim, considere todas elas como um único conjunto de informações durante a estimação. Como o AGCM faz uma análise 


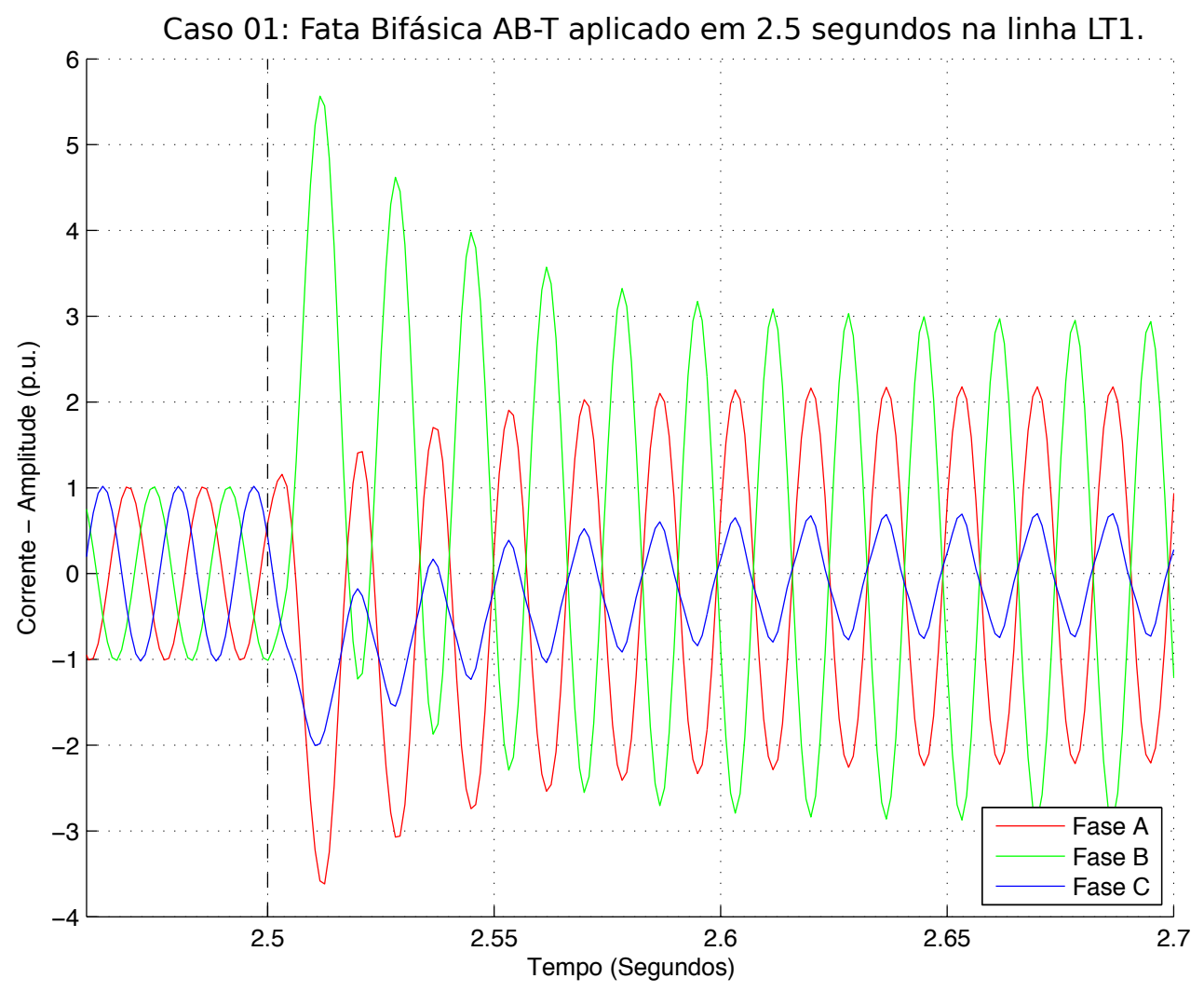

Figura 26 - Sinal Trifásico de Corrente Resultante da Simulação do ATP - Falta e Atuação da Proteção

multiobjetivo do problema, mesmo quando a informação de uma das fases é inexistente, é possível obter uma boa estimação da variável da frequência, com erros e tempos de recuperação menores que uma análise mono-objetiva tradicional quando medido diretamente a fase problemática.

Para a variável de amplitude, a informação da estimação de cada fase está disponível em forma de modelo probabilístico contido nos vetores de probabilidade, bastando para tanto decodificá-la. Para fins de comparação e métrica dos resultados obtidos, foi executado um pré-processamento utilizando-se do cálculo do valor Root Mean Square (RMS) através do método de DFT para validar a estimação da variável de amplitude e o cálculo do Root Mean Square Error (RMSE) para validar a estimação da variável da frequência para as quatro diferentes implementações de algoritmos genéticos: o Algoritmo Genético Tradicional (AG), o Algoritmo Genético Multiobjetivo (AGM), o Algoritmo Genético Compacto (AGC) e o Algoritmo Genético Compacto Multiobjetivo (AGCM).

Os resultados apresentados para os métodos mono-objetivos AG e AGC, estão explícitos conforme a fase utilizada na estimação, permitindo visualizar a influência da escolha da melhor fase na estimativa da frequência. É importante ressaltar que não é papel do método genético aqui desenvolvido a escolha da melhor fase. No caso dos métodos mono-objetivos AG e AGC, a escolha da melhor fase é feita previamente, antes do início do processo de estimação. Para os métodos multiobjetivo, os quais consideram a informação das três fases de forma conjunta, a informação já se encontra inclusa na análise, 
dispensando a escolha da fase.

\subsubsection{Caso 01}

O primeiro caso simulado utilizando o SEP da Figura 24 trata-se de um caso em que ocorre um evento do tipo Falta Bifásica AB-T, ocorrida na linha LT1, no instante $t=2,5 \mathrm{~s}$. A estimação da variável de amplitude da tensão obtida pelo AGCM está representada na Figura 27 em relação as fases utilizadas como referência.

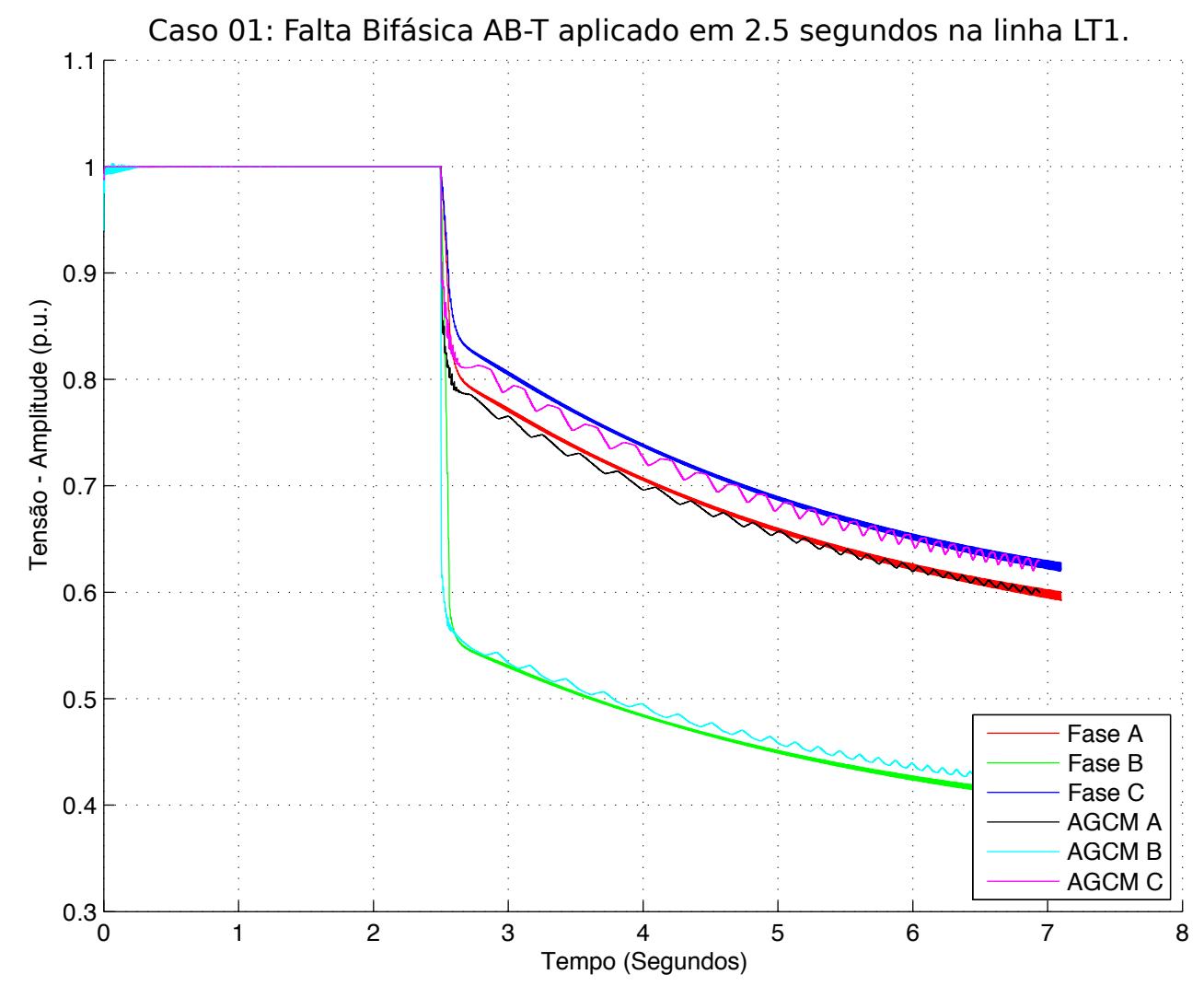

Figura 27 - Amplitude das Tensões Trifásicas Estimadas para o Caso 01.

É sabido que uma PMU deve estimar os fasores de tensão e corrente dos sinais existentes no SEP. Para contemplar este cenário, também é ilustrado através da Figura 28 a estimação da variável de amplitude da corrente obtida pelo AGCM para este caso.

Como a corrente é um sinal sinusoidal, assim como o sinal da tensão, para os próximos casos ensaiados, são exibidos apenas as estimações dos sinais da tensão do SEP, pois a modelagem do AGCM permite estimar qualquer tipo de sinal sinusoidal, seja ele de tensão ou corrente. Esta estratégia foi aqui utilizada como forma de tornar este trabalho mais objetivo, sem comprometer a qualidade dos resultados apresentados.

Quando analisado a estimação da variável da frequência pelo AGCM é possível perceber que a solução segue a linha de referência esperada durante toda a duração do sinal conforme mostra a Figura 29. Após a ocorrência do evento, a estimação apresenta um comportamento ondulatório devido a função de regularização utilizada, a qual estabelece 


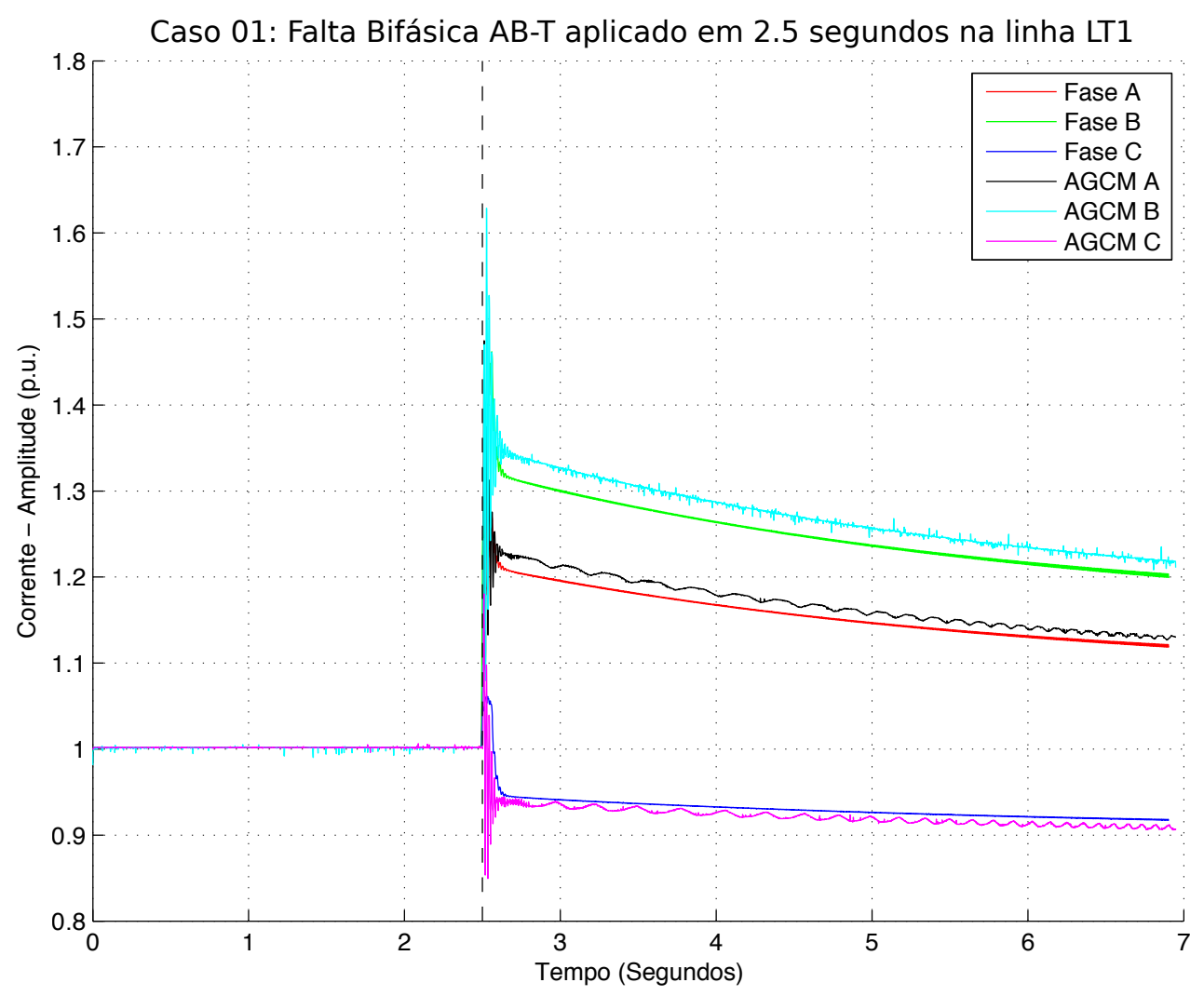

Figura 28 - Amplitude das Correntes Trifásicas Estimadas para o Caso 01.

limites plausíveis de variação da frequência, evitando assim uma divergência da solução. A frequência de referência aqui utilizada é a frequência fornecida pelo software ATP, medida diretamente no eixo do gerador, a qual nem sempre refletirá a frequência nos barramentos de carga.

Para uma análise mais detalhada, é apresentado através das Figuras 30, 31 e 32 um comparativo dos métodos genéticos durante a estimação das variáveis de amplitude de tensão, corrente e frequência, esta última tendo também seu Root Mean Square Error (RMSE) calculado e representado pela Figura 33. Esta estrutura de apresentação dos resultados segue ao decorrer de todo este capítulo.

Quando analisada a estimação da variável de amplitude da tensão no período próximo do instante de ocorrência do evento, nota-se que a estimação de todos os método genéticos acompanham a referência quando o sistema encontra-se em regime, porém é observado pequenos ruídos nas fases estimadas pelo método AGM. No instante em que ocorre o evento, denotado pela linha pontinhada, existe uma divergência entre os valores estimados e de referência, indiferente do método genético utilizado. É possível identificar através da análise da fase B estimada, que o AGCM converge rapidamente para valores próximos da referência, antes mesmo que o sistema apresente tal comportamento. No período pós evento, a estimação apresenta maiores ruídos para os métodos multiobjetivos AGM e AGCM, enquanto que o AG apresenta uma estimação mais suave.

Já para a variável de amplitude da corrente, ilustrado pela Figura 31, é possível ob- 


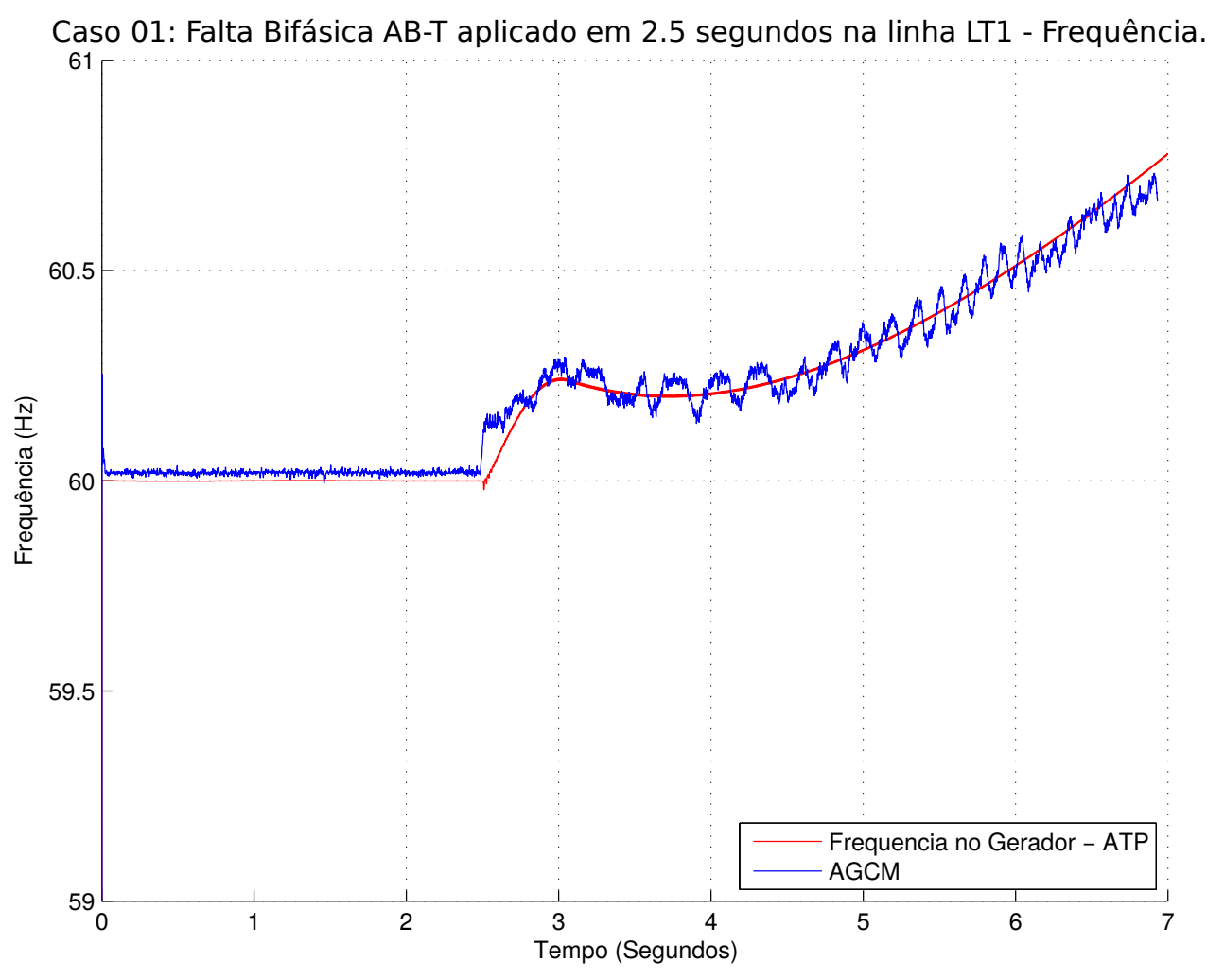

Figura 29 - Frequência Estimada para o Caso 01.

servar que as estimações de todos os métodos genéticos são igualmente precisas com o sistema operando em regime. Durante a ocorrência de um evento, as estimações dos métodos mono-objetivos divergem mais que as dos modelos multiobjetivos quando analisado as fases A e B envolvidas no evento, porém todos apresentam um tempo de recuperação de aproximadamente $100 \mathrm{~ms}$.

Ao verificar a estimação da variável da frequência através da Figura 32, executada pelos quatro diferentes métodos evolutivos, é necessário lembrar que os métodos mono-objetivos AG e AGC executam tal estimativa considerando uma única fase, desta forma, foram necessárias a execução de três instâncias do algoritmo, uma para cada fase, extraindo assim 3 valores de frequência, referente a cada fase analisada. Durante uma estimação fasorial mono-objetiva, é necessária a escolha prévia da fase do SEP que será analisada. Note que durante a ocorrência de um evento, a fase escolhida pode não conter as informações necessárias para a estimativa da frequência. Já a análise multiobjetiva proposta, considerando as três fases, torna-a imune a este problema, garantindo sempre um único valor de frequência estimada, o melhor entre os representados pelo modelo probabilístico de cada fase estimada pelo AGCM.

Na Figura 33 é possível visualizar o erro associado na estimação da variável da frequência para os métodos multiobjetivos e pelos métodos mono-objetivo, para cada fase analisada. É possível notar através das fases A e C do método AG a importância da escolha da fase antes da estimação. No instante em que ocorre o evento no sistema, a fase C 

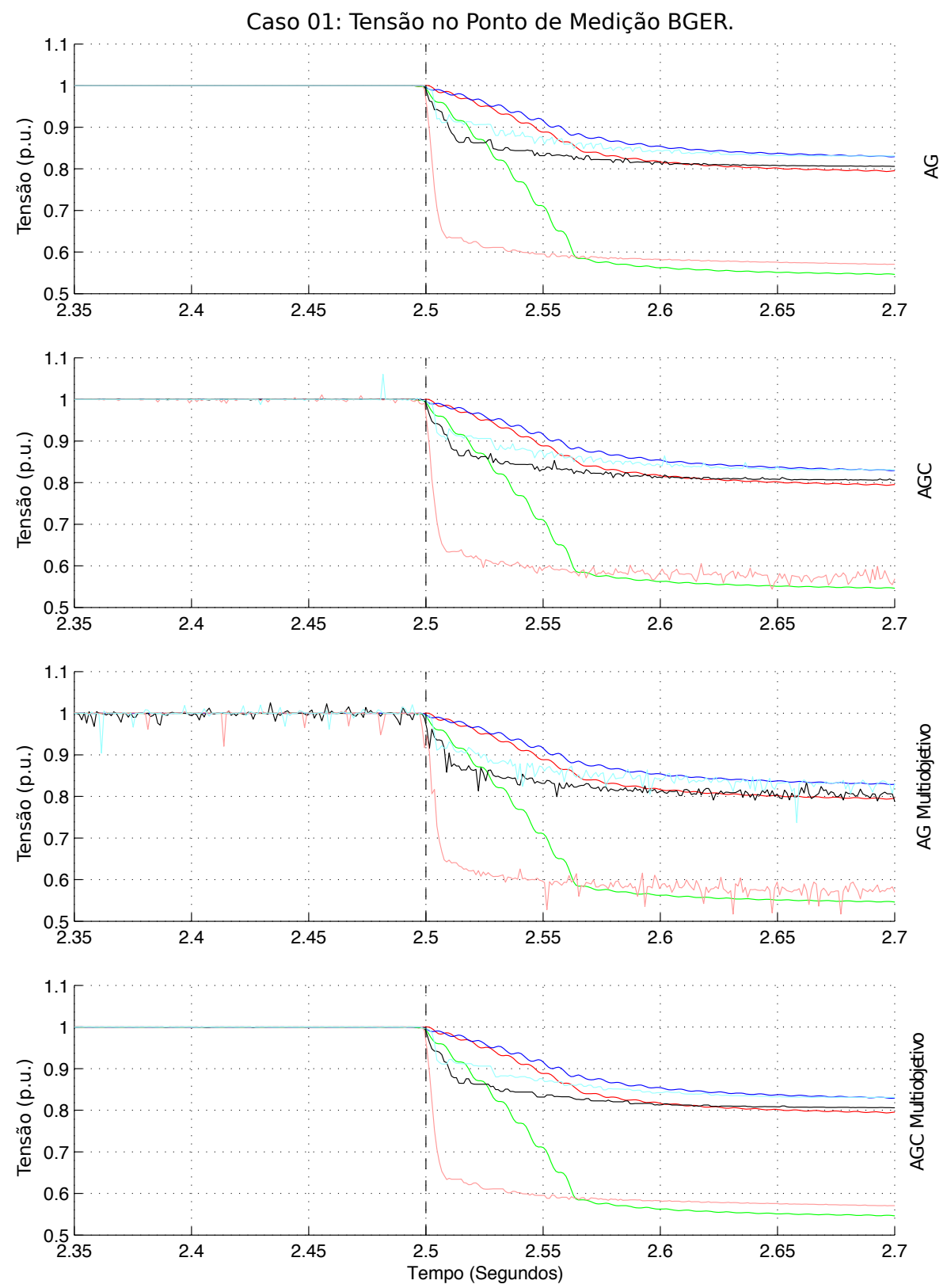

RMS Fase A $\longrightarrow$ RMS Fase B $\longrightarrow$ RMS Fase C $\longrightarrow$ Estim. Fase A $\longrightarrow$ Estim. Fase B Estim. Fase C

Figura 30 - Detalhe da Amplitude das Tensões Estimadas para o Caso 01.

apresenta uma estimação pior que a fase $\mathrm{A}$, sendo neste caso a fase $\mathrm{B}$, o melhor caso para estimação da frequência conforme a referência esperada. O mesmo comportamento pode ser observado no método AGC. Os métodos multiobjetivos, AGM e AGCM, ponderam a informação das três fases para estimar um único valor de frequência, ambos apresentando uma estimação intermediária entre as apresentadas pelas três instâncias dos métodos mono-objetivos AG e AGC e com uma convergência mais rápida se comparado com a pior fase analisada pelos métodos mono-objetivos. 

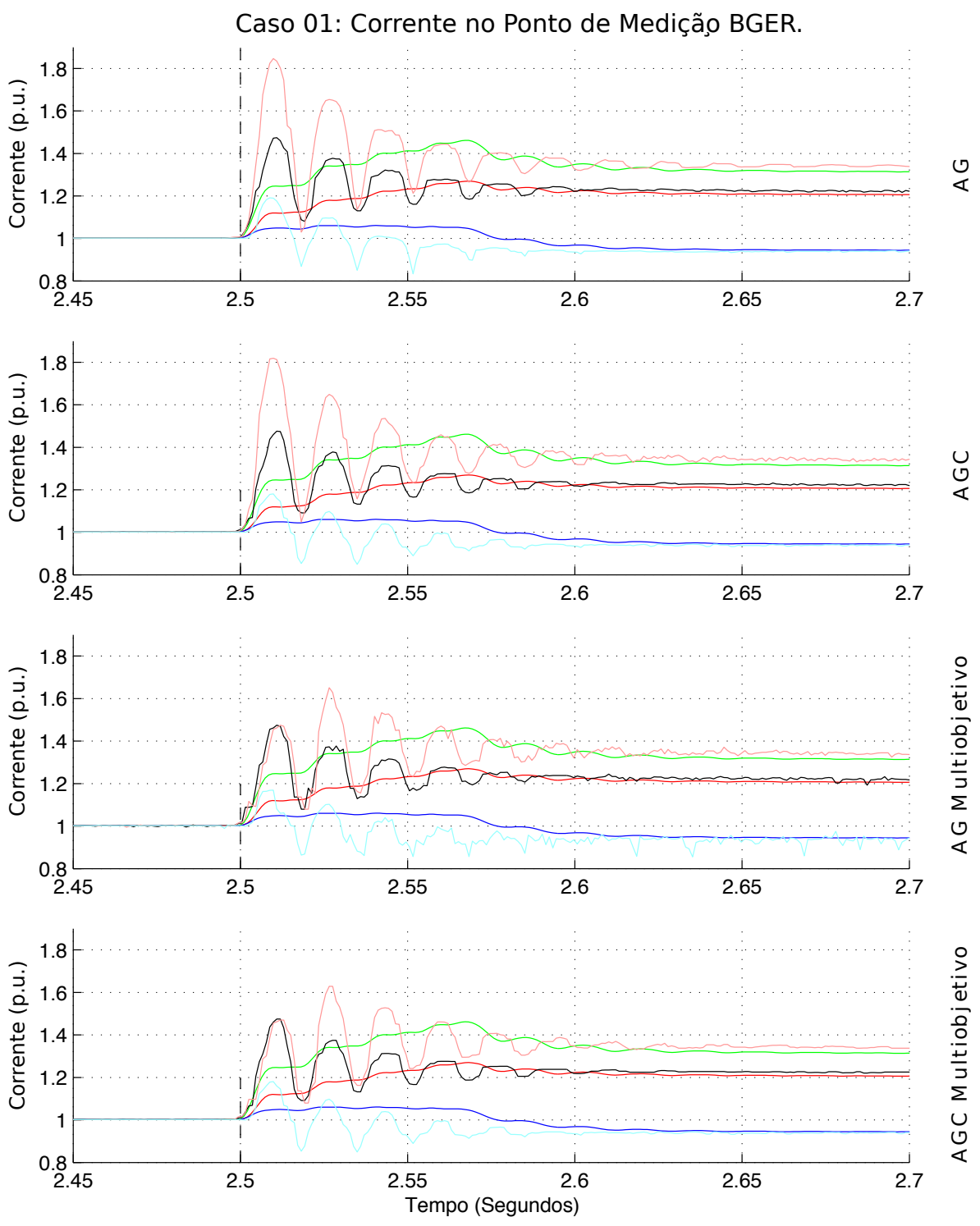

RMS Fase A $\longrightarrow$ RMS Fase B $\longrightarrow$ RMS Fase C $\longrightarrow$ Est. Fase A $\longrightarrow$ Est. Fase B $\longrightarrow$ Est. Fase C

Figura 31 - Detalhe da Amplitude das Correntes Trifásicas Estimada para o Caso 01.

\subsubsection{Caso 02}

No segundo caso simulado para validação do AGCM, com o SEP em regime, foi então aplicado no instante $t=2,455 \mathrm{~s}$ uma manobra de rejeição de carga no barramento BCGH3, ocasionando a elevação da tensão nas fases do sistema conforme mostra a Figura 34. Neste caso, o AGCM apresenta uma máxima divergência da estimação da tensão em -0,05 p.u. ao final da duração do sinal.

A estimação da variável da frequência exibida na Figura 35 mostra que embora ruidosa, apresenta uma pequena divergência da estimação apenas no instante de ocorrência do evento, se recuperando rapidamente para estimações precisas justificadas e detalhadas posteriormente. 

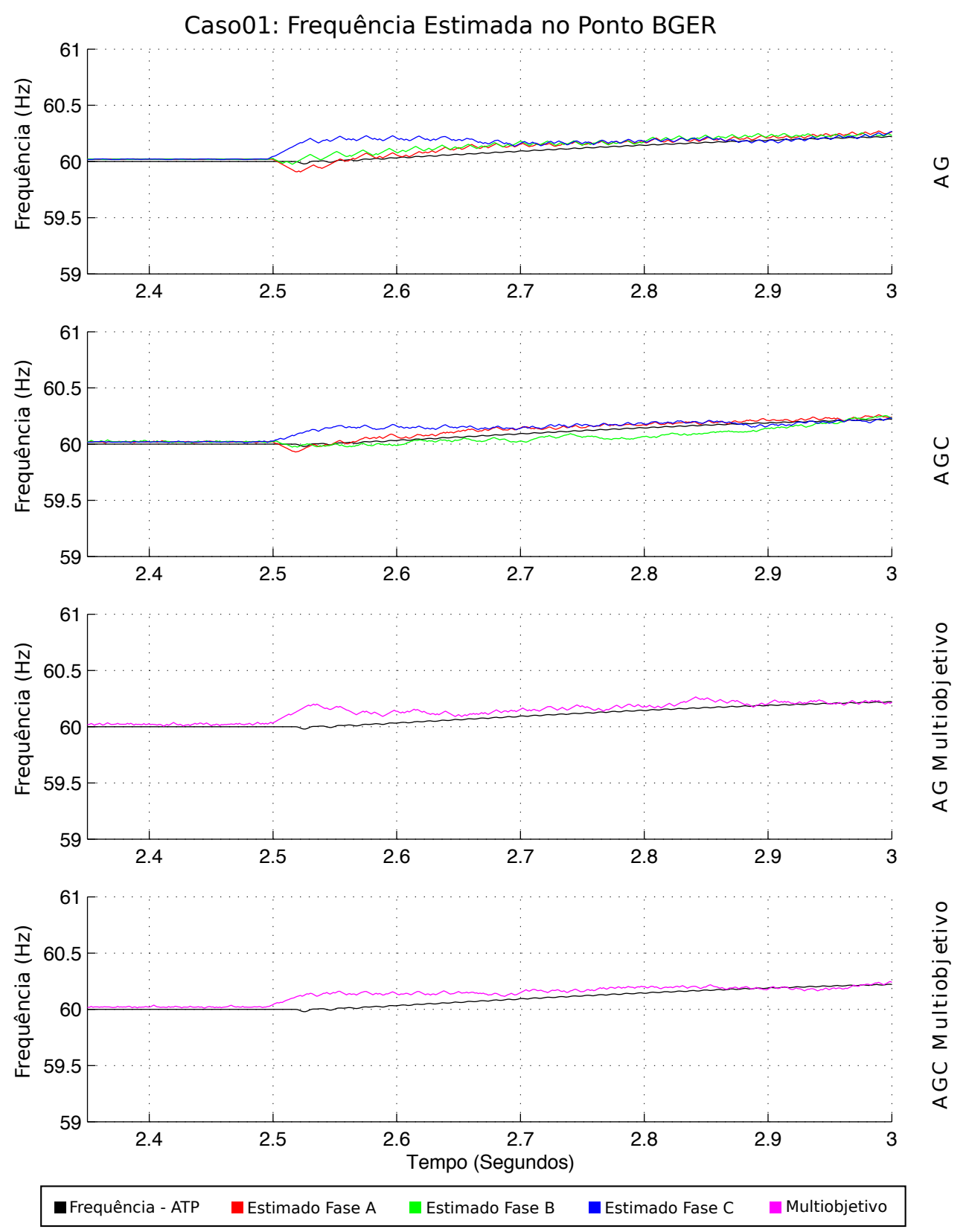

Figura 32 - Detalhe da Frequência Estimada para o Caso 01.

Quando comparado a estimação da variável de amplitude pelos quatro diferentes algoritmos genéticos, apresentados na Figura 36, a qual ilustra com detalhes a estimação das três fases no período próximo da ocorrência do evento, no instante $t=2,455 \mathrm{~s}$. Pode-se observar que todos os algoritmos genéticos estimam corretamente a amplitude das fases do sistema em regime, exceto o AGM que apresenta uma estimação ruidosa, a qual pode ser suprida com a aplicação de um filtro de média móvel descrito posteriormente na Seção 4.3. No instante em que ocorre o evento de rejeição de carga, o método AGCM apresenta uma estimação mais suave quando comparado com o Algoritmo Genético Compacto (AGC), enquanto que no período pós evento, todos os métodos apresentam uma diferença de 0.02 p.u. na estimação. Note também que o método AGCM apresenta estimativas menos 


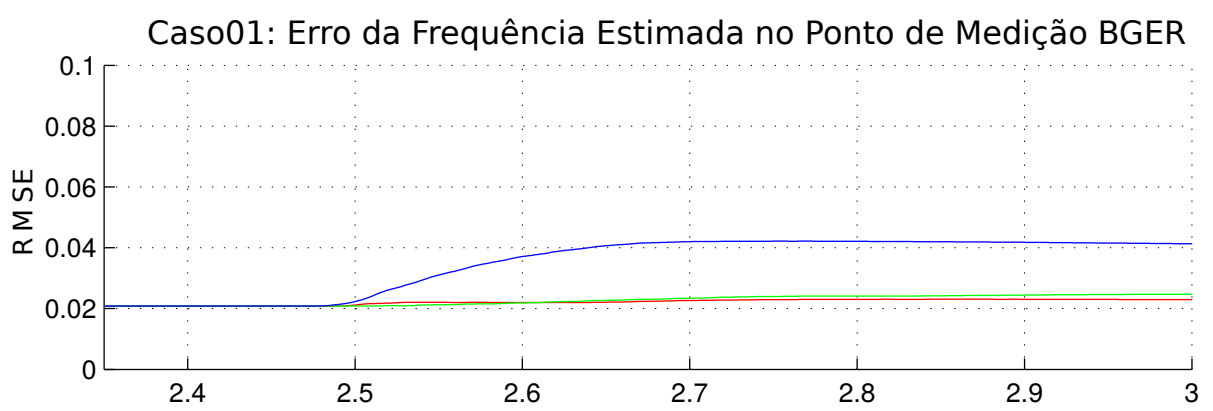

$\stackrel{\square}{4}$

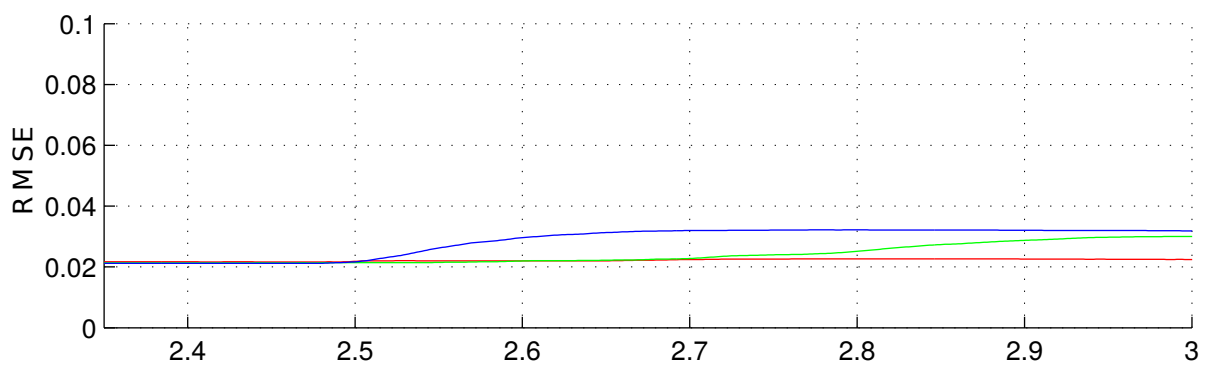

U

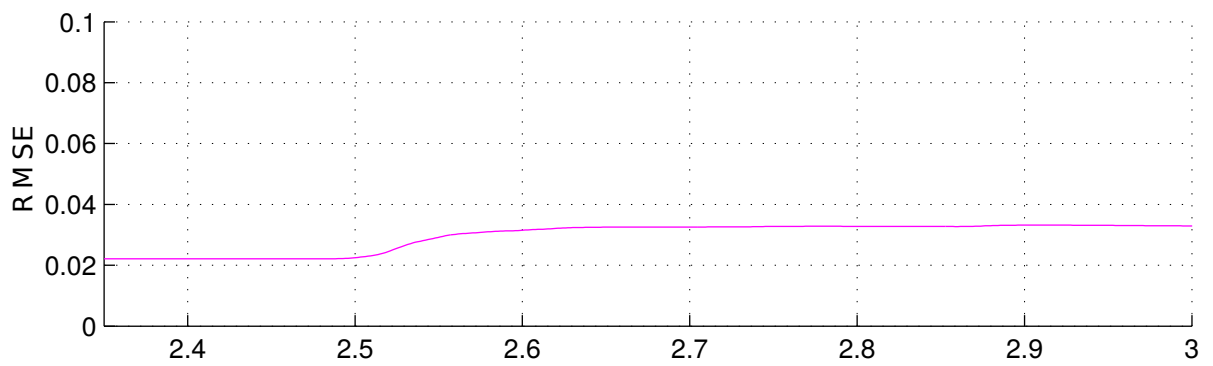

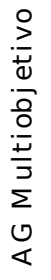

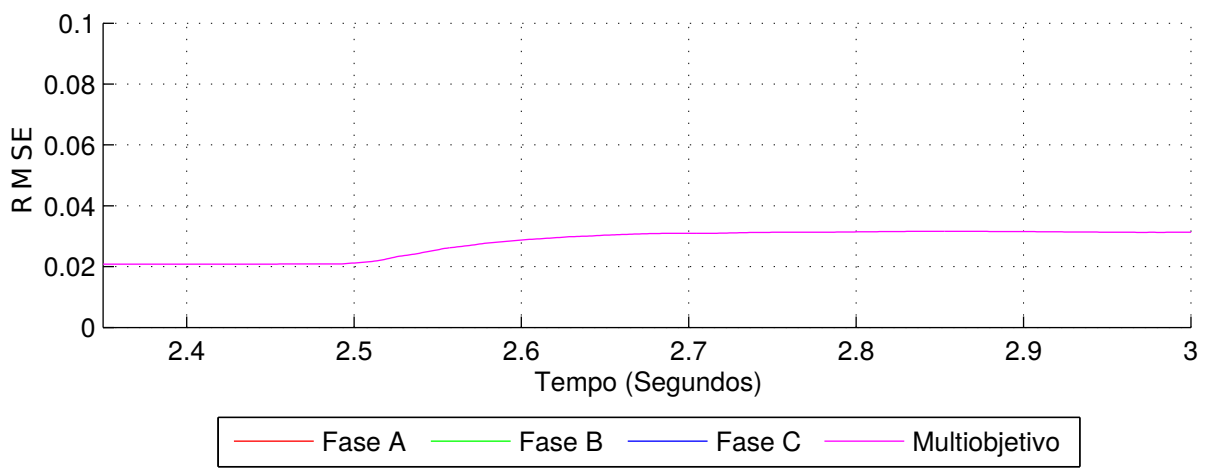

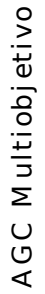

Figura 33 - Erro da Frequência Estimada para o Caso 01.

ruidosas, parecidas com a do Algoritmo Genético (AG). 


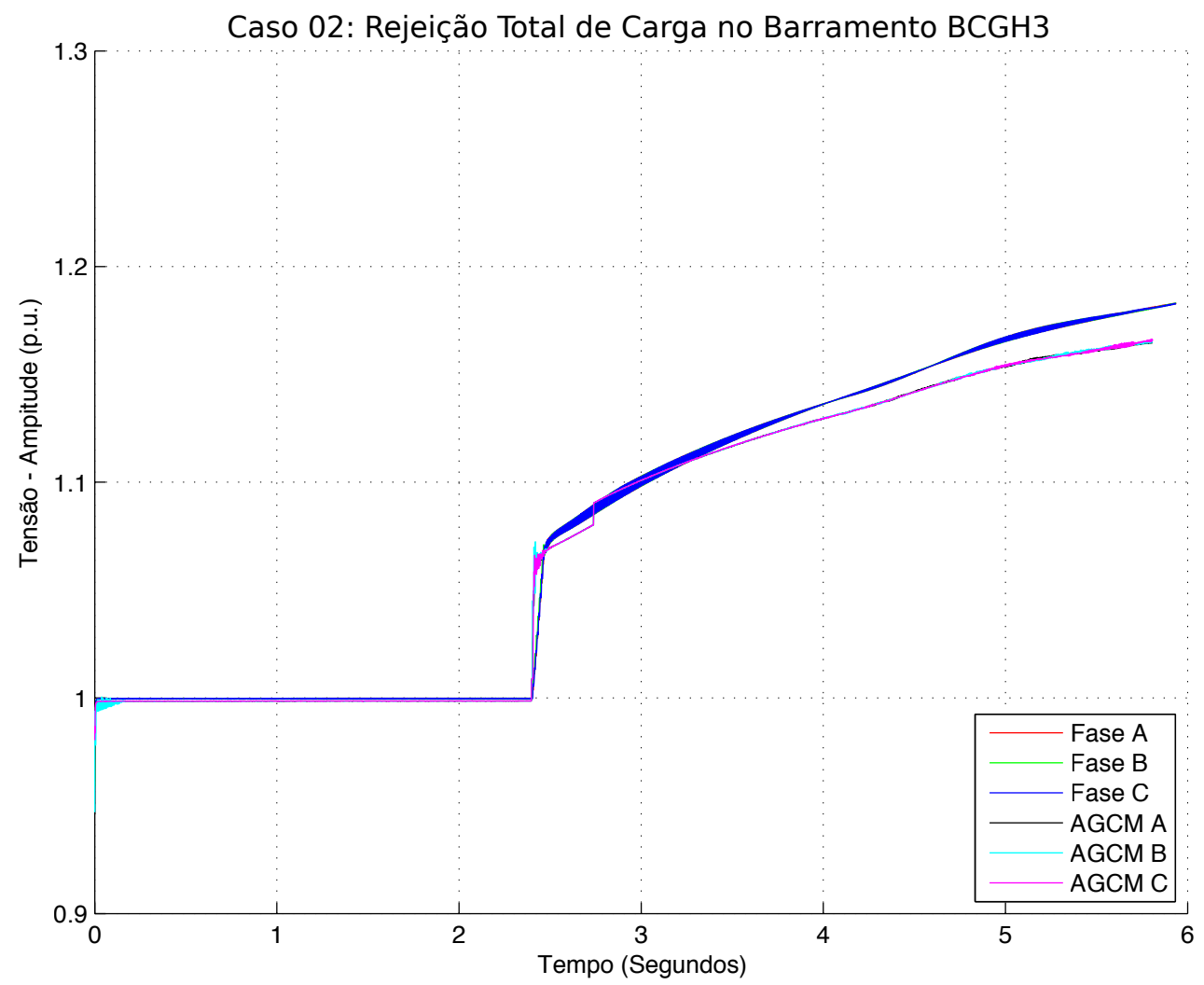

Figura 34 - Amplitude das Tensões Trifásicas Estimadas para o Caso 02.

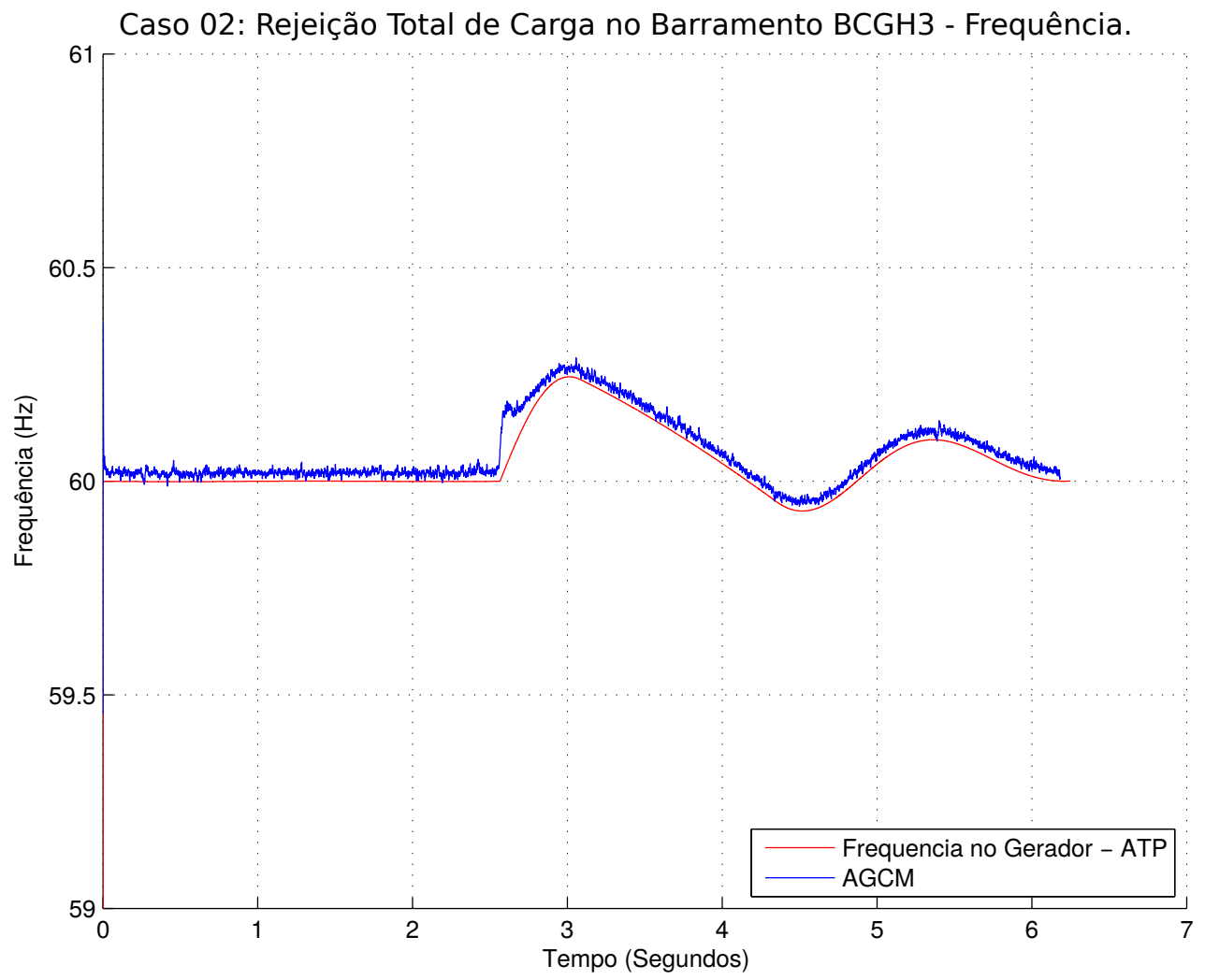

Figura 35 - Frequência Estimada para o Caso 02. 

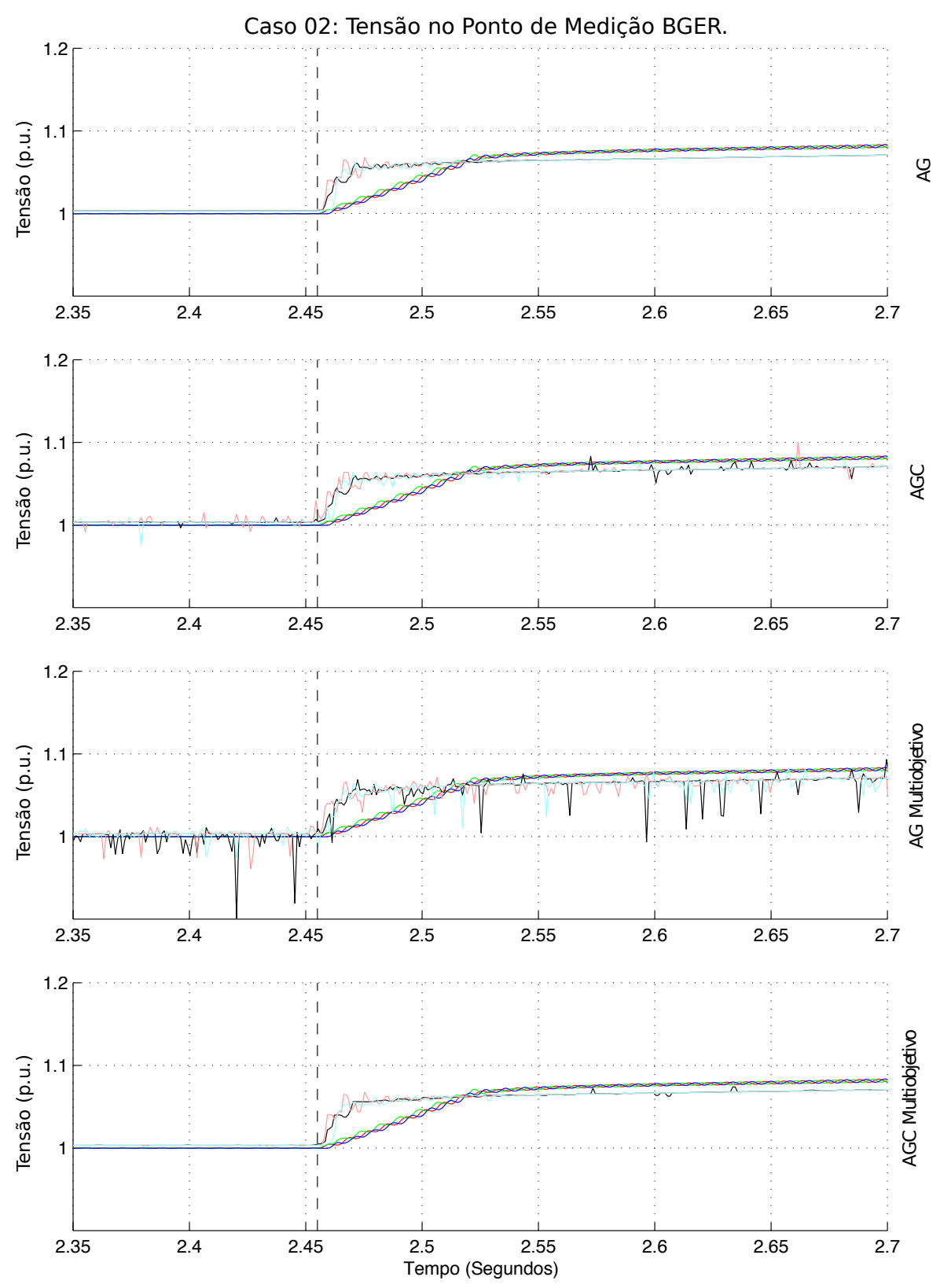

RMS Fase A $\longrightarrow$ RMS Fase B $\longrightarrow$ RMS Fase C $\longrightarrow$ Estim. Fase A $\longrightarrow$ Estim. Fase B Estim. Fase C

Figura 36 - Detalhe da Amplitude das Tensões Estimadas para o Caso 02.

A estimação da variável da frequência representada através da Figura 37 mostra uma estimação precisa, com uma pequena divergência na estimação no instante em que ocorre a manobra de rejeição de carga. De maneira geral os métodos multiobjetivos apresentam uma convergência mais rápida da estimação após a ocorrência do evento, com tempos próximos de $100 \mathrm{~ms}$ para o AGCM e estimações com erro aproximado de 0,1 Hz. 

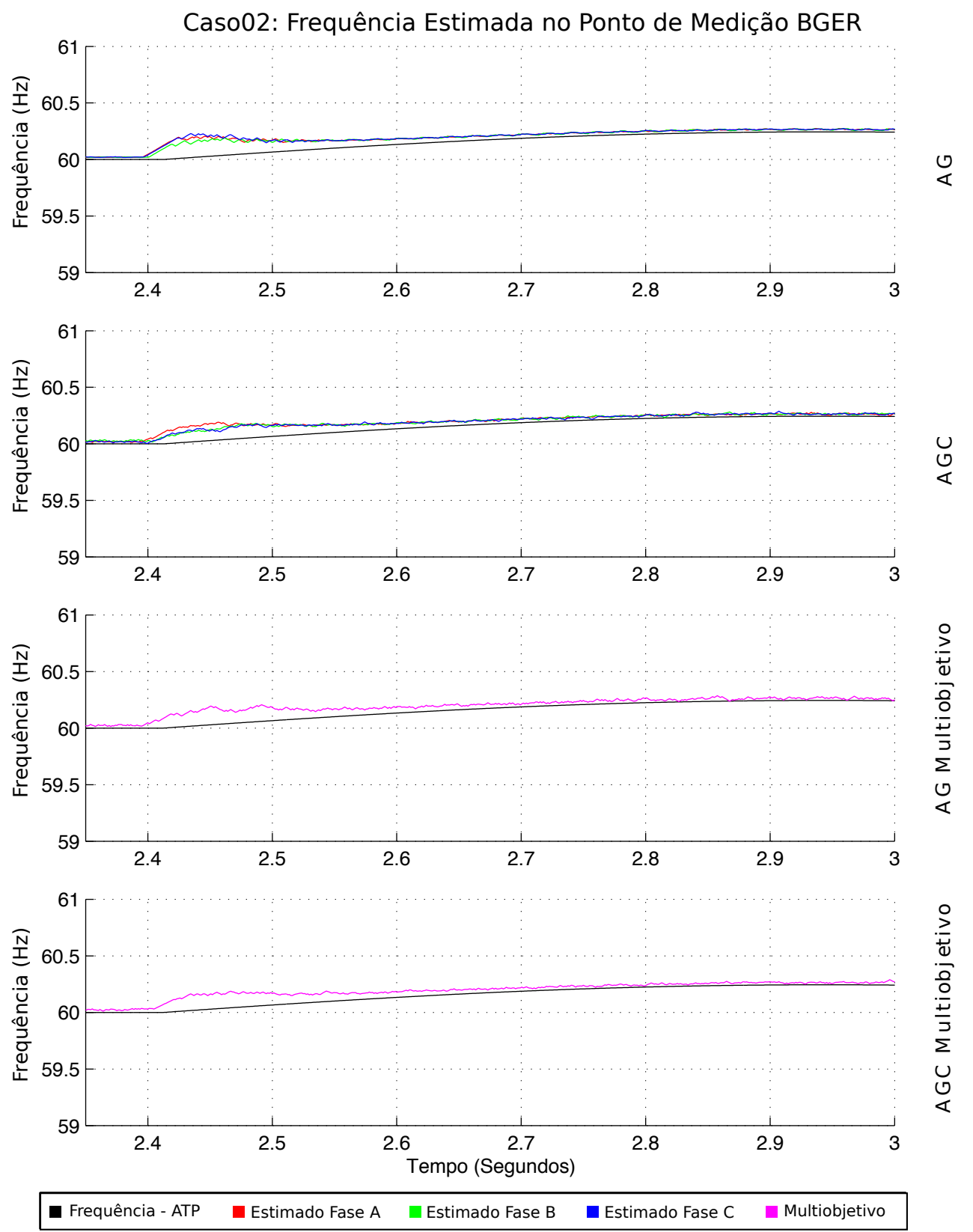

Figura 37 - Detalhe da Frequência Estimada para o Caso 02.

Na Figura 38 é possível visualizar com detalhes o erro associado na estimação da variável da frequência realizada pelos métodos multiobjetivos, e para cada fase processada dos métodos mono-objetivos. Conforme ilustrado, o AGCM proposto apresenta um RMSE de 0,02 em regime, elevando-se para um valor de 0,03 após a ocorrência do evento. 

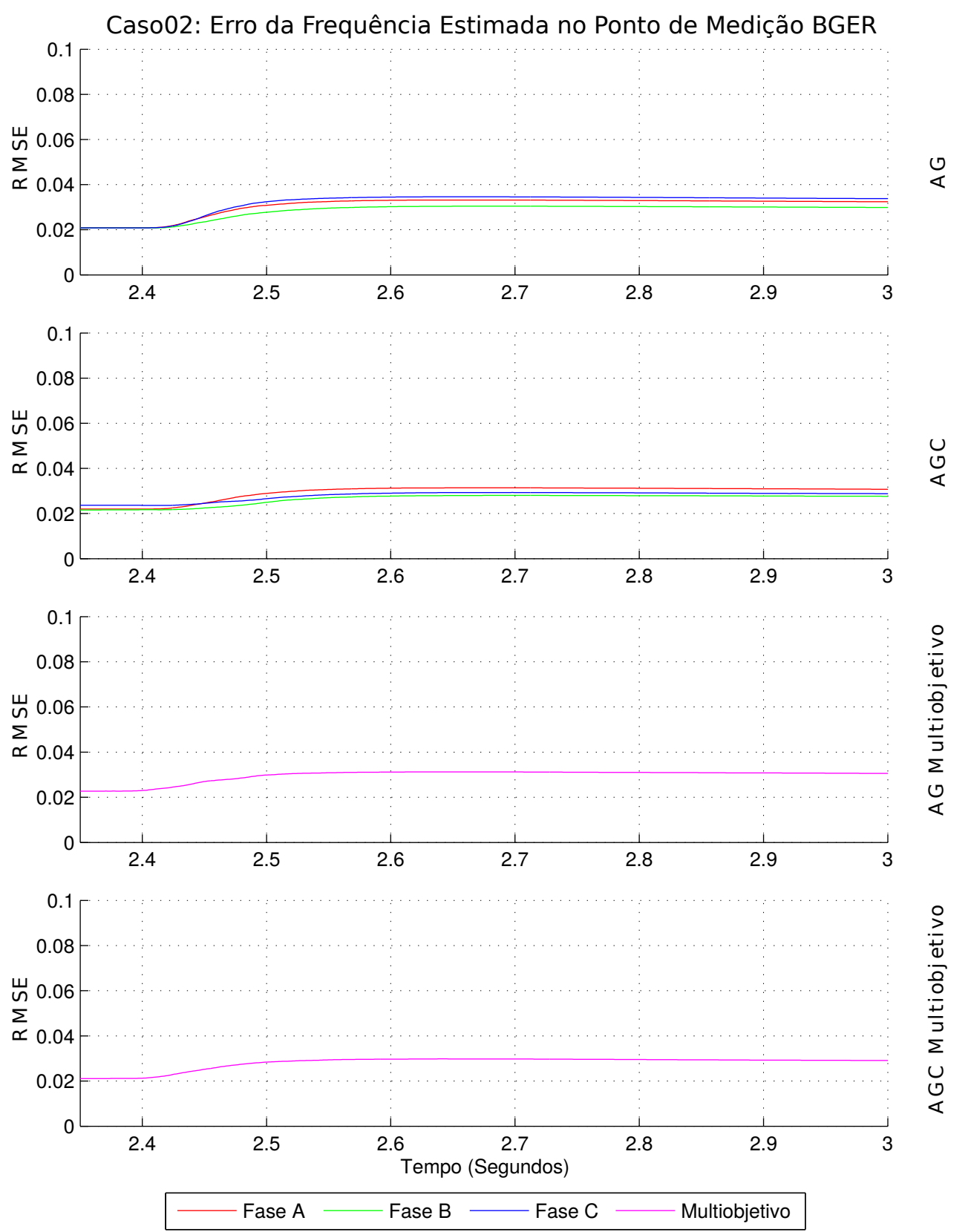

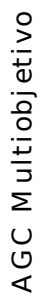

Figura 38 - Erro da Frequência Estimada para o Caso 02.

\subsubsection{Caso 03}

Dando continuação aos ensaios, o terceiro caso simulado com o software ATP, contempla um SEP operando em regime, quando no instante $t=2,4 \mathrm{~s}$ ocorre um evento do tipo falta monofásica A-T, aplicada no ponto BLT3O do circuito e com resistência de falta de 10 ohms, ocasionando a atuação do sistema de proteção na linha LT3. É possível observar através da Figura 39 que o AGCM estima com precisão as variáveis do SEP operando em regime, no instante da ocorrência do evento, sua estimação é comprometida, porém ainda acompanha a referência esperada. No período pós evento, em que o sistema encontra-se com as fases desbalanceadas, o AGCM exibe uma estimação com desvios absolutos de até 0,05 p.u. 


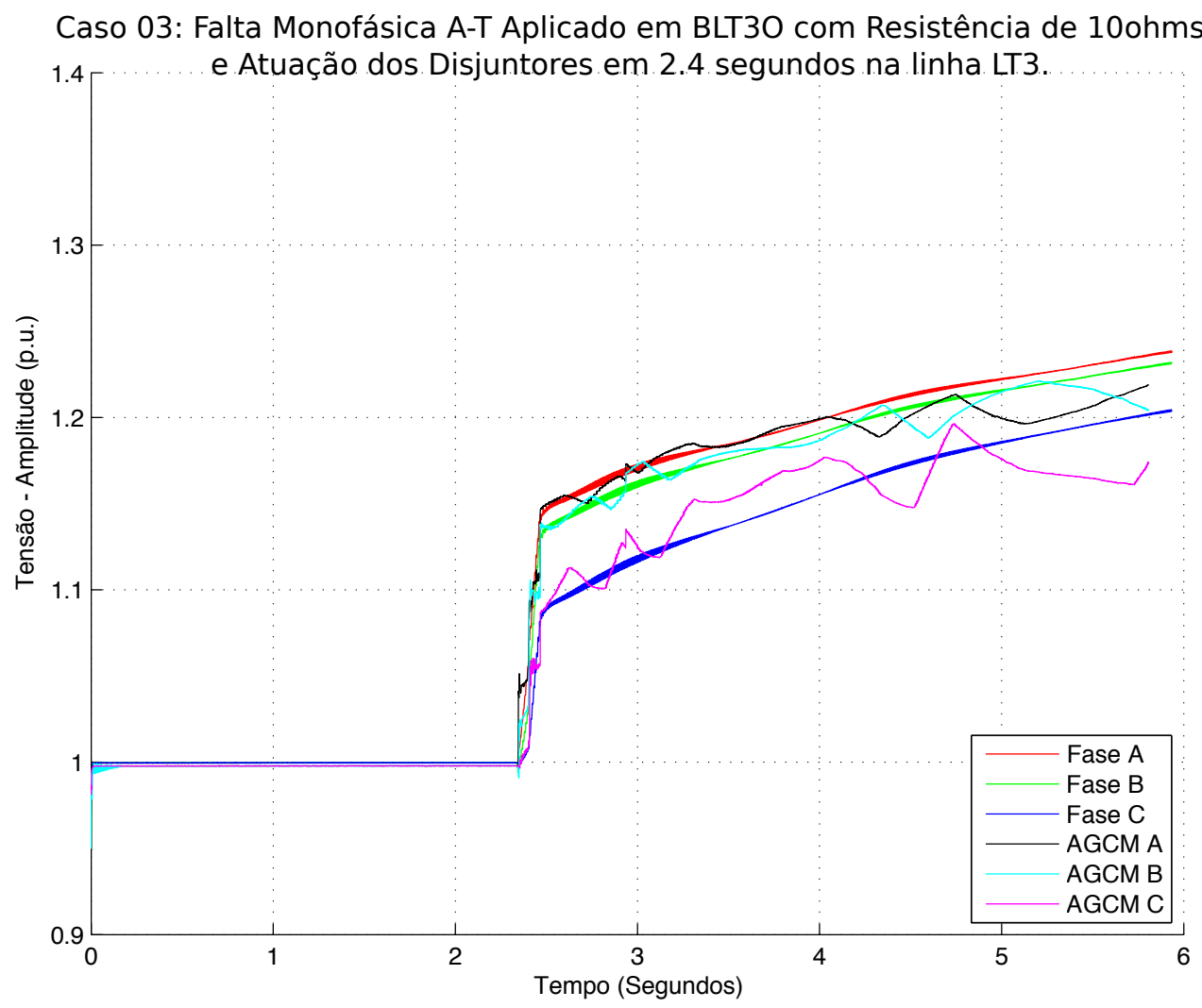

Figura 39 - Amplitude das Tensões Trifásicas Estimadas para o Caso 03.

A Figura 40 mostra a estimação da variável da frequência, a qual apresenta um comportamento ruidoso, e no período de pós evento, tem sua estimação afetada pelo método de regularização, ocasionando assim algumas pequenas divergências da referência esperada. 


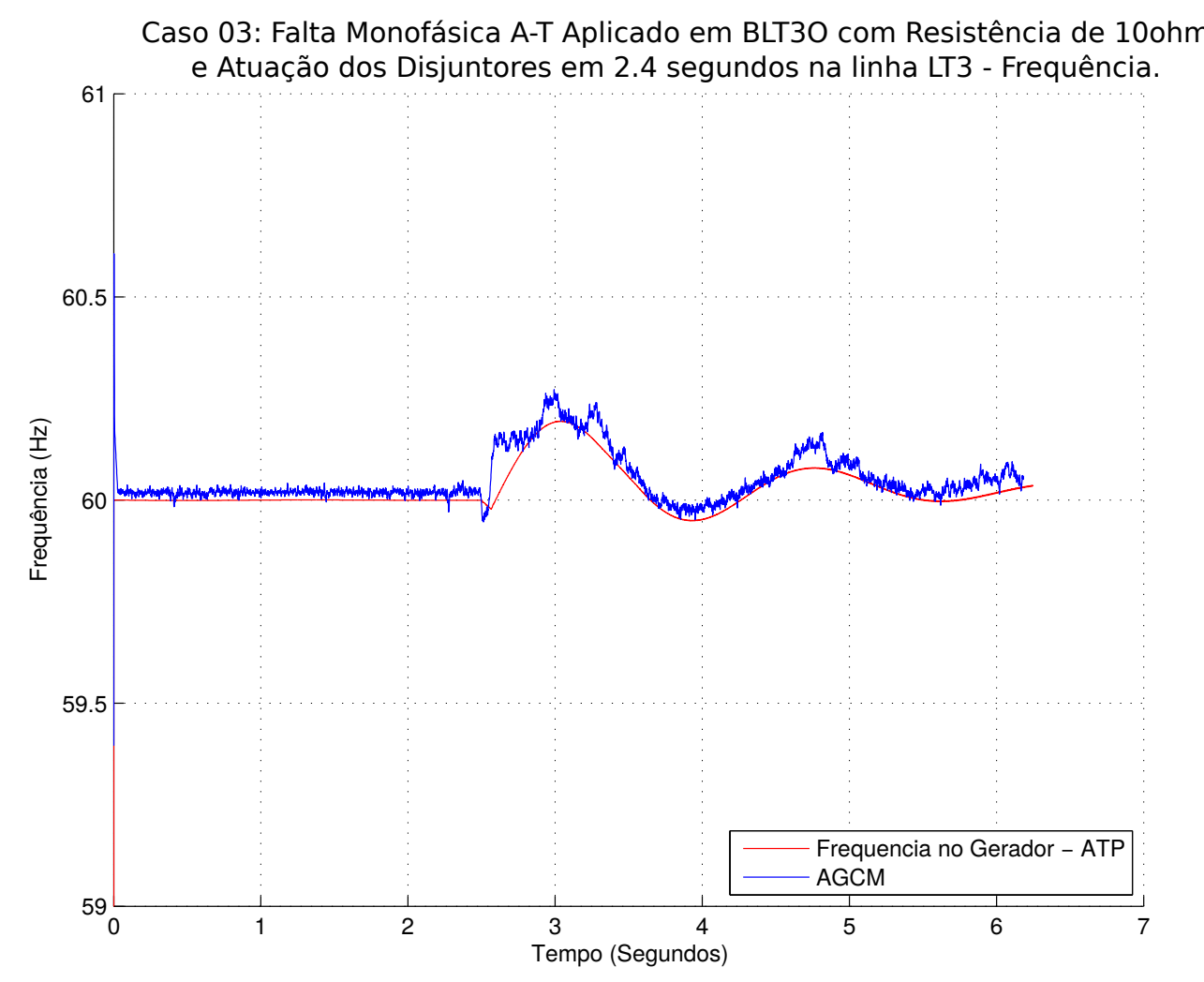

Figura 40 - Frequência Estimada para o Caso 03.

Ao analisar com detalhes o instante em que ocorre o evento, pode-se observar através da Figura 41 que todos os algoritmos testados apresentam uma estimação correta em regime, embora mais uma vez, o método AGM apresente também ruídos que podem afetar a precisão da estimação. No instante da ocorrência do evento, os métodos testados apresentam uma divergência na estimação esperada, porém nota-se a tentativa de convergência dos algoritmos para um degrau de amplitude mais preciso em relação referência. Como novamente o evento afeta os sinais de referência, os algoritmos estimam este novo estado, convergindo novamente para um degrau de amplitude mais próxima da nova referência, recuperando suas estimações no período de pós evento. 

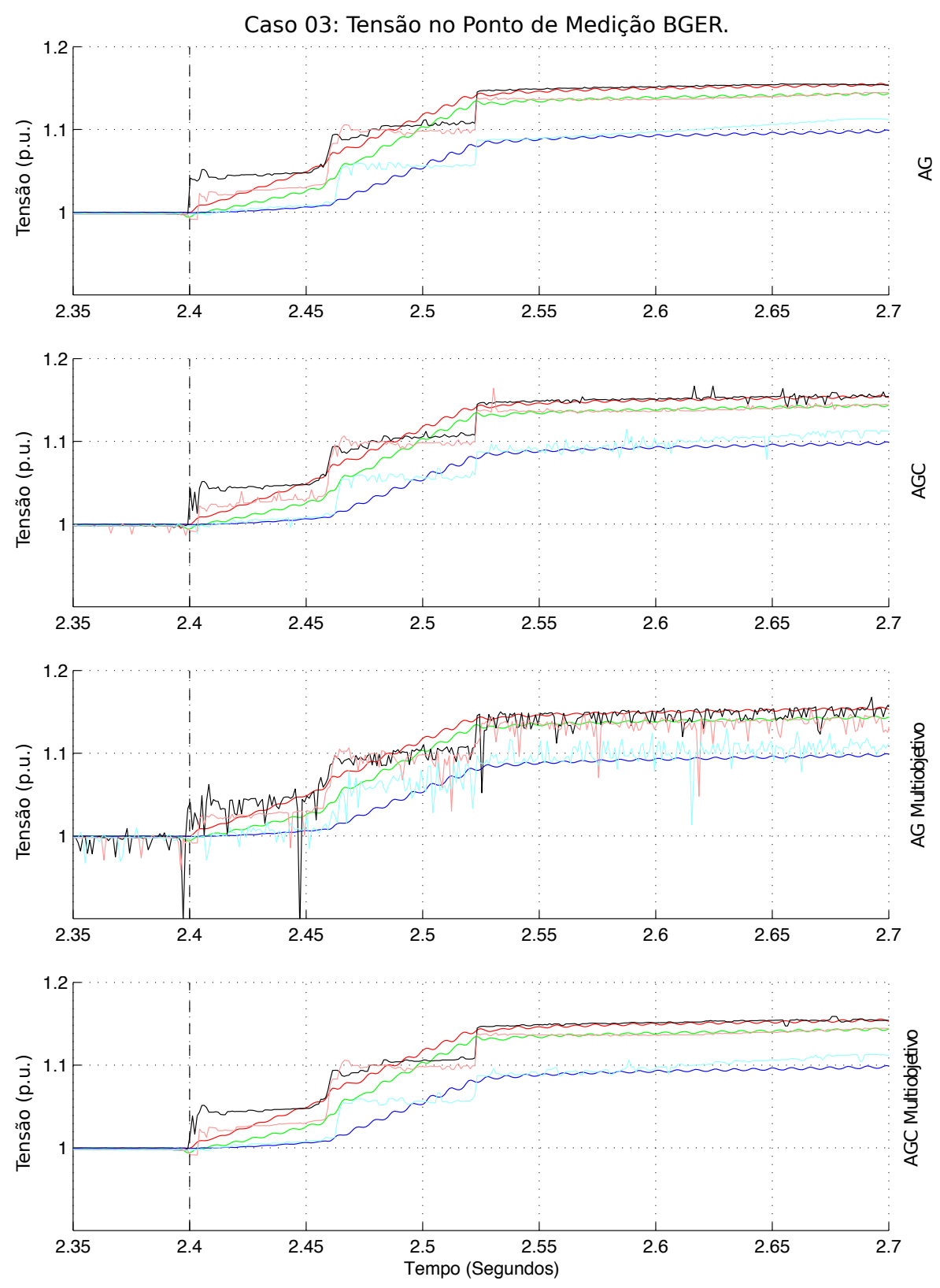

RMS Fase A $\longrightarrow$ RMS Fase B RMS Fase C $\longrightarrow$ Estim. Fase A Estim. Fase B Estim. Fase C

Figura 41 - Detalhe da Amplitude das Tensões Estimadas para o Caso 03.

O detalhamento da estimação da variável da frequência apresentado pela Figura 42 mostra que todos os métodos genéticos estimam com precisão a frequência do sistema, com o SEP operando em regime. No instante de ocorrência do evento, uma pequena divergência é apresentada, chegando próximo a $0.1 \mathrm{~Hz}$. Essa divergência é superada pela AG em aproximadamente 100 ms enquanto que o AGCM consome $200 \mathrm{~ms}$ para se recuperar. 

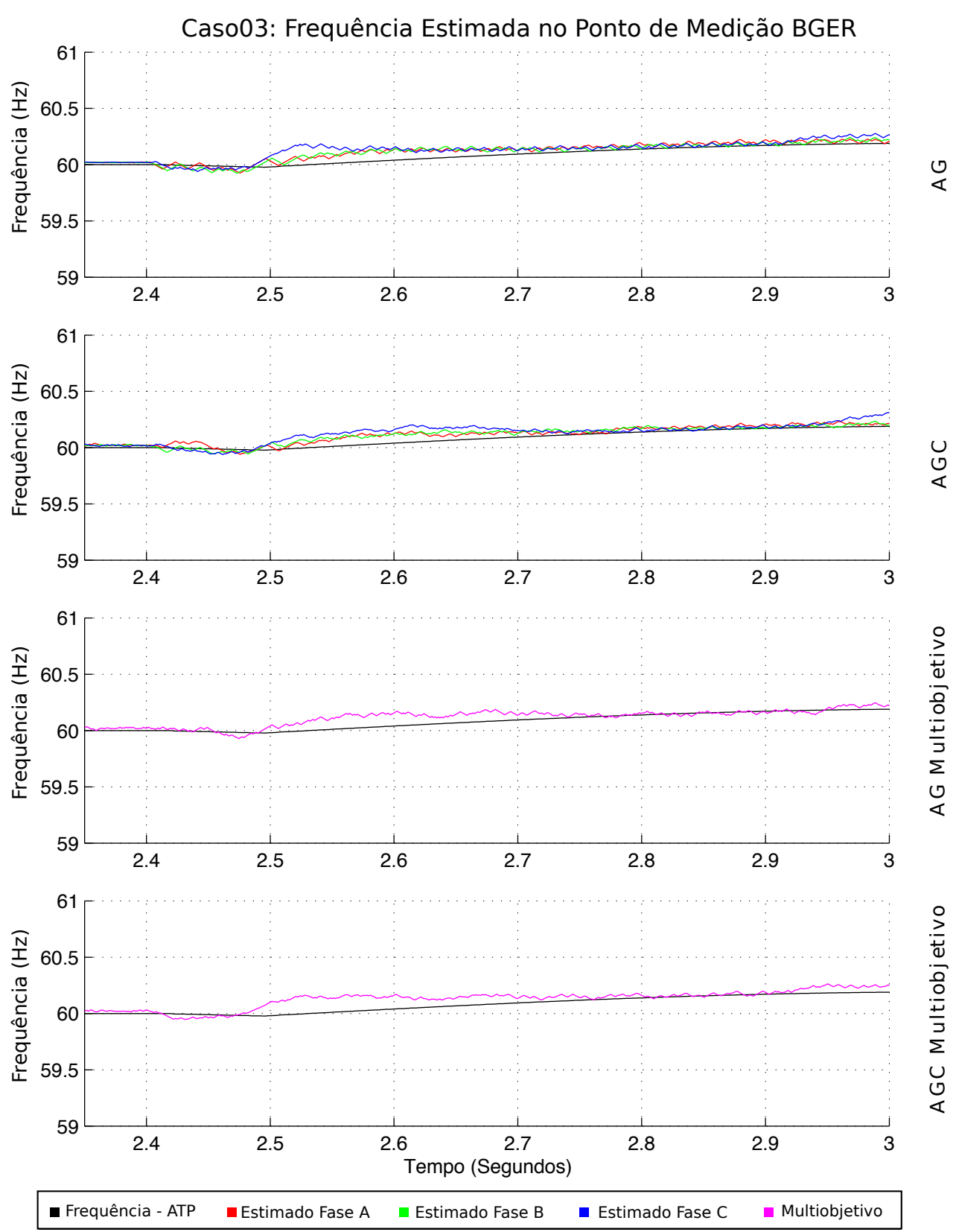

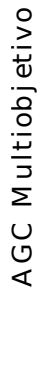

Figura 42 - Detalhe da Frequência Estimada para o Caso 03.

O erro associado a cada estimação da frequência apresentada anteriormente, pode ser visualizado através da Figura 43, e segue a mesma forma de apresentação dos casos anteriormente apresentados. Note que o AGCM para este caso, apresenta um Root Mean Square Error (RMSE) de 0,032 em seu pior caso de estimação, não estando distante dos outros métodos. 

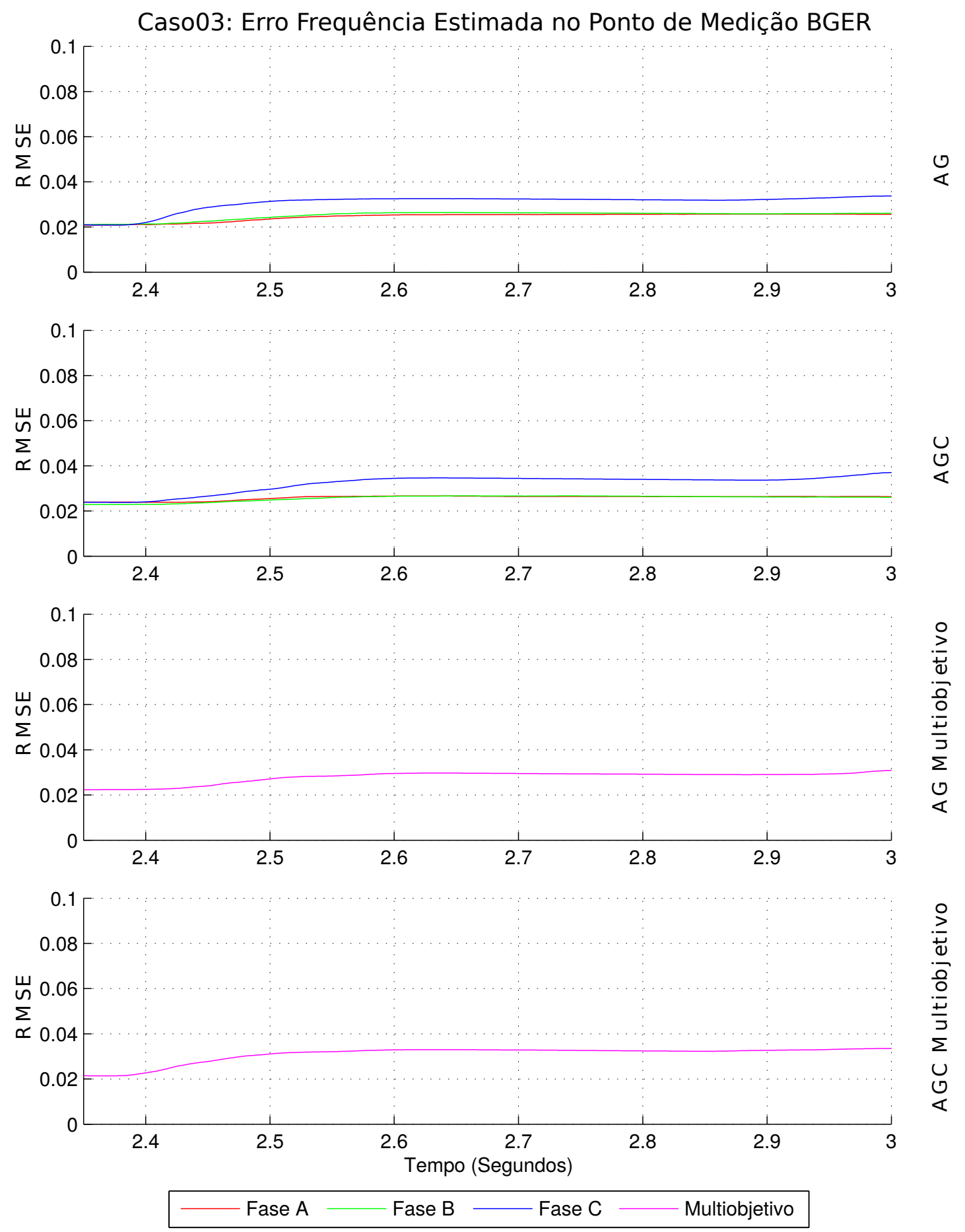

Figura 43 - Erro da Frequência Estimada para o Caso 03.

\subsubsection{Caso 04}

O quarto caso simulado, contempla o SEP operando em regime, quando acontece uma falta entre as fase C do circuito 1 e fase B do circuito 2, ambos em $50 \%$ do comprimento da linha LT1, no instante $t=2,44 \mathrm{~s}$. Pode-se conferir através da análise da Figura 44 que a estimação permanece precisa quando o SEP opera em regime, até mesmo em momento de desequilíbrio de fases, antes da ocorrência do evento de falta. O AGCM foi capaz de 
estimar com precisão a referência perturbada, divergindo a estimação em no máximo 0,04 p.u. A estimação da variável da frequência associada a este caso é ilustrada pela Figura 45, e demonstra uma estimação precisa, indiferente do instante do sinal analisado.

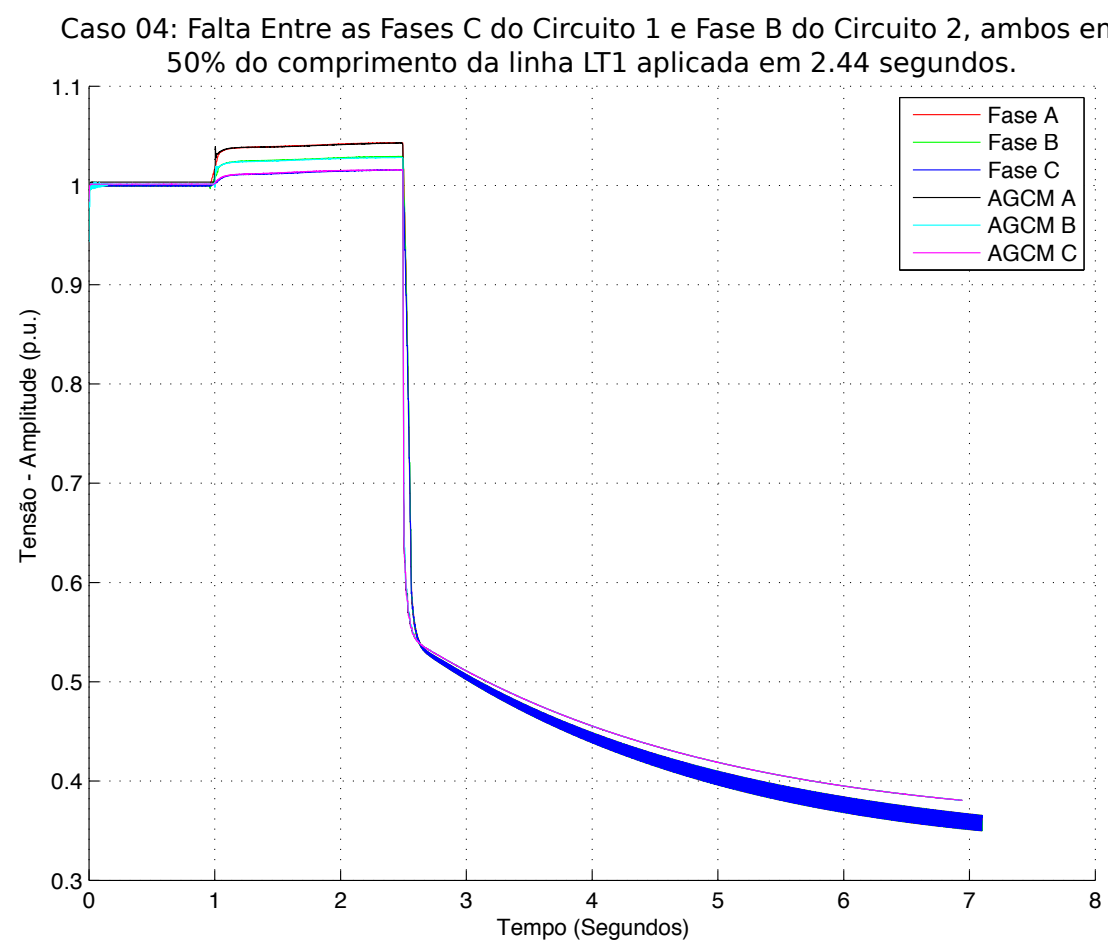

Figura 44 - Amplitude das Tensões Trifásicas Estimadas para o Caso 04.

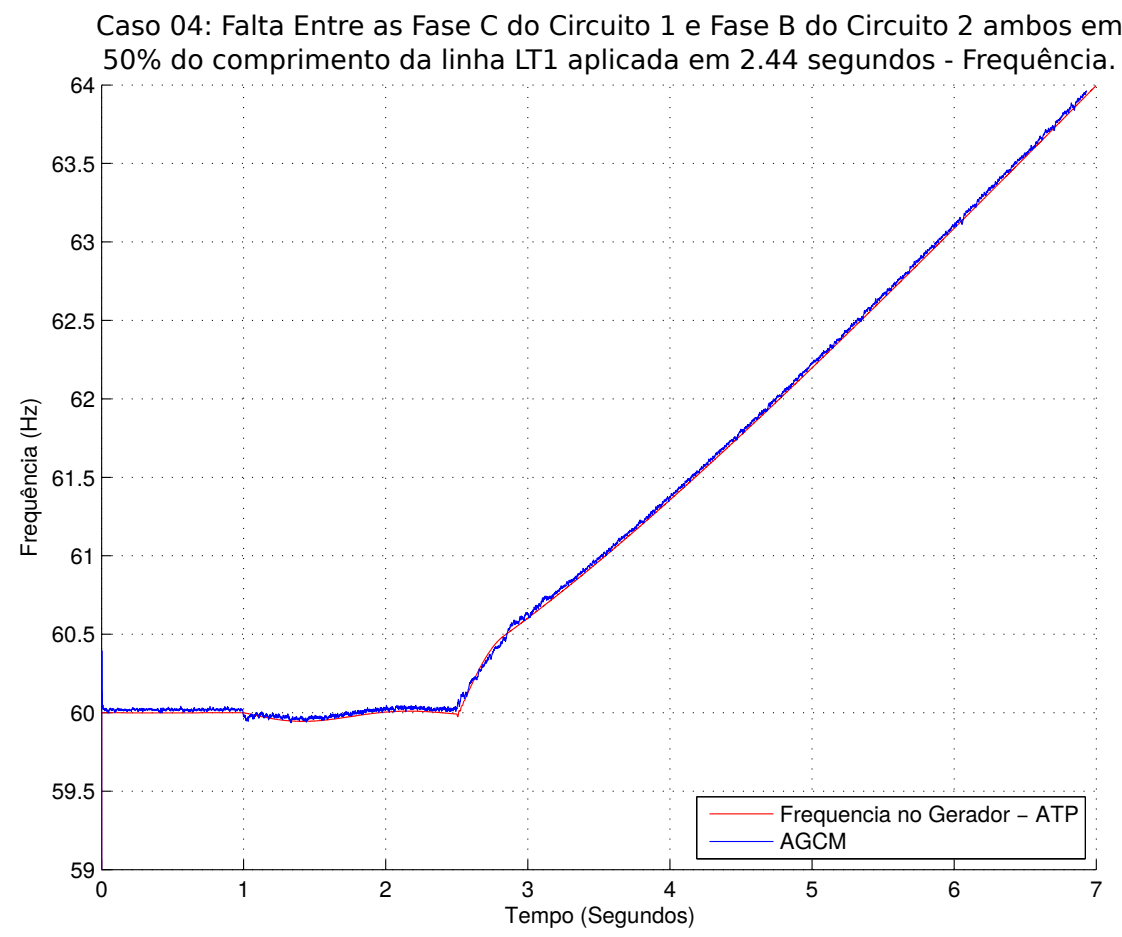

Figura 45 - Frequência Estimada para o Caso 04. 
Observando os detalhes da estimação da amplitude mostrados na Figura 46, notase que todos os quatro tipos de algoritmos genéticos tiveram o mesmo comportamento, embora os métodos AGC e AGM apresentem ruídos em sua estimação. No período de pós evento, a estimação diverge em aproximadamente 0,04 p.u.
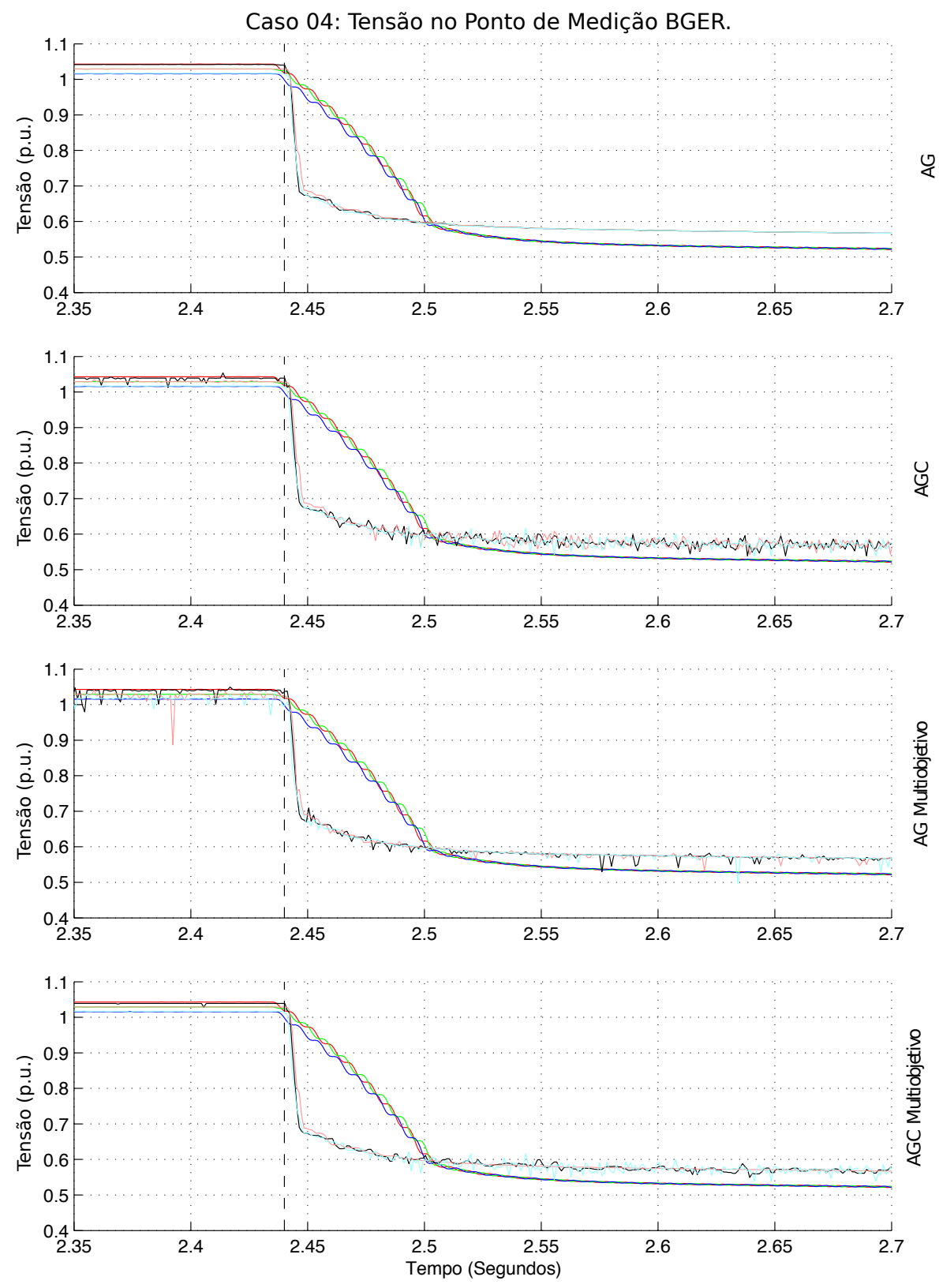

RMS Fase A RMS Fase B $\longrightarrow$ RMS Fase C $\longrightarrow$ Estim. Fase A $\longrightarrow$ Estim. Fase B Estim. Fase C

Figura 46 - Detalhe da Amplitude das Tensões Estimadas para o Caso 04. 
Já os detalhes da estimação da variável da frequência ilustrado pela Figura 47, é possível observar que os métodos multiobjetivos AGCM e AGM apresentam uma menor divergência da referência esperada, principalmente se comparado com os resultados insatisfatórios apresentados pelo AGC e AG quando analisado a fase A do sistema.
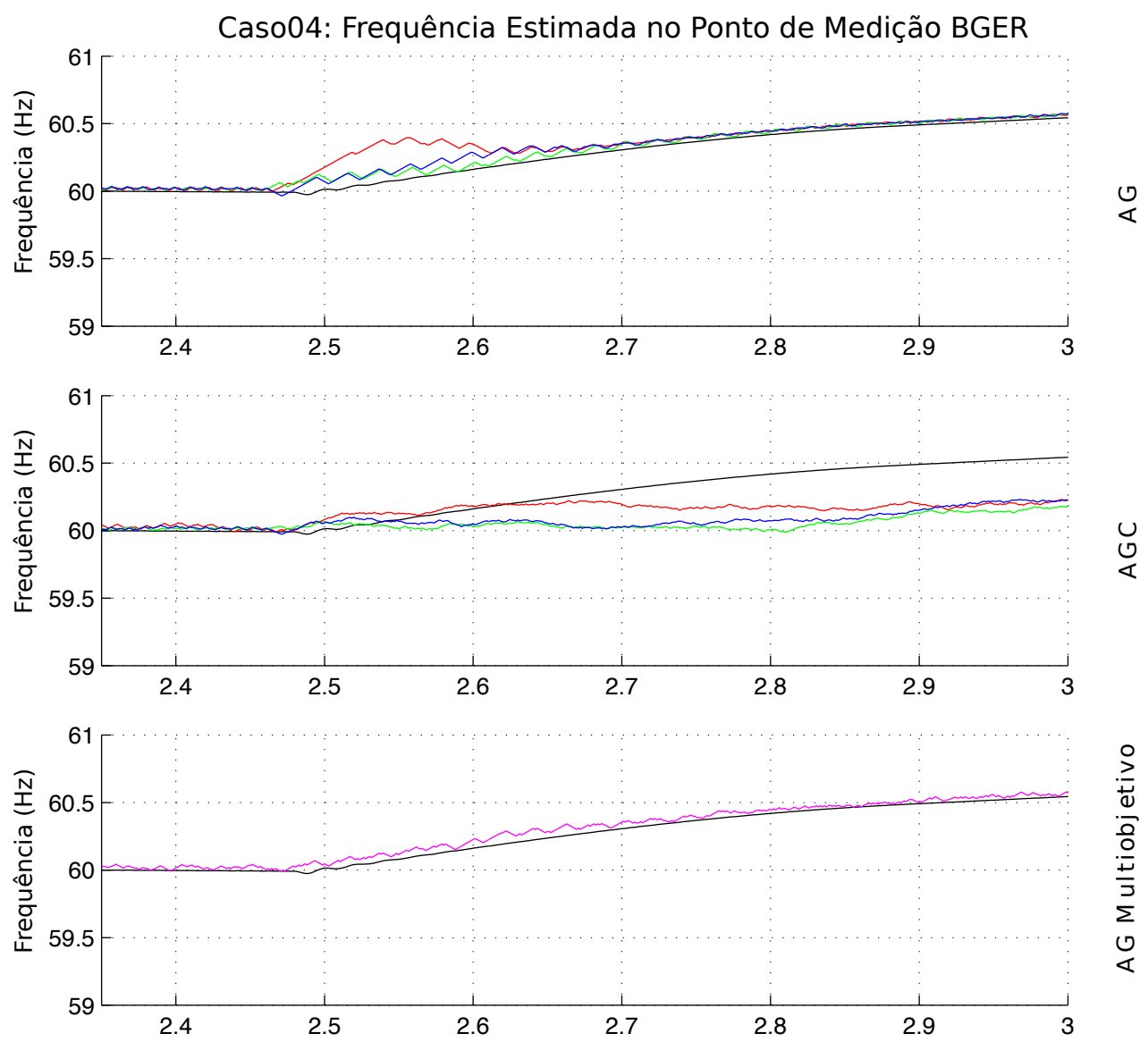

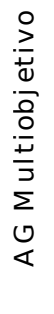

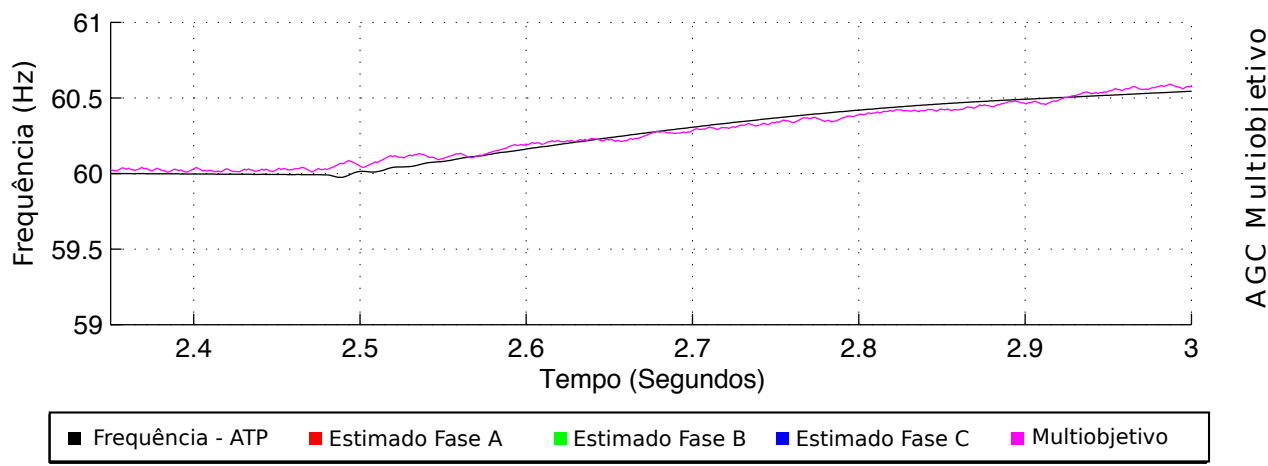

Figura 47 - Detalhe da Frequência Estimada para o Caso 04. 
Nos erros associados à estimação da variável da frequência ilustrado pela Figura 48, é possível observar que os métodos multiobjetivos AGCM e AGM são os mais precisos, apresentando um RMSE constante de 0,022, indiferente se o SEP opera em condições de regime ou com ocorrência deste tipo de evento.
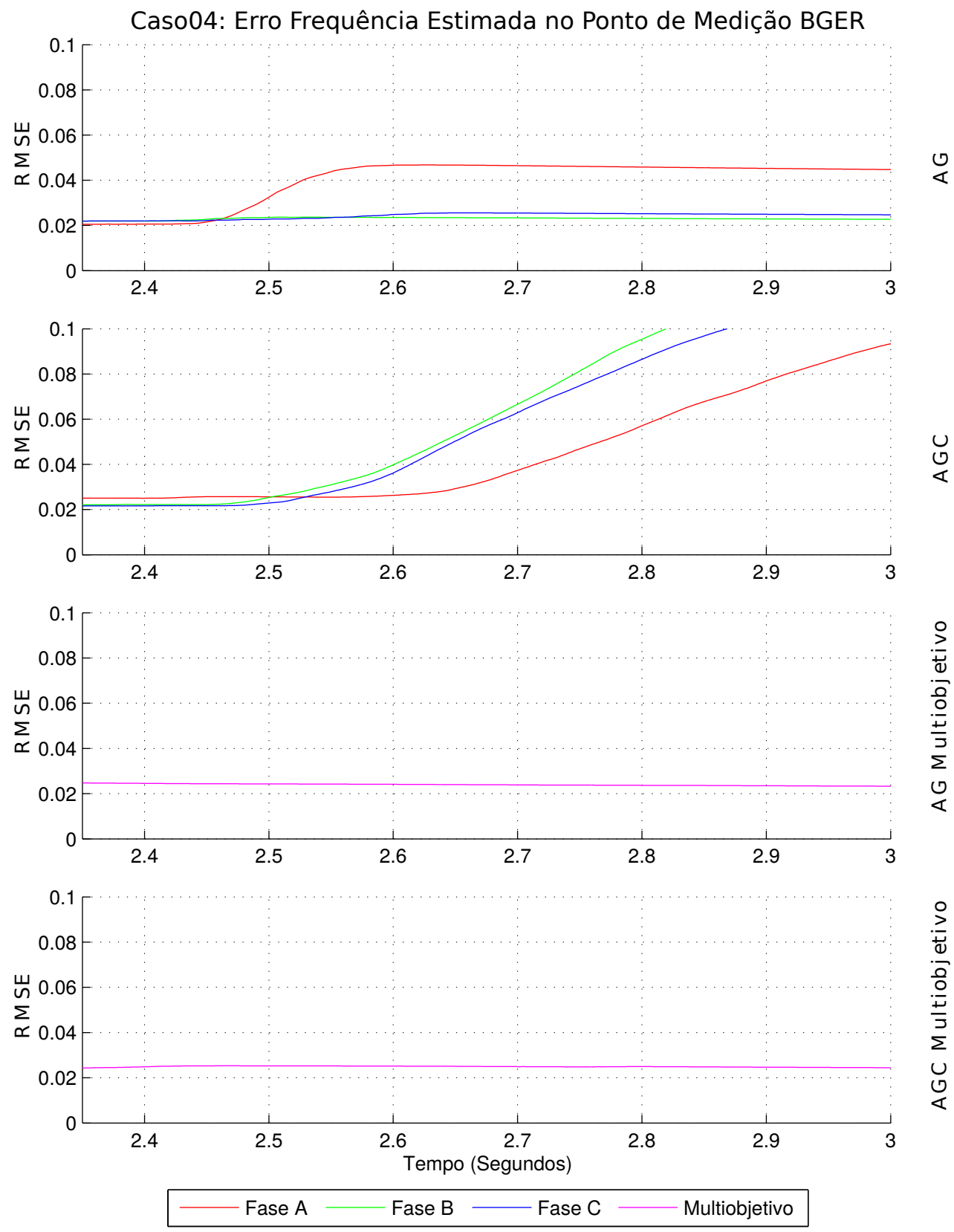

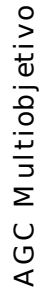

Figura 48 - Erro da Frequência Estimada para o Caso 04. 


\subsubsection{Caso 05}

O quinto caso simulado e estimado pelo AGCM assume o SEP em regime, até que um evento do tipo falta bifásica AB é aplicada no ponto BLT1, no instante $t=2,4 \mathrm{~s}$, ocasionando uma abertura do disjuntor de proteção no ponto BLT3 do sistema. A Figura 49 exibe a estimação da variável de amplitude resultante do AGCM, acompanhando a referência como esperado.

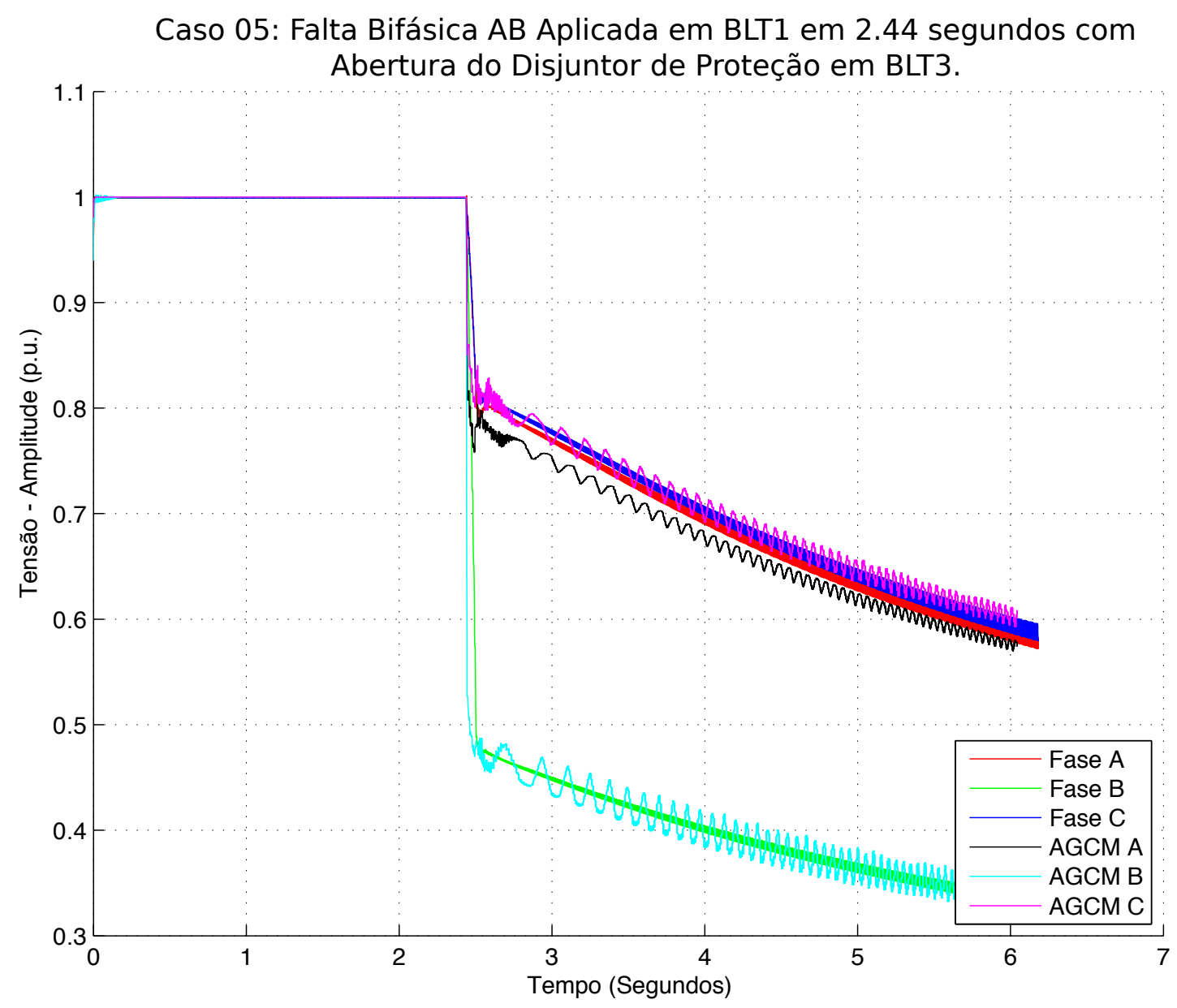

Figura 49 - Amplitude das Tensões Trifásicas Estimadas para o Caso 05. 
Quando analisado a estimação da variável da frequência para este caso, é possível notar através da Figura 50, a divergência do valor da frequência estimada no momento da ocorrência do evento, persistindo durante todo o período de pós evento. Graças mais uma vez a função de regularização, essa divergência apresentada, oscila sempre próxima à referência esperada.

Caso 05: Falta Bifásica AB Aplicada em BLT1 em 2.44 segundos com Abertura do Disjuntor de Proteção em BLT3.

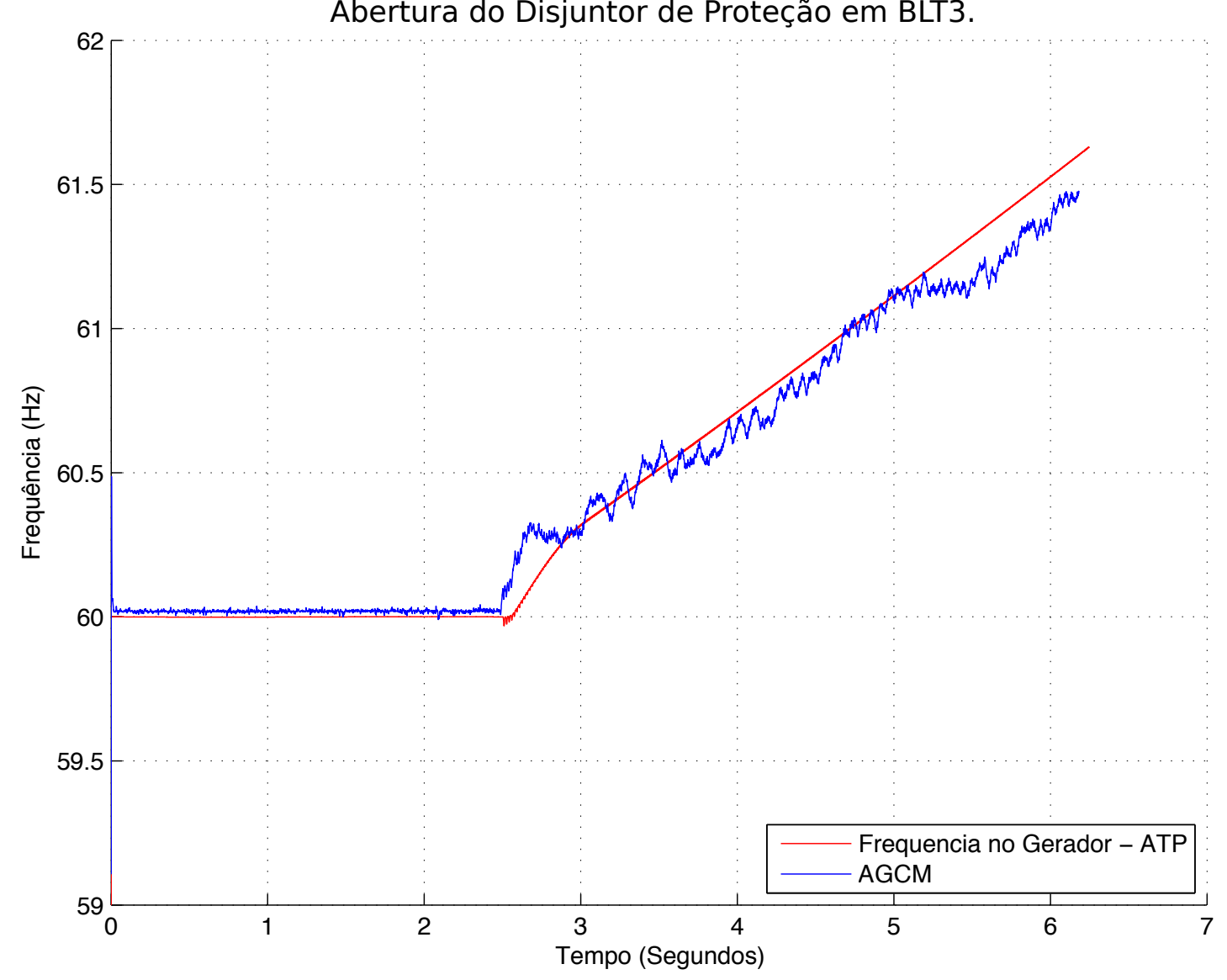

Figura 50 - Frequência Estimada para o Caso 05. 
A comparação das estimações das variáveis de amplitude resultantes do AGCM, assim com dos outros algoritmos genéticos, podem ser observadas com mais detalhes na Figura 51. É possível perceber que a estimação das fases A e C são as mais precisas se comparadas com a estimação da fase B, onde após a ocorrência do evento, apresentam divergência de 0,018 p.u. da referência esperada para fase B, a pior fase estimada..
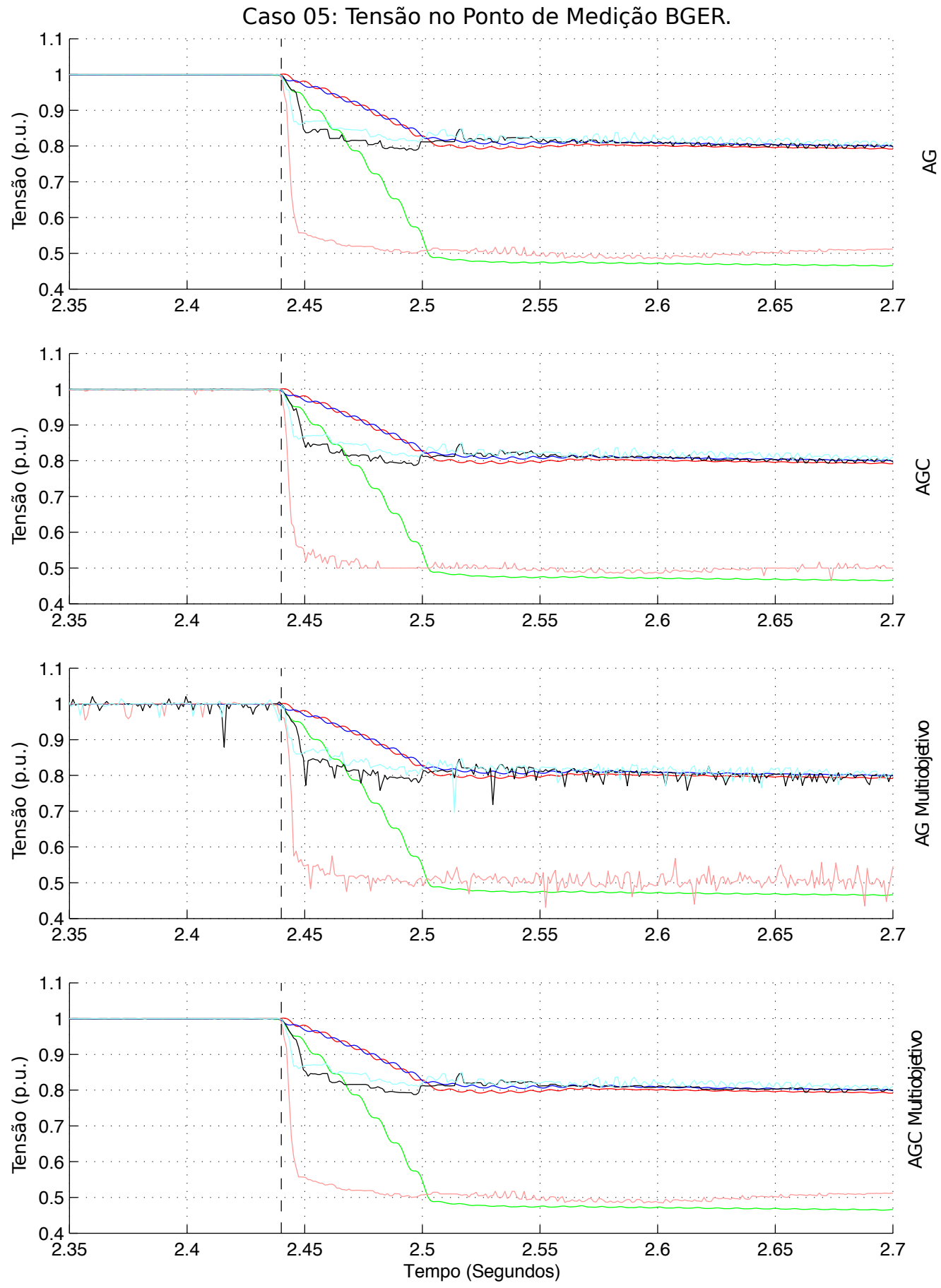

RMS Fase A RMS Fase B RMS Fase C Estim. Fase A Estim. Fase B $\quad$ Estim. Fase C

Figura 51 - Detalhe da Amplitude das Tensões Estimadas para o Caso 05. 
A próxima figura, a Figura 52 exibe a estimação da variável da frequência para o período próximo da ocorrência do evento no SEP. Nesta figura pode-se avaliar um desvio máximo de $0.3 \mathrm{~Hz}$ com duração de aproximadamente $250 \mathrm{~ms}$ na estimação efetuada pelo AGCM, ao contrário dos métodos mono-objetivos estimando a fase A, a qual apresentam uma estimação fasorial aceitável durante toda a duração do sinal.
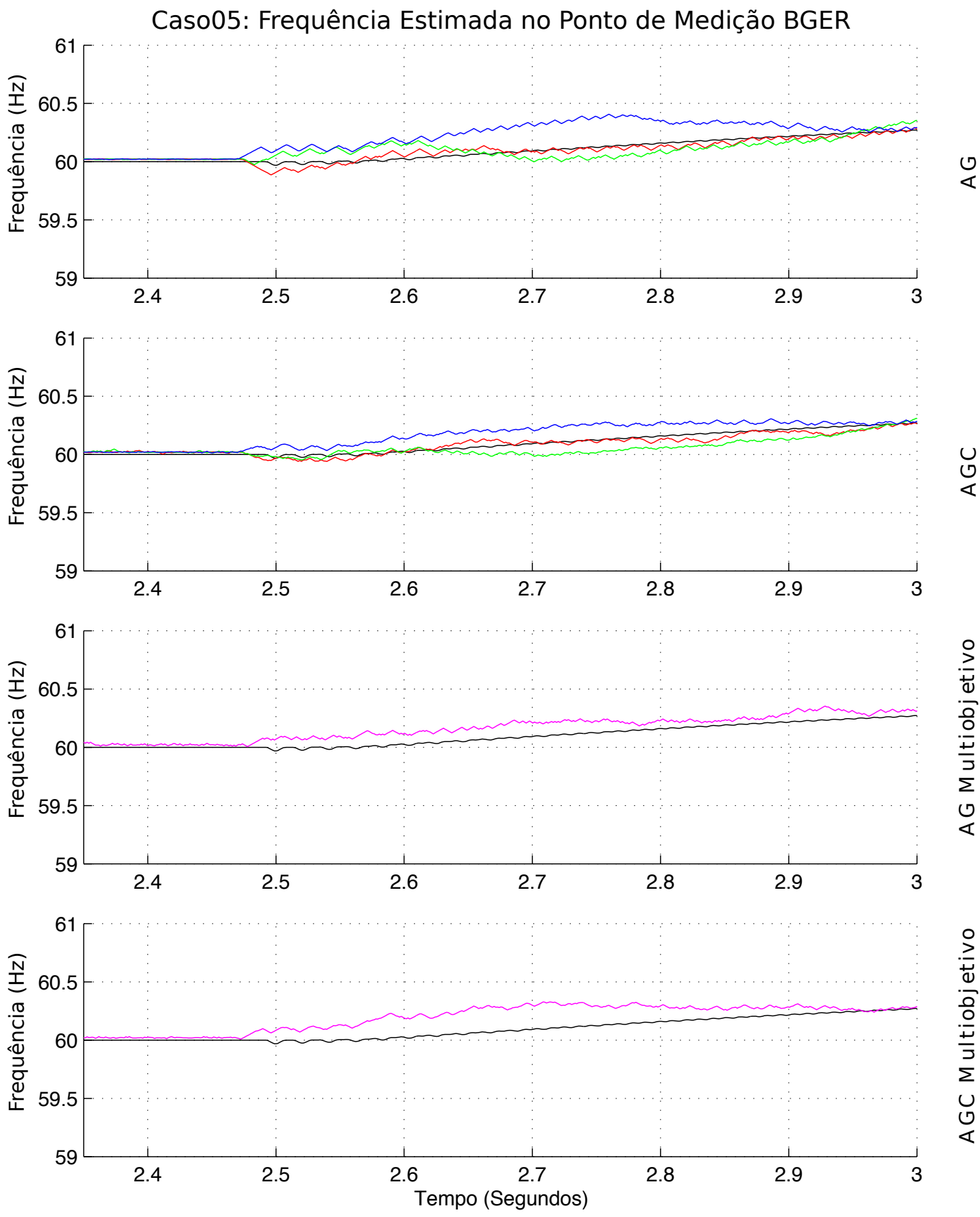

Frequência - ATP $\square$ Estimado Fase A $\square$ Estimado Fase B $\square$ Estimado Fase C $\square$ Multiobjetivo

Figura 52 - Detalhe da Frequência Estimada para o Caso 05. 
Maiores detalhes do RMSE associado na estimação da variável da frequência é ilustrado pela Figura 53. Nela pode-se observar um erro considerável na estimação realizada pelo AGCM, e também confirma a eficiência dos métodos mono-objetivos estimando sobre a fase A.
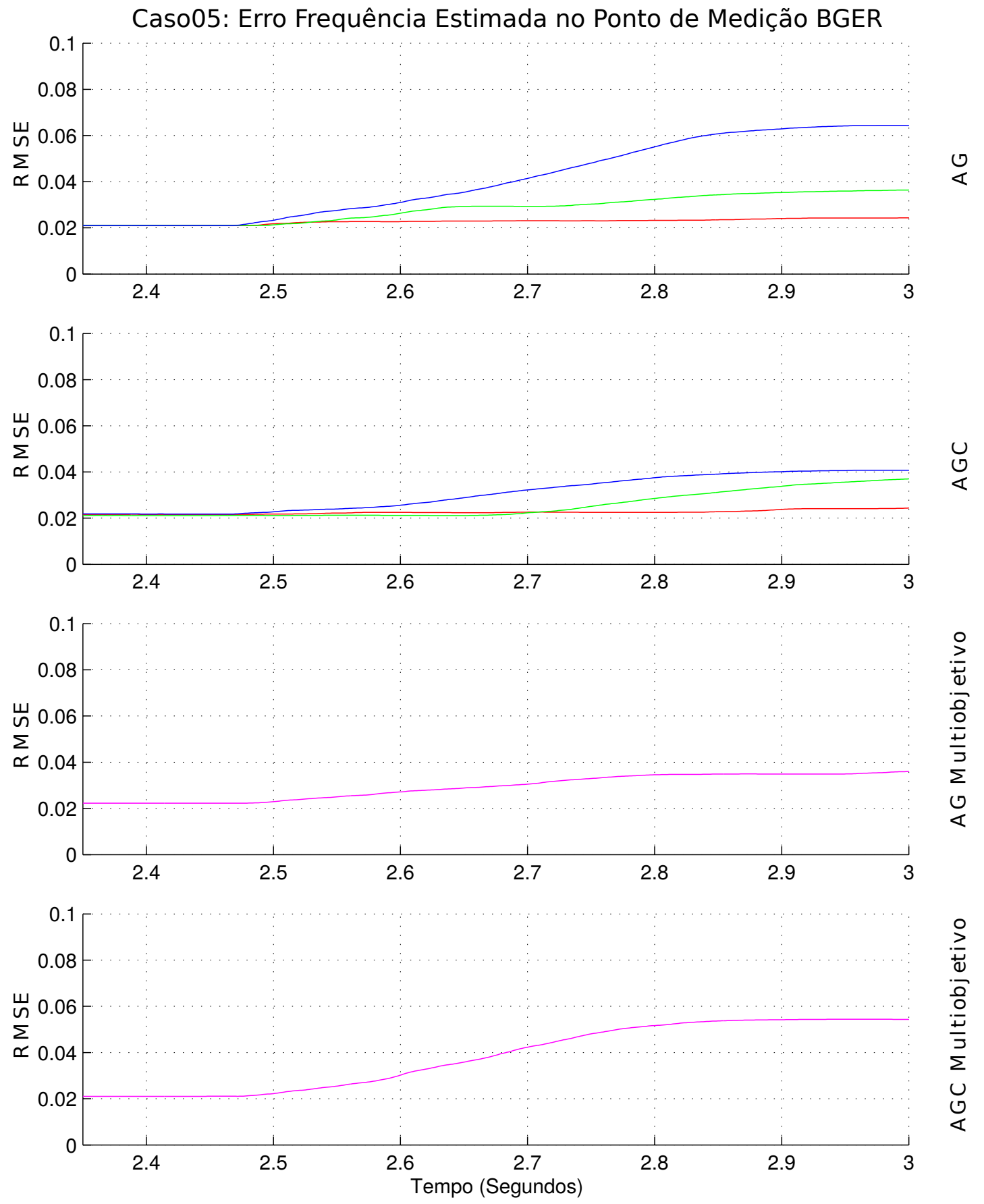

Fase A Fase B Fase C Multiobjetivo

Figura 53 - Erro da Frequência Estimada para o Caso 05. 


\subsubsection{Caso 06}

O sexto caso simulado para a validação do AGCM contempla o SEP operando em regime, quando é efetuada a abertura do disjuntor entre os pontos BGER e TR1E. Esta abertura tripolar do disjuntor foi modelada nas simulações com uma defasagem de tempo entre elas, simulando assim um comportamento próximo do real dos disjuntores de proteção. A abertura defasada ocorre nos instantes $t=2,458, t=2,460$ e $t=2,462$ segundos. Note que as fases do SEP aqui utilizadas como referência nas estimações, apresentam um aspecto ondulatório, aumentando com o decorrer do tempo. Este comportamento é devido ao cálculo do valor RMS utilizado, e não inviabiliza a análise tampouco interfere no processo de estimação fasorial.

A Figura 54 mostra a estimação da variável da amplitude da tensão apresentada pelo AGCM, onde é possível observar um desvio de 0.006 p.u. no momento em que o SEP opera em regime, divergindo sua estimação durante e após a ocorrência do evento. Devido a sobreposição das linhas no gráfico, algumas fases não estão visíveis claramente, pois obtiveram valores estimado bem próximos.

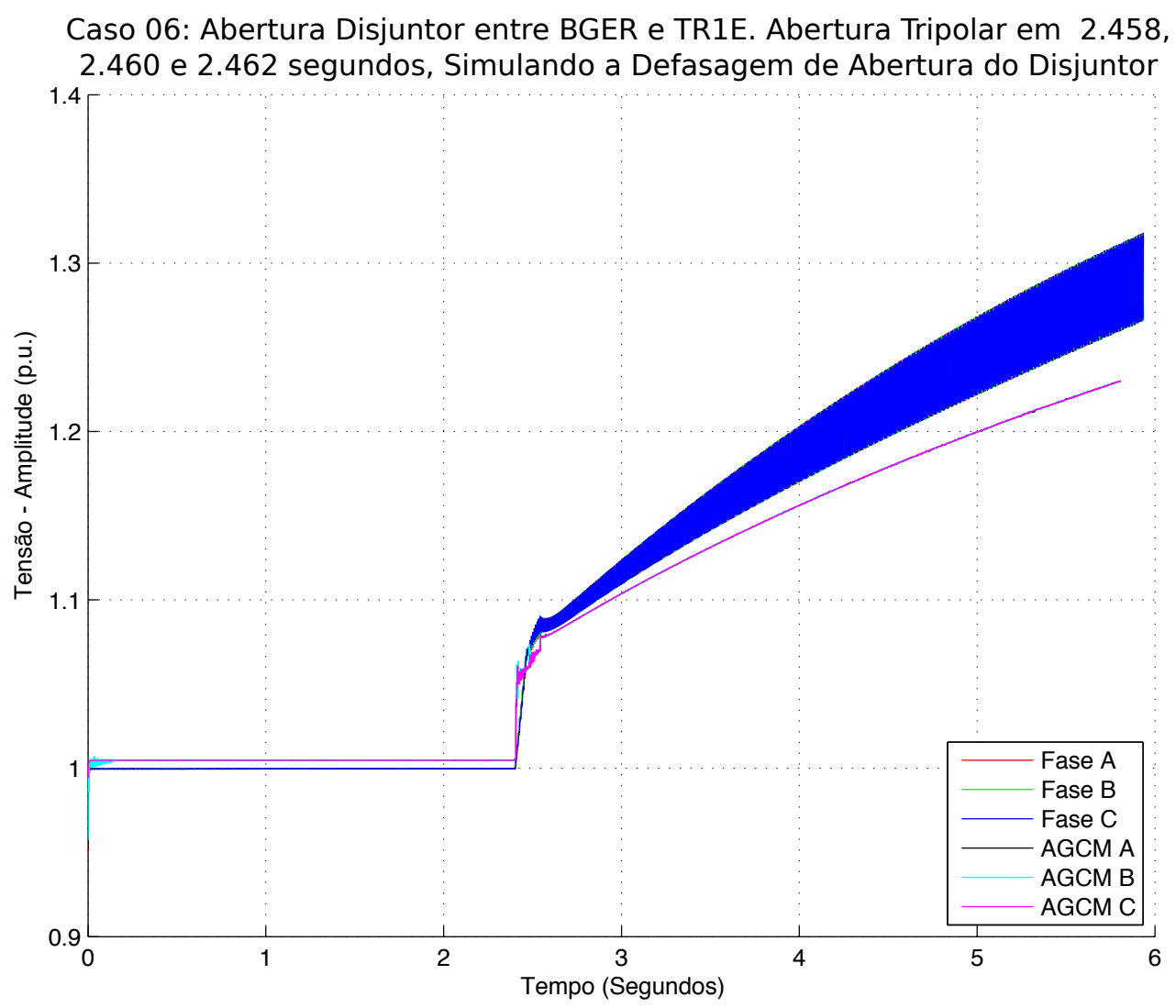

Figura 54 - Amplitude das Tensões Trifásicas Estimadas para o Caso 06. 
A Figura 55 ilustra a estimação do AGCM para a variável da frequência neste caso em que ocorre a abertura tripolar do disjuntor. A estimação apresentada é precisa em durante toda a duração do sinal, exceto no exato momento em que ocorre o evento, tendo então sua estimativa é comprometida por um curto período de tempo.

Caso 06: Abertura Disjuntor entre BGER e TR1E. Abertura Tripolar em 2.458,

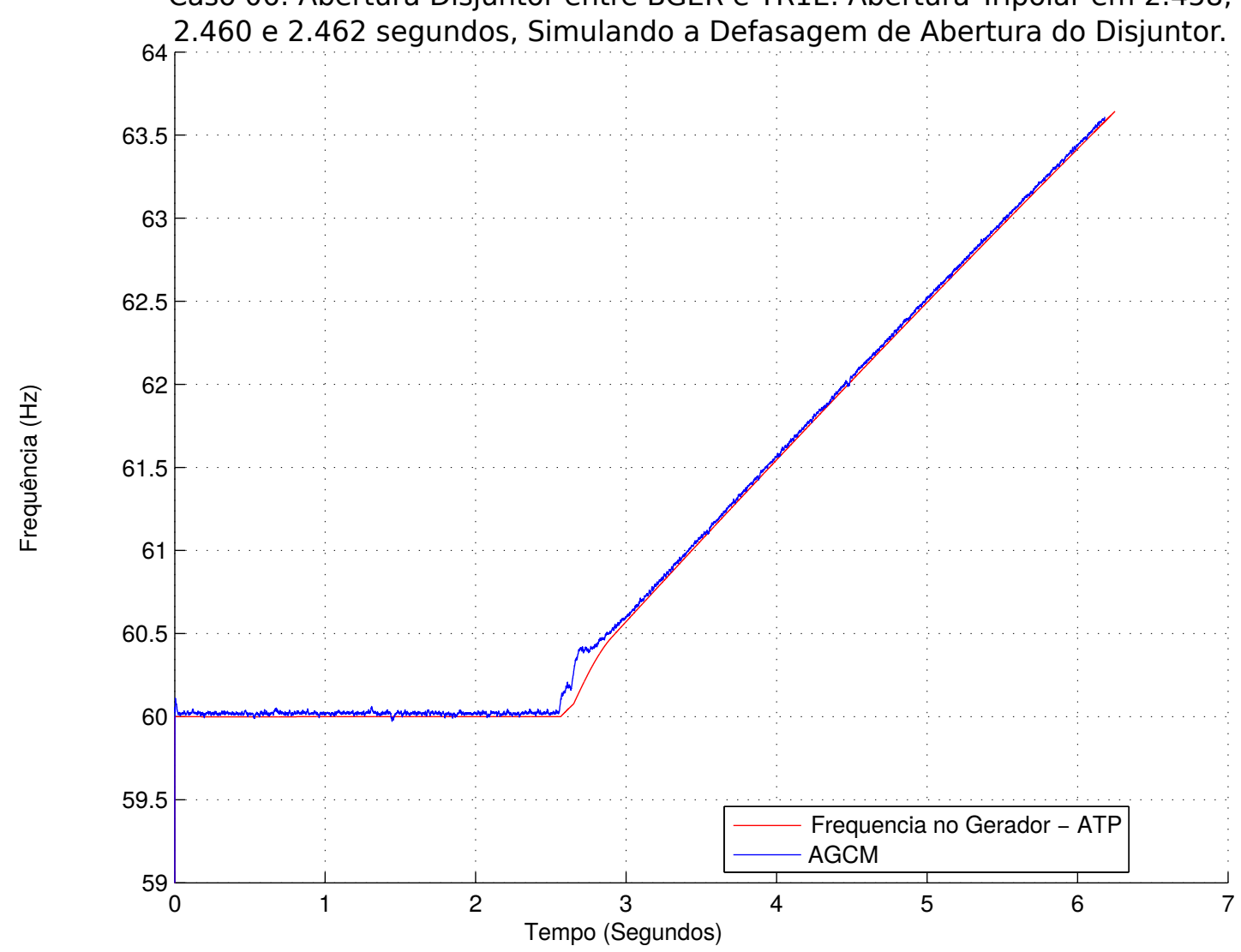

Figura 55 - Frequência Estimada para o Caso 06. 
Detalhes da estimação da variável de amplitude realizada pelo AGCM, quando comparado com os outros métodos evolutivos, pode ser visualiza na Figura 56. É possível perceber a estimação precisa dos métodos com o SEP em regime, embora o método AGM ainda apresente ruídos indesejáveis. No instante em que ocorre o evento a estimação diverge, porém se recupera rapidamente para valores com erros de 0,02 p.u.

\section{Caso 06: Tensão no Ponto de Medição BGER.}
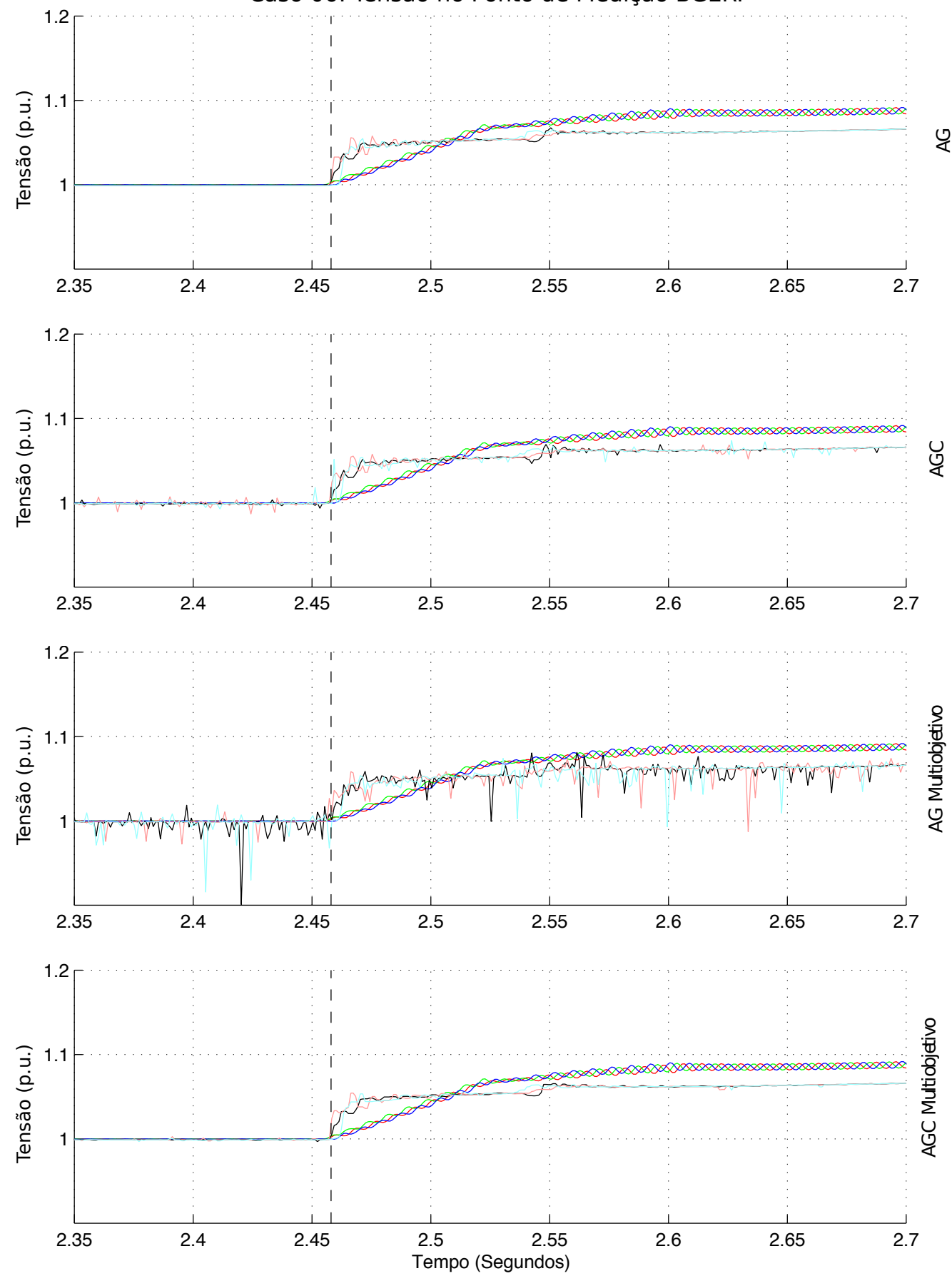

RMS Fase A RMS Fase B RMS Fase C Cstim. Fase A C Estim. Fase C

Figura 56 - Detalhe da Amplitude das Tensões Estimadas para o Caso 06. 
Já a Figura 57 ilustra, mais uma vez, os detalhes da estimação da variável de frequência, onde todos os métodos evolutivos apresentam um comportamento próximo, divergindo da estimação em até $0,3 \mathrm{~Hz}$, recuperando-se em aproximadamente $300 \mathrm{~ms}$.
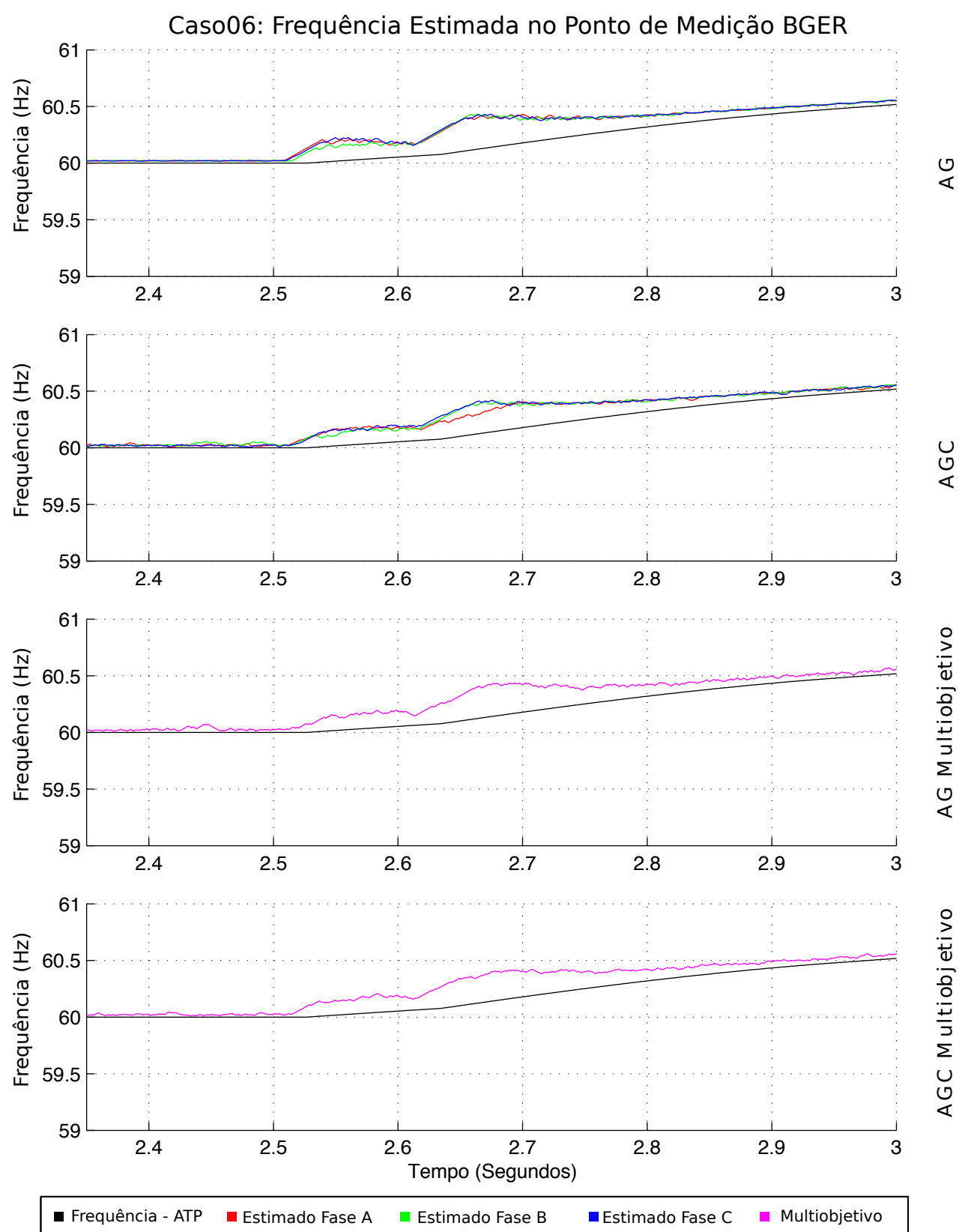

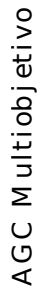

Figura 57 - Detalhe da Frequência Estimada para o Caso 06. 
O RMSE associado na estimação da variável da frequência é mostrado na Figura 58, atingindo um valor máximo de 0,05 no período pós evento, para todos os métodos multiobjetivos.
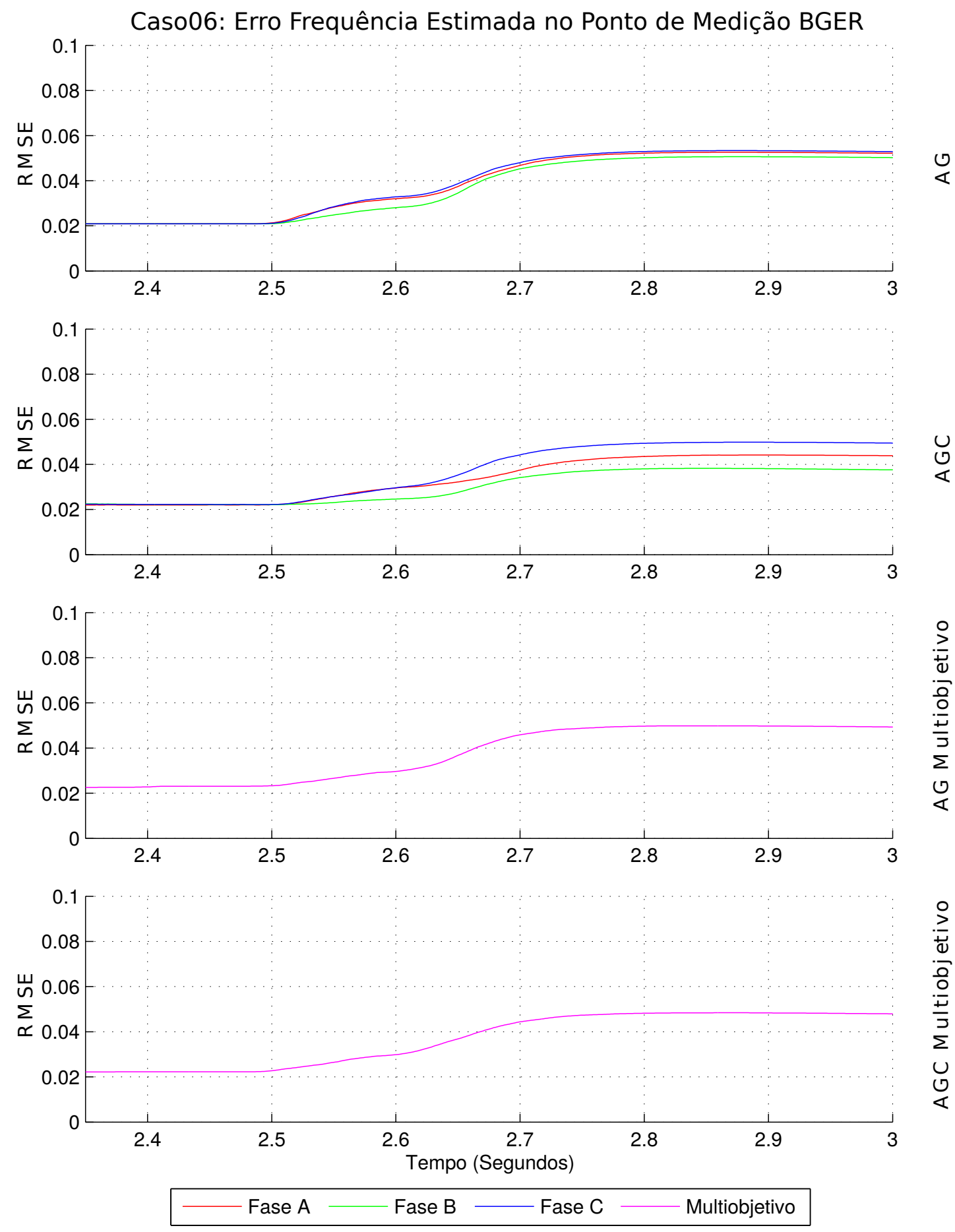

Figura 58 - Erro da Frequência Estimada para o Caso 06. 


\subsubsection{Caso 07}

O caso de número sete simulado considera o SEP operando em com as fases desequilibradas, quando um evento do tipo falta franca A-T, no enrolamento secundário do transformador TR1E é aplicado no instante $t=2.4 \mathrm{~s}$. Nota-se através da Figura 59, que a estimação efetuada pelo AGCM segue a referência apresentando um desvio de 0,05 p.u. na estimação da fase A após a ocorrência do evento.

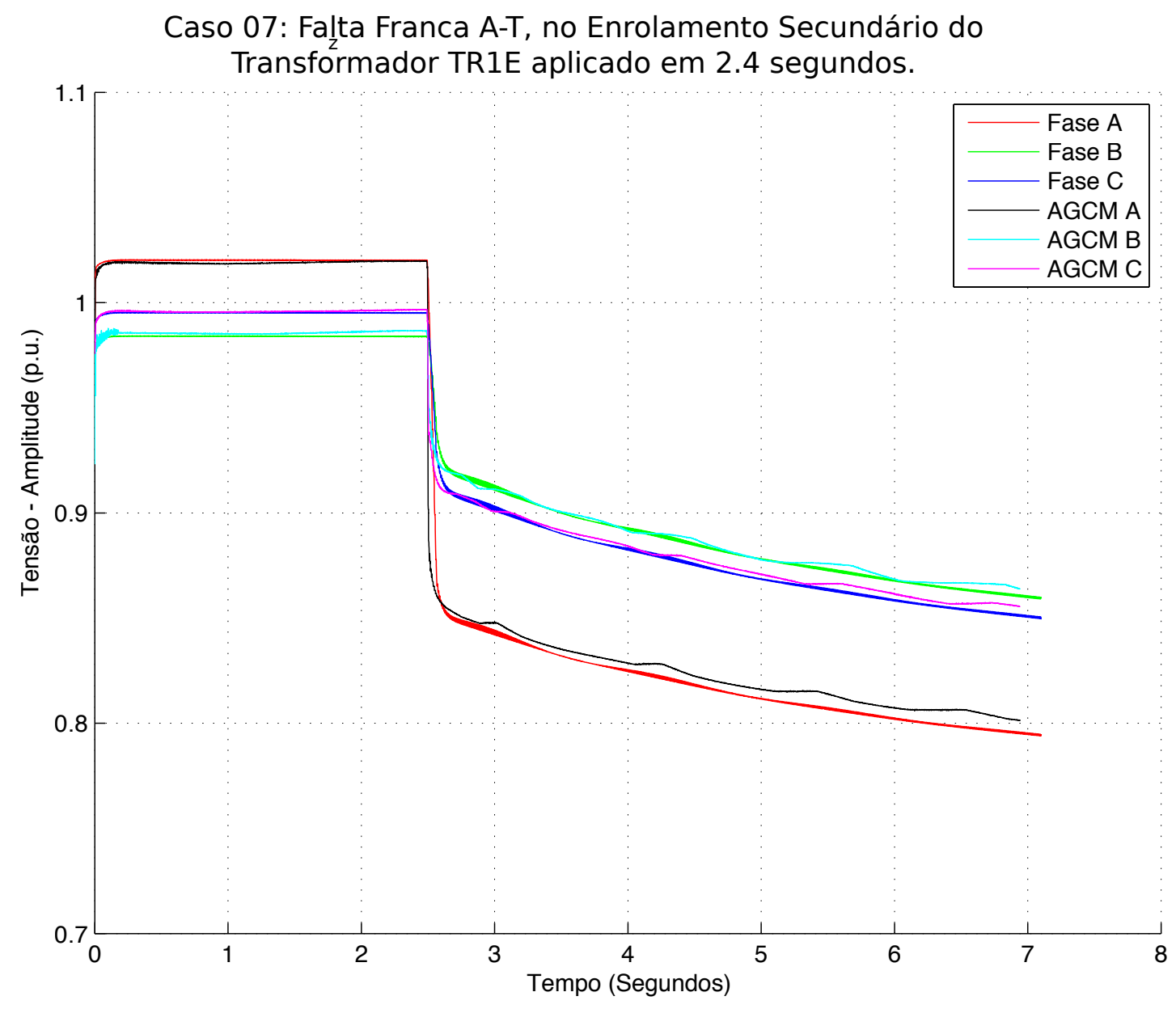

Figura 59 - Amplitude das Tensões Trifásicas Estimadas para o Caso 07. 
Analisando a estimação da variável da frequência representada na Figura 60, é possível observar que o AGCM apresenta uma estimação satisfatória embora com aspecto ruidoso.

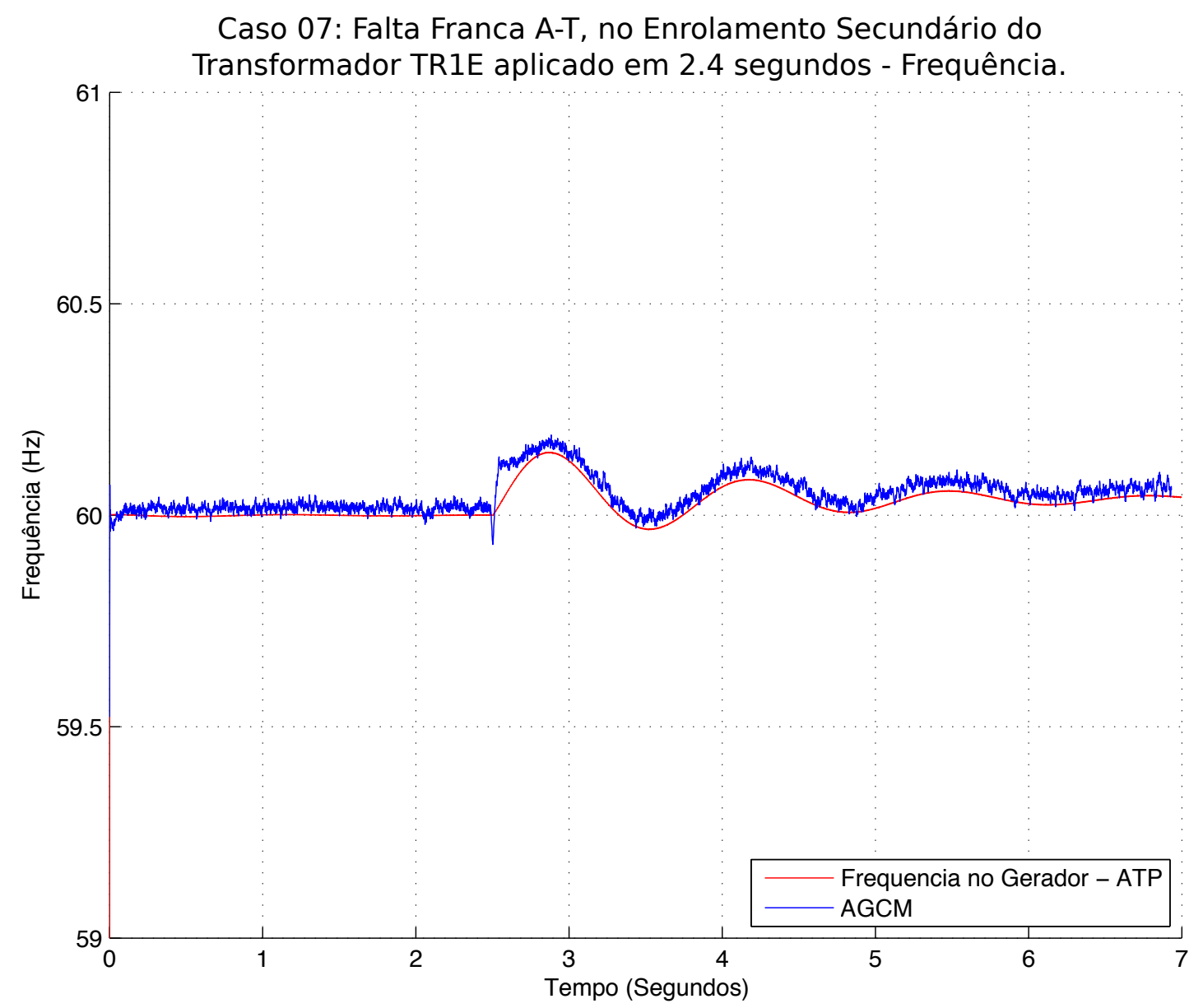

Figura 60 - Frequência Estimada para o Caso 07.

Os detalhes da estimação da variável da amplitude pode ser vista através da Figura 61, permitindo assim, a comparação entre as estimações dos métodos evolutivos. Exceto o método AGM, todos os outros apresentam uma estimação limpa e precisa durante o período de operação em regime do SEP. Durante e após a ocorrência do evento, as estimações divergem, recuperando-se em aproximadamente $70 \mathrm{~ms}$ com um desvio da estimação da amplitude de 0,01 p.u. 

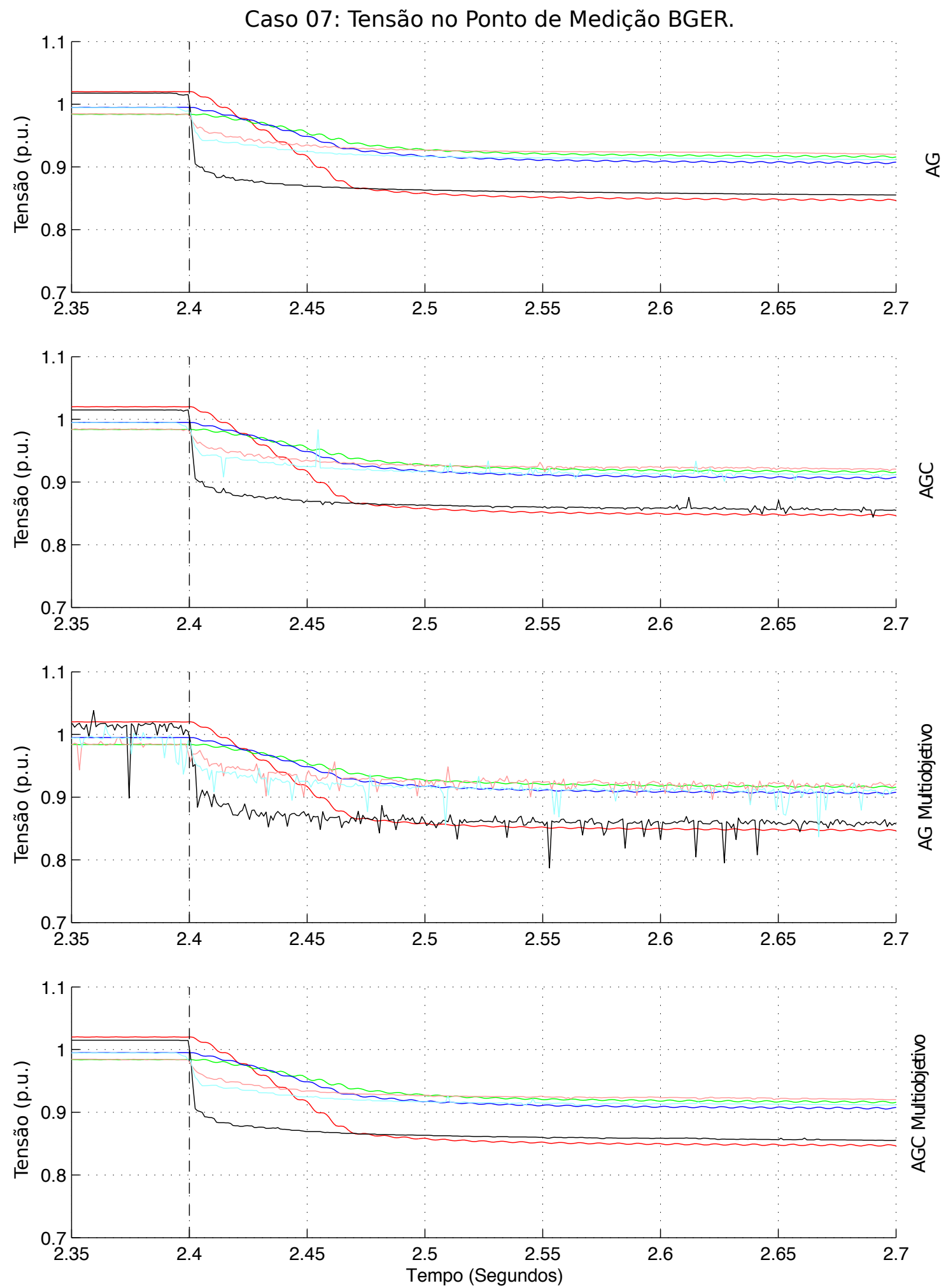

RMS Fase A

RMS Fase B

RMS Fase C

Estim. Fase A

Estim. Fase B

Figura 61 - Detalhe da Amplitude das Tensões Estimadas para o Caso 07. 
Aqui, a Figura 62 detalha, assim como feito para a variável de amplitude, a estimação da variável da frequência, onde o AGCM foi capaz de apresentar, mais uma vez uma estimativa aceitável, com divergência máxima de 0,08 Hz com duração menor que 100 ms. Já o método Algoritmo Genético Multiobjetivo (AGM) apresentou uma estimação próxima da pior fase estimada pelo seu modelo mono-objetivo Algoritmo Genético (AG).
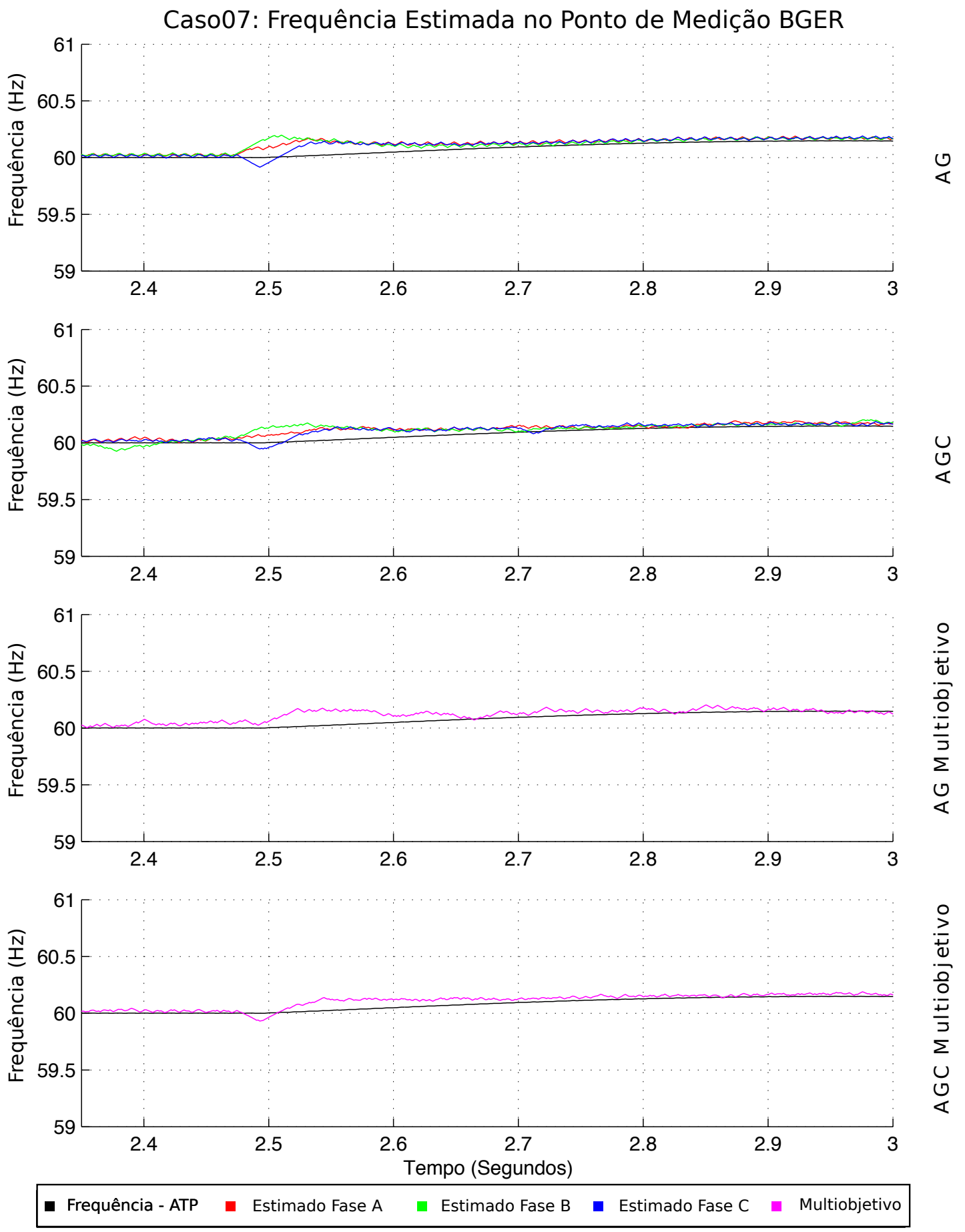

Figura 62 - Detalhe da Frequência Estimada para o Caso 07. 
Conforme a Figura 63, é possível visualizar o erro associado à estimação da variável da frequência pelo AGCM em relação aos outros métodos, note que o RMSE apresentado pelo AGCM é o menor entre os quatro métodos, apresentando um valor igual a 0,025, um pouco distante do valor 0,035 apresentado pelo AGM e pelo AG quando estimado a fase B.
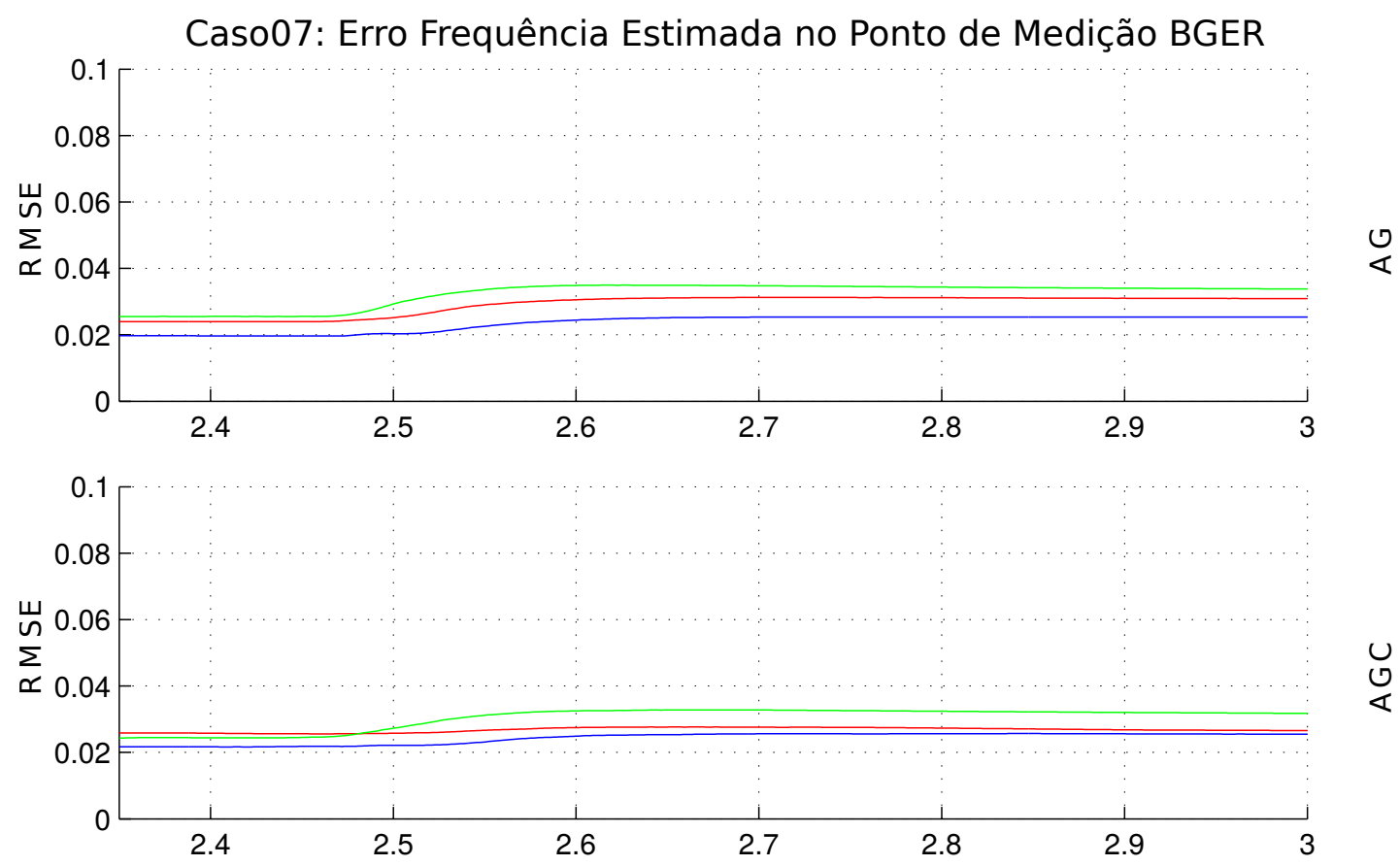

$\underset{\cup}{\cup}$
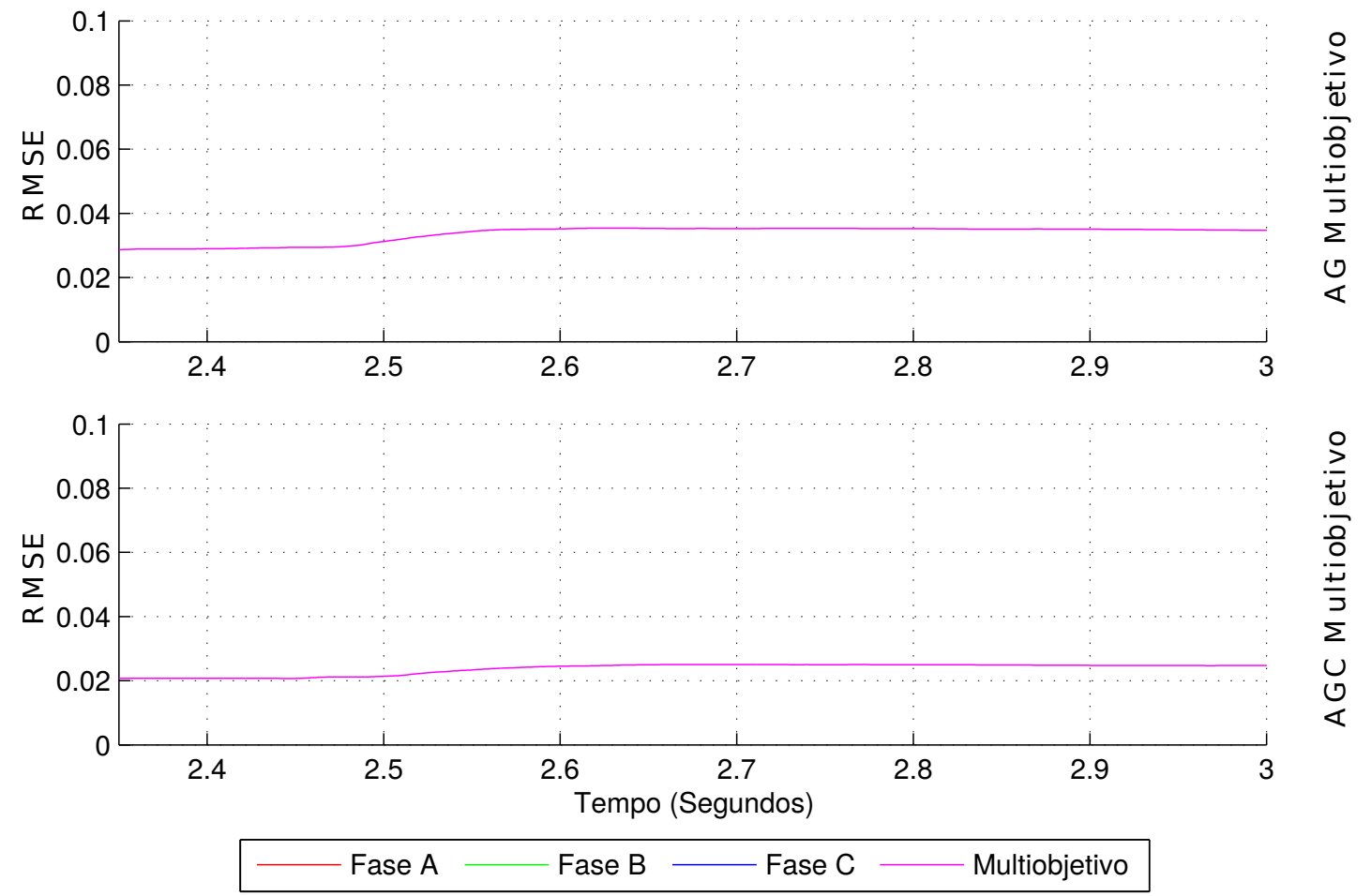

Figura 63 - Erro da Frequência Estimada para o Caso 07. 


\subsubsection{Caso 08}

O último caso simulado e aqui apresentado, o Caso 08, assume o SEP operando em regime, quando no instante $t=2,4 \mathrm{~s}$, um evento do tipo falta monofásica A-T com resistência de 3 ohms é aplicada no barramento BGER. Este ensaio tem uma duração especial de 30 segundos, visando apresentar a estabilidade do método AGCM desenvolvido ao longo de um período maior de operação. É verificado através da Figura 64, que o AGCM é capaz de apresentar uma estimação aceitável, mesmo em casos onde ocorram eventos de maior duração, apresentando uma divergência máxima de 0,02 p.u. para a estimação da fase A, no período próximo ao instante $t=21 \mathrm{~s}$.

Caso 08: Falta Monofásica A-T no Barramento BGER Aplicado em 2.4 segundos, com Resistência de Falta de 3 ohms.

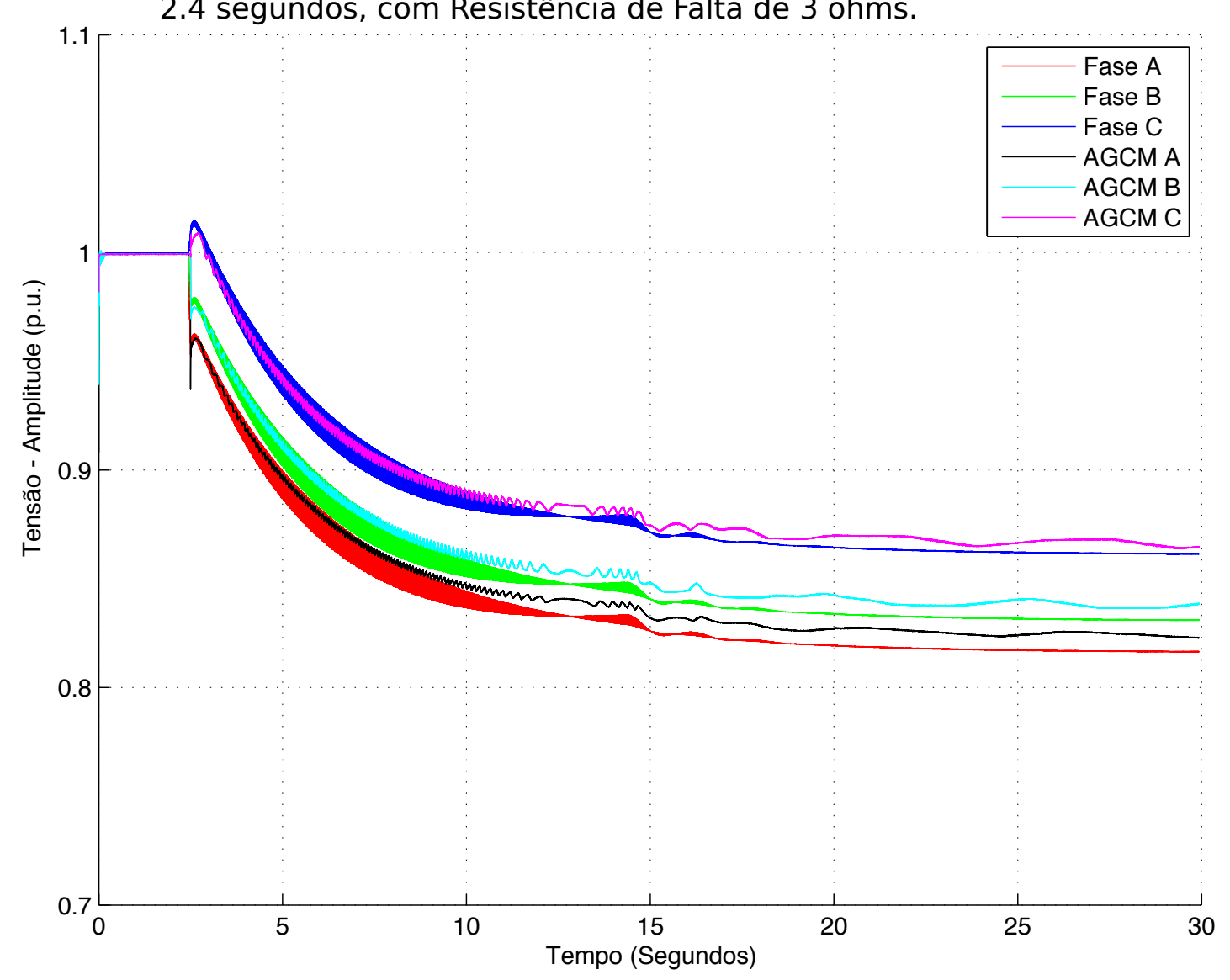

Figura 64 - Amplitude das Tensões Trifásicas Estimadas para o Caso 08. 
O gráfico da Figura 65 mostra a estimação da variável da frequência pelo método AGCM. Embora a estimação apresente ruídos, ela pode ser considerada satisfatória, e se justifica através da posterior análise da Figura 68 com o valor do RMSE apresentado.

Caso 08: Falta Monofásica A-T no Barramento BGER Aplicado em

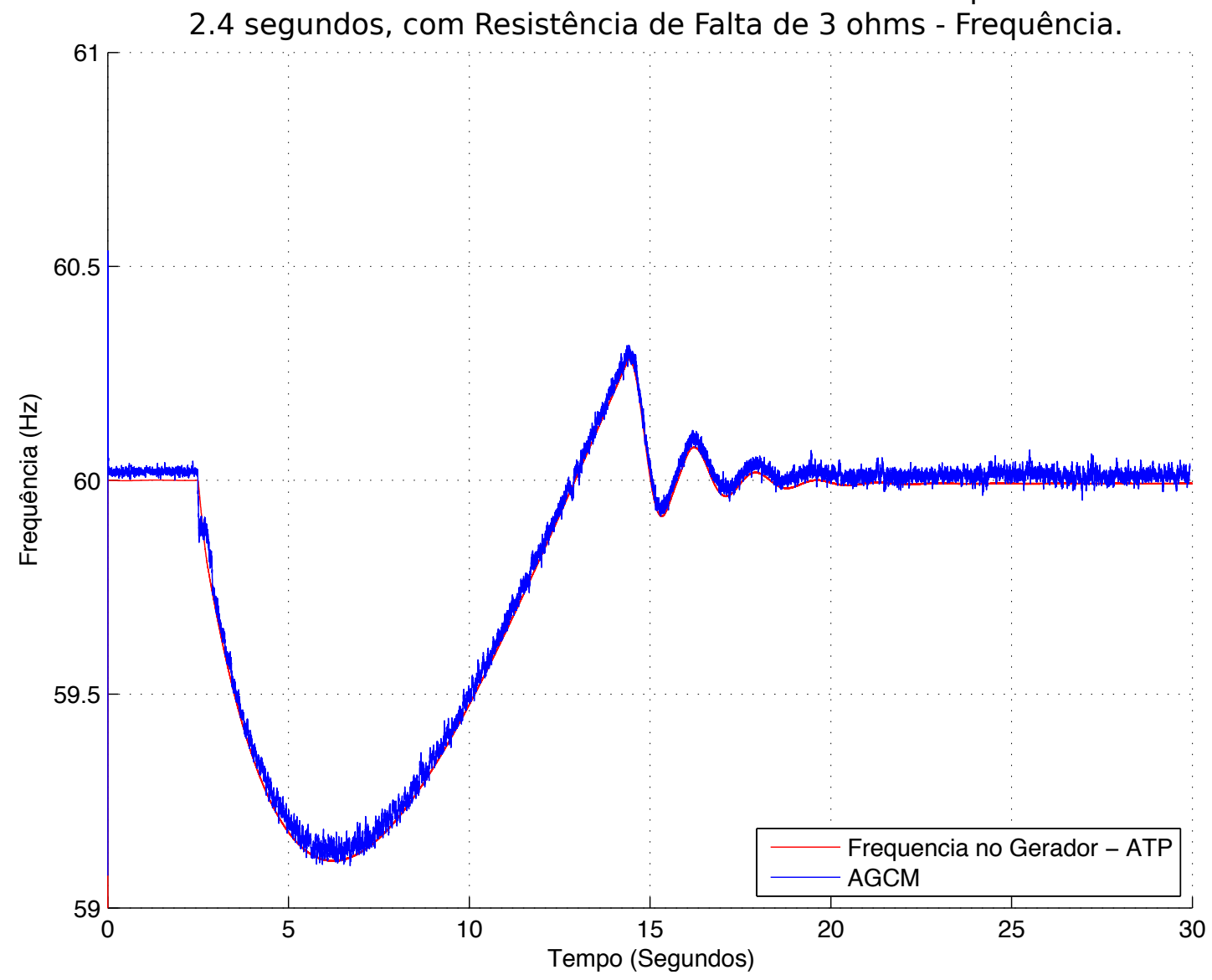

Figura 65 - Frequência Estimada para o Caso 08. 
Seguindo a estrutura apresentada com o detalhamento das estimações no período próximo da ocorrência do evento, a Figura 66 mostra então as características da estimação da variável da amplitude. Nesta figura pode-se observar que os métodos AGCM e AG mostraram-se mais eficazes, fornecendo uma estimação mais suave e precisa. Apenas no instante de ocorrência do evento é apresentado uma divergência, recuperada em aproximadamente 50 ms após sua ocorrência.

Caso 08: Tensão no Ponto de Medição BGER.
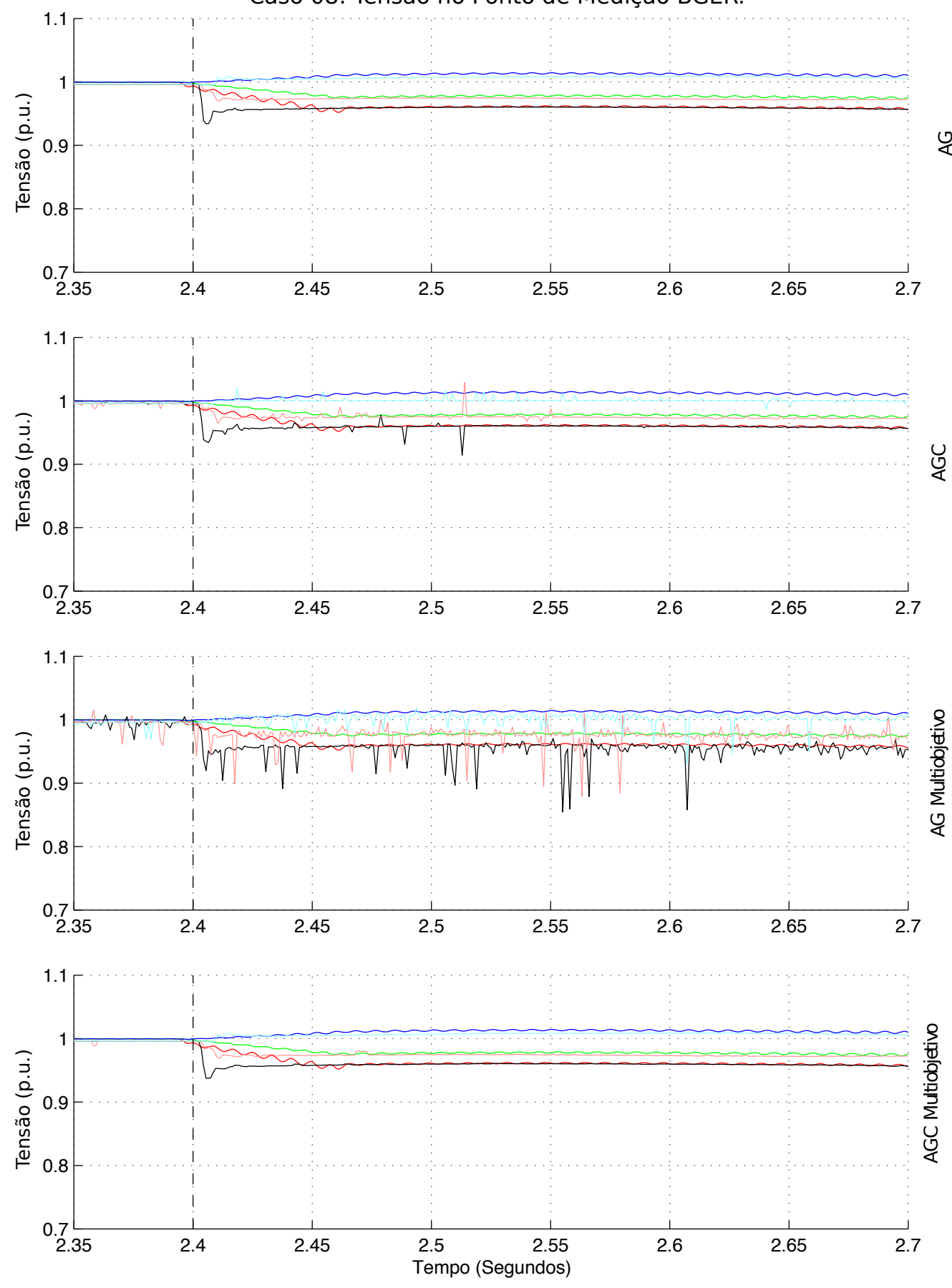

Figura 66 - Detalhe da Amplitude das Tensões Estimadas para o Caso 08. 
Já quando analisado o detalhamento das estimações da variável de frequência, é observado que os métodos multiobjetivos AGM e AGCM se mostram mais eficazes, apresentando um baixo desvio em suas estimações. Note que o método AGC quando estimado a fase $\mathrm{C}$, apresenta o pior resultado no instante próximo de $t=2,8 \mathrm{~s}$.
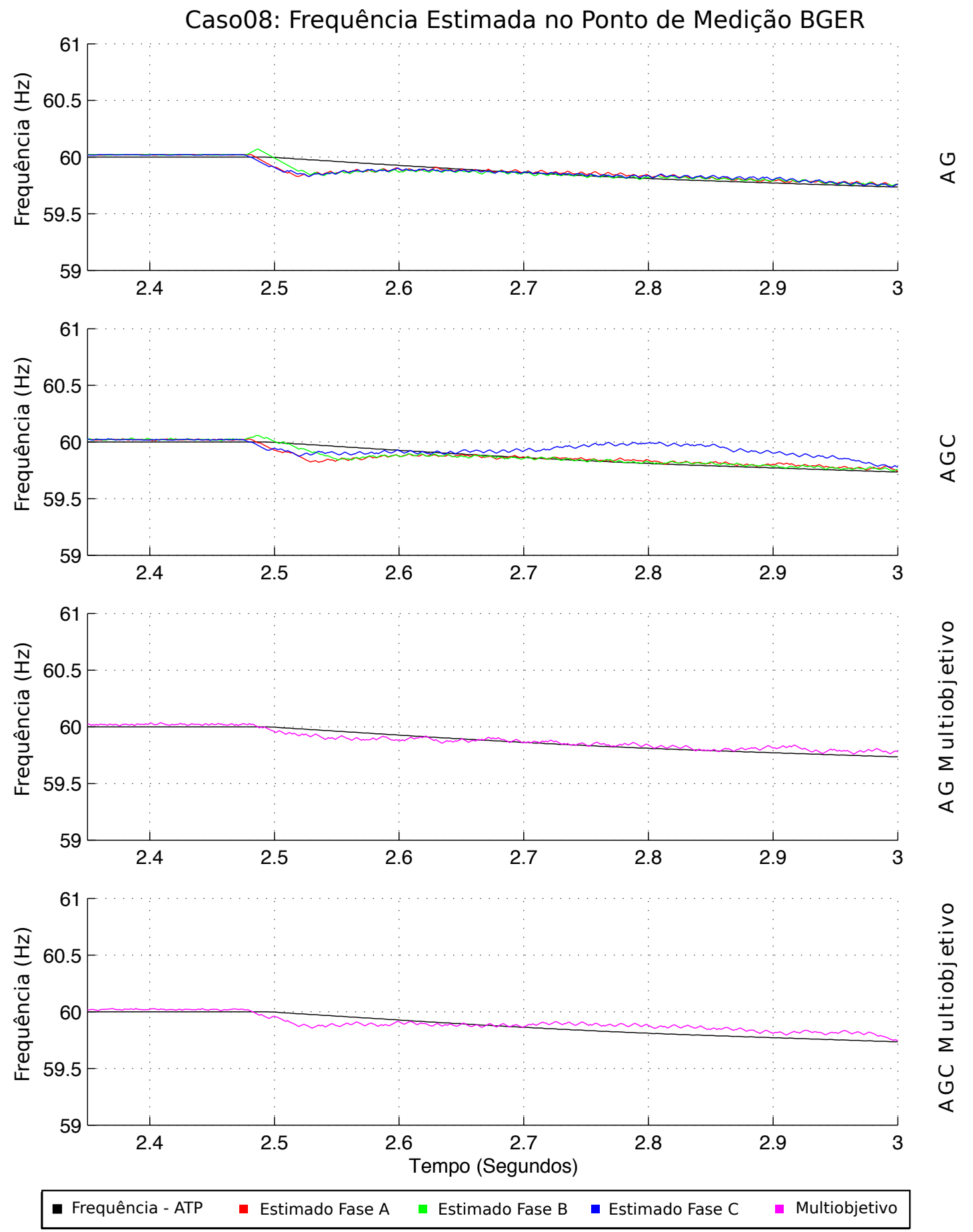

Figura 67 - Detalhe da Frequência Estimada para o Caso 08. 
Concluindo esta Seção de casos de testes e resultados, a Figura 68, mais uma vez demonstra o erro associado à estimação da variável da frequência pelo método AGCM em relação aos outros métodos evolutivos. Nesta figura podemos observar que o AGM apresenta o menor valor de RMSE entre todos os métodos avaliados, enquanto que o AGCM proposto apresentou um valor de RMSE máximo de 0,03.
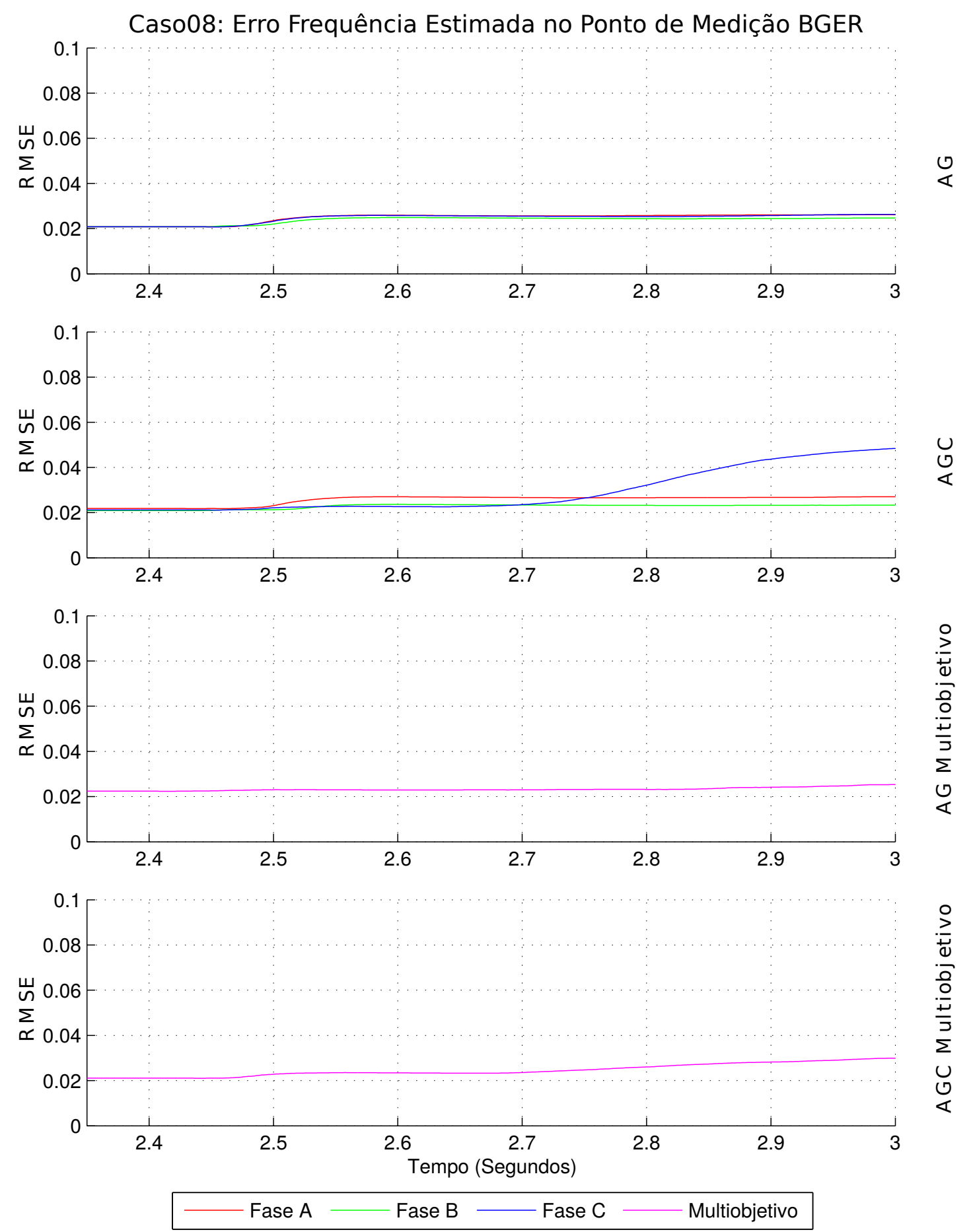

Figura 68 - Erro da Frequência Estimada para o Caso 08.

Estes casos propostos permitiram explorar a sensibilidade e robustez do AGCM aplicado ao problema de estimação fasorial. Como várias estimativas apresentadas continham 
ruídos indesejáveis, é proposto na Seção 4.3, uma forma simples de atenuar tais ruídos através do uso de um filtro de média móvel.

\subsection{Aplicação de Filtro de Média Móvel}

Durantes os testes, foram notados ruídos nas respostas fornecidas pelos métodos genéticos. Visando melhorar o aspecto da resposta, sem depreciar o tempo de resposta do método, é proposto nesta Seção a aplicação de um filtro de média móvel.

O filtro de média móvel como o próprio nome sugere, utiliza uma janela móvel de dados com $n$ amostras para calcular a média de uma sequencia de dados. Durante o processo de filtragem, esta média é calculada para cada instante de tempo do sinal. Caso seja conhecida a frequência do ruído, pode-se ajustar a janela do filtro para o valor do período deste ruído ou algum múltiplo deste. Para este trabalho, utilizou-se o valor de 4 amostras, submúltiplo da janela de dados com 16 amostras por ciclo. A Equação 45 denota matematicamente um filtro de média móvel, onde $n$ é o tempo atual da amostra, $n+1$ é o número de amostras utilizada na filtragem, e $\mathrm{x}[\mathrm{n}-\mathrm{k}]$ o conjunto de amostras a ser filtrado.

$$
y[n]=\frac{1}{n+1} \sum_{k=0}^{n} x[n-k]
$$

Para ilustrar a influência da aplicação do filtro nas respostas do AGCM, foram testados novamente alguns casos de estimação da variável de amplitude e frequência do sinal, fazendo uso do filtro de média móvel aqui descrito. Foram escolhidos para este ensaio, 3 diferentes casos de testes propostos no cenário simulado com o auxílio do software ATP conforme ilustram as Figuras 69, 70, 71 e 72. Nestas ilustrações foram destacados o comportamento do filtro utilizado, no momento de ocorrência do evento.

O sinal ilustrado pela Figura 69 trata-se da estimação realizada no teste Caso 01, contemplando um evento do tipo Falta Bifásica AB-T aplicado em 2,5 segundos na linha LT1. Como esperado, pode-se observar a atenuação aparente dos ruídos presentes na estimação da variável de amplitude de todas as três fases, ficando mais evidente na estimativa da fase A. Posteriormente, o Caso 06 também proposto no cenário de testes simulados, garante o correto o comportamento do filtro indiferente do tipo de sinal amostrado e estimado, conforme mostra a Figura 70. Este caso contém um evento do tipo abertura do disjuntor de proteção entre os pontos BGER e TR1E do sistema simulado. A abertura tripolar do disjuntor ocorre em diferentes instantes, 2,458, 2,460 e 2,462 segundos, simulando a defasagem de abertura do mesmo. 


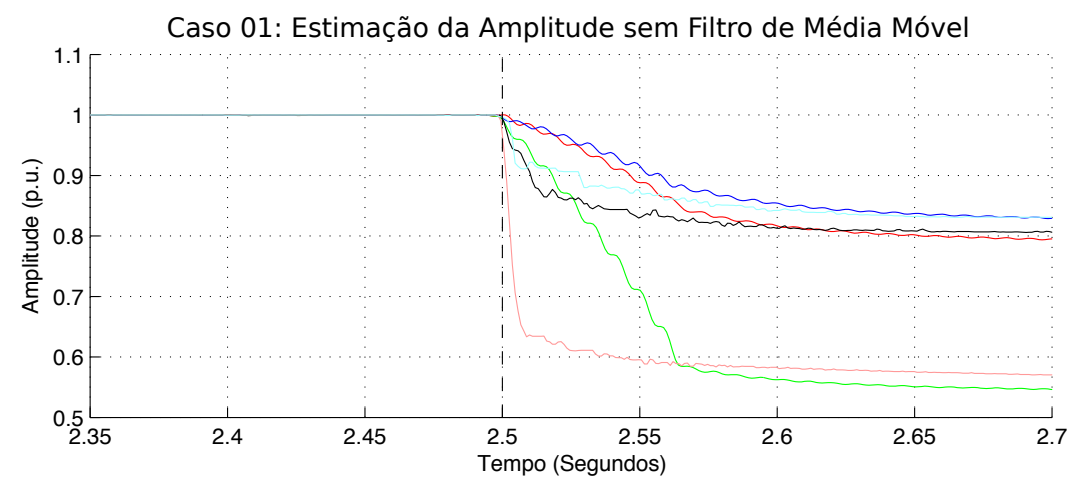

Caso 01: Estimação da Amplitude com Filtro de Média Móvel

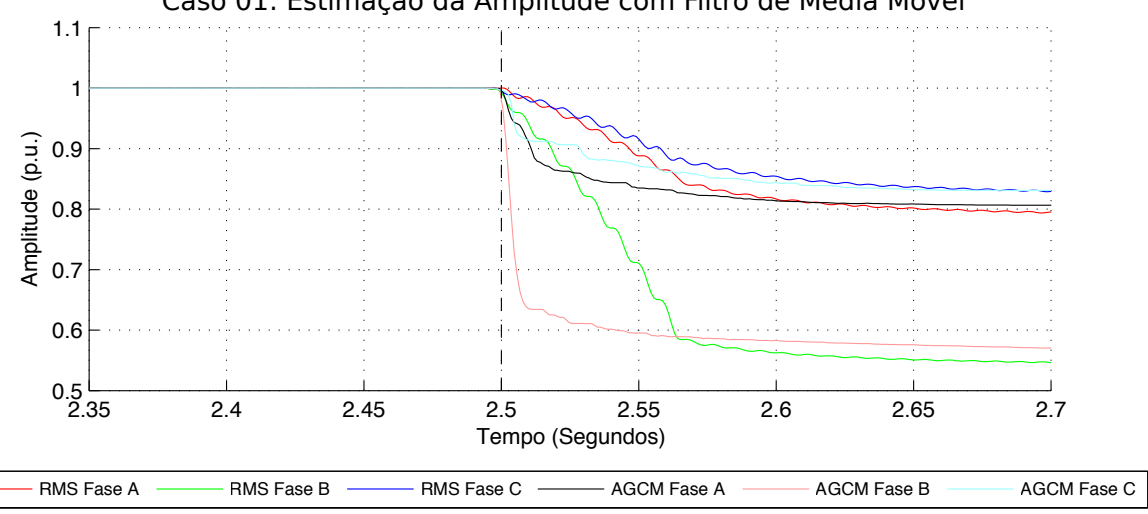

Figura 69 - Influência do Filtro de Média Móvel na Estimação da Amplitude das Tensões do AGCM para o Caso 01. 
Caso 06: Estimação da Amplitude sem Filtro de Média Móvel

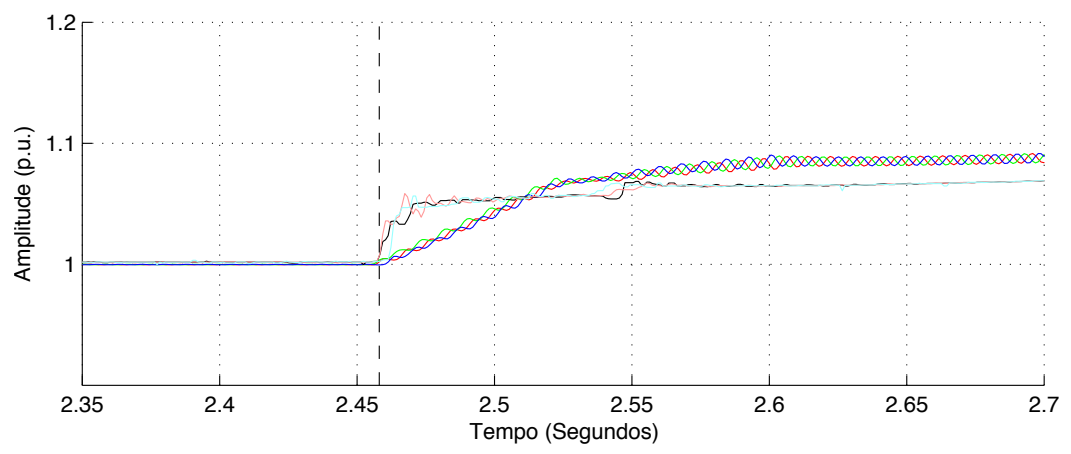

Caso 06: Estimação da Amplitude com Filtro de Média Móvel

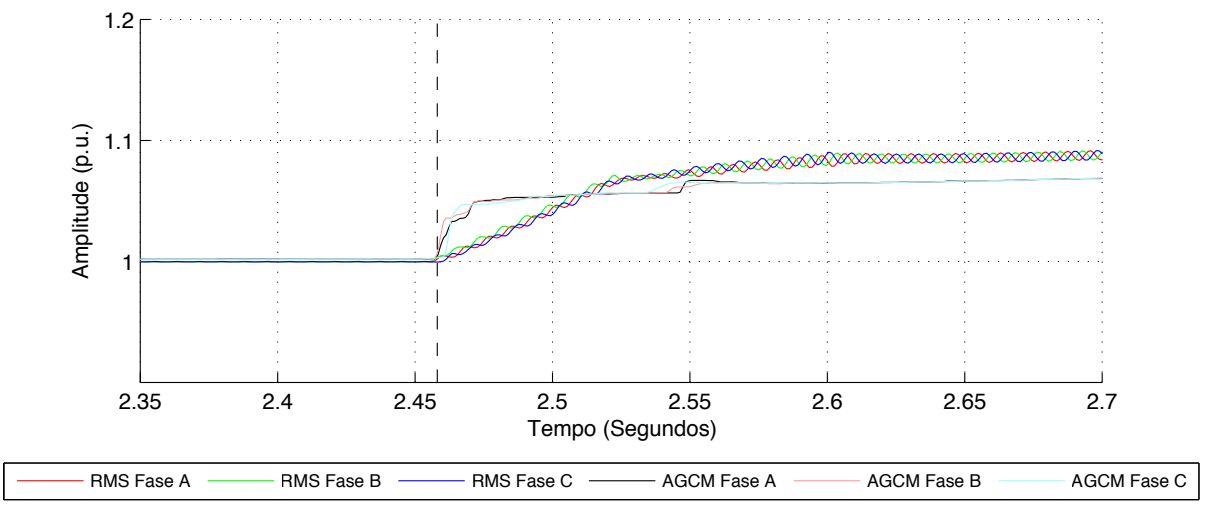

Figura 70 - Influência do Filtro de Média Móvel na Estimação da Amplitude das Tensões do AGCM para o Caso 06.

Novamente, é perceptível a atenuação dos ruídos existentes após a aplicação do filtro de média móvel. Aproveitando o mesmo caso, é apresentado através da Figura 71 a influência do filtro na estimativa da variável da frequência. Mais uma vez é possível notar que embora apresente uma pequena divergência na estimativa durante a ocorrência do evento, os ruídos presentes foram eliminados.

O último caso ilustrado pela Figura 72, trata-se do Caso 08 ensaiado no cenário utilizando o SEP simulado. Este caso contempla a ocorrência de um evento do tipo falta monofásica A-T, no barramento BGER aplicada em 2,44 segundos com resistência de falta de 3 ohms. Assim como ocorrido na Figura 71, os ruídos presentes na estimação da variável da frequência foram atenuados, apresentando um aspecto mais suave, bem próximo da referência esperada.

Diversos ensaios foram realizados e consolidados, destacando-se a importância para o momento da ocorrência de eventos, com e sem a aplicação de filtro. Como a estimação das variáveis de amplitude e frequência, durante a ocorrência de eventos no SEP, não é especificada pela norma IEEE C37.118-2011, toda a análise apresentada foi necessária para validar a robustez do método AGCM. 
Caso 06: Estimação da Frequência sem Filtro de Média Móvel

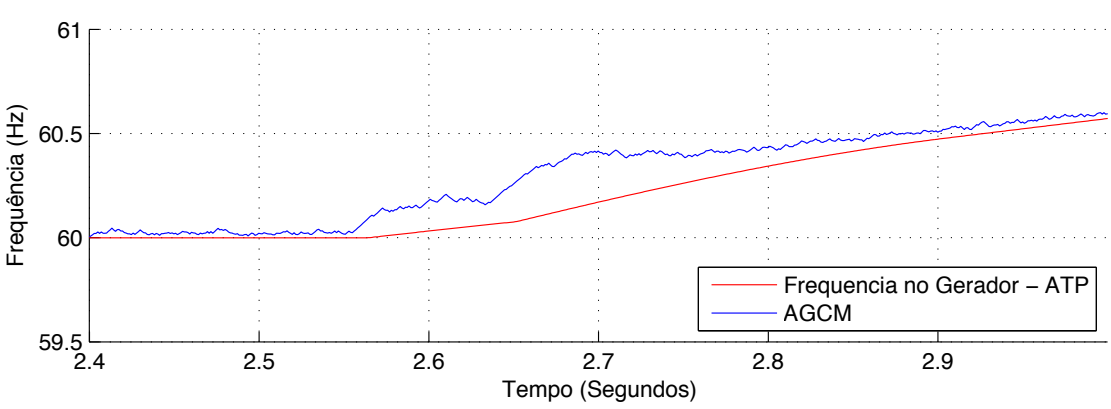

Caso 06: Estimação da Frequência com Filtro de Média Móvel

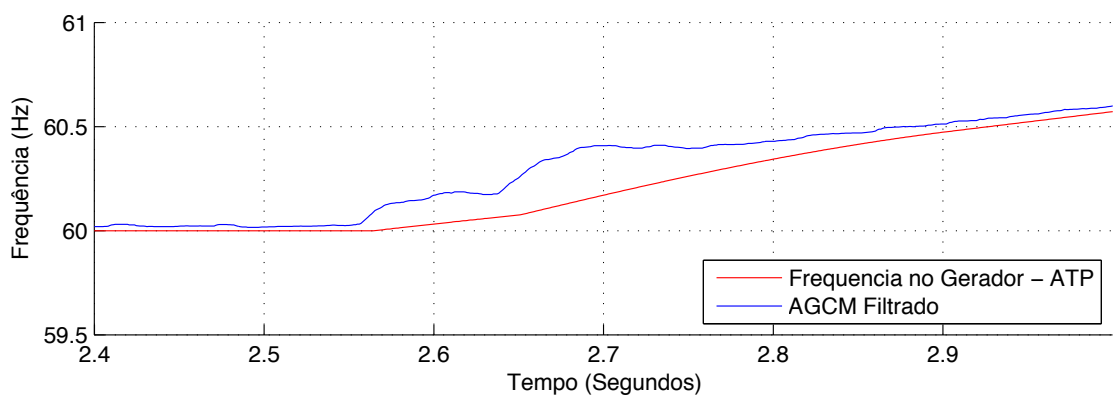

Figura 71 - Influência do Filtro de Média Móvel na Estimação da Frequência do AGCM no Momento da Falta - Caso 6.

Caso 08: Estimação da Frequência sem Filtro de Média Móvel

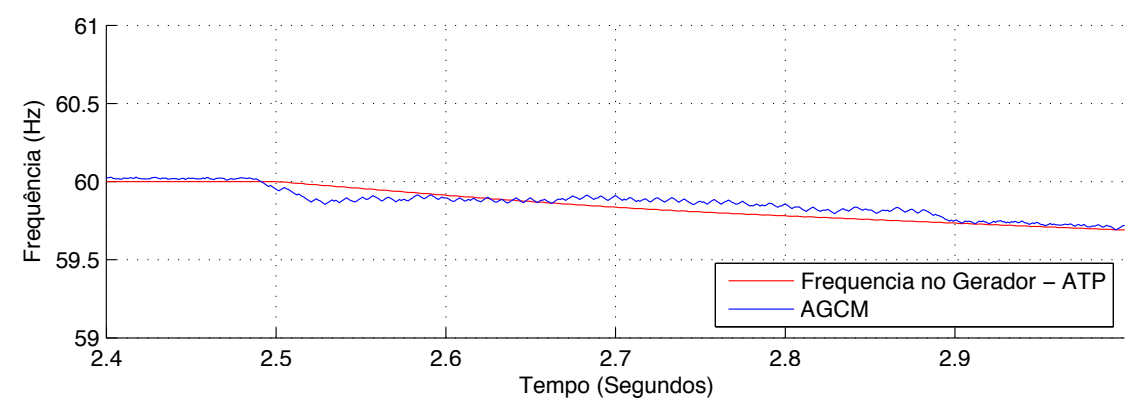

Caso 08: Estimação da Frequência com Filtro de Média Móvel

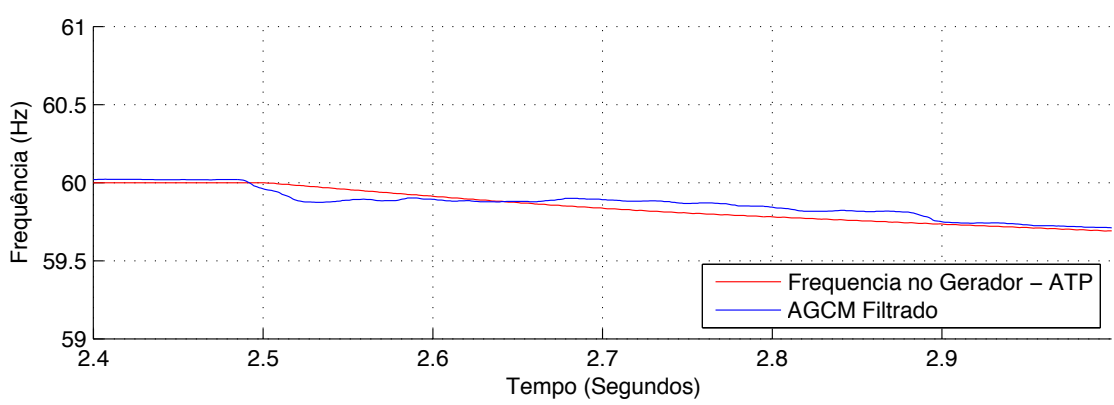

Figura 72 - Influência do Filtro de Média Móvel na Estimação da Frequência do AGCM no Momento da Falta - Caso 8.

Todos os métodos evolutivos estudados demonstram, como esperado, uma aptidão em estimar os casos propostos no cenário descrito pela norma IEEE C37.118-2011. Para o cenário simulado com o software ATP, novamente todos os métodos foram capaz de estimar as variáveis de amplitude e frequência quando o SEP opera em regime, embora 
o AGM apresente ruídos indesejáveis, possíveis de eliminação com a aplicação do filtro proposto.

Quando aplicado eventos no SEP simulado, as informações disponíveis nos sinais das fases podem não caracterizar o real estado do sistema e para estes casos, o AGCM demonstrou-se mais robusto, principalmente na estimação da variável da frequência, como o ocorrido no Caso 04, ilustrado pela Figura 47, apresentando um baixo valor do RMSE conforme comprovado pela Figura 48. Já os valores das variáveis de amplitude, após a ocorrência do evento, apresentam um valor bem próximo da referência esperada, com um desvio máximo de 0,05 p.u., encontrado no Caso 02, ilustrado pela Figura 34.

Até este momento, os resultados apresentados foram processados offline, em software desenvolvido em linguagem $\mathrm{C}$, disponível no Apêndice A deste trabalho, e implementado em um computador com processador Core-it padrão X64 e 16GB de memória RAM. Segundo Silva (2012a) e Silva (2012b) a plataforma FPGA pode contribuir para o alcance do cenário em tempo real, assim, na Seção 5.1 é apresentado a plataforma FPGA que auxiliará no processamento paralelo durante a avaliação dos indivíduos em busca de uma solução, atuando como módulo coprocessador genético de uma solução completa de tempo real também apresentada posteriormente. 


\section{Implementação da Plataforma PMU em Tempo Real}

Este capítulo apresenta o desenvolvimento de um sistema integrado de software e hardware provendo uma plataforma robusta de desenvolvimento e aplicações em tempo real, com a finalidade de estimar parâmetros de qualidade em um Sistema Elétrico de Potência (SEP).

O objetivo final deste sistema é permitir a estimação dos fasores de sinais amostrados de tensão e corrente, comportando-se assim como um PMU. Nas próximas seções são apresentadas as macro estruturas que compõem o sistema. Inicialmente a configuração do AGCM foi testado em linguagem C. Posteriormente esta implementação deverá ser migrada para linguagem VHDL para execução na plataforma FPGA, a qual executará o algoritmo genético com alta eficiência devido ao forte paralelismo existente nesta arquitetura.

Posteriormente para integrar a plataforma FPGA citada, será utilizado o mini computador industrial, padrão PCI/104. Este padrão garante robustez e confiabilidade à solução de tempo real. Para integração dos módulos e correto funcionamento da plataforma, será necessário um software conforme descrito na Seção 5.4, mencionando o sistema operacional utilizado e as modificações necessárias para um ambiente de execução em tempo real.

Finalmente são apresentadas a biblioteca OpenRelay, responsável neste projeto pela aquisição e pré processamento das amostras dos sinais elétricos, permitindo análise realista do SEP naquele instante tempo e a biblioteca OpenC37118 desenvolvida neste trabalho como forma de permitir o envio e recebimento das medições fasoriais através de um canal de comunicação. 


\subsection{Field Programmable Gate Array (FPGA)}

Uma plataforma FPGA é um dispositivo lógico que contém células lógicas, células de I/O e comutadores programáveis dispostos em uma forma matricial como ilustrado pela Figura 73. Assim uma célula lógica pode ser configurada (programada) para desempenhar uma função simples, e um comutador também pode ser personalizado para proporcionar as interligações entre as células lógicas (CHU, 2008).

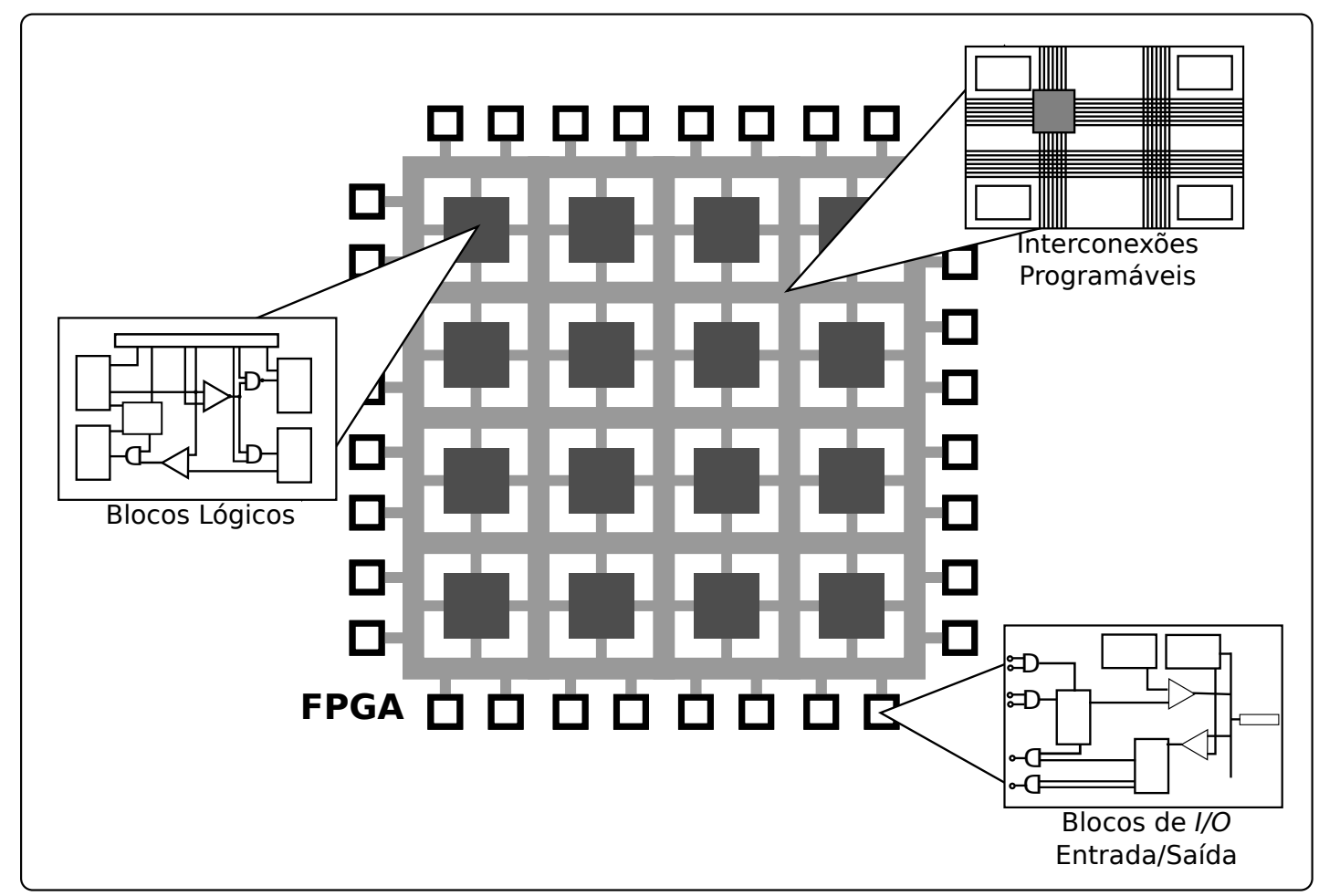

Figura 73 - Diagrama da Matriz FPGA.

Adaptado de (CHU, 2008)

Esta arquitetura flexível permite então um design de circuito personalizado através de um computador convencional utilizando linguagens de programação como a VHSIC Hardware Description Language (VHDL) e/ou Verilog, onde cada célula lógica é programada conforme a necessidade de execução e interconectada conforme determinada lógica. Uma vez que o design e a síntese são concluídos, uma interface externa é utilizada para transferir as configurações programadas para o hardware FPGA.

No contexto deste trabalho, um conjunto de células serão programadas em linguagem VHDL e interconectadas formando processadores genéticos capazes de estimar a aptidão de cada indivíduo de uma população de forma paralela, encontrando uma ótima solução em tempo hábil de resposta quando utilizado em medições de um SEP com frequência fundamental de $60 \mathrm{~Hz}$. 
A plataforma FPGA utilizada neste trabalho pode ser vista na Figura 74, e trata-se de uma placa do tipo Peripheral Component Interconnect (PCI) padrão PCI/104, com as seguintes especificações técnicas:

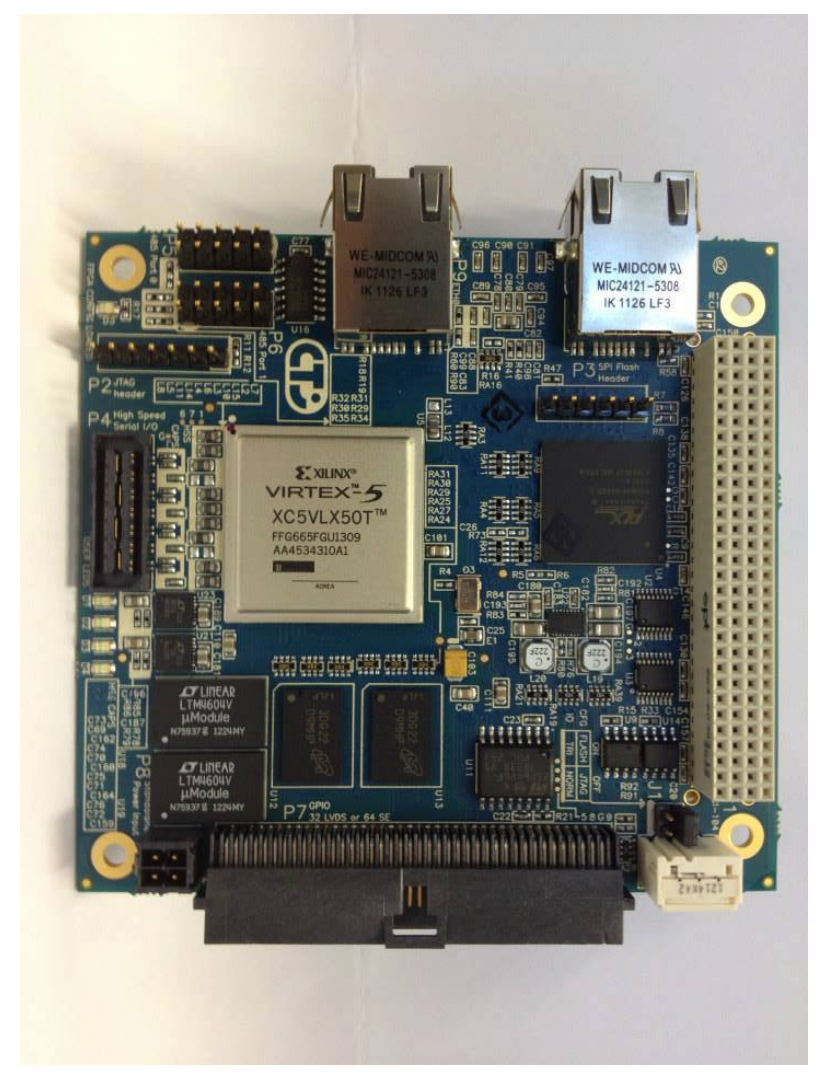

Figura 74 - Módulo PCI FPGA Virtex 5

$\square$ Virtex-5 FPGA - 3 milhões de blocos lógicos;

$\square$ Clock base de 100 Mhz, até 500 Mhz via multiplicador;

$\square$ Memória flash de 32MB e 128MB DDR2-400 de memória RAM;

$\square$ Barramento PCI 32 Bits;

$\square$ Conectividade LVDS (32 Pinos);

$\square 2$ interfaces 10/100 Ethernet;

$\square 2$ interfaces RS-485 serial;

$\square$ Interface JTAG para programação;

$\square$ Temperatura de operação entre -40 to +85 Celcius;

\ Suporte a processadores embarcados. Ex.: MicroBlaze; 
Para o desenvolvimento da lógica de operação nesta plataforma, é utilizado a linguagem VHDL, a qual descreve os passos de processamento do AGCM, e também o ambiente Xilinx PlanAhead para sintetizar e transferir o código para a plataforma FPGA.

Neste momento ainda não é possível estimar o nível de utilização final de portas lógicas da plataforma FPGA devido a necessidade de migração e adequação do código fonte para a correta integração com o sistema de aquisição de dados em tempo real baseado no mini computador industrial PCI/104.

\section{$5.2 \quad \mathrm{PCI} / 104$}

Nesta seção serão discutidos os aspectos que levaram à escolha da plataforma PCI/104 (CONSORTIUM, 2003), assim como os módulos selecionados para compor a plataforma de tempo real. PCI/104 ou PCI104 é um padrão e placas para computadores industriais controlado pelo PCI104 Embedded Consortium que define um padrão de formato e de barramento para computadores embarcados robustos.

PCI/104 é destinado às aplicações de computação embarcada onde depende-se de processamentos confiáveis em ambientes extremos, como em casos reais de equipamentos de medição. O padrão PCI/104 permite que os módulos (placas) sejam empilhados, sem a necessidade de planos de fixação, o que torna a conectividade dos barramentos ainda mais robusta (MONARO, 2013).

Para este trabalho, foi escolhido uma plataforma PCI/104, que contém um barramento PCI ao invés de um barramento Industry Standard Architecture (ISA) tradicional. Este novo barramento PCI permite a integração da plataforma FPGA diretamente com a pilha de módulos que compõe a solução final, nomeada simbolicamente de "Cubo 2".

A Figura 75 representa as dimensões físicas, em polegadas, de um módulo conforme as normas PCI/104, assim como a forma de empilhamento entre eles.

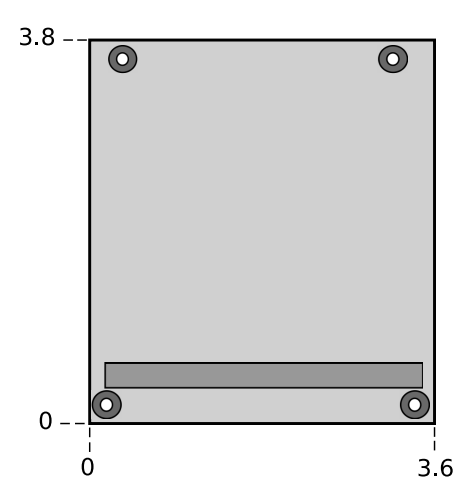

(a) Vista Frontal e Lateral

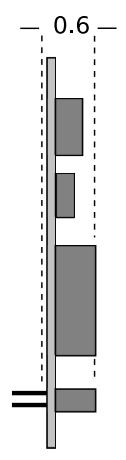
6

Figura 75 - Dimensões Módulo Padrão PCI/104

Além da robustez, esta plataforma permite o uso de sistemas operacionais convencionais, provendo assim flexibilidade no seu uso. Ainda é possível a utilização de sistemas 
operacionais de tempo real para suprir a necessidade de aplicações de controle que têm requisitos de tempo. Tais características fazem da plataforma PCI/104 uma excelente base de desenvolvimento para aplicações industriais, pois une robustez com flexibilidade (MONARO, 2013).

\subsubsection{Cubo 2}

Um arranjo computacional para que tenha um comportamento de um equipamento PMU, é necessário a análise de vários outros aspectos, os quais devem ser previamente definidos. A Figura 76 ilustra através de um diagrama de blocos, um possível arranjo composto de vários módulos, que integrados permitem a análise fasorial em tempo real.

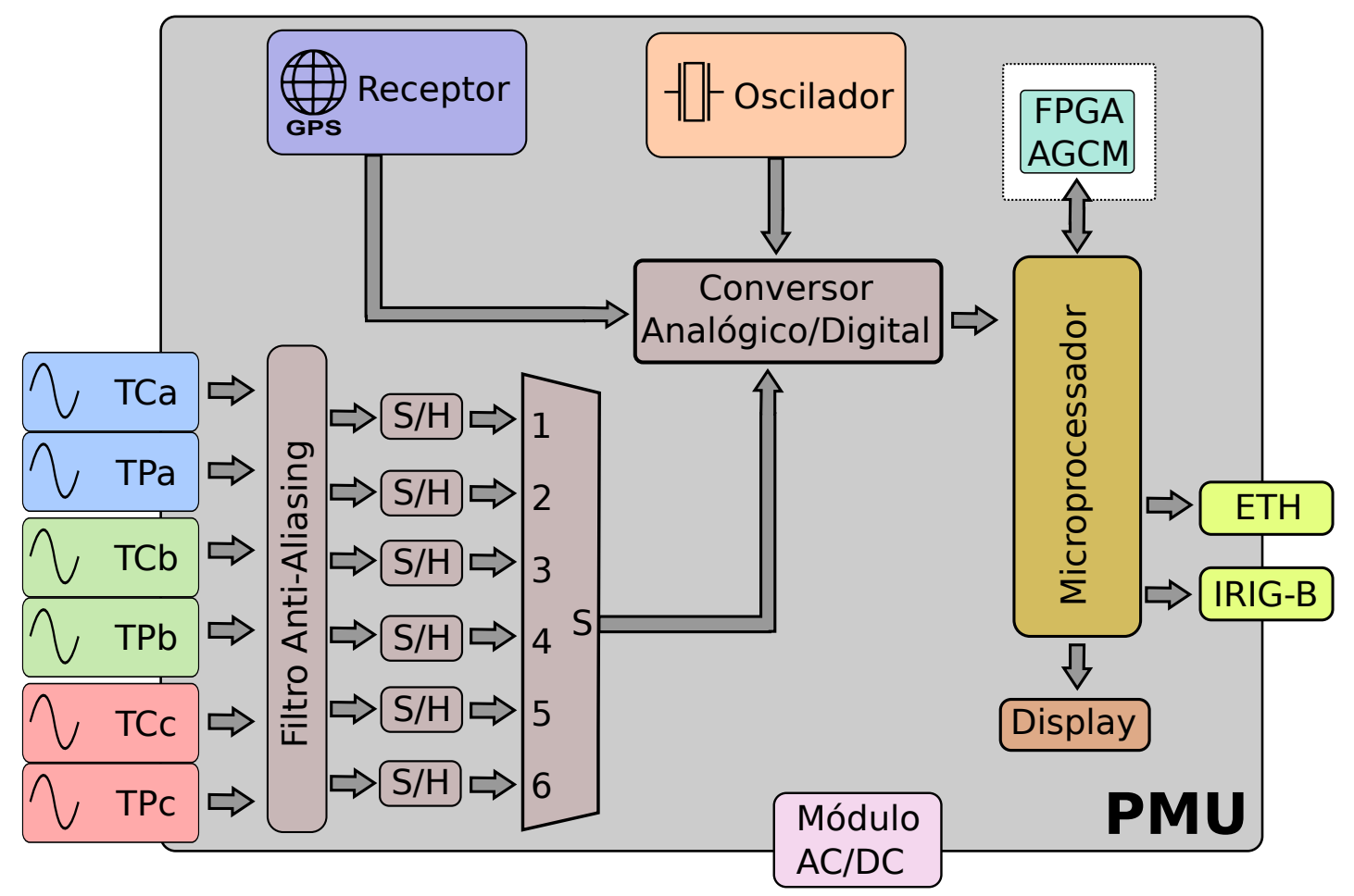

Figura 76 - Diagrama do PMU.

Conforme a ilustração é possível notar a necessidade do módulo de aquisição de dados analógico/digital conectado aos transformadores de potencial e corrente permitindo a correta aquisição do sinal existente no SEP. Desta forma o conversor analógico/digital escolhido possui as seguintes características conforme o padrão PCI/104:

$\square$ Resolução de 12 bits;

$\square$ Tempo de conversão de $0,8 \mu \mathrm{s}(125 \mathrm{MHz})$;

$\square 16$ Canais de entrada analógica em modo comum ou 8 em modo diferencial;

- 16 Canais de entrada/saída digital; 
Buffer de 1024 amostras.

Para que a plataforma de tempo real atue como um PMU ainda faz-se necessário a integração com um sistema de sincronia garantindo a todos os equipamentos uma referência de tempo comum. Para cumprir este requisito, encontra-se em estudo alguns sistemas de sincronismos existentes, como o sistema GPS, onde a hipótese de utilizá-lo ainda não está comprovada em prática, servindo neste momento como um motivador para atividades futuras. O módulo GPS disponível hoje para análise da possibilidade de integração com a plataforma de tempo real, contempla as seguintes características.

$\square$ Receptor GPS Fastrax iTrax03-02;

$\square 12$ canais de rastreamento de satélites;

Acurácia de posicionamento $=3 \mathrm{~m}$;

Acurácia de velocidade $=0,2 \mathrm{~m} / \mathrm{s}$

Taxa atualização $1 \mathrm{~Hz}$ (configurável até $5 \mathrm{~Hz}$ );

$\square$ Saída TTL para sinal PPS, via interface UART;

Uma vez definido um sistema de sincronismo preciso, o sistema deverá ser capaz de fornecer uma estampa de tempo, a qual será anexada aos valores dos sinais lidos e processados, garantindo o sincronismo das informações em posições geográficas distintas.

Ainda assim, para que todo o sistema funcione adequadamente foi escolhido o módulo de energia, fonte (power supply), com as seguintes características elétricas:

Potência de saída total de 154 W;

Tensão de entrada variável entre $6 \mathrm{~V}$ e $36 \mathrm{~V}$;

$\square$ Saídas $+3,3 \mathrm{~V} \pm 5 \mathrm{~V}$ e $\pm 12 \mathrm{~V}$.

Todos os módulos anteriormente citados constituem o hardware da plataforma de tempo real proposta. Para que todos os módulos funcionem de forma adequada, ainda é necessário um sistema operacional, assim como drivers de controle para os módulos instalados.

\subsection{Sistemas de Tempo Real}

Um Sistema Operacional (SO) é um programa ou conjunto de programas cuja função é gerenciar os componentes físicos disponíveis no computador, sendo assim um intermediário entre os demais programas executados e o hardware, além de servir como interface entre 
a máquina e o usuário final, permitindo assim o seu controle (SILBERSCHATZ; GALVIN; GAGNE, 2009).

Os SOs estão presentes em sistemas embarcados, que são largamente utilizados para controle e monitoramento de aplicações de risco, como aviões, carros, plantas industriais e relés de proteção de SEPs. Tais aplicações são caracterizadas como sistemas de tempo real, em que o tempo de resposta para o tratamento a um evento deve ser pré-definido e obedecido conforme o cenário de aplicação, e caso não seja, pode-se resultar em severas consequências, como falhas ou danos físicos (MONARO, 2013).

O escalonador de tarefas de um SO de tempo real precisa ser preemptivo, ou seja, os processos devem contemplar níveis de prioridades, uns sobre os outros, permitindo que um processo de menor prioridade seja interrompido para que um processo de maior prioridade seja executado, alcançando assim o requisito de tempo de resposta necessário.

Para este trabalho, foram analisados dois diferentes SOs de tempo real sob licença GNU Public License (GPL): O primeiro deles o Xenomai (GERUM, 2004) e o segundo, o escolhido, Real-Time Application Interface (RTAI) (MANTEGAZZA; DOZIO; PAPACHARALAMBOUS, 2000), ambos baseados no sistema Sistema Operacional GNU Linux (Linux).

\subsection{GNU/Linux e Real-Time Application Interface}

O Linux é um SO de código fonte aberto, sob licença GPL, sendo utilizado em diversas aplicações, de computadores pessoais a supercomputadores. A grande flexibilidade provida pelo código aberto e a existência de documentação abundante faz deste uma alternativa atraente para a implementação de aplicações diversas.

Porém o Linux foi concebido como um SO multiusuário de propósito geral e essa característica geralmente conflita com as características de um SO de tempo real.

Como alternativa aos SOs de tempo real proprietários e para aqueles que querem tirar vantagem do uso do Linux, surge o RTAI, uma extensão para que o Linux opere em tempo real, permitindo o desenvolvimento de aplicações críticas em tempo. O RTAI funciona baseado no modelo de abstração de interrupções, em que modificações fazem com que o Linux seja executado como uma tarefa de baixa prioridade sobre um pequeno kernel de tempo real.

As funções de tempo real então são tratadas com alta prioridade neste pequeno Leonel. O restante das aplicações, como gráficos e inputs de usuários são tratadas pelo Linux executado em baixa prioridade. A Figura 77 ilustra a arquitetura do ROTAI.

Este novo kernel RTAI tem como característica a utilização de um escalonador de tarefas preemptivo, ou seja, ele tem controle sobre os tempos de execução de cada um dos processos e consegue aplicar diferentes prioridades entre os mesmos. Deste modo, as interrupções do hardware são gerenciadas e o tempo de processamento é dividido entre os processos, garantido o requisito de tempo real (MONARO, 2013). 


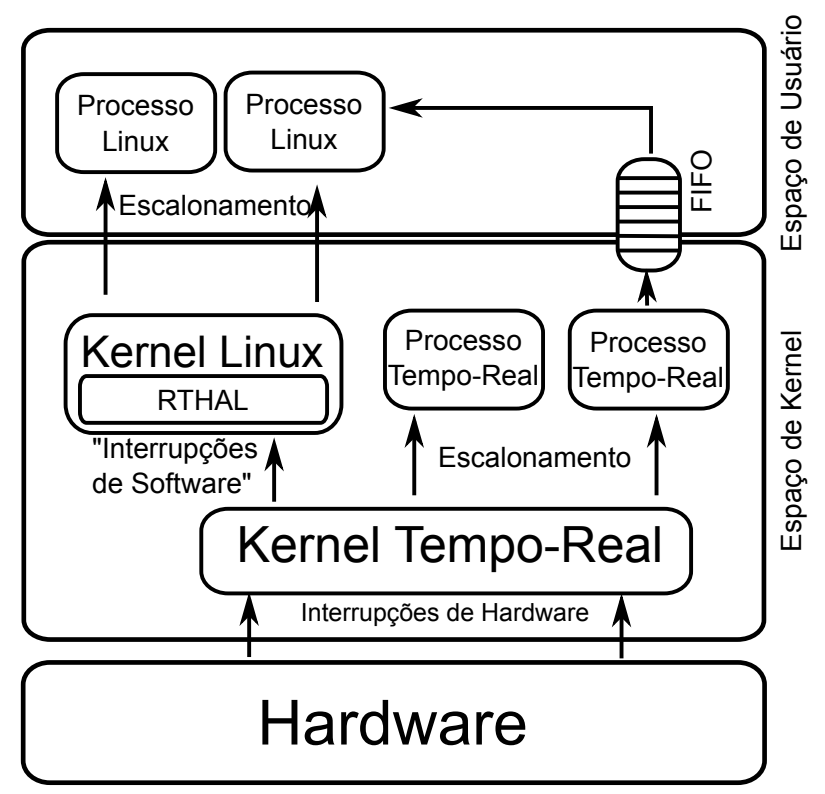

Figura 77 - Arquitetura RETAI.

(MONARO, 2013)

\subsection{Comedi}

O Control and Measurement Device Interface (Comedi) (SCHLEEF; HESS; BRUYNINCKX, 2004) é um conjunto padrão de drivers e bibliotecas para aquisição de dados do Linux, que suporta diversos fabricantes e modelos de placas através de uma interface comum, a Application Programming Interface (API). A API é um conjunto de funções disponíveis no Comedi através do comedilib onde é possível acessar os vários dispositivos de uma placa de aquisição de dados.

O Comedi está organizado em canais, sub-dispositivos e dispositivos. Um canal é o nível mais baixo de medição e controle. Existem diversos tipos de canais que possibilitam:

Leitura e escrita de sinais analógicos;

$\square$ Leitura e escrita de sinais digitais;

$\square$ Contadores de pulso e frequência;

Geração de pulsos;

Leitura de encoders;

Os canais de um mesmo tipo são agrupados em um conjunto comum, chamado subdispositivo. Os sub-dispositivos são agrupados em um dispositivo. A Figura 78 ilustra esta organização.

Uma vez conhecido o dispositivo de aquisição de dados, e com o uso da API fornecida, é possível programar uma sua própria lógica computacional para controlar o dispositivo de aquisição de dados. Esta metodologia aplicada em diversos trabalhos anteriores já 


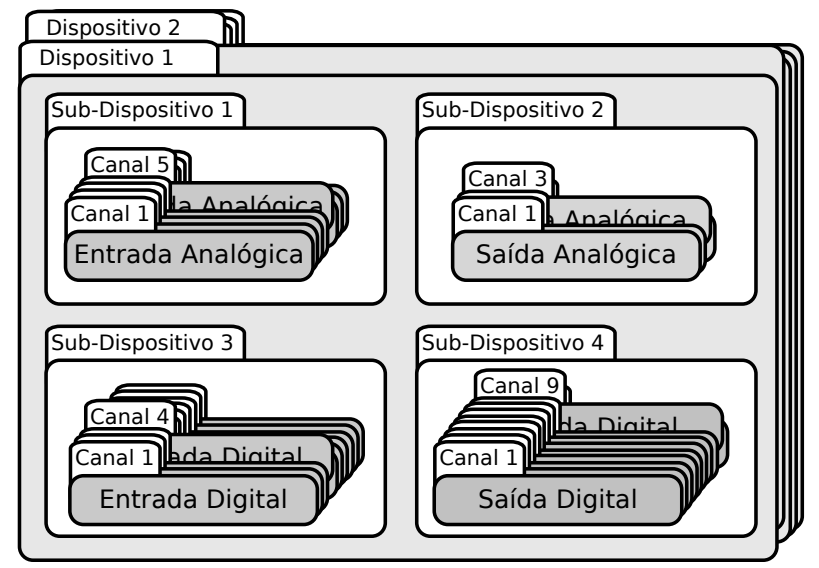

Figura 78 - Organização Comedi.

(MONARO, 2013)

existentes, resultou em uma biblioteca de códigos sob licença GPL denominada OpenRelay (MONARO, 2013).

\subsection{Biblioteca OpenRelay}

Nos equipamentos microprocessados, as medições são realizadas por meio de algoritmos, programados e dedicados à uma determinada funcionalidade. Novamente uma analogia as relés digitais pode ser feita. Um relé digital tem seu funcionamento baseado no condicionamento, filtragem, digitalização e processamentos dos sinais elétricos provenientes do SEP (MONARO; SILVA; COURY, 2012). Esses passos descritos para o relé digital também são primordiais para o PMU garantindo a correta amostragem do sinal, sua análise e precisão dos resultados.

Para facilitar a implementação dos algoritmos tradicionais de aquisição de sinais, filtragem e escalonamento das tarefas, é utilizado a biblioteca OpenRelay, que concentra todas as funções necessárias para o funcionamento base de um relé digital e/ou sistemas de proteção conforme o diagrama ilustrado pela Figura 79.

Esta biblioteca é desenvolvida pelo Laboratório de Sistemas de Energia Elétrica (LSEE) para ambientes Linux, em linguagem $\mathrm{C}++$, sob licença GPL permitindo a alteração e adição de novos métodos computacionais como o método genético aqui apresentado.

É proposto como atividade futura de continuação desta pesquisa, o desenvolvimento e integração de duas novas classes, destacadas em cor vermelha na Figura 79, permitindo assim explorar o novo método genético em uma plataforma de tempo real para estimação fasorial.

Primeiramente, a classe Xilinx RTD (Real Time Driver) responsável pela comunicação via barramento PCI entre as placas FPGA e PCI/104 utilizando a interface RTAI. Desta forma, qualquer dado disponível no barramento PCI, e endereçado à placa FPGA, será capturado e processado pelo AGCM, sendo o resultado também disponibilizado no 


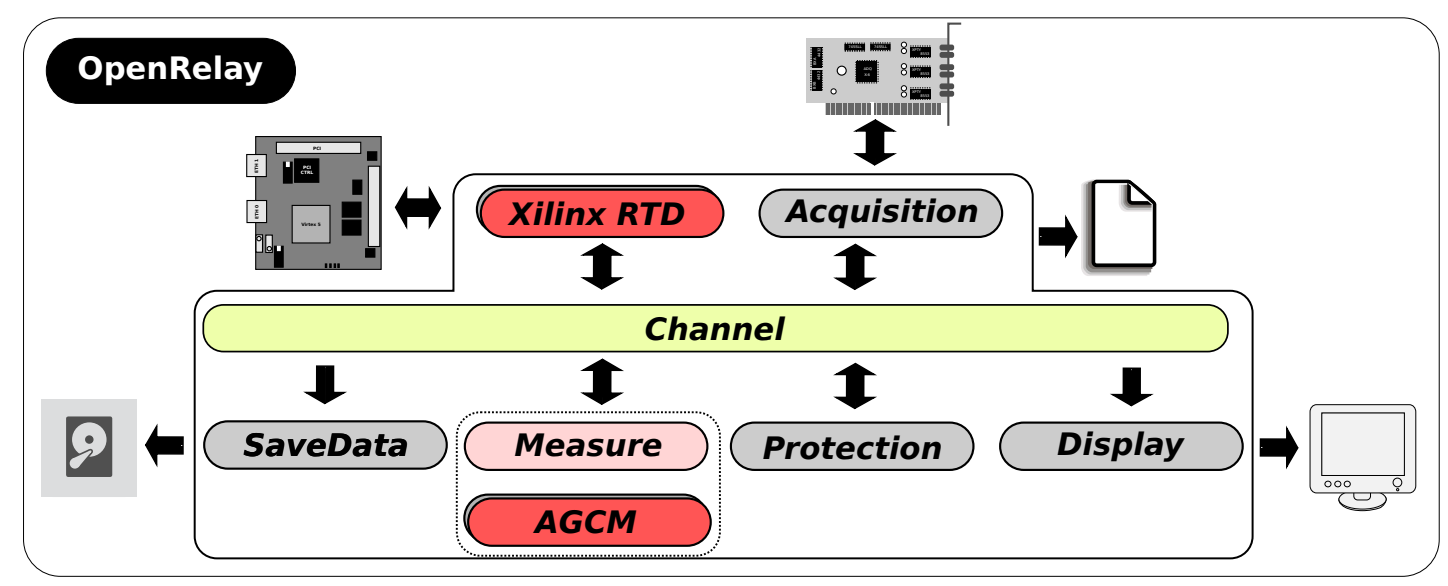

Figura 79 - Organização Biblioteca OpenRelay.

Adaptado de (MONARO, 2013)

barramento PCI para que posteriormente possa ser capturado e utilizado pela biblioteca OpenRelay.

Uma vez concretizada a comunicação em tempo real entre os módulos FPGA e PCI/104, a classe Measure já existente é estendida com a classe $A G C M$ permitindo que a OpenRelay execute a medição fasorial utilizando o AGCM aqui proposto na plataforma de tempo real PCI/104.

Estes e outros desenvolvimentos necessários são descritos posteriormente no Capítuloi 6 , onde a Seção 6.2 formaliza as ideias e as necessidades para a conclusão deste trabalho como uma plataforma de medição fasorial em tempo real.

\subsection{Biblioteca OpenC3\%.118}

Para que fosse possível a comunicação do protótipo PMU com outros equipamentos existentes na rede, como o Real-Time Digital Simulator (RTDS) e simuladores de PDC para a troca de dados de medição, foi necessário o desenvolvimento de uma biblioteca de comunicações conforme descrito em norma do IEEE C37.118-2011. Este protocolo também conhecido como Synchrophasor Protocol é uma forma simples de organizar os dados de medição para sua transmissão até outros equipamentos.

Basicamente está divido em 4 quadros (frames) de dados distintos, são eles:

- Header Frame: Responsável por informar detalhes característico do equipamento de medição, como número de série, versão do firmware, etc;

$\square$ Config Frame: Responsável por informar detalhes de configuração das medições, assim como o número de PMUs envolvidos na comunicação;

$\square$ Command Frame: Responsável por informar comandos de controle do PMU;

$\square$ Data Frame: Responsável por informar os valores dos fasores medidos; 
Assim foram implementadas algumas classes em linguagem $\mathrm{C}++$, originando a biblioteca OpenC37118, também sob licença GPL, para tratar as informações fasoriais estimadas e transmití-las através da rede de comunicação de dados. A estrutura de organização da biblioteca em suas classes é ilustrada pela Figura 80.

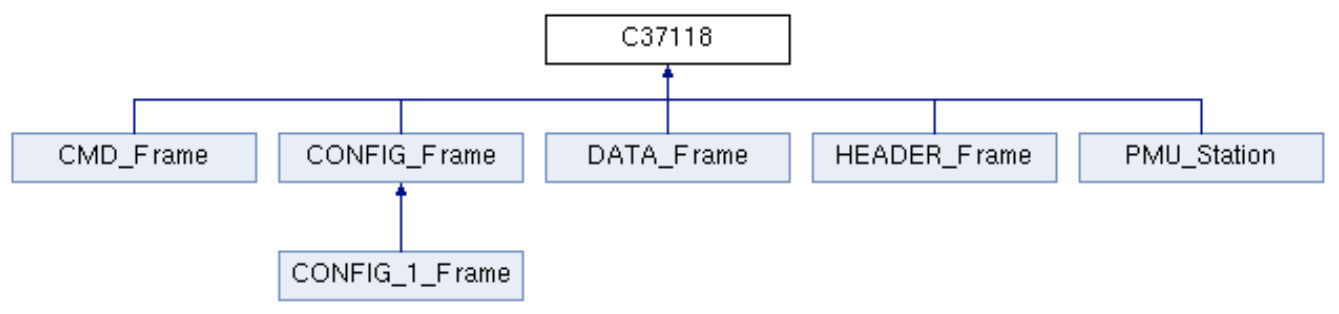

Figura 80 - Organização das Classes da Biblioteca OpenC37118.

- Classe C37118: Responsável por criar um objeto que irá englobar todos os possíveis quadros de dados utilizados na comunicação, além de controlar a identificação do dispositivo;

-Classe CMD_Frame: Responsável por criar um objeto de comandos ao PMU controlando sua operação remotamente através do canal de comunicação;

$\square$ Classe CONFIG_Frame: Cria um objeto que informa as configurações do PMU em operação;

$\square$ Classe CONFIG_1_Frame: Assim como o item anterior, também informa as configurações do PMU, porém utilizando a versão 1 de configuração. Maiores detalhes sobre as versões podem ser obtidos na norma IEEE C37.118-2011;

$\square$ Classe DATA_Frame: Cria um objeto contendo as informações de medição fasorial;

$\square$ Classe HEADER_Frame: Cria um objeto com as características da unidade PMU como o número de sério do dispositivo;

- Classe PMU_Station: Permite a criação, diferenciação e controle de diversos PMUs utilizados na monitoração do SEP;

De maneira geral as classes desenvolvidas são responsáveis por preencher os campos dos quadros de dados acima citados, empacotando e desempacotando a informação de medição fasorial. Para que esta operação ocorra de forma correta, é importante salientar a necessidade de popular os campos dos quadros de dados corretamente também com as informações de identificação da unidade PMU utilizada, antes de qualquer transmissão de medição fasorial. Posteriormente, métodos pack() e unpack() empacotam e desempacotam a informação transmitida e recebida respectivamente. Testes de validação foram 
executados utilizando uma comunicação com o simulador de tempo real RTDS validando as informações transmitidas.

Maiores detalhes de uso desta biblioteca e seus de seus métodos, são encontrados diretamente no site do LSEE ${ }^{1}$.

\subsection{Custo de Projeto}

Esta seção estima o custo aproximado da plataforma PMU, considerando custos com a tecnologia da plataforma. Não são apresentados valores de desenvolvimento e pesquisa de engenharia envolvidos, assim como os materiais de laboratório já existentes. A tabela 6 exibe de forma breve os maiores custos envolvidos no desenvolvimento da plataforma de tempo real.

\begin{tabular}{c|c|c|c}
\hline \multicolumn{4}{|c}{ Estimativa de Preço da Plataforma PMU. } \\
\hline Quantidade & Descrição & Preço & Total (BRL) \\
\hline 1 & $\begin{array}{c}\text { PCI-104 SBC N455 } \\
\text { 1.6G,LVDS,GbE,1GB DDR3 }\end{array}$ & BRL 3430,00 & 3430,00 \\
\hline 1 & Xtreme/PSU,+6Vto+36V DC input & USD 257,00 & 645,00 \\
\hline 1 & FPGA - Virtex 5 PCI/104 std. & USD 2500,00 & 6250,00 \\
\hline 1 & AD - DM8520 & USD 845,00 & 2112,00 \\
\hline 1 & LANCard - 18222HR & USD 445,00 & 1112,00 \\
\hline & Despesa Postal & BRL 1200,00 & 1200,00 \\
\hline
\end{tabular}

Tabela 6 - Custo Estimado da Plataforma PMU.

Alguns dos custos justificam-se por se tratar de uma plataforma robusta, capaz de operação em ambientes extremos, pertinentes a um equipamento de campo. A precisão dos elementos de aquisição de dados e sincronismos de tempo também colaboram para elevar o custo da plataforma computacional de tempo real. O cartão FPGA essencial para a aplicação do método aqui desenvolvido, embora tenha um elevado custo se comparado a outros componentes da plataforma, trata-se de um valor aceitável quando comparado com outras plataformas de desenvolvimento FPGA mais comumente utilizadas. Alguns outros dispositivos como o módulo GPS já existente, TP's e TC's, tampouco custos de infra estrutura de instalação e armazenagem de dados foram considerados. Este preço é aceitável quando comparado com um relé digital comercial, que tem seu custo variando entre $\mathrm{R} \$ 15.000,00$ e $\mathrm{R} \$ 60.000,00$ reais de acordo com o número de funcionalidades definidas em seu software.

Esta plataforma computacional foi concebida para além de permitir a estimação fasorial, servir de propósito pra ensaios de medição e sistemas de proteção. A flexibilidade do sistema utilizado, juntamente com as bibliotecas desenvolvidas no LSEE, permitem

\footnotetext{
${ }^{1}$ http://lsee.sel.eesc.usp.br/index.php/midia/arquivos/38-biblioteca-c-protocolo-c37-118
} 
a implementação e o estudo dos mais diversos tipos de algoritmos. O desenvolvimento desta plataforma, deverá permitir a validação deste trabalho em um ambiente de testes utilizando a técnica de laço-fechado com simuladores de SEPs, como o RTDS disponível para ensaios mais realísticos.

Neste momento, o método AGCM desenvolvido ainda não foi embarcado na plataforma de tempo real, pois é necessário a integração do cartão FPGA e a migração do método genético para linguagem VHDL. A integração da interface de aquisição de dados encontrase completamente funcional, sendo possível seu uso para ensaios de algoritmos de medição e proteção, como em relés digitais, porém sem o uso do cartão FPGA.

Já o sistema de sincronia de tempo, é baseado no sistema GPS, o qual recebe o sinal PPS e o publica na rede de comunicações IP, utilizando o protocolo Precise Time Protocol (PTP). Esta estampa de tempo transmitida, é recebida pela interface de rede IP da plataforma computacional de tempo real. Para integrar a estampa de tempo recebida do sistema GPS com os valores estimados, em tempo real, é necessário o término do desenvolvimento do protocolo PTP pelos mantenedores oficiais do protocolo ou pesquisadores independentes, além de equipamentos de comunicação (switches) homologados segundo norma IEEE-1588 hoje não disponíveis. 


\section{Conclusão e Heranças}

Este capítulo apresenta a visão consolidada do trabalho executado e algumas atividades sugeridas para continuação da pesquisa, para que o objetivo de desenvolver um novo equipamento PMU possa ser alcançado.

Conforme testes realizados e resultados apresentados para os cenários descritos no Capítulo 4, a configuração do AGCM encontra-se satisfatória para o problema de estimação fasorial, visto que os resultados obtidos têm precisão adequada segundo especificado pela norma IEEE C37.118-2011.

Foi detectado uma maior dificuldade na estimação da frequência no momento do teste degrau de frequência especificado pela norma, sendo necessário um maior tempo de recuperação para estimações precisas. A influência do modelo multiobjetivo permitiu então convergências mais suaves e a garantia de não necessitar de uma prévia escolha da fase a ser analisada.

Outra condição importante é a constante de inércia do gerador utilizada pelo método de regularização da frequência. Como o caso especificado pela norma, assume um degrau de $+5 \mathrm{~Hz}$ instantâneo, incompatível com a realidade de operação de um gerador, que opera com uma constante de inércia, neste caso $H$ igual a $6 \frac{M W}{M V A} s$, o método de regularização contribui também para um maior tempo de recuperação.

Embora os casos testados anteriormente com sucesso sejam descritos na norma IEEE C37.118-2011, novos casos foram simulados como forma de garantir a confiabilidade, estabilidade e robustez do método AGCM em diversos cenários de operação do SEP, seja eles em regime ou transitórios.

\subsection{Conclusão deste Trabalho}

Para este trabalho foram descritas as técnicas utilizadas na modelagem do problema de estimação fasorial quando proposto um método evolutivo, o AGCM. Também foi estudado e proposto uma plataforma de sistema de tempo real para que o método evolutivo seja explorado em seu pleno potencial além de uma biblioteca de funções que permite a 
comunicação desta plataforma com outros dispositivos obedecendo a normatização pertinente.

Toda a análise da configuração utilizada no AGCM foi executada utilizando um algorítimo implementado em $\mathrm{C}$, devido a sua flexibilidade e eficiência de execução. Nesta etapa foram necessários diversos testes de configuração dos parâmetros do AGCM como forma de garantir sua eficiência de execução e precisão nos resultados. Note que uma codificação do algoritmo diretamente em linguagem VHDL, utilizado pela FPGA teria um alto custo de tempo de desenvolvimento de projeto.

Os sinais utilizados em testes laboratoriais foram gerados sinteticamente com o auxílio do software Octave e baseados no Anexo G da norma IEEE C37.118-2005 como modo de medir a precisão do algoritmo desenvolvido. Para simular um cenário de operação de um SEP, com o auxílio do software ATP, utilizou-se um sistema já modelado e com alguns casos já disponíveis no LSEE. Para complementar, foram ensaiados novos casos, gerando assim os oito casos de simulações aqui apresentados.

Neste momento, os valores estimados e apresentados contemplam um RMSE médio de 0.02 para a variável de frequência. O TVE conhecido segue a normatização, sempre menor que $1 \%$ em regime, e inclusive em alguns casos de ocorrência de eventos, permitindo perceber a vantagem do uso deste método evolutivo em estimar corretamente os parâmetros fasoriais mesmo quando existem momentos de eventos inesperados refletindo diretamente no sinal analisado. Este resultado mais uma vez demonstra a sensibilidade e precisão alcançadas pelo método.

Para garantir o desempenho do método em uma aplicação de tempo real, integrações iniciais dos módulos PCI/104 já foram executadas em atividades paralelas, utilizando-se dos sistemas Linux, RTAI e Comedi, e hoje, contemplam uma solução básica de tempo real para aquisição de dados e processamento utilizando a biblioteca OpenRelay e OpenC37118 para a comunicação entre dispositivos.

Existem ainda outros passos para a conclusão desta plataforma de tempo real, os quais são brevemente descritos na Seção 6.2.

\subsection{Propostas Futuras e Heranças}

Embora o método genético proposto tenha sido desenvolvido e testado com sucesso até este momento, algumas atividades idealizadas inicialmente perderam a prioridade de desenvolvimento no decorrer deste trabalho, sendo parcialmente executadas. Desta forma é proposto aqui algumas atividades de continuação da pesquisa para trabalhos futuros e também as heranças dos resultados que poderão ser utilizados em outros desenvolvimentos.

Grande parte das atividades aqui propostas referem-se a plataforma de tempo real, entre elas: 
\ Término da migração do código C para linguagem VHDL necessário para execução em plataforma Xilix, garantindo assim os requisitos de tempo real;

Como foram encontrados diversos desafios de implementação computacional até que o método genético estivesse apto para a aplicação proposta, a migração do código em C para linguagem VHDL não foi possível completamente, ficando aqui pendente de desenvolvimento.

$\square$ Desenvolvimento de um driver em tempo real para interface PCI entre o PCI/104 e FPGA;

A placa Xilix FPGA utilizada contempla drivers PCI de comunicação, porém devido ao uso da interface de tempo real RTAI faz-se necessário o desenvolvimento de um novo driver de comunicação PCI, garantindo assim os requisitos de tempo real na comunicação entre a plataforma PCI/104 e a FPGA.

$\square$ Extensão da biblioteca OpenRelay para utilização da placa FPGA executando o método genético aqui proposto.

Como esta biblioteca já contempla métodos de aquisição de dados, tratamento do sinal amostrado, e algumas funções de medição, o mais simples seria a expansão dos métodos de medição, permitindo o envio dos sinais amostrados para o método genético, o qual estimará as variáveis fasoriais, e devolverá tal resultado para a biblioteca, permitindo o registro da informação e até mesmo uma atuação direta no sistema monitorado.

$\square$ Estudo e integração de um sistema de tempo preciso como forma de garantir o sincronismo das medições fasoriais efetuadas;

Um sistema GPS ou o protocolo PTP poderá garantir uma estampa de tempo precisa nas medições efetuadas, indiferente da localização geográfica, sempre baseado em uma referência de tempo também precisa, como o sinal PPS no caso do sistema GPS o qual poderá inclusive ser usado como trigger do conversor analógico digital durante a amostragem do sinal.

$\square$ Modelagem de um novo SEP no Real-Time Digital Simulator (RTDS), um simulador de SEP em tempo real, flexível e capaz de fornecer uma estrutura de testes em laço fechado, para estudo da confiabilidade do método genético em novos casos de eventos, e da comunicação entre os dispositivos de medições fasoriais;

Acredita-se que vencido os passos anteriores, e com o uso do método genético aqui desenvolvido, será possível construir um equipamento PMU o qual estimará os fasores de um SEP em tempo real, com alta precisão. 
Entre as heranças deixadas por este trabalho e que podem auxiliar no estudo e desenvolvimento de novos métodos evolutivos para análise de qualidade e proteção de sistema elétricos de potência estão:

$\square$ AG e AGM;

Dois métodos genéticos tradicionais já existentes e agora devidamente calibrados para a estimação fasorial nos cenários aqui testados.

$\square$ AGC;

Um método de estimação fasorial utilizando um algoritmo genético compacto monoobjetivo desenvolvido em linguagem C, o qual permitirá extrair informações dos sinais do SEP utilizando cada fase individualmente.

\section{$\square$ AGCM;}

Um método de estimação fasorial utilizando um algoritmo genético compacto multiobjetivo desenvolvido em linguagem C, o qual permitirá extrair informações dos sinais do SEP utilizando a informação disponível em todas as fases do sistema de uma forma conjunta.

\section{$\square$ CUBO 2;}

Uma plataforma computacional de tempo real, de baixo custo, para ensaios e testes de métodos computacionais em loop fechado com simuladores e/ou sistemas elétricos.

\section{$\square$ OpenC37118;}

Uma biblioteca de comunicação desenvolvida em linguagem $\mathrm{C}++$ com o intuito de permitir o envio e recebimento de dados de medição fasorial conforme normatizado. Pesquisas sobre desempenho e confiabilidade da comunicação também podem ser explorados utilizando esta biblioteca.

Todo o trabalho aqui desenvolvido, foi além de executado, pensado de forma a permitir o máximo reúso, garantindo a continuidade da pesquisa por outros pesquisadores. No contexto deste trabalho, a principal contribuição para a área de sistemas elétricos de potência é a criação de um novo PMU, mais eficiente na estimação de fasores, mesmo quando ocorra eventos inesperados no SEP, momentos estes em que os métodos matemáticos tradicionais hoje utilizados podem apresentar uma estimação incorreta. A contribuição do modelo compacto permite uma implementação mais eficiente, consumindo menos recursos computacionais, como a memória utilizada em um sistema embarcado. Por outro lado o modelo multiobjetivo proposto contribui para uma maior robustez da estimação quando comparado com estratégias mono-objetivas de implementação dos algoritmos genéticos. 


\section{Referências}

AGOSTINI, M. N. Estudo de Aplicação de Medição Fasorial Sincronizada em Sistemas de Energia Elétrica. Tese (Doutorado) - Departamento de Engenharia Elétrica - Universidade Federal de Santa Catarina - UFSC., 2006.

ALMEIDA, L. A. D.; LIMA, A. d. C. Covariance management based rls algorithm for phasor estimation in severely noisy systems. IEEE Transactions on Power Delivery, IEEE, v. 13, n. 4, p. 1067-1072, 1998.

BEATY, H. W.; MAHROUS, H.; SEIDMAN, A. H. Handbook of electric power calculations. [S.l.]: McGraw-Hill New York, 2001.

BENMOUYAL, G. Removal of dc-offset in current waveforms using digital mimic filtering. Power Delivery, IEEE Transactions on, IEEE, v. 10, n. 2, p. 621-630, 1995 .

BURNETT, R. O. J.; BUTTS, M. M.; STERLINA, P. S. Power system applications for phasor measurement units. IEEE Computer Applications in Power, IEEE, v. 7, n. 1 , p. 8-13, 1994.

CARvalho, J. R. de; COURY, D. V.; JORGE, D. C.; DelBem, A. C.; SIMÕeS, E. V. Algoritmos genéticos aplicados à medição fasorial e projeto de pmus. CBQEE 2009, p. 1Y6, 2009.

CASSEB, M. V. G. Algoritmos Genéticos Compactos aplicados à estimação fasorial em tempo real. Dissertação (Trabalho Conclusão de Curso) - Escola de Engenharia de São Carlos da Universidade de São Paulo, 2012.

CHU, P. P. FPGA prototyping by VHDL examples: Xilinx Spartan-3 version. [S.1.]: Wiley. com, 2008.

CONSORTIUM, P. E. PCI-104 Specification Version 1.0. 2003.

COURY, D. V.; DELBEM, A. C.; CARVAlhO, J. R. D.; OLESKOVICZ, M.; SIMÕES, E. V.; BARBOSA, D.; SILVA, T. V. da. Frequency estimation using a genetic algorithm with regularization implemented in fpgas. Smart Grid, IEEE Transactions on, IEEE, v. 3, n. 3, p. 1353-1361, 2012.

COURY, D. V.; OLESKOVICZ, M.; GIOVANINI, R. Proteção Digital de Sistemas Elétricos de Potência: dos Relés Eletromecânicos aos Microprocessados Inteligentes. [S.1.]: EESC/USP, 2011. 
DElBem, A. C.; CARVAlho, A. de; POliCAStro, C. A.; PinTO, A. K.; HONDA, K.; GARCIA, A. C. Node-depth encoding for evolutionary algorithms applied to network design. p. 678-687, 2004.

DIAS, A. H.; VASCONCELOS, J. A. D. Multiobjective genetic algorithms applied to solve optimization problems. IEEE Transactions on Magnetics, IEEE, v. 38, n. 2, p. 1133-1136, 2002.

EL-NAGGAR, K. M.; YOUSSEF, H. K. A genetic based algorithm for frequency-relaying applications. Electric Power Systems Research, Elsevier, v. 55, n. 3, p. 173-178, 2000 .

FORMIGA, D. A. Estimação de fasores para proteção de sistemas elétricos baseada em mínimos quadrados e morfologia matemática. Dissertação (Dissertação de Mestrado) — Universidade Federal do Rio Grande do Norte - Centro de Tecnologia de Engenharia Elétrica e de Computação, 2012.

GERUM, P. Xenomai-implementing a rtos emulation framework on gnu/linux. White Paper: http://www. xenomai. org, 2004.

GOLDBERG, D. E. The Design of Innovation: Lessons from and for Competent Genetic Algorithmsby David E. Goldberg. [S.l.]: Springer, 2002.

GOLUB, G. H.; HANSEN, P. C.; O'LEARY, D. P. Tikhonov regularization and total least squares. SIAM Journal on Matrix Analysis and Applications, SIAM, v. 21, n. 1, p. 185-194, 1999.

GOMES, P. H. d. C. Análise e Síntese de um Algoritmo PLL Robusto para Estimação de Amplitude, Fase e Frequência de Sinais Elétricos. Dissertação (Dissertação de Mestrado) — Faculdade de Engenharia da Universidade Federal de Juiz de Fora., 2007.

HARIK, G. R.; LOBO, F. G.; GOLDBERG, D. E. The compact genetic algorithm. IEEE Transactions on Evolutionary Computation, IEEE, v. 3, n. 4, p. 287-297, 1999.

HARRIS, F. J. On the use of windows for harmonic analysis with the discrete fourier transform. Proceedings of the IEEE, IEEE, v. 66, n. 1, p. 51-83, 1978.

HART, D.; NOVOSEL, D.; HU, Y.; SMITH, B.; EGOLF, M. A new frequency tracking and phasor estimation algorithm for generator protection. IEEE Transactions on Power Delivery, IEEE, v. 12, n. 3, p. 1064-1073, 1997.

HAUPT, R. L.; HAUPT, S. E. Practical genetic algorithms. [S.l.]: John Wiley \& Sons, 1998.

HOLLAND, J. H. Adaptation in natural and artificial systems: An introductory analysis with applications to biology, control, and artificial intelligence. [S.l.]: U Michigan Press, 1975.

IEEE. Ieee standard for synchrophasors for power systems. In: IEEE. [S.l.], 1995. Ieee standard for synchrophasors for power systems - c37.118. In: IEEE. [S.l.], 
2011. . Ieee standard for synchrophasors for power systems - c37.118. In: IEEE. [S.l.],

JIANG, J.-A.; LIN, Y.-H.; YANG, J.-Z.; TOO, T.-M.; LIU, C.-W. An adaptive pmu based fault detection/location technique for transmission lines. ii. pmu implementation and performance evaluation. Power Delivery, IEEE Transactions on, IEEE, v. 15, n. 4, p. 1136-1146, 2000.

JIANG, J.-A.; YANG, J.-Z.; LIN, Y.-H.; LIU, C.-W.; MA, J.-C. An adaptive pmu based fault detection/location technique for transmission lines. i. theory and algorithms. Power Delivery, IEEE Transactions on, IEEE, v. 15, n. 2, p. 486-493, 2000.

JUNIOR, L. M. Implementação de controladores para conversores trifásicos, sem transformação de coordenas: análise geométrica através de vetores espaciais. Dissertação (Dissertação de Livre Docência) — Escola Politécnica da Universidade de São Paulo. Departamento de Engenharia de Energia e Automação Elétricas II, 2012.

KAMWA, I.; GRONDIN, R. Fast adaptive schemes for tracking voltage phasor and local frequency in power transmission and distribution systems. In: IEEE. Proceedings of the Transmission and Distribution Conference, 1991. IEEE Power Engineering Society. [S.1.], 1991. p. 930-936.

KARIMI-GHARTEMANI, M.; KARIMI, H.; IRAVANI, M. R. A magnitude/phaselocked loop system based on estimation of frequency and in-phase/quadrature-phase amplitudes. IEEE Transactions on Industrial Electronics, IEEE, v. 51, n. 2, p. 511-517, 2004.

LEE, D.-G.; KANG, S.-H.; NAM, S.-R. New modified fourier algorithm to eliminate the effect of the dc offset on phasor estimation using dft. In: IEEE. Transmission and Distribution Conference and Exposition, 2008. T\&\# x00026; D. IEEE/PES. [S.1.], 2008. p. 1-6.

MACEDO, R. A. de; FILHO, D. da S.; COURY, D.; CARNEIRO, A. de F. M. An evolutionary optimization approach to track voltage and current harmonics in electrical power systems. In: IEEE. Power Engineering Society General Meeting, 2003, IEEE. [S.l.], 2003. v. 2.

MACHADO, T. M.; STEFAnELlO, N.; JR, G. C.; MORAIS, A. P. de; MARIOTTO, L. Análise da resposta em regime transitório e permanente de algoritmos para filtragem digital utilizados em relés numéricos: Velocidade de convergência, overshoot e sensibilidade em relação a constante de tempo. SciELO Brasil, 2011.

MANTEGAZZA, P.; DOZIO, E.; PAPACHARALAMBOUS, S. Rtai: Real time application interface. Linux Journal, Belltown Media, v. 2000, n. 72es, p. 10, 2000.

MONARO, R. M. Lógica Fuzzy Aplicada na Melhoria da Proteção Digital de Geradores Sincronos. Tese (Doutorado) — Escola de Engenharia de São Carlos da Universidade de São Paulo, 2013.

MONARO, R. M.; SILVA, R. P. M. d.; COURY, D. V. Integrated system for development and real time execution of protection algorithm in electrical systems. Sba: Controle \& 
Automação Sociedade Brasileira de Automatica, SciELO Brasil, v. 23, n. 2, p. 202-215, 2012.

ONS, O. N. do S. E. Recomposição da rede de operação após perturbação.

Procedimentos de Rede, 2010.

OPPENHEIM, A. V.; SCHAFER, R. W.; BUCK, J. R. et al. Discrete-time signal processing. [S.l.]: Prentice-hall Englewood Cliffs, 1989.

PHADKE, A. G. Synchronized phasor measurements-a historical overview. In: IEEE.

Transmission and Distribution Conference and Exhibition 2002: Asia Pacific. IEEE/PES. [S.1.], 2002. v. 1, p. 476-479.

RUBEENA, R. An accurate offline phasor estimation technique for fault location in series compensated lines. 2014.

SANTOS, A.; DELBEM, A.; LONDON, J.; BRETAS, N. Node-depth encoding and multiobjective evolutionary algorithm applied to large-scale distribution system reconfiguration. Power Systems, IEEE Transactions on, IEEE, v. 25, n. 3, p. 1254-1265, 2010.

SCHLEEF, D.; HESS, F.; BRUYNINCKX, H. Comedi: Linux control and measurement device interface. 2004.

SILBERSCHATZ, A.; GALVIN, P. B.; GAGNE, G. Operating system concepts. [S.l.]: J. Wiley \& Sons, 2009.

SILVA, R. P. M. Algoritmos Genéticos aplicados à estimação fasorial em sistemas elétricos de potência. Dissertação (Dissertação de Mestrado) — Escola de Engenharia de São Carlos da Universidade de São Paulo, 2012.

SILVA, T. Vieira da. Algoritmos Evolutivos como Estimadores de Frequência e Fase de Sinais Elétricos: Métodos Multiobjetivos e Paralelização em FPGA. Dissertação (Dissertação de Mestrado) - Instituto de Ciências Matemáticas e de Computação da Universidade de São Paulo, 2012.

STALLINGS, W. Computer organization and architecture 7th edition. 2006.

STEUER, R. Multiple criteria optimization: theory, computation, and application. 1986. Willey, New York, 1996.

STEVENSON, W. D. Elements of power system analysis. McGraw-Hill, 1975.

WANG, M.; SUN, Y. A practical, precise method for frequency tracking and phasor estimation. IEEE Transactions on Power Delivery, IEEE, v. 19, n. 4, p. 1547-1552, 2004 .

YU, S.-L.; GU, J.-C. Removal of decaying de in current and voltage signals using a modified fourier filter algorithm. Power Delivery, IEEE Transactions on, IEEE, v. 16, n. 3, p. 372-379, 2001.

ZHANG, C. K.; HU, H. An effective feature selection scheme via genetic algorithm using mutual information. In: Fuzzy Systems and Knowledge Discovery. [S.l.]: Springer, 2005. p. 73-80. 
ZIARANI, A.; KONRAD, A. A method of extraction of nonstationary sinusoids. Signal processing, Elsevier, v. 84, n. 8, p. 1323-1346, 2004.

ZIMA, M.; LARSSON. Design aspects for wide-area monitoring and control systems. Proceedings of the IEEE, IEEE, v. 93, n. 5, p. 988, 2005. 
Apêndice 
ApÊndICE

\section{Implementação do Algoritmo Genético} Compacto Multiobjetivo (AGCM) em linguagem $C$ 
\}

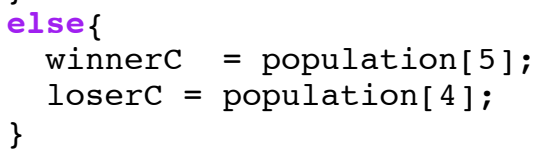


\#ifndef_DATA_H

\#define _DATA_H

\#include "definitions.h"

\#include "ga.h"

int data_setup(int argc, char *argv[]);

void save_result(u32 window, individual *ind, individual *winnerA, individual *winnerB, $i$ ndividual *winnerC, individual *winnerD, u32 f_min, u32 f_max);

void data_finish(void);

\section{\#endif}




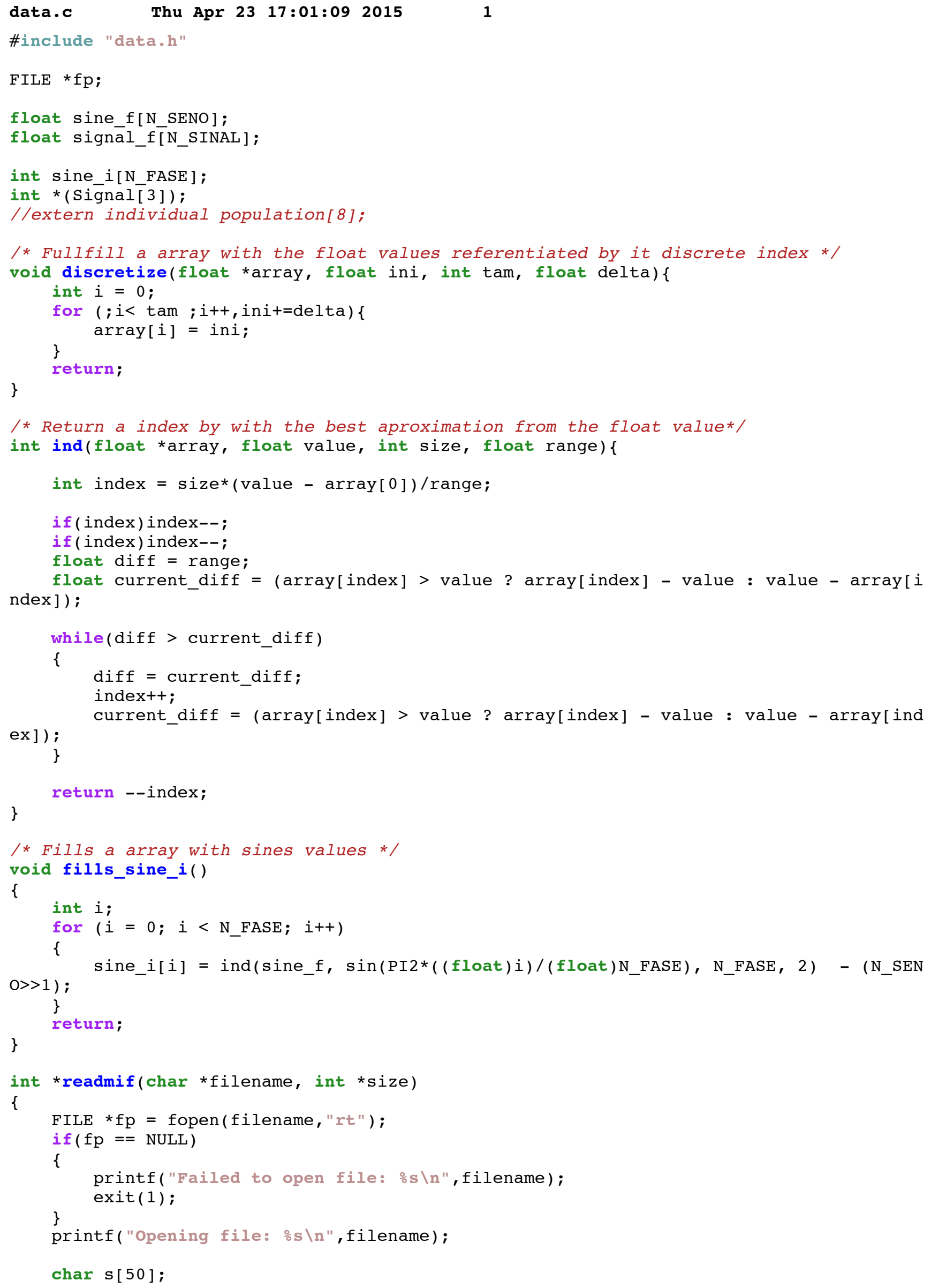




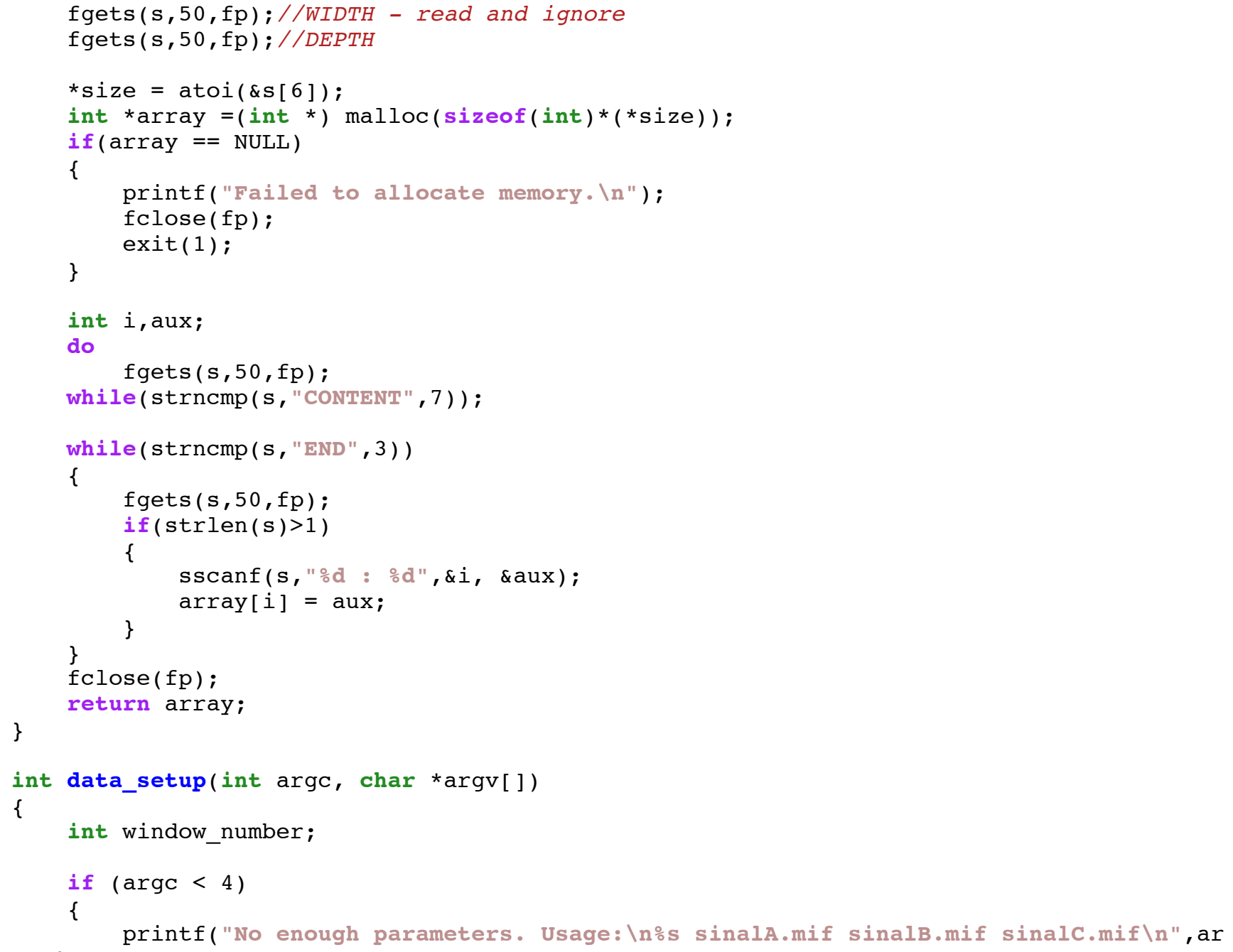




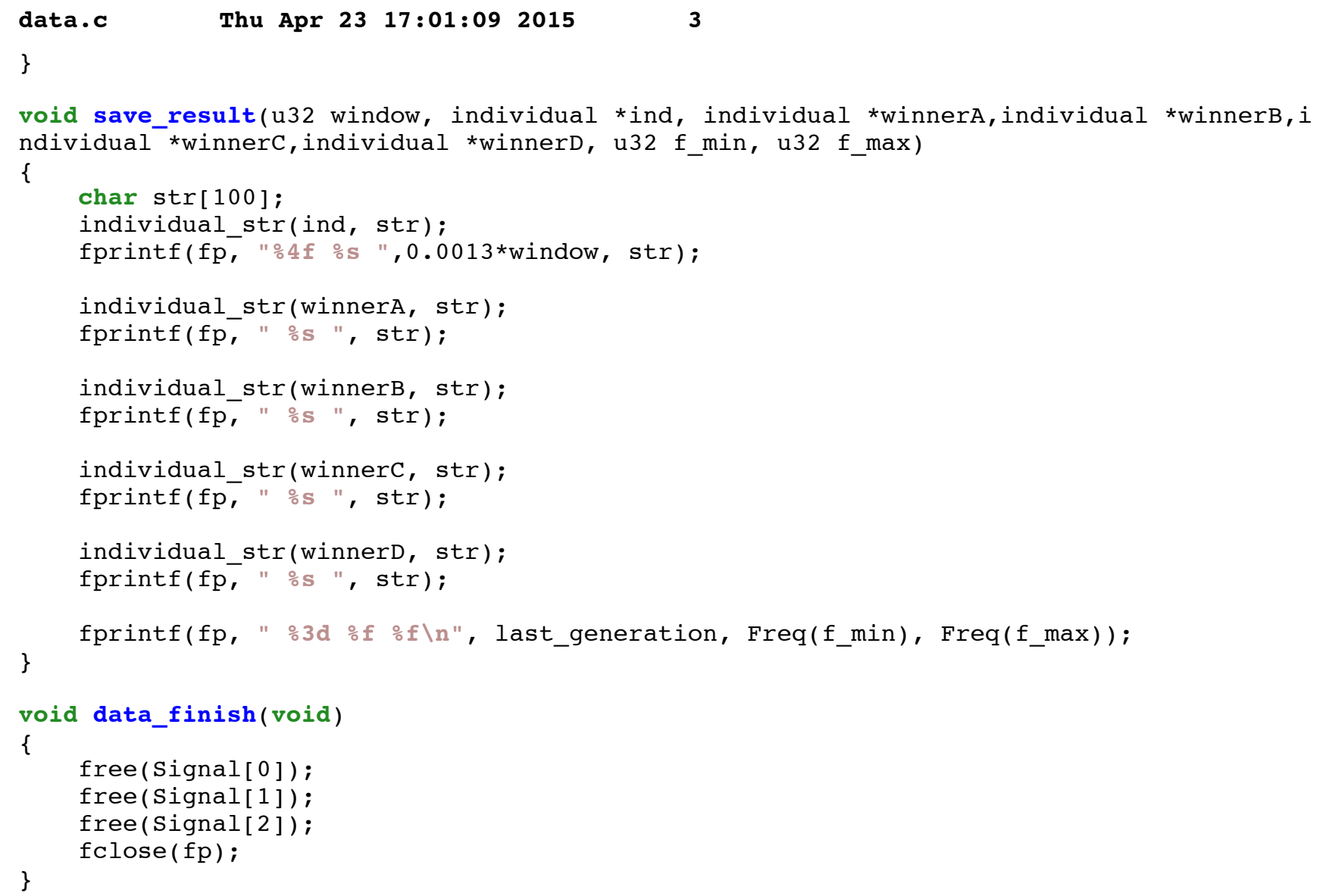

void save_result(u32 window, individual *ind, individual *winnerA, individual *winnerB, ndividual *winnerC, individual *winnerD, u32 f_min, u32 f_max)

\{

char str[100];

individual_str(ind, str);

fprintf( $\mathrm{fp}$, , " $4 \mathrm{f} \% \mathrm{~s}$ ",0.0013*window, str);

individual_str(winnerA, str);

fprintf(fp, " \% $"$, str);

individual_str(winnerB, str);

fprintf(fp," $\% \mathrm{~s} "$, str);

individual_str(winnerc, str);

fprintf(fp, " \%s ", str);

individual_str(winnerD, str);

fprintf (fp," $\%$ s ", str);

\}

fprintf(fp, " $\frac{0}{d d} \circ f \circ f \backslash n "$, last_generation, Freq(f_min), Freq(f_max)) ;

void data_finish(void)

\{

free (Signal [0]);

free (Signal [1]);

free (Signal [2]);

fclose (fp) ; 
\#ifndef GA H

\#define _ ${ }^{-}{ }_{-}{ }^{-}-$

\#include "definitions.h"

typedef struct \{

u32 freq;

u32 fase;

int ampl;

u32 fitness:

\} individual;

extern int sine_i[N_FASE];

extern int *(Signal[3]);

int last_generation;

extern int generation;

extern u32 f min;

extern u32 f_max;

void fitness_evaluation(u32 window, individual* I,int phase_type);

void update_ProbArray(individual winner, individual loser, int phase_type);

individual compare(individual ia, individual ib);

void init_probArray();

void generate individual(u32 window, individual *I, int phase type);

void regulariz̄ation (void);

void individual_str(individual *I, char *str);

\#endif 
\#include "ga.h"

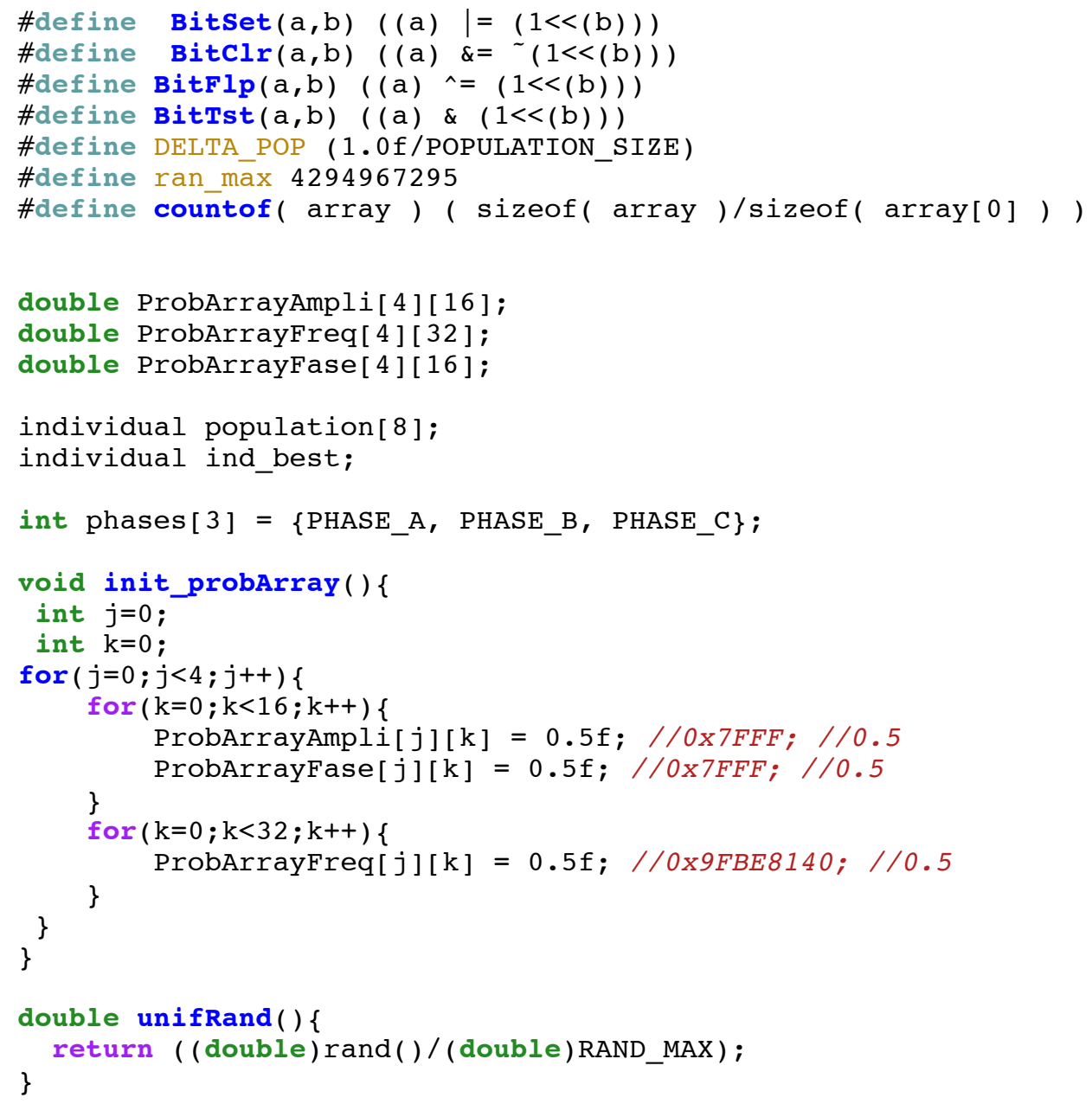


for $(\mathrm{p}=0 ; \mathrm{p}<$ PHASE_NUMBER; $\mathrm{p}++)\{$

to $=0$ i

$I->$ fitness $=0$;

for $(t=$ window-WINDOW SIZE; $t<$ window; $t++, t 0++)\{$

int intsinal $=S I N \bar{A} L$ CALC $(I->a m p l$, sine_i[ANGLE_CALC $($ freqs $[t 0], I->$ fase+phase

s[p] ) ] ;

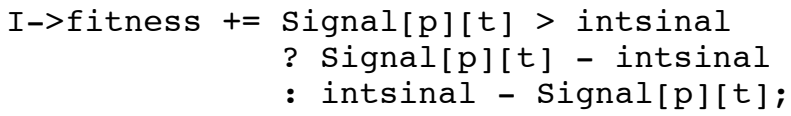

\} diff $+=$ I->fitness;

//Choose ProbArray on table

switch (phase_type) \{ case PHASE A: phase prob index $=0$; break; case PHASE_B: phase_prob_index $=1$; break; 


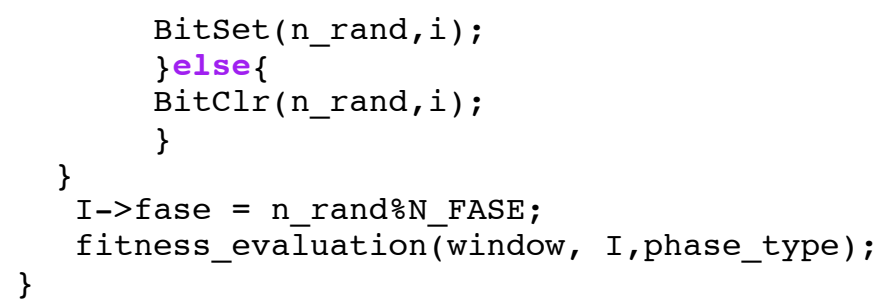




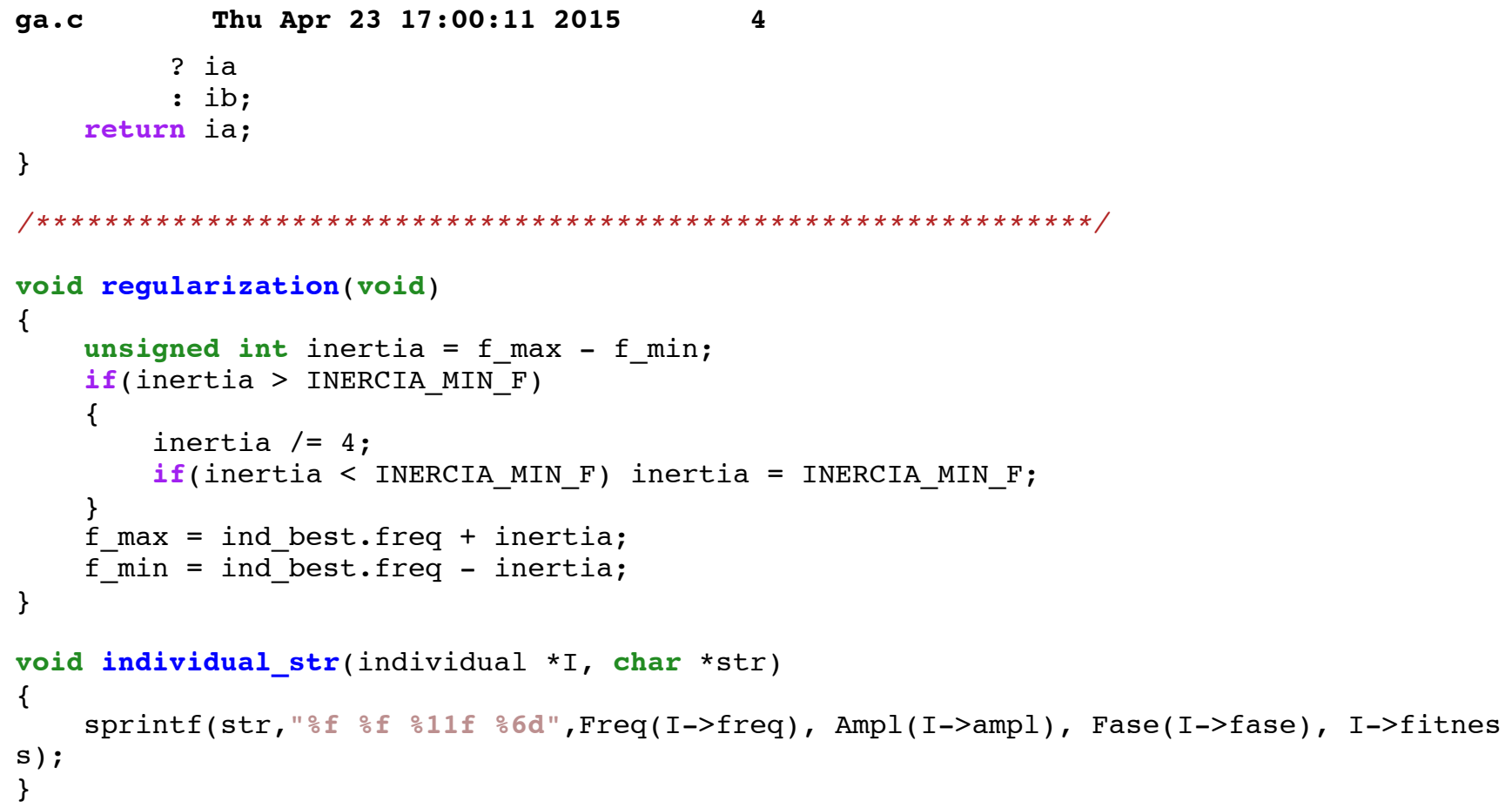




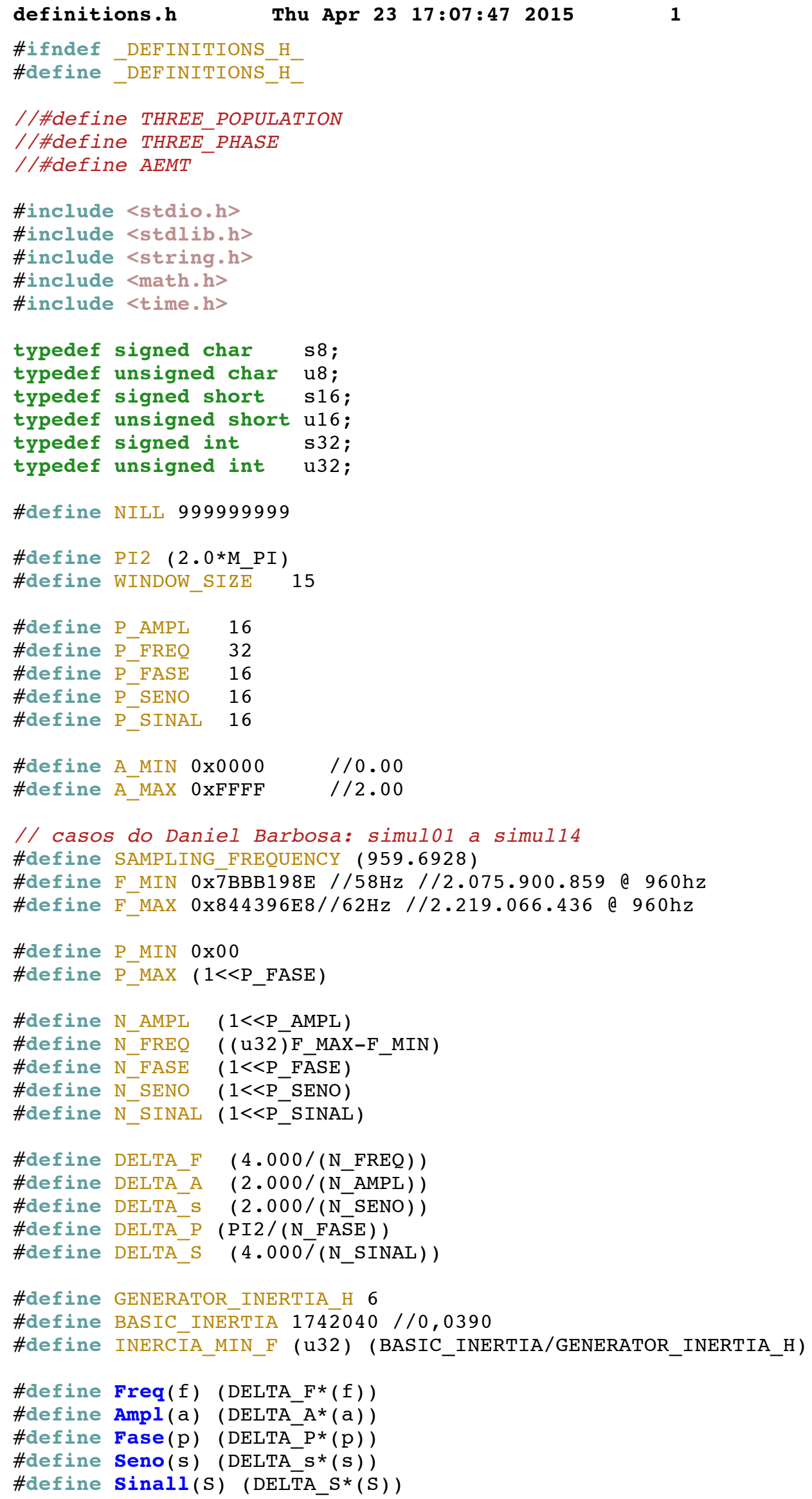

\#ifndef DEFINITIONS $\mathrm{H}$

\#define _DEFINITIONS_- ${ }^{-}$

//\#define THREE_POPULATION

//\#define THREE PHASE

//\#define AEMT

\#include <stdio.h $\rangle$

\#include <stdlib.h>

\#include <string.h>

\#include <math.h>

\#include <time.h>

$\begin{array}{ll}\text { typedef signed char } & \text { s8; } \\ \text { typedef unsigned char u } & \text {; } \\ \text { typedef signed short } & \text { s6; } \\ \text { typedef unsigned short } & \text { u16; } \\ \text { typedef signed int } & \text { s32; } \\ \text { typedef unsigned int } & \text { u32; }\end{array}$

\#define NILL 999999999

\#define PI2 (2.0*M_PI)

\#define WINDOW SIZE 15

\#define P AMPL 16

\#define P FREQ 32

\#define P FASE 16

\#define P SENO 16

\#define P_SINAL 16

\#define A_MIN 0x0000 //0.00

\#define A MAX 0xFFFF $\quad / / 2.00$

// casos do Daniel Barbosa: simul01 a simul14

\#define SAMPLING FREQUENCY (959.6928)

\#define F_MIN 0x7̄BBB198E //58Hz //2.075.900.859 @ 960hz

\#define F MAX 0x844396E8//62 Hz //2.219.066.436 @ $960 \mathrm{hz}$

\#define P MIN 0x00

\#define P_MAX $(1<<$ P_FASE $)$

\#define $N$ AMPL $(1<<$ P_AMPL $)$

\#define N_FREQ ( (u32)F_MAX-F_MIN $)$

\#define $N$ FASE $\quad(1<<P$ FASE $)$

\#define N_SENO $(1<<$ P_SENO $)$

\#define N_SINAL $(1<<$ P_SINAL $)$

\#define DELTA_F (4.000/(N_FREQ))

\#define DELTA A $(2.000 /(\mathrm{N}$ AMPL $))$

\#define DELTA ${ }^{-}$S $\left(2.000 /\left(N_{-}\right.\right.$SENO $\left.)\right)$

\#define DELTA_P (PI2/(N_FASE))

\#define DELTA $(4.000 /($ N_SINAL $))$

\#define GENERATOR INERTIA H 6

\#define BASIC_INERTIA $174 \overline{2} 040 / / 0,0390$

\#define INERCIA_MIN_F (u32) (BASIC_INERTIA/GENERATOR_INERTIA_H)

\#define Freq(f) (DELTA_F*(f))

\#define Ampl (a) (DELTA_A*(a))

\#define Fase $(p)$ (DELTA_P* $(p)$ )

\#define Seno(s) (DELTA $S^{*}(\mathrm{~S})$ )

\#define Sinall(S) (DELTA_S*(S)) 


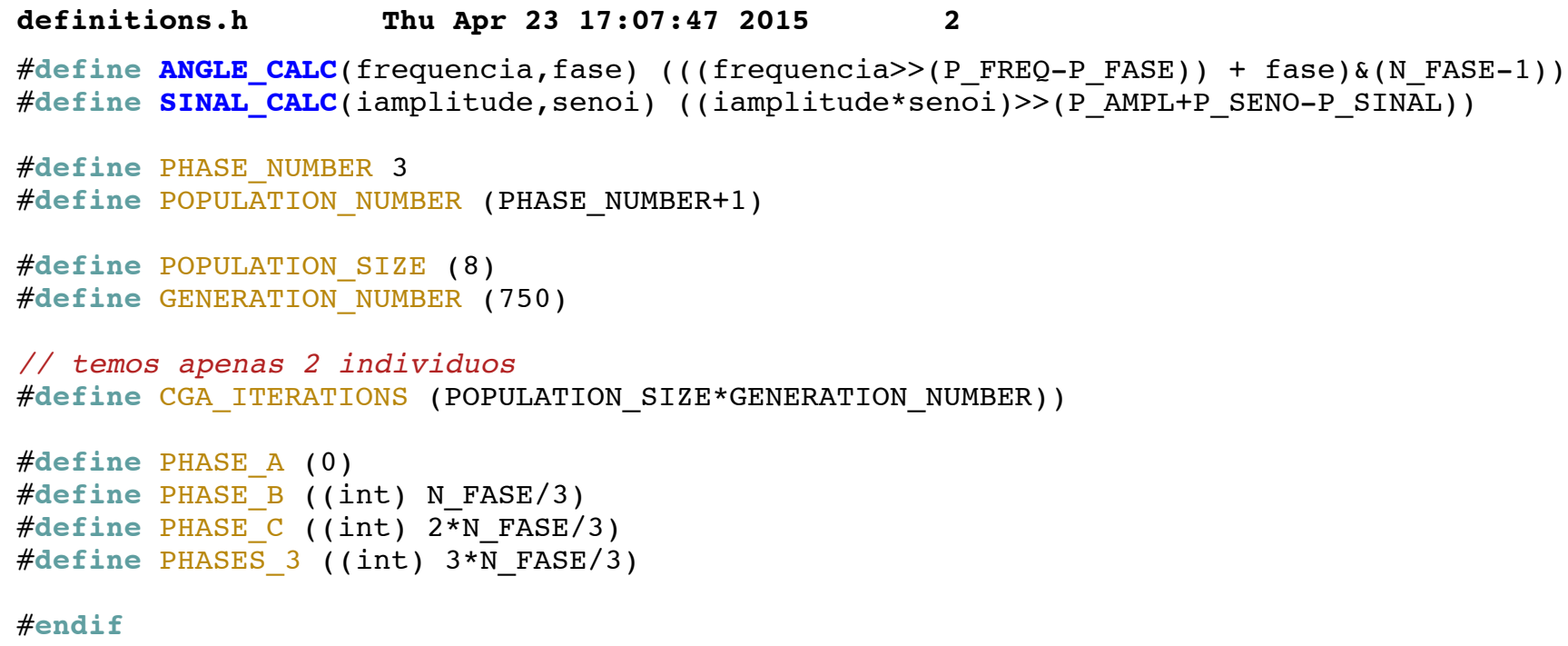

